University of Tennessee Health Science Center UTHSC Digital Commons

$12-2018$

\title{
Genetic Exploration of Hereditary Immune Diseases
}

Cheng Tian

Follow this and additional works at: https://dc.uthsc.edu/dissertations

Part of the Pharmaceutics and Drug Design Commons

\section{Recommended Citation}

Tian, Cheng (http://orcid.org/https://orcid.org/0000-0002-0770-4508), "Genetic Exploration of Hereditary Immune Diseases" (2018). Theses and Dissertations (ETD). Paper 476. http://dx.doi.org/10.21007/ etd.cghs.2018.0463.

This Dissertation is brought to you for free and open access by the College of Graduate Health Sciences at UTHSC Digital Commons. It has been accepted for inclusion in Theses and Dissertations (ETD) by an authorized administrator of UTHSC Digital Commons. For more information, please contact jwelch30@uthsc.edu. 


\title{
Genetic Exploration of Hereditary Immune Diseases
}

\begin{abstract}
An autoimmune disease is a condition arising from an abnormal immune response to a normal body part. There are at least 80 types of autoimmune diseases, rheumatoid arthritis and systemic sclerosis are two of them. My study focuses on these two diseases. Our hypothesis is that mutated genes lead to autoimmune diseases that cause the immune system to attack the human body. The mutated genes cause the gene expression levels to change which fail to properly regulate the body's functions, resulting in immune system diseases. I used existing mouse models to improve the understanding of these two diseases.
\end{abstract}

The first study concerns Arthritis (Chapter 2). This study has been designed to evaluate the molecular mechanism that regulates spontaneous arthritis disease (SAD) in mice that are deficient in production of interleukin 1 receptor antagonist protein (IL-1 ra). Mice with a BALB/c genomic background and IL-1Ra deficiency (BALB/c-/-) have shown susceptibility to SAD while those with a DBA/1 background are resistant to SAD. This study was based on our data accumulated over a decade of working with this mouse model of SAD. Our hypothesis is that there are nucleotide mutations in the gene or genes that cause the differences in expression level between BALB/c-/- and DBA/1-/- to regulate resistance or susceptibility to SAD. We obtained the IL-1Ra BALB/C-/- mouse model from the laboratory of Dr. John Stuart in order to test the susceptibility of IL-1Ra deficient mice on different genetic backgrounds. By transferring the IL-1Ra mutation onto the DBA/1 background, it was found that although BALB/c-/- mice spontaneously developed chronic inflammatory arthritis, DBA/1 IL-1Ra-deficient (DBA/1-/-) mice did not. We then determined the location of a genomic component that regulates susceptibility to SAD by identifying a QTL for spontaneous arthritis on mouse chromosome 1 from a F2 population derived from $\mathrm{DBA} / 1-/-$ and BALB/c-/- mice. We created a congenic strain carrying the DBA/1-/- region of chromosome 1 that contains the QTL on the BALB/c-/- background. We also created a congenic strain carrying the BALB/c-/- region of chromosome 1 that contains the QTL on the DBA/1-/- background. We then tested the susceptibility of these strains to SAD. When the DBA/1-/- fragment was placed on a BALB/c-/background, arthritis was delayed and became less severe. When the BALB/c-/- fragment was placed on a DBA/1-/ background, arthritis occurred in varying degrees. A study of the whole genome expression profiles of these congenic strains and their parental strains was performed in order to identify a candidate gene. We linked the Ifi204 gene in Ifi200 cluster to the potential causal pathway of spontaneous arthritis in a mouse model. We identified the function of Ifi204 gene in congenic strains and their parental strains to confirm our theory. We used state of the art technology to investigate the molecular mechanism that regulates the susceptibility to SAD. Through this analysis, a strategy to improve the therapeutic outcome of drugs designed based on alternative targets of the interleukin-1 (IL-1) receptor antagonist may be identified.

The second study concerns systemic sclerosis (SSc) (Chapter 3). SSc is a polygenic autoimmune disorder. It is of unknown etiology and is characterized by the excessive accumulation of extracellular matrix (ECM) proteins, vascular alterations, and $v$

autoantibodies. The tight skin 2 (Tsk2/+) mouse model of SSc demonstrates signs similar to SSc including tight skin and excessive deposition of dermal ECM proteins. Our hypothesis is that ENU caused single nucleotide mutations in one or more genes in the Tsk2/+ locus interval that determines the disease phenotype. From the literature, Tsk2/+ mice have a mutation on chromosome 1 between 42.5 and 52.5 megabases. We used microarray data to analyze the genes' expression level to narrow down the number of candidate genes. Based on studies of the genes' functions, we determined that Fhl2 is our primary candidate gene. We performed both RNA sequencing of skin transcripts and DNA sequencing of the region spanning this gene in Tsk2/+ and wild-type littermates. As of now, we have not found any 
nucleotide polymorphisms between Tsk2/+ and normal mice. We found that there are two transcripts of this gene and they are expressed differently in the various tissues. This can help us explain why there is only fibrosis in skin. We compared the expression levels of the two transcripts in each organ. The high expression level of one of the transcripts in the skin can help us understand the mechanism of skin fibrosis manifested by Tsk2/+ mice. Understanding the mechanism of skin fibrosis in the mouse model will help us and other researchers understand the mechanism in SSc.

\section{Document Type}

Dissertation

Degree Name

Doctor of Philosophy (PhD)

\section{Program}

Pharmaceutical Sciences

\section{Research Advisor}

Weikuan Gu, Ph.D.

\section{Keywords}

arthritis, gene mutation, genetic, tight skin

\section{Subject Categories}

Medicine and Health Sciences | Pharmaceutics and Drug Design | Pharmacy and Pharmaceutical Sciences 


\title{
Genetic Exploration of Hereditary Immune Diseases
}

\author{
A Dissertation \\ Presented for \\ The Graduate Studies Council \\ The University of Tennessee \\ Health Science Center \\ In Partial Fulfillment \\ Of the Requirements for the Degree \\ Doctor of Philosophy \\ From The University of Tennessee
}

By

Cheng Tian

December 2018 
Chapter 2 (C) 2018 by Elsevier.

All other material (C) 2018 by Cheng Tian. All rights reserved. 


\section{ACKNOWLEDGEMENTS}

I am whole heartedly thankful to my research advisor, Dr. Weikuan Gu, who tutored, supported, and guided the research. The inspiration for doing the research came from his insightful mind. The six years $\mathrm{PhD}$ study was one of the most important experiences in my life. He will always encourage me in my future time as a scholar.

I would like to use this opportunity to thank my committee, Dr. Tao Lowe, Dr. David Brand, Dr. Hongsik Cho, and Dr. Wei Li for their supervision, comments, and assistance. I thank them for encouraging and helping me to develop my background and knowledge in research.

I am sincerely thankful to Dr. Yan Jiao, who taught me every increment since the first day I went to the lab. I would also like to thank Jiwen Luo, for teaching me flow cytometry and her technical support. I appreciate my colleagues who have contributed to my project, including Dr. Lishi Wang, Wei Dong and Yue Huang.

I would like to acknowledge the College of Graduate Health Sciences at UTHSC, especially the joint program pharmaceutical science and Veterans affairs grant that supported my learning and researching.

I am deeply grateful for all of my friends, colleagues, mentors, and family over the years. Without their support, I would not have survived through these tough times. I feel so lucky to have all of you. Finally, I wish to give thanks to everyone who helped in the last six years. It is the greatest motivation on my way to better myself. 


\begin{abstract}
An autoimmune disease is a condition arising from an abnormal immune response to a normal body part. There are at least 80 types of autoimmune diseases, rheumatoid arthritis and systemic sclerosis are two of them. My study focuses on these two diseases. Our hypothesis is that mutated genes lead to autoimmune diseases that cause the immune system to attack the human body. The mutated genes cause the gene expression levels to change which fail to properly regulate the body's functions, resulting in immune system diseases. I used existing mouse models to improve the understanding of these two diseases.
\end{abstract}

The first study concerns Arthritis (Chapter 2). This study has been designed to evaluate the molecular mechanism that regulates spontaneous arthritis disease (SAD) in mice that are deficient in production of interleukin 1 receptor antagonist protein (IL-1 ra). Mice with a BALB/c genomic background and IL-1Ra deficiency (BALB/ $\left./ \mathrm{c}^{-/}\right)$have shown susceptibility to SAD while those with a DBA/1 background are resistant to SAD. This study was based on our data accumulated over a decade of working with this mouse model of SAD. Our hypothesis is that there are nucleotide mutations in the gene or genes that cause the differences in expression level between BALB/ $\mathrm{c}^{-/-}$and $\mathrm{DBA} / 1^{-/-}$to regulate resistance or susceptibility to SAD. We obtained the IL-1Ra BALB $/ \mathrm{c}^{-/-}$mouse model from the laboratory of Dr. John Stuart in order to test the susceptibility of IL-1Ra deficient mice on different genetic backgrounds. By transferring the IL-1 Ra mutation onto the DBA/1 background, it was found that although BALB $/ \mathrm{c}^{-/ /}$mice spontaneously developed chronic inflammatory arthritis, DBA/1 IL-1Ra-deficient (DBA/1 $\left.1^{-/}\right)$mice did not. We then determined the location of a genomic component that regulates susceptibility to SAD by identifying a QTL for spontaneous arthritis on mouse chromosome 1 from a F2 population derived from $\mathrm{DBA} / 1^{-/-}$and $\mathrm{BALB} / \mathrm{c}^{-/-}$mice. We created a congenic strain carrying the $\mathrm{DBA} / 1^{-/}$region of chromosome 1 that contains the QTL on the BALB/ $\mathrm{c}^{-/}$background. We also created a congenic strain carrying the $\mathrm{BALB} / \mathrm{c}^{-/-}$region of chromosome 1 that contains the QTL on the DBA $/ 1^{-/}$background. We then tested the susceptibility of these strains to SAD. When the DBA $/ 1^{-/}$fragment was placed on a BALB/ $/ \mathrm{c}^{-/}$background, arthritis was delayed and became less severe. When the $\mathrm{BALB} / \mathrm{c}^{-/}$fragment was placed on a $\mathrm{DBA} / 1^{-/}$background, arthritis occurred in varying degrees. A study of the whole genome expression profiles of these congenic strains and their parental strains was performed in order to identify a candidate gene. We linked the Ifi204 gene in Ifi200 cluster to the potential causal pathway of spontaneous arthritis in a mouse model. We identified the function of Ifi204 gene in congenic strains and their parental strains to confirm our theory. We used state of the art technology to investigate the molecular mechanism that regulates the susceptibility to SAD. Through this analysis, a strategy to improve the therapeutic outcome of drugs designed based on alternative targets of the interleukin-1 (IL-1) receptor antagonist may be identified.

The second study concerns systemic sclerosis (SSc) (Chapter 3). SSc is a polygenic autoimmune disorder. It is of unknown etiology and is characterized by the excessive accumulation of extracellular matrix (ECM) proteins, vascular alterations, and 
autoantibodies. The tight skin $2($ Tsk2/+) mouse model of SSc demonstrates signs similar to SSc including tight skin and excessive deposition of dermal ECM proteins. Our hypothesis is that ENU caused single nucleotide mutations in one or more genes in the Tsk2/+ locus interval that determines the disease phenotype. From the literature, Tsk2/+ mice have a mutation on chromosome 1 between 42.5 and 52.5 megabases. We used microarray data to analyze the genes' expression level to narrow down the number of candidate genes. Based on studies of the genes' functions, we determined that Fhl2 is our primary candidate gene. We performed both RNA sequencing of skin transcripts and DNA sequencing of the region spanning this gene in Tsk $2 /+$ and wild-type littermates. As of now, we have not found any nucleotide polymorphisms between Tsk $2 /+$ and normal mice. We found that there are two transcripts of this gene and they are expressed differently in the various tissues. This can help us explain why there is only fibrosis in skin. We compared the expression levels of the two transcripts in each organ. The high expression level of one of the transcripts in the skin can help us understand the mechanism of skin fibrosis manifested by Tsk $2 /+$ mice. Understanding the mechanism of skin fibrosis in the mouse model will help us and other researchers understand the mechanism in SSc. 


\section{TABLE OF CONTENTS}

CHAPTER 1. BACKGROUND AND LITERATURE STUDY ..................................1

\section{CHAPTER 2. GENETIC STUDY OF HUMAN RHEUMATOID ARTHRITIS USING THE SPONTANEOUS ARTHRITIS DISEASE MOUSE MODEL ...............9}

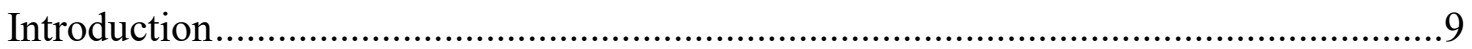

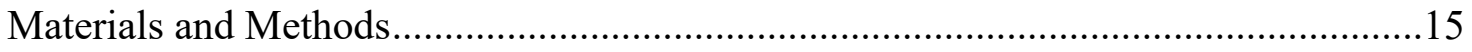

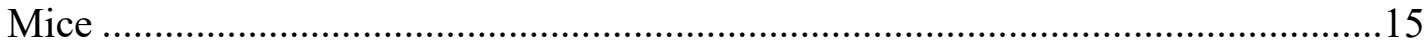

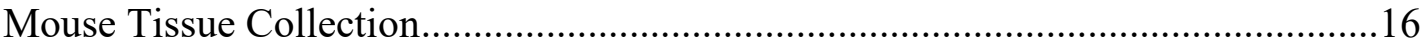

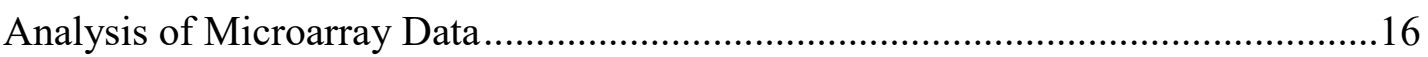

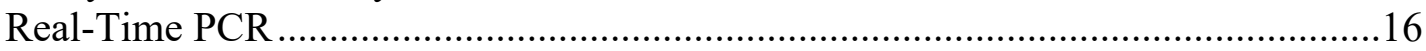

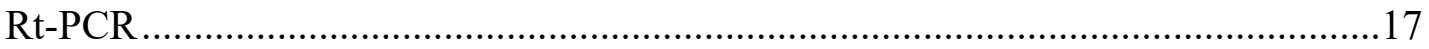

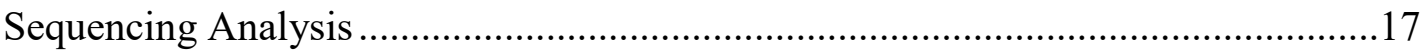

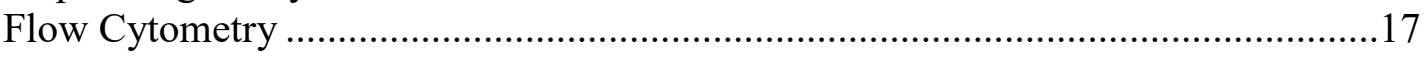

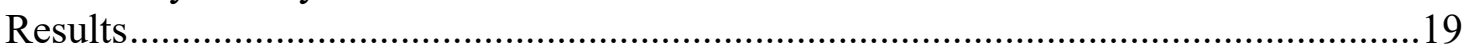

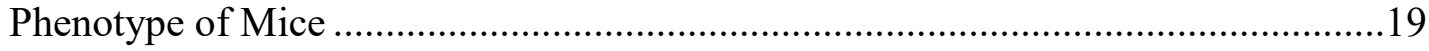

Expression Profile Among Different Strains .....................................................23

Gene Expression Profiling Between BALB.D-1 ${ }^{-/-}$and DBA/1 Wild Type ...............23

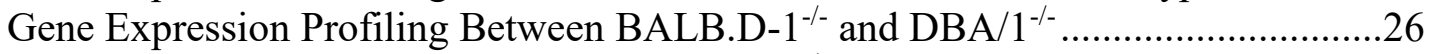

Gene Expression Profiling Between BALB.D-1 ${ }^{-/-}$and BALB/c Wild Type .............26

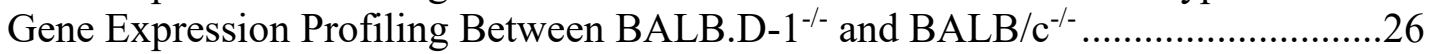

Gene Expression Profiling Between DBA.B-1 ${ }^{-/}$and DBA/1 Wild Type....................30

Gene Expression Profiling Between DBA.B-1 $1^{-/}$and BALB/c Wild Type..................30

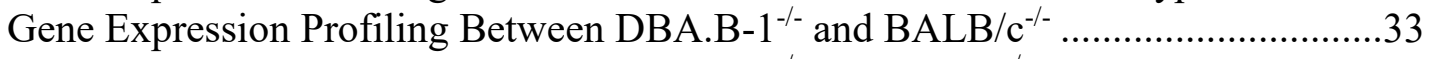

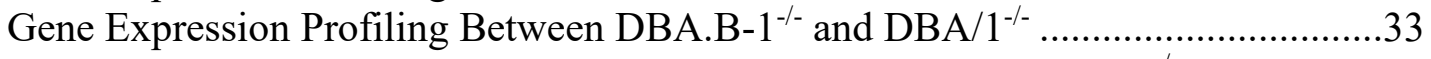

Interferon-activatable Protein Gene Expression Levels in BALB.D-1 ${ }^{-/-}$and

DBA.B-1 ${ }^{-/}$Compared with the Four Parental Strains ............................................ 33

The Potential Involvement of Interferon-activatable Protein Genes in the

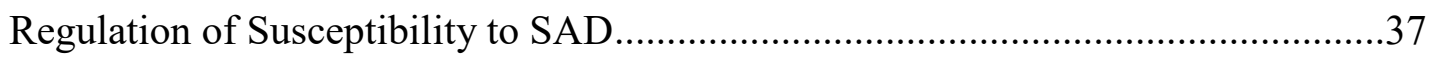

The Ifi204 as the Most Favorable Candidate Gene for SAD ....................................37

The Potential Connection Between Ifi204 and Differentially Expressed Genes within QTL Regions and Arthritis Relevant Genes ...............................................39

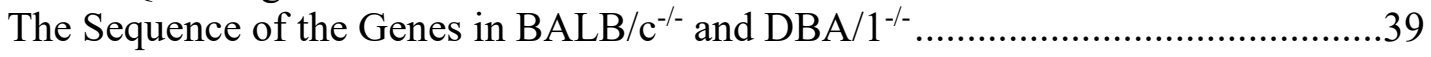

The Ifi204 Expression Levels in Different Strains ..............................................44

Foxp3+ Regulatory T Cells in Each Strain ......................................................48

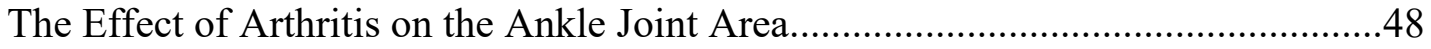

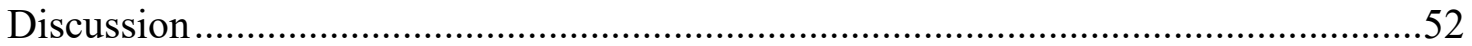

\section{CHAPTER 3. GENETIC STUDY OF HUMAN SCLERODERMA USING THE} TIGHT SKIN MOUSE MODEL .............................................................................58

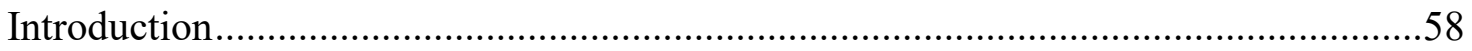

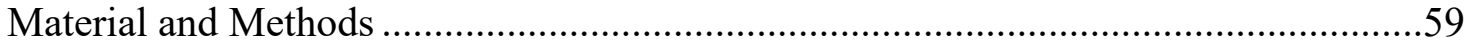

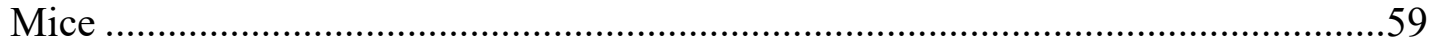

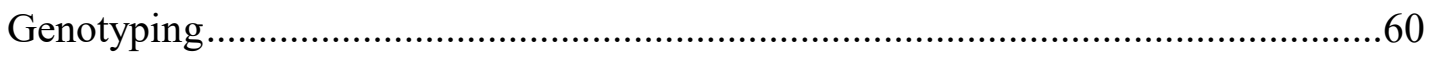




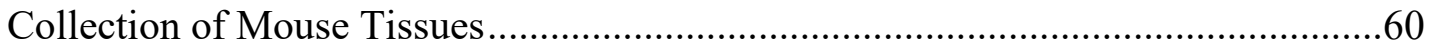

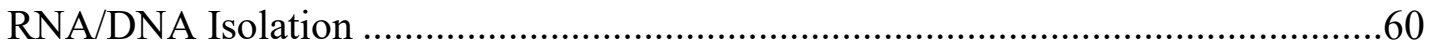

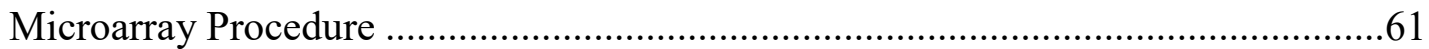

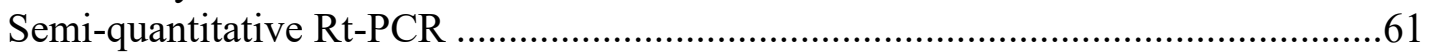

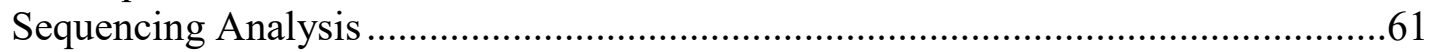

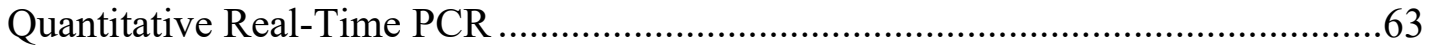

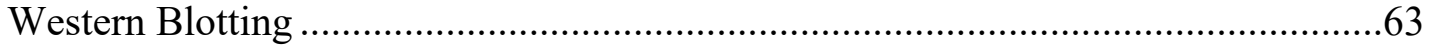

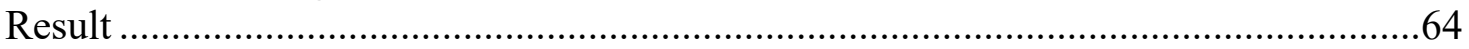

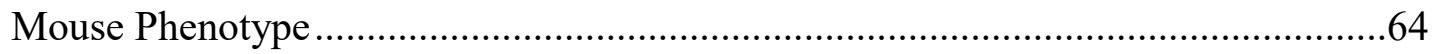

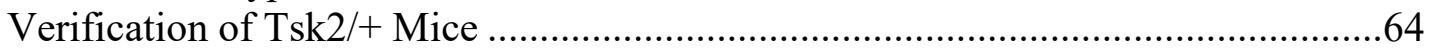

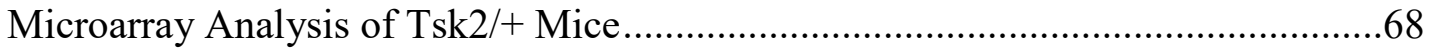

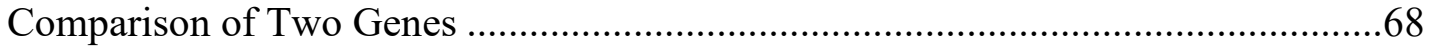

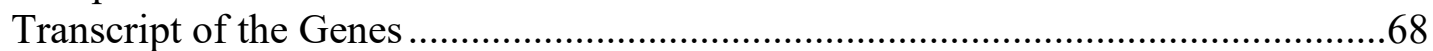

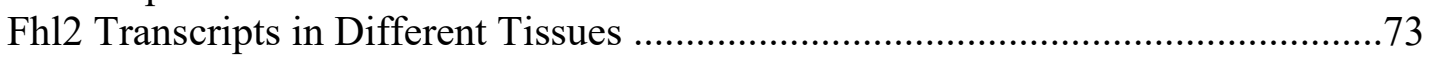

Fhl2 Gene Expression in Different Tissues at Different Ages....................................73

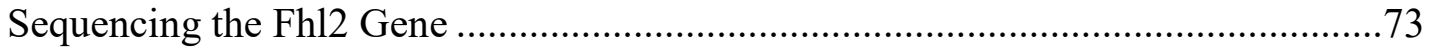

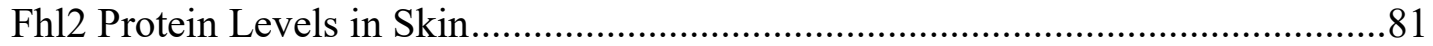

Gene Regulation of the Expression of Fhl2 in the Spleen ........................................81

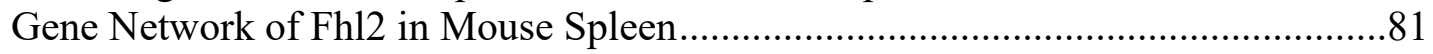

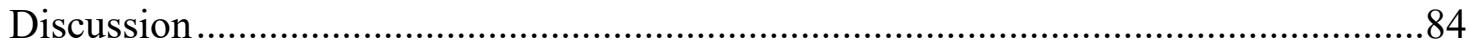

CHAPTER 4. CONCLUSION ..............................................................................................89

LIST OF REFERENCES ...............................................................................................91

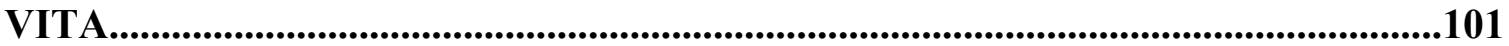




\section{LIST OF TABLES}

Table 2-1. The Ifi202b, Ifi203, Ifi204, Ifi205, and Mndal cDNA designed primers.....18

Table 2-2. Tissue weight comparison in males and females of the four strains at time of collection. (4 months old) $(n=6)$...............................................22

Table 2-3. The Ifi202b, Ifi203, Ifi204, Ifi205, and Mndal genes ID..........................42

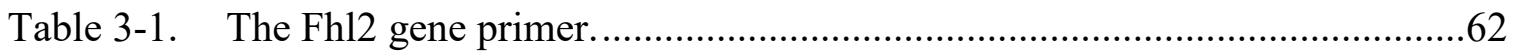

Table 3-2. The Fh12 and Col3al gene expression levels in each tissue or organ...........71

Table 3-3. The Ifi202b, Ifi203, Ifi204, Ifi205, and Mndal genes ID..........................74 


\section{LIST OF FIGURES}

Figure 2-1. MHC genomic region on mouse chromosome 17 and non-MHC QTL loci on other chromosomes marked by molecular markers on 9 out of 19 autosomal chromosomes.

Figure 2-2. Genomic region of the QTL on chromosome 1 and two congenic strains. ..14

Figure 2-3. The phenotype of DBA $/ 1^{-/-}$, DBA.B-1 ${ }^{-/-}$, BALB.D-1 $1^{-/}$, and BALB $/ \mathrm{c}^{-/-}$ strains.

Figure 2-4. Arthritis relative severity and incidence in male and female $\mathrm{BALB} / \mathrm{c}^{-/}$, DBA $/ 1^{-/}$, BALB.D-1 $1^{-/}$, and DBA.B- $1^{-/-}$mice.

Figure 2-5. Correlation of whole genome gene expression levels between DBA.B-1-

${ }^{/-}$, BALB.D-1 ${ }^{-/ /}$, and their four parental strains.

Figure 2-6. Up and down regulated genes in BALB.D-1/- mice in comparison to that of DBA/1 wild type mice.

Figure 2-7. Up and down regulated genes in BALB.D-1//- mice in comparison to that of $\mathrm{DBA} / 1^{-/-}$mice.

Figure 2-8. Up and down regulated genes in BALB.D-1 ${ }^{-/}$mice in comparison to that of $\mathrm{BALB} / \mathrm{c}$ wild type mice.

Figure 2-9. Down regulated genes in BALB.D-1/- mice in comparison to that of $\mathrm{BALB} / \mathrm{c}^{-/-}$mice.

Figure 2-10. Up and down regulated genes in DBA.B-1/- mice in comparison to that of DBA/1 wild type mice.

Figure 2-11. Up and down regulated genes in DBA.B-1 $1^{-/}$mice in comparison to that of BALB/c wild type mice.

Figure 2-12. Up and down regulated genes in DBA.B-1/- mice in comparison to that of $\mathrm{BALB} / \mathrm{c}^{-/-}$mice.

Figure 2-13. Up and down regulated genes in DBA.B-1 ${ }^{-/-}$mice in comparison to that of $\mathrm{DBA} / 1^{-/-}$mice.

Figure 2-14. Gene expression levels of Ifi family congenic strain BALB.D-1 ${ }^{-/-}$and DBA.B- $1^{-/-}$in comparison with four parental strains.

Figure 2-15. Comparison of expression levels of genes in Ifi family. .38

Figure 2-16. Graphic gene network between Ifi204 and genes within the QTL region and genes relevant to the immune system. 
Figure 2-17. Ifi200 cluster is located on chromosome 1 between in $173.7 \mathrm{Mb}$ and $174.1 \mathrm{Mb}$.

Figure 2-18. Ifi204 gene sequencing and designed primers on cDNA

Figure 2-19. BALB $/ \mathrm{c}^{-/-}$and $\mathrm{DBA} / 1^{-/-}$have multiple polymorphisms on Ifi204 gene sequencing.

Figure 2-20. Ifi204 gene expression levels in both genders of each strain.

Figure 2-21. Analysis of foxp3 in lymphocyte cells of BALB. D-1//- compare with $\mathrm{BALB} / \mathrm{c}^{-/-}$and DBA $/ 1^{-/-}$

Figure 2-22. The structure of ankle joint bones shows in BALB $/ \mathrm{c}^{-/-}, \mathrm{DBA}^{-/-}$, BALB.D$1^{-/}$, and DBA.B- $1^{-/-}$.

Figure 3-1. The phenotype of Tsk2/+ and B6 skin tightness when they are 4 and 6 weeks of age.

Figure 3-2. Comparison of body length, body weight, tail length, and skin tightness score in male and female Tsk2/+ and B6 mice.

Figure 3-3. Identifying and comparing the Tsk2/+ and B6 by Col3al candidate mutation gene and Col3a1 gene expression levels between Tsk2/+ and B6 tissues.

Figure 3-4. Up and down regulated genes and networks in Tsk2/+ mice in comparison to that of $\mathrm{B} 6$ mice.

Figure 3-5. Fhl2 and Col3al are located on chromosome 1 and they are expressed in different tissues.

Figure 3-6. There are two transcripts of the Fhl2 gene............................................. 75

Figure 3-7. Comparing transcripts Fhl2-201 and Fhl2-202 in different tissues. ............76

Figure 3-8. The Fhl2 gene expression in Tsk2/+ and B6 mice tissues at 4, 6, and 10 weeks.

Figure 3-9. Fhl2 gene sequencing and designed primers on mRNA, genomic DNA, promoter and intron.

Figure 3-10. Western blot analysis of skin from Tsk2/+ and B6 mice.

Figure 3-11. Detection of QTL for Fhl2 gene expression levels using RI strains.

Figure 3-12. Gene network among Fhl2 genes, which are upregulated or downregulated in mice, constructed using expression profiles from spleen BXD mouse strains. 


\section{LIST OF ABBREVIATIONS}

\begin{tabular}{|c|c|}
\hline$\mu \mathrm{CT}$ & Micro- Computed Tomography \\
\hline$\mu \mathrm{g}$ & Microgram \\
\hline$\mu 1$ & Microliter \\
\hline$\mu \mathrm{M}$ & Micromolar \\
\hline$\mu \mathrm{m}$ & Micrometer \\
\hline $\mathrm{A}$ & Adenine \\
\hline AIM 2 & Absent in melanoma 2 \\
\hline ANAs & Antinuclear antibodies \\
\hline APS & Ammonium persulfate \\
\hline BMD & Bone mineral density \\
\hline Bps & Base pairs \\
\hline $\mathrm{C}$ & Cytosine \\
\hline${ }^{\circ} \mathrm{C}$ & Degree centigrade \\
\hline CCDs & Consensus Coding Sequence \\
\hline cDNA & complementary Deoxyribonucleic acid \\
\hline $\mathrm{Chr}$ & Chromosome \\
\hline CIA & Collagen-induced arthritis \\
\hline $\mathrm{cm}$ & centimeter \\
\hline Col3a1 & Collagen type III alpha 1 \\
\hline cRNA & complementary Ribonucleic acid \\
\hline ddATP & 2', 3' -Dideoxyadenosine 5' -Triphosphate \\
\hline ddCTP & 2',3' -Dideoxycytidine 5' -Triphosphate \\
\hline ddGTP & $2^{\prime}, 3^{\prime}$-Dideoxyguanosine 5' -Triphosphate \\
\hline ddNTPs & dideoxynucleotide triphosphates \\
\hline ddTTP & $2^{\prime}, 3^{\prime}$-Dideoxythymidine $5^{\prime}$-Triphosphate \\
\hline DNA & Deoxyribonucleic acid \\
\hline dNTPs & deoxyribonucleotide triphosphates \\
\hline ECM & Extracellular matrix \\
\hline
\end{tabular}




$\begin{array}{ll}\text { EDTA } & \text { Ethylenediaminetetraacetic acid } \\ \text { EL } & \text { Erythrocytes lysis } \\ \text { ENU } & \text { N-Ethyl-N-Nitrosourea } \\ \text { Fhl2 } & \text { Four and A half lim domains 2 } \\ \text { g } & \text { Gram } \\ \text { G } & \text { Guanine } \\ \text { GAPDH } & \text { Glyceraldehyde-3-phosphate dehydrogenase } \\ \text { HLA } & \text { Human leukocyte antigen } \\ \text { IFI 16 } & \text { Gamma-interferon-inducible protein 16 } \\ \text { Ifi202b } & \text { Interferon activated gene 202b } \\ \text { Ifi203 } & \text { Interferon activated gene 203 } \\ \text { Ifi204 } & \text { Interferon activated gene 204 } \\ \text { Ifi205 } & \text { Interferon activated gene 205 } \\ \text { IFNs } & \text { Interferons } \\ \text { IGF1 } & \text { Insulin-like growth factor 1 } \\ \text { IL-1 } & \text { Interleukin 1 } \\ \text { IL-1ra } & \text { Interleukin 1 receptor antagonist protein } \\ \text { IL-1rn } & \text { Interleukin 1 receptor antagonist gene } \\ \text { Mb } & \text { Megabase } \\ \text { MHC } & \text { Rajor histocompatibility complex } \\ \text { mL } & \text { Rilliliter } \\ \text { MNDA } & \text { Myeloid cell nuclear differentiation antigen } \\ \text { Mndal } & \text { Myeloid cell nuclear differentiation antigen-like } \\ \text { mRNA } & \text { Messenger ribonucleic acid } \\ \text { ng } & \text { nanogram } \\ \text { PBS } & \text { Phosphate buffered saline } \\ \text { PCR } & \text { Polymerase chain reaction } \\ \text { QTL } & \text { Quantitative trait locus } \\ \text { RA } & \text { Rheumatoid arthritis } \\ \text { RI } & \text { RNA }\end{array}$




$\begin{array}{ll}\text { RT } & \text { Room temperature } \\ \text { rt-PCR } & \text { Reverse transcription polymerase chain reaction } \\ \text { SAD } & \text { Spontaneous arthritis disease } \\ \text { SDS } & \text { Sodium dodecyl sulfate } \\ \text { SNPs } & \text { single nucleotide polymorphisms } \\ \text { SSC } & \text { Systemic sclerosis } \\ \text { T } & \text { Thymine } \\ \text { TBS } & \text { Tris buffered saline } \\ \text { TBST } & \text { Tris buffered saline with Tween 20 } \\ \text { TEMED } & \text { N, N, N', N'-Tetramethylethylenediamine } \\ \text { Tsk1/+ } & \text { Tight skin 1 } \\ \text { Tsk2/+ } & \text { Tight skin 2 }\end{array}$




\section{CHAPTER 1. BACKGROUND AND LITERATURE STUDY}

The immune system is a mechanism used to protect organisms from exogenous attack. Without the immune system, our bodies would be open to attack from many infectious organisms such as bacteria, viruses, parasites, among others[1,2].

Approximately 50 million American people, around one-sixth of the U.S. population, suffer from different forms of immune disease[3,4]. The immune system is the one of the most complex systems in humans. It uses cells, organs, proteins, and tissues to work in accordance with the nervous system to keep us healthy. In the immune system, leukocytes, also called white blood cells, are one of the most important cell types[1,2]. Leukocytes are produced and stored in the bone marrow, thymus, lymph nodes, and spleen. They circulate throughout organs through the lymphatic system and blood vessels. As the leukocytes circulate throughout the body, the immune system works efficiently to seek out and solve problems. There are two basic types of leukocytes: phagocytes and lymphocytes. The responsibility of the phagocytes is to attack the invading organisms, and the lymphocytes' responsibility is to remember and recognize the invaders and to help the body have a quick response. Lymphocytes are important immune recognition cells[5]. They can be divided into T cells, B cells, and NK cells. While lymphocytes are in the bone marrow, they mature to B cells. When part of a pluripotent stem cell or pre-T cell from the bone marrow migrates into the thymus, they differentiate and mature into immunocompetent $\mathrm{T}$ cells under the induction of thymosin[6]. These two types of lymphocytes serve different functions. B cells seek out their targets and send defenses to lock onto them, then $\mathrm{T}$ cells either destroy the foreign invaders that the $\mathrm{B}$ cells have identified $\left(\mathrm{CD} 8^{+}\right)$or they provide help to the $\mathrm{B}$ cells in generating signals that give rise to antibody production $\left(\mathrm{CD}^{+}\right)$. Many immune diseases can be detected by looking at the ratio of T cells, B cells, and other cell subpopulations[59].

An immune disease is caused by an immunoregulatory imbalance that affects the body's immune response[1]. These diseases include structural or functional abnormalities of the immune system that are caused by genetic and environmental factors[10]. Environmental factors include viruses, bacteria, humidity, air, and food[11, 12]. These factors can cause immune diseases like HIV[13], rheumatoid arthritis[14], thyroiditis[15], and diabetes[16]. Congenital immune diseases are caused by genetic defects. Many immune diseases are caused by both environmental and genetic factors. For example, rheumatoid arthritis is affected by temperature, humidity, and genetics[17, 18]. Autoimmune diseases are caused mainly by the accumulation of immune cells and immunoglobulin produced by excessive immune reactions, thereby damaging normal tissues and causing lesions and functional impairment. Scleroderma and rheumatoid arthritis are both autoimmune diseases that have a hereditary component [19, 20]. By comparing the genomic background of normal and diseased people, we can search for mutated genes. Identifying the mutated genes is very helpful for the selection of molecular targets for gene therapy. 
A gene is a sequence of DNA and is the hereditary code for proteins. Genes are the building block of heredity: they pass from parents to children and hold the DNA and instructions for producing proteins[21]. Genes are transcribed to RNA, which in turn are translated to proteins that makeup living matter and are the catalysts of every single cellular process[22]. All organisms' physical traits are determined by these proteins. The DNA that makes up a gene is a double-helix structure made up of Deoxyribonucleic acid, that was first proposed by Watson and Crick in 1953[23, 24]. DNA is composed of five organic elements - carbon, hydrogen, oxygen, nitrogen, and phosphorous - that are organized into highly ordered substructures called nucleotides[25-27]. There are four different nucleotides, Adenine (A)[28], Guanine (G)[29], Cytosine (C)[30], and Thymine (T) that form the basis for DNA, and are linked by $\beta$-N-glycosidic bond from their first carbons[28, 31]. Adenine bonds with Thymine and Cytosine bonds with Guanine. The change in a single nucleotide can cause protein denaturation, which can cause a disease. There are approximately 35,000 genes in the human body, and approximately 19,000 of them are coding genes[32]. There are also approximately 35,000 genes in mice[33]. Within this huge number of genes, even one nucleotide that has been added, deleted, or switched can cause a genetic disorder.

The proteins encoded by genes have functions that include breaking down ingested toxins, transferring molecules, and building structures[34, 35]. Mutations in genes can affect protein expression or the protein's structure, thus causing a loss or change in the function and/or excessive or insufficient expression[36, 37]. There are three types of genetic disorders that can cause a change of the structure and function of proteins; single gene mutations, multifactorial diseases and chromosomal abnormalities. A single gene disorder is caused by a nucleotide mutation, deletion and/or insertion into the coding gene[38]. The characteristics of each disease is related to the specific gene that is affected and the role its product plays in the body. A multifactorial disease is due to alterations in two or more genes as well as lifestyle or environmental factors. The inheritance of these diseases is not clear; they can be inherited or sporadic[39]. A chromosomal abnormality is a chromosomal disorder that occurs when part or all of a chromosome is deleted or altered[40]. Down syndrome and Turner syndrome are examples of such chromosomal disorder.

To study genetic disorders, we must understand the gene mutation causing the disorder. A gene mutation is a permanent modification in the DNA sequence that results in the gene coding region differing from what is found in most normal people[41]. The change can be anywhere from a single nucleotide polymorphism to multiple large segments on a chromosome that affects multiple genes[42]. Polymorphisms are genetic alterations and they occur in more than one percent of DNA sequences in the human body. Polymorphisms determine a person's physical traits, such as their eye color, blood type, or handedness $[43,44]$. Polymorphisms are common results from natural variability in the DNA, and most of them do not negatively affect a person's health, although certain mutations may increase the risk of various disorders[43]. There are two major categories of gene mutations: hereditary and acquired. Hereditary mutations are those inherited from a parent and they remain in a person's cells throughout his or her life. These mutations, also called germline mutations, are present in the parent's germ cells as well. An acquired 
mutation is limited to certain cells after conception[45]. In this type of mutation, the change passes from these limited cells to their offspring cells. An acquired mutation is caused by environmental factors, such as radiation or an error in the copying of DNA during cell division. When the mutation is in the somatic cells, the mutation cannot be passed to the next generation. When the mutation is in the fertilized egg, the mutation will be delivered to the next generation, and the mutation will become a hereditary genetic disorder. Sometimes, the mutation occurs only in the fertilized egg and will be present in the reproductive cell but not any of the other cells. As the fertilized egg continues to divide, each cell will also contain the mutation[46]. Genetic disorders in which all of a child's cells have the mutation but the parents' do not and the disease is not present in other family members could be the result of de novo mutations. These gene mutations that lead to diseases are rather uncommon amongst the general population.

Protein production is initiated with transcription, where DNA is turned into RNA, and proceeds with translation, where RNA is turned into a protein. The functions of a cell can be determined by the amounts and types of mRNA molecules found inside the cell[47]. The start of transcription is the main control point for gene expression[48]. Controlling the transcription initiation processes determines the types and the amounts of proteins present in the cell. In addition, how a cell processes RNA transcripts and new proteins can affect protein levels to a significant degree. A primary transcript synthesized by RNA polymerase will contain a sequence that does not appear in the RNA's final mature form[49]. These sequences are defined as introns and are discarded before the mature mRNA exits the nucleus. The remaining regions of the transcript contain the protein coding region and are called exons[50, 51]. These regions are then spliced together, and the final product is mature mRNA. Each step allows the cell to self-regulate many of its functions through the adjustment of the amount and type of proteins it manufactures. The quantity of any protein in a cell reflects the balance between the synthesis and degradation biochemical pathways of said protein[48]. The gene expression level in each tissue is relative, thus we can find the mutated gene by comparing gene expression.

The promoter and enhancer play very important role in balancing the gene expression level $[52,53]$. The promoter is a short DNA sequence that is used to identify, bind and initiate RNA polymerase transcription, often located about 2000 base pairs directly upstream of the transcription initiation site[54]. To commence transcription, RNA polymerase and other required transcription factors bind to the promoter sequence. The promoter sequence defines the direction of transcription and indicates which DNA strand will be transcribed; this transcribed strand is called the sense strand. The TATA box is a promoter sequence approximately 25 to 35 base pairs above the transcription start site[55]. Certain transcription factors will bind to the TATA box to begin the production of an RNA polymerase transcription complex[54-56]. When there are changes in gene expression level, we not only need to sequence the gene, but also the promoter. Promoters sometimes have enhancers that act upon them in a cis-regulatory fashion to either increase or decrease transcription. By interacting with promoters through DNA looping, enhancers are able to regulate gene expression's temporal and spatial patterns. Enhancers can be located as much as 1,000,000 base pairs away and are 50-1500 base 
pairs in size $[57,58]$. Compared to the promoter, the enhancer is not easy to find, because it does not have an obvious feature and the range is relatively large.

When we want to study a genetic disease, we should know the whole genome expression levels differences between the patient and normal people. Microarray technology is a great exploratory tool, and is commonly used in both scientific and clinical research[59]. It can help us look at the gene expression profile and can also be used to simultaneously measure thousands of gene expression levels. DNA microarray is a special microscope glass slide (also called gene chip) with thousands of small probes containing a known DNA sequence or gene at defined locations. For microarray analysis, researchers collect mRNA samples from experimental and control groups. The reference sample is collected from a healthy individual, while the experimental sample is taken from a diseased individual (samples are from people of the same age, gender, etc.). These mRNA samples are then converted to complementary DNA (cDNA) and labeled with fluorescent probes containing the color. The experimental and control samples are then hybridized with the microarray slide. Hybridization is the process of binding a cDNA molecule to a DNA probe on a slide. After hybridization, the expression levels of genes are scanned by the microarray fluorescent scanner. Data analysis is done using microarray software[59, 60]. There are two types of Microarray; one type (two-color technique) uses red and green fluorescent dyes to hybridize experimental and control sample separately and then load them on one chip. When gene expression levels in the experimental sample are higher than the control sample, they will show one color (normally red); when gene expression levels in the experimental sample are lower than the control sample, they will show another color (normally Green). We can judge the strength of the expression levels based on the gradient of the two colors. The data collected by the microarray can be used to create a gene expression profile. These high or low expressed genes will be our candidate genes. However, since microarray data only shows the difference in expression, not the fold change, it cannot be looked at as accurate because it may show a low difference while actually having a large fold change. Another type of Microarray uses the one-color technique. The experimental and control samples are separately hybridized on two chips with one fluorescent color. There are multiple standard control probes on the chips to quantify the genes expression levels. Each probe is quantified comparing with standard control probes, thus avoiding errors in different batches. At the same time, each probe can determine the individual absolute expression levels according to the standard control probes. The digital expression levels of the experimental and control samples can be analyzed by fold changes[61, 62].

For these up or down expressed genes, an important step is to narrow down the region to identify the mutated genes. Using the recombinant inbred (RI) strain to find the quantitative trait locus (QTLs) that can help to narrow down the candidate genes[63-66]. RI strains are a very important and useful resources for mapping a complex trait. The RI principle is simple and can work on many species. We use two strains to crossover, beginning with the F2 generation, and paired to establish a new set of inbred lines through repeated sibling mating. The RI strain has two characteristics[64, 67]. First, as with the F2 progeny, each contains different chromosome segments randomly selected from two progenitor cells, and thus each new strain has a random different chimera 
arrangement. Second, unlike the F2 progeny, each pair of chromosomes is homozygous for an extension of the mosaic of alternating chromosomes derived from two progenitor cells within each strain. The RI resource is very useful for mapping a gene of a basic phenotype and is particularly useful for complex phenotypes such as developmental processes, regulatory phenomena, and disease progression. The completion of the mouse genome sequence and extensive genotyping of RI strains greatly enhanced QTL mapping and candidate gene discovery in QTL studies[68]. The combination of RI strains and genomic information will enable the rapid development of QTL gene discovery[67]. QTL uses molecular marker to link the complex phenotypes with chromosomes specific region to identify the candidate genes. Usually, a single phenotypic trait is affected by many genes in multiple QTLs. The QTLs can be used to identify the action, interaction, and number of genes in these precise regions. When the gene or genes are identified as contributing to a phenotype on this region and have expression level changes. The gene or genes can be sequenced to compare with the normal gene or genes. Basically, QTL mapping is used to find the association between genes and the variation of a trait. The difference between the mapping of QTL and a simple trait is that QTL needs to conduct correlations between many genes and many small changes in the trait, which turns out to be much more difficult to do. As the number of genes for a trait becomes larger, the effect of each gene on the variation of the trait gets smaller. The influence of the environment becomes important, at least in terms of the measurement of the influence of a genetic locus. By examining the up- and down-regulation of genes and the location of the genes on QTLs, we narrowed down the number of genes to a relatively small range, though finding the candidate gene out of all the genes in this range still very difficult. For some chronic diseases, it seems that the causative mutation does not exclusively appear in well-known candidate genes.

GeneNetwork is an online software tool that can be used to search complex genes and molecular networks to understand their functions and phenotypes[69]. Utilizing sets of linked data to quantify the genes correlation, it can be used to study humans, mice, rats, fruit flies, and more. There are many sequences and extensive transcriptome data available on GeneNetwork[69-71]. It can be used to measure the extent to which genes are correlated with the same biological substrates in genetically similar individuals. Genetic correlations analyze gene expressions and traits within varying strains of interest. The QTL mapping module allows users to quickly analyze traits controlled by genetic variation and environmental factors online[70]. Genetic maps from the database can aid in finding genetic modifiers that cause phenotypic differences. An important association shows the presence of a QTL correlated with the tag that displays the association. Simple interval mapping can test the association between the trait values at multiple analysis points between each pair of adjacent marker loci and the expected genotype of the target QTL. The bootstrap method can be performed to estimate the confidence interval at the QTL location. Composite interval mapping and simple interval mapping is very similar. However, unlike simple interval mapping, within each analysis point composite interval mapping also analyzes other markers at different locations in the genome[70]. These markers have previously been shown to be associated with traits, so we can assume that they are close to background QTL. Paired scans evaluate all pairs of markers in the dualtrack model, including the main effects and interactions at each locus. These multiple 
QTL models can help to find complex phenotypes. For all mapping methods, the empirical significance threshold can be determined by adding a displacement test. Some examples include the dominance of various traits in breeding or what would happen if only one trait is selected but other genetically related traits are expressed in unison[6971].

Genetically related assays can be applied to the same methods used to determine heritability. There are several types of genetic correlations[72-75]. One type of correlation is Matrix/PCA, which can compare the values of more than 100 features in the set. The correlation matrices can then be exported, and new composite phenotypes can be generated by using the principal component derivative of the feature set. QTL heatmaps are another type of genetic correlation that efficiently identify common and/or unique genetic determinants amongst large and complicated phenotypes[70]. This method can be used to analyze up to 100 traits simultaneously, sorted either by hierarchical clustering or their order within the genome[73]. Another type of genetic correlation, compare dependencies, looks for shared genetic correlations in a set of features by cross checking these traits with records across many databases. Lastly, network graphs examine the network of associations between large phenotypes. The diagrams are interactive, which allow users to select certain sets of features that can then be stored briefly for further analysis in data sets such as GeneNetwork[69, 71, 72, 74].

An important step is to identify every possible genetic factor within this region. It is essential to obtain not only accurate genome information, but also every possible candidate gene within the genome sequences, though there are still gaps and errors in the sequence assembly. Based on previous knowledge of its biochemical functionality and mutant phenotypes, the candidate mutation gene was widely thought to contain alleles causing a mutation disorder or contributing to a complex phenotype closely related to said gene[71, 75].

Candidate gene studies use markers derived from prior hypotheses regarding the phenotypic effect of one or multiple selected genes. The advantage of this gene approach is that the most relevant and crucial genes will be tested[76]. Researchers use various methods to detect such genes that are most likely to treat diseases. One method utilizes several candidate genes that perform similar functions to find the genetic pathway. Pathways are genes associated with drug metabolism (pharmacokinetics) and drug reactions (pharmacodynamics)[77-79]. Researchers utilize the candidate gene pathway strategy so that they can easily identify the effect of gene aggregation on the phenotype with less influence of the individual gene on the downstream phenotype. Its success, however, largely depends on the hypothesis used to select the gene to be studied[77, 79]. A risk of this method is that some genes that play an important role in pharmacokinetics and pharmacodynamics may be passed over. In the past, candidate gene studies across all traits have been severely lacking. Usually, diseases are linked to many different genes and thus makes it difficult to judge whether they result from mutations or pathway genes[41,80]. 
Candidate gene studies have often failed to determine the genetic basis of common characteristics, suggesting that this method has some limitations[81, 82]. First, the selection of candidate genes may not be suitable. Second, the selected SNP may provide limited coverage and could miss several mutations. Third, the gene in question may be located at the point of action of the selected candidate or upstream of the downstream signaling pathway. Fourth, most of the studies are underpowered; therefore, they face population stratification, phenotypic, and site heterogeneity issues. Lastly, and most notably, candidate gene studies are completely reliant on past data and prior hypotheses on disease, so it is impossible to discover genetic variants in new pathways.

Once one or a small number of candidate gene have been selected, we will examine the difference between the candidate genes and normal genes. As we mentioned before, the change may be only on a single nucleotide or may have a large segment missing. Sequencing is an important method used to detect genetic mutations. The sequencing technology can make the biological signal into a digital figure, making the data more accessible to researchers[83, 84]. Sequencing is a method developed in 1975 by Frederick Sanger, who would later go on to win the Nobel Prize, and is thus also commonly referred to as Sanger sequencing[85]. Sequencing is used to determine the exact sequence of a DNA molecule. The DNA molecule itself serves as a template for its own sequencing. DNA primers first synthesize a fragment of DNA, then the fragment is evaluated. We used ABI Model 3130XL Genetic Analyzers with four-color fluorescencebased sequencing to detect the DNA sequence[86]. For the DNA synthesis reaction, the key lies in the addition of a small amount of the corresponding dideoxynucleotide triphosphates (ddNTPs) to bind A, G, T, C with the four fluorescence colors. The DNA samples go through the four-capillary array and read the fluorescence color from the capillary array detection, then a schematic representation of the in-capillary detection is made. By finding the nucleotide polymorphisms between the experimental and control group, we can calculate the changes in the amino acids. When we know the full amino acid sequence, we get the new protein structure by protein modeling. Based on the protein change, the protein function can also be changed.

Progress in the research of the nucleotides or protein changes help people get to the next step in the study of immune-mediated diseases and gene therapy. It is the introduction of exogenous normal genes into target cells to correct or compensate for diseases caused by genetic defects and abnormalities for therapeutic purposes[87]. Gene therapy is currently only in the laboratory stage and is thus not yet universal[ 88,89$]$. Currently, many labs want to use the genetic material of stem cells to treat a genetic disorder. There are several approaches to gene therapy that have been tested[87, 89].1) Replace a disease-causing mutated gene with a healthy copy. 2) Knock out a mutated gene that is not functioning correctly. 3) Insert a new gene into the body to help fight a disease. The gene or genes can synthesize unique proteins, that can be used to correct these genetic disorders. In the future, this technique can help doctors treat a disease by inserting a gene or protein into a patient instead of using drugs or surgery[89]. Although gene therapy shows promise as a treatment option for diseases, it is still very risky. Currently, it is still being tested to ensure that it will be safe and effective[90]. 
Animal models are useful tools to help us study human diseases. The model usually is an animal with a disease or a phenotype similar to a human one[91]. Animal models are widely used in genetic mapping and transgenic studies for many reasons. The main reason for using animal models in genetic research is to obtain data that cannot be obtained from humans [92]. One example is gene therapy: genetic material can be put into animals, but it is not yet possible to test on humans. Genetic studies need heritable materials such as DNA and RNA. While we can easily obtain tissues such as the liver, heart, and brain from animals to extract RNA, it is extremely difficult to get them from humans[92]. Several benefits to using the mouse model include: a short generation time, a short life span, large population size, easy manipulation of environmental conditions, diseases or conditions that can be created that are similar to the human's, and possible manipulation of genetic materials. However, there is also a disadvantage to using animal models. Depending on different situations, sometimes the differences between humans and animals are so large that the results from animal models are not reflective of those of humans[93]. Selection of a species of animal model should not be based on availability, familiarity, or cost, but rather on the biology, the suitability for the disease or trait, and the impact of the study on humans. There are many animal models that have been well developed. Mammal models have been most commonly used because of their obvious similarities in both structures and function to those of humans [94].

The mouse is an excellent model system for understanding the development of mammals, especially humans[95]. Mice and humans are very similar in development and physiology, and many comparisons can be drawn between the two. There is a lot of knowledge about human and mouse genomes. In most regions of the genome, the order of genes, and therefore, the linkage of genes, is conserved between mice and humans. These homologous or heterologous regions drive the advancement of human and mouse genome projects because information about one system can be directly translated to the other system $[8,95]$. In addition, since a very large portion of the human and mouse genomes have been sequenced, direct sequence comparisons are now possible. Moreover, the mouse genome has been extensively characterized and its whole genome sequence has been completed, allowing for the execution of gene-targeted "knockouts" of every gene and transgenic over-expression in mice. We will use the mouse model to discuss the methodology and application of animal models in QTL mapping[94]. 


\section{CHAPTER 2. GENETIC STUDY OF HUMAN RHEUMATOID ARTHRITIS USING THE SPONTANEOUS ARTHRITIS DISEASE MOUSE MODEL ${ }^{1}$}

\section{Introduction}

Rheumatoid arthritis (RA) is a common autoimmune arthritis. The disease involves pain, swelling, and damage in the joints. Genetic and environmental factors control the disease[96, 97]. For example, susceptible genes, humidity, and temperature all affect RA. It is a systemic, chronic, inflammatory disorder that is presented in the wrists, ankles, and small joints of the hands and feet. There are around 1.5 million people that have the disease in the United States. RA normally starts between the ages of thirty and fifty, but having the disease at any age is possible. The etiology of RA is not yet completely known; it is a complex disease caused by many factors, with genetics and the environment being the most important factors[98]. The chronic multi-synovial inflammation in arthritis can cause extra-articular pathological changes[99]. RA occurs repeatedly and is distributed symmetrically in the body. There are several stages of RA. In the first stage, the inflammation is in the joint capsule, there is swelling in the synovial tissues, and the symptoms include pain, swelling, and stiffness in the joint. In the second stage, the cartilage is damaged by the inflammation of the synovial tissue. During the third stage, inflammation is found not only in the synovium and cartilage. It also causes bone erosion and decreases muscle strength[100]. During the last stage, the joints lose their function and patients have the possibility of crippling. No matter which stage, swelling and pain are always present. From the pathology, the major involvement of rheumatoid arthritis is in the joints, and includes the synovium, cartilage, bone, muscle, and joint ligaments[101]. Symptoms of systemic rheumatoid arthritis include fever, fatigue, pericarditis, subcutaneous nodules, pleurisy, and peripheral neuropathy. The inflammation also influences the other connective tissues, such as the serosa[102], heart[103], lung[104], and eyes[105].

Studies of the genetic factors affecting arthritis have been conducted using animal models, and research on the genetic basis of arthritis has had significant results. A rat model was first used to report the susceptibility of multiple QTLs to regulate Collageninduced arthritis (CIA) in 1996[106]. In the study, CIA in rats and mice are both major histocompatibility complex (MHC)-linked, and a considerable portion of arthritis cases are caused by a non-MHC-linked molecular mechanism on other chromosomes.

Identification of genes that regulate susceptibility to non-MHC-linked arthritis is essential for understanding the molecular mechanism of non-MHC-linked arthritis and selecting molecular targets for therapy[107]. Many non-MHC QTLs have been located on different chromosomes by various research groups. For example, Remmers et al. found non-MHC QTLs in chromosomes 1, 4, 7 and 10[106]. Otto et al. identified an instructive QTL on

\footnotetext{
${ }^{1}$ Used with permission. Tian, C*, Liu, $X^{*}$, et al. Ifi204 as the most favored candidate gene that regulates susceptibility to spontaneous arthritis in mice deficient in IL-1ra. Gene Reports. 2018, Volume 12, 21-29. *Co-first authors. doi: 10.1016/j.genrep.2018.05.006 [97].
} 
chromosome $8[107,108]$. They identified many QTLs on other chromosomes, scanned a genomic mouse model of arthritis and found that it was independent of proteoglycaninduced arthritis and did not rely on a QTL associated with MHC QTL. Ibrahim's group used (DBA/1×FVB/N) F11/12 AIL mice to improve arthritis severity and seizures as well as antibody responses in CIA by QTL[109]. (DBA/1 $\times \mathrm{FVB} / \mathrm{N}) \mathrm{F} 2$ generation has been used to identify the QTL region[109, 110].

The major histocompatibility complex is a generic name for the gene groups that encode the antigens of biocompatible complexes. This is a group of tightly linked gene groups that are located in a specific region of an animal or human chromosome and are highly polymorphic. The encoded molecules are expressed on different cell surfaces and participate in antigen presentation, restricting mutual recognition between cells and inducing immune responses. The names of the different species of mammalian MHC and their encoded products vary. The MHC is called the $\mathrm{H}-2$ complex in mice. Human MHC is often referred to as human leukocyte antigens (HLA) genes or HLA complexes. Its encoded molecules are expressed on leukocytes. The distinction between genes is often referred to as HLA molecules or HLA antigens[111]. Progress has been made on the study of the MHC-linked molecular mechanism of arthritis. CIA was one of the mouse models of arthritis found to be associated with the MHC[112-114]. From the literature, collagen induced arthritis is MHC-linked in both rats and mice[115-117]. However, there is a portion of arthritis diseases that are not MHC-linked. Our goal is to study and improve the understanding of the non-MHC-linked molecular mechanism that leads to spontaneous arthritis disease[118-123]. Identification of genes that regulate via nonMHC-linked arthritis can improve our understanding of this disease and help us to choose better molecular treatment (Figure 2-1). Many non-MHC-linked loci have been identified, yet the causal genes for these QTLs have yet to be identified [124, 125].

Many different mouse models have been used to study non-MHC-linked arthritis. In mice, an interleukin-1 receptor antagonist (IL-1 ra) deficiency leads to spontaneous arthritis. This serves as an important model for studying human arthritis. The proinflammatory cytokine IL-1 is an important mediator of inflammation and arthritis in mice. IL-1 is present in the immune system in the body[120, 126]. In animal studies, researchers directly injected IL-1 into normal rabbit joints and this was shown to induce severe arthritis. Treating BALB/c mice with IL-1 enhances the development of arthritis. IL-1ra is an endogenous neuroprotectant that can inhibit IL-1. The action of IL-1ra binding to the IL-1 receptor can prevent the IL-1receptor from binding to IL-1.

IL-1ra is a member of the Interleukin-1 gene family. It is a very important cytokine to regulate the biologic activity of IL-1. IL-1 is produced by monocytes, endothelial cells, fibroblasts, and other types of cells in response to infection. It is a general term for the two different proteins IL-1 $\alpha$ and IL-1 $1 \beta$, both of which bind to the same receptor in the immunoglobulin superfamily[127]. IL-1 is a regulatory and inflammatory cytokine. In the immune system, IL-1 production can often lead to inflammation. The role of IL-1 is not just inducing inflammation, it is also involved in bone formation and remodeling, insulin secretion, appetite regulation, fever induction, 


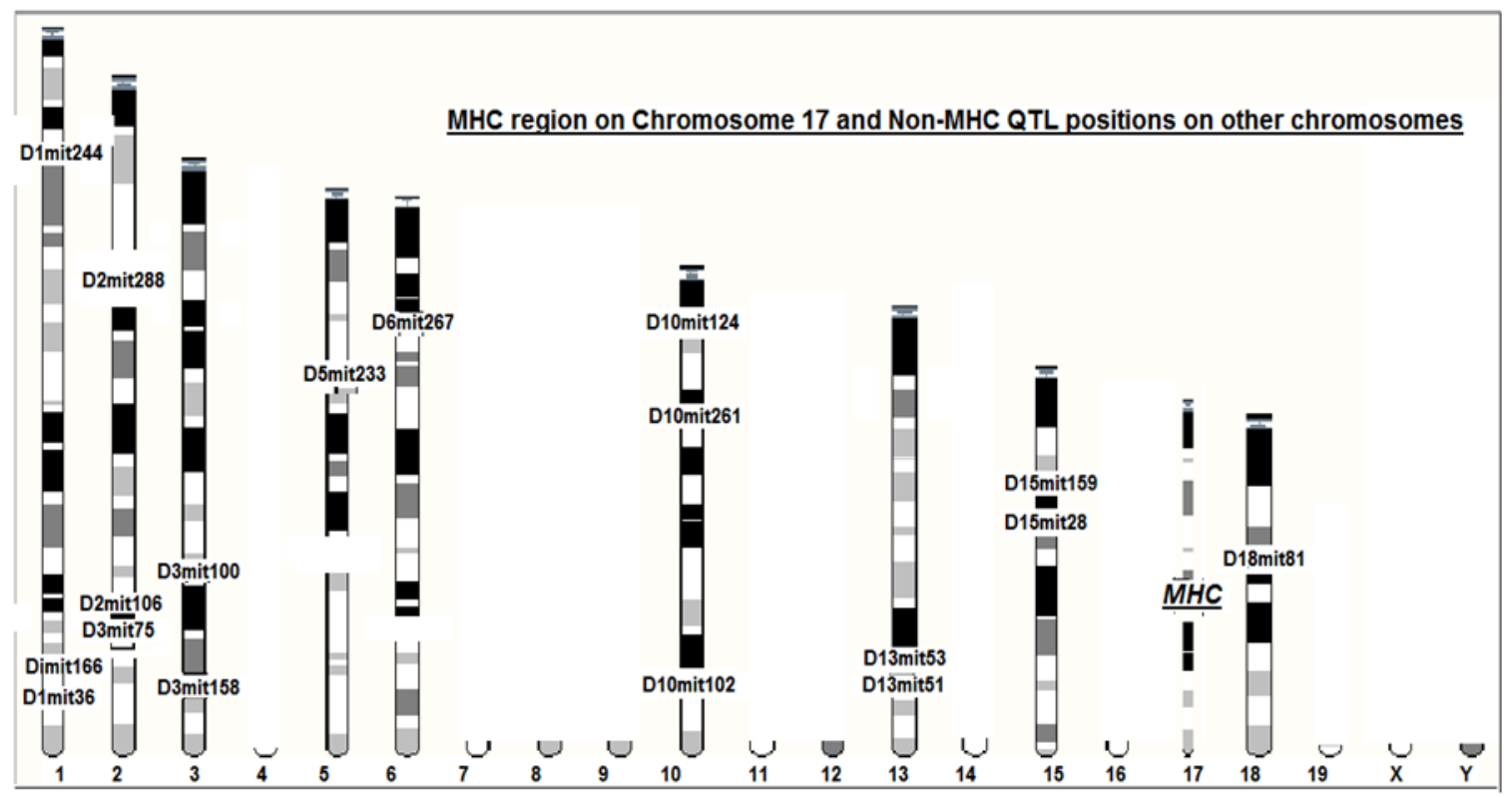

Figure 2-1. MHC genomic region on mouse chromosome 17 and non-MHC QTL loci on other chromosomes marked by molecular markers on 9 out of 19 autosomal chromosomes.

MHC genomic region on mouse chromosome 17 and the non-MHC QTL loci have been identified on Chromosome 1, 2, 3, 5, 6, 10, 13, 15, 17, and 18 . 
neuronal phenotypic development, and IGF/GH physiology. IL-1 has been widely reviewed, and there is an understanding of its biological activities and properties[126]. Our hypothesis is that the Ifi200 gene cluster regulates susceptibility to SAD in mice. Within the Ifi200 cluster we focused on the Ifi204 gene. Our hypothesis is based on the fact that expression levels of Ifi2 200 cluster genes decreased while resistance to SAD increased in the congenic strain with BALB/c background, and the Ifi2 200 cluster genes are the only group of genes relevant to SAD within the QTL region which showed the differential expression[97].

IL-1ra plays an important role in regulating the effects of IL-1, which in turn plays a significant role in the up-regulation and down-regulation of inflammation [128]. IL-1ra is a competitive and endogenous inhibitor produced by mononuclear and macrophages. It can bind to IL-1 receptors because IL-1 ra has similar affinity to IL-1 $\alpha$ and IL-1 $\beta$. IL-1ra binds to the IL-1 receptor and blocks the activity of IL-1. IL-1ra can terminate the inflammatory response[129]. The IL-1 ra level normally increases later than the IL-1 level in inflammatory response. Increasing the IL-1ra levels in mice can reduce inflammation in various diseases[128].

Spontaneous arthritis disease (SAD) has been used to study rheumatoid arthritis in humans. Horai and his coworkers showed that IL-1ra- deficient BALB/c mice develop spontaneous arthritis[130]. Zhou developed DBA/1 mice with a deficiency in IL-1 ra, but found that the DBA/1 strain exhibits a resistance to arthritis [131]. The BALB/c and DBA/2 strains have the same MHC haplotype, but these two strains are genetically distanced from each other. The DBA/1 and C57BL/6J (B6) are susceptible to CIA, but CIA cannot be induced in BALB/c mice. It is well known that DBA/1 and B6 mouse strains have been widely used in CIA while BALB/c show resistance to CIA. SAD is dependent on non-MHC genes in BALB/c mice that lack IL-1 ra. IL-deficient mice can be used to show the disease incidence of SAD in different mouse strains. Understanding the molecular mechanism that leads to SAD in IL-1rn-deficient mice will represent a breakthrough in the study of non-MHC-linked arthritis. Histopathological examination of the ankle joints of these mice revealed inflammatory cell infiltration and synovial proliferation in $\mathrm{BALB} / \mathrm{c}^{-/-}$, but not in $\mathrm{DBA} / 1^{-/-}$mice[132]. The bone structure and density are also changed in $\mathrm{BALB} / \mathrm{c}^{-/-}$, but not in $\mathrm{DBA} / 1^{-/-}$mice. $\mathrm{BALB} / \mathrm{c}^{-/-}$mice are sensitive to nearly $100 \%$ incidence and high severity of arthritis at 7 weeks, but the DBA $/ 1^{-/}$mice are resistant to spontaneous arthritis until they are very old. BALB $/ \mathrm{c}^{-/-}$mice develop spontaneous chronic inflammatory arthritis, whereas DBA/1/-- mice are resistant $[97,132]$.

A classic genetic technique, whole genome linkage analysis was used to detect QTLs regulating the disease incidence and severity. Two different strains were used to obtain the F2 generation and the QTL differences were identified between the two parental strains[133]. F1 mice were created by intercrossing a resistant strain $\left(\mathrm{DBA} / 1^{-/}\right)$ and a susceptible strain $\left(\mathrm{BALB} / \mathrm{c}^{-/}\right.$) of spontaneous arthritis under IL-1 ra deficiency. F2 mice were used to map the QTL region that regulates IL-1 ra deficient spontaneous arthritis. There are many QTL locations to be determined because spontaneous arthritis is a complex disease and is controlled by many genetic factors. Many pathways associated with IL-1 ra are of importance. The whole-genome mapping shows the potential QTLs of 
the disease are on chromosomes 1, 6, 11, 12 and 14. The QTL on chromosome 1 has a major genetic effect on spontaneous arthritis in F2 mice. The pathogenic genes are narrowed down within this QTL[133].

The F2 generation was not only used to identify the QTLs, but also continued to generate two congenic mouse strains using BALB $/ \mathrm{c}^{-/-}$and $\mathrm{DBA} / 1^{-/-}$as the parental strains. These two congenic stains can help us to understand more of the molecular mechanisms with the parental strains[133]. Congenic strains are generated by transferring a DNA fragment from one genetic background to a specific inbred strain through repeated backcrossing. Backcrossing is a process where the mouse containing the donor allele is bred with the recipient inbred partner. Recipient inbreeds are inbred lines that provide the genetic background for the newly formed isogenic lines. The donor allele is the allele of interest. Subsequent hybridization is the backcross of the recipient's inbred line. Congenic strains are used because they differ by a specific chromosomal region. Our group developed a mouse DBA.B-1//- congenic strain with a BALB $/ \mathrm{c}^{-/-}$DNA fragment in the $\mathrm{DBA} / 1^{-/-}$mouse background (by comparing the genetic markers, the genomic transferred region is between D1Mit400/506; chromosome 1, 163,306,348 bp to the distal end of the chromosome) and determined its susceptibility to spontaneous disease. But at a later point, the limbs of DBA.B-1/- congenic mice can develop inflammation. Our group also developed a BALB.D-1 $1^{-/-}$congenic mouse strain with a DBA $/ 1^{-/-}$DNA fragment in the $\mathrm{BALB} / \mathrm{c}^{-/-}$mouse background. By comparing genetic markers, the genomic transferred region is between D1Mit1 10 (chromosome 1, 167,758,517 bp) and D1Mit209 (chromosome 1, 191,493284 bp) (Figure 2-2). At approximately eight weeks of age, limbs in BALB.D-1 ${ }^{-/-}$congenic mice start to develop inflammation. The two congenic strains were relatively susceptible to spontaneous arthritis in varying degrees. BALB.D-1 ${ }^{-}$ ${ }^{1-}$ congenic mice delayed the onset and reduced the severity of disease compared to BALB $/ \mathrm{c}^{-/}$. Compared to congenic DBA.B- $1^{-/}$and DBA $/ 1^{-/}$, the incidence and severity in DBA.B- $1^{-/-}$were higher than in DBA/ $1^{-/-}$mice[97, 131, 132, 134, 135].

Microarray gene expression analysis was used to analyze whole genome expression profiles. This technique has been used for more than a decade and is already very mature. This technology was used to compare the whole genome expression profiles between congenic BALB.D-1 ${ }^{-/-}$and DBA.B-1 $1^{-/-}$to the four other parental strains: $\mathrm{BALB} / \mathrm{c}, \mathrm{DBA} / 1, \mathrm{DBA} / 1^{-/-}$, and BALB/ $/ \mathrm{c}^{-/-} \mathrm{IL}-1 \mathrm{ra}$ deficient mice. The expression levels of the Ifi gene family had a similar change in all of the SAD susceptible mice. The Ifi gene family expression levels are correlated with the resistance or susceptibility to SAD [134]. The Ifi genes in BALB.D-1 ${ }^{-/}$are lower than in BALB $/ \mathrm{c}^{-/}$, and in DBA.B-1 $1^{-/-}$they are higher than in DBA/1. The Ifi gene family is also in the QTL region on chromosome 1[136]. The Ifi204 gene had the most different expression levels between the susceptible and resistant strains within the Ifi 200 family.

The interferon-activatable 200 gene cluster is a family of interferons. Interferons (IFNs) are cytokines that regulate host resistance against infections by exerting antimicrobial, immunomodulatory and cell growth-regulatory functions. The biological activities of interferons are mediated by IFN-induced proteins. The Ifi200 family (lfi200 

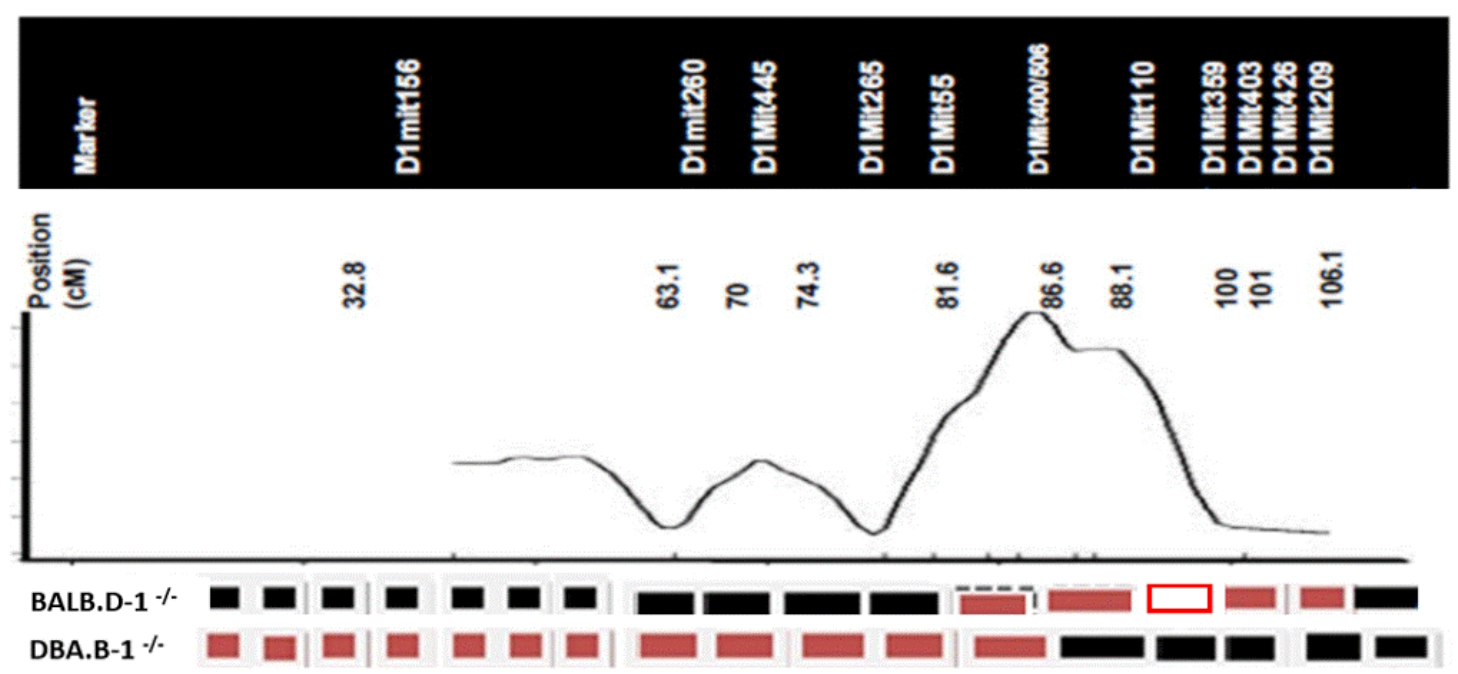

Figure 2-2. Genomic region of the QTL on chromosome 1 and two congenic strains.

The top part uses the F2 generation to represent the location on QTL mapping for arthritis that has been previously identified. Numbers on the top are the genetic distance along the chromosome. According to the genetic map, the QTL that regulate the SAD may be located in the region between $81 \mathrm{cM}$ and $100 \mathrm{cM}$. The bottom part depicts the transferred genomic regions in the two congenic strains. Microsatellite markers are listed along the chromosome as molecular markers during the congenic breeding. Below the markers are the chromosomal components of the two congenic strains. Genomic components of $\mathrm{BALB} / \mathrm{c}^{-/-}$are indicated by black boxes. While the genomic components of DBA $/ 1^{-/-}$are indicated with red boxes. Congenic strain BALB.D1-1// contains a genomic region (red boxes) from $\mathrm{DBA} / 1^{-/-}$into $\mathrm{BALB} / \mathrm{c}^{-/}$genomic background between D1Mit55 and D1Mit209. In congenic strain DBA.B $-1^{-/}$, the genomic region from $\mathrm{BALB} / \mathrm{c}^{-/}$into $\mathrm{DBA} / 1^{-/}$strain is from D1Mit400/506 until the distal end. Based on the transferred genomic regions in these two congenic strains, the QTL is most likely within the region between D1mit400/506 and D1mit209. 
cluster) is encoded by several structurally related genes located on murine chromosome 1 and three homologous genes (MNDA, IFI 16 and AIM2) located in the human chromosome, within a linkage group highly conserved between mouse and human. There are at least six members in the Ifi200 family, designated Ifi202a, Ifi202b, Ifi203, Ifi204, Ifi205, and Mndal. In human studies, IFI16 is connected to rheumatoid arthritis. The arthritis mouse models were used to study the Ifi2 200 gene cluster to better understand the arthritis diseases in humans. The Ifi204 gene is located from 173,747,293 to 173,766,943 bp on Chromosome 1 in the genomic QTL region[137]. It has two transcripts, but only one can encode protein. The mRNA size of Ifi204 is $2302 \mathrm{bp}$ and it consists of 9 exons[138]. The Ifi204 gene encodes a $72 \mathrm{kDa}$ polypeptide whose synthesis can be increased by treatment with IFN- $\alpha$ and $\beta$ in several murine cell lines, with the sole exception of those derived from the B6 inbred strain[139]. The Ifi204 protein functions as a growth suppressor in sensitive cell lines, as determined by cell focus assays. Ifi204 is the most important interferon-activated gene in the Ifi2 200 cluster for the study of inflammation diseases in mice. The Ifi204 gene was sequenced between BALB/ $\mathrm{c}^{-/-}$and DBA $/ 1^{-/}$strains, and it was shown that they had multiple polymorphisms between them[97, 140-143].

\section{Materials and Methods}

\section{Mice}

BALB/c and DBA/1 wild-type mice were purchased from the Jackson Laboratory (Bar Harbor, ME). Animals that had an IL-1ra deficiency on the BALB/c background $\left(\mathrm{BALB} / \mathrm{c}^{-/}\right)$were initially provided by Dr. Yoichiro Iwakura (Tokyo Medical and Dental University, Tokyo, Japan)[130]. Animals that had an IL-1ra deficiency in the DBA/1 background $\left(\mathrm{DBA} / 1^{-/}\right)$were generated at the University of Tennessee Health Science Center (UTHSC)[131]. We used congenic DBA.B- $1^{-/ /}$mice $\left(B A L B / \mathrm{c}^{-/}\right.$fragment in DBA $/ 1^{-/}$background strain) and BALB.D-1/- $\left(\mathrm{DBA} / 1^{-/}\right.$fragment in BALB $/ \mathrm{c}^{-/-}$ background strain) mice. All mice were developed and bred in the Veterinary Medical Unit of the Memphis VA Medical Center. All experiments followed approved laboratory animal protocols and were approved by the VA Institutional Animal Care and Use Committee.

Arthritis disease phenotype BALB/ $\mathrm{c}^{-/}$, DBA $/ 1^{-/-}$, BALB.D-1 $1^{-/-}$, and DBA.B-1 $1^{-/-}$ mice were maintained in standard microisolator cages for 4 months. The severity of arthritis was graded on each ankle joint on a scale from 0 to 4 for the degree of redness and swelling on the left anterior limb, left posterior limb, right posterior limb, and right anterior limb, as viewed from behind the mice. The grades: $0=$ no evidence of swelling, $1=$ mild swelling of the joint and/or redness of the footpad, 2 = obvious joint swelling, 3 $=$ severe swelling of the entirety, and $4=\mathrm{limb}$ burned out and deformed. The BALB/c and DBA/1 wild-type mice do not have SAD[132]. Each ankle joint was graded twice a week. 


\section{Mouse Tissue Collection}

Mice were sacrificed and tissue samples collected when they were 4 months old and all tissues were stored separately in $1.5 \mathrm{ml}$ tubes. The heart, muscle, liver, spleen, lung, kidney, cerebrum, and cerebellum were put on dry ice immediately. One of the two legs was stored in RNAlater solution (Thermo Fisher, CA) at $4{ }^{\circ} \mathrm{C}$ for a few days. The other leg was stored in $70 \%$ ethanol in a $4{ }^{\circ} \mathrm{C}$ refrigerator. All the tissues except for the leg stored in $70 \%$ ethanol were stored in a $-80{ }^{\circ} \mathrm{C}$ freezer for subsequent experiments.

\section{Analysis of Microarray Data}

Total RNAs were isolated from the spleen in three individuals from each group using the Trizol reagent (Invitrogen, CA) and purified using the RNAeasy Cleanup kit (Qiagen, CA). RNAs were quantified using NanoDrop-2000 (Thermo, DE) and quality was checked using the 2100 Bioanalyzer (Agilent, CA). The high-quality RNA was reverse transcribed to cDNA. Then, cDNA was transcribed to cRNA by using the Illumina ${ }^{\circledR}$ TotalPrep ${ }^{\text {TM }}$ RNA Amplification Kit (Ambion, CA). For each strain, three individual mouse samples were pooled together. The Illumina mouse- 6 v1.1 expression beadchips were used for the generation of whole genome expression profiles. Each chip well required $1.5 \mu \mathrm{g}$ of cRNA sample. The beadchips were hybridized overnight in a multiple-step procedure according to the manufacturer's instructions. After washing and drying the chips, they were scanned on the BeadArray Reader (Illumina, CA). Raw data were analyzed using Illumina BeadStudio 2.3.41 (Illumina, CA).

Raw data were normalized using BeadStudio software. The gene expression profiles of the two congenic strains were compared to the parental strains. The Diff Score from the quantile method is a proprietary algorithm that uses the bead standard deviation to build an error model; this used for the measurement of the significant difference in the expression levels of genes. The Diff Score was set up \pm 10 at initial analysis to avoid missing the candidate genes.

\section{Real-Time PCR}

50ng total RNA was used for TaqMan real-time PCR with the Ifi204 probe Mm00492602_m1. The TaqMan Real-Time PCR reactions were carried out with an ABI 7900 Real-Time PCR System (software: Sequence Detection System 2.3 (ABI)) using ABI's standard protocol for Real-Time PCR and PCR. Samples were normalized to GAPDH expression levels. Data for treatment groups are shown as $\Delta \Delta C T$ normalized to an endogenous reference. 


\section{Rt-PCR}

The expression levels of Ifi202b, Ifi203, Ifi204, Ifi205, and Mndal genes were confirmed by endpoint rt-PCR after being determined by microarray analysis (Table 2-1). The genes expression levels were tested by using the spleen. Individual RNA samples were separately subjected to the assay. Reverse transcription (rt) and PCR were conducted using the One-step rt-PCR kit (Thermo Scientific, CA), as recommended by the manufacturer. Specific primers for selected genes are designed by Primer3. The rtPCR amplified products were tested on a $1.8 \%$ agarose gel.

\section{Sequencing Analysis}

All of the chromosomal regions of interest were sequenced. Ifi204 was identified between BALB $/ \mathrm{c}^{-/-}$and DBA $/ 1^{-/-}$mice. The primers were designed from Primer 3 online (http://bioinfo.ut.ee/primer3-0.4.0/). Products were amplified by PCR and rt-PCR. All of the PCR and rt-PCR products were cleaned by EXOSA-IT PCR CLEAN-UP PROTOCOL; $5 \mu$ PCR or rt-PCR products and $2 \mu 1$ ExoSAP-IT mix were incubated at $37^{\circ} \mathrm{C}$ for $25 \mathrm{~min}$, then at $80^{\circ} \mathrm{C}$ for $15 \mathrm{~min} .3 \mu$ cleaned DNA samples, with $1 \mu 1$ single primer and $8 \mu$ water, was used for sequencing. Samples were loaded on ABI Model 3130XL Genetic Analyzers (Thermo Fisher Scientific, CA). The data were analyzed by Finch TV and ABI Sequence Scanning Software.

\section{Flow Cytometry}

Splenocytes: Fresh spleen tissues were stored in $1 \mathrm{ml} \mathrm{RPMI} \mathrm{1640,} \mathrm{LX} \mathrm{at} \mathrm{RT} \mathrm{when}$ they were collected. Using a frosted-glass microscope slide, the spleen tissues were gently dissociated. Spleen cell suspensions were made by hemolysis with Gey's solution (Gey's stock solution: Stock A: $8.75 \mathrm{~g} \mathrm{NH}_{4} \mathrm{Cl}, 0.46 \mathrm{~g} \mathrm{KCl}, 0.27 \mathrm{~g} \mathrm{Na}_{2} \mathrm{HPO}_{4} \cdot 7 \mathrm{H}_{2} \mathrm{O}, 0.03 \mathrm{~g}$

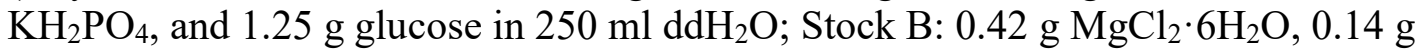
$\mathrm{MgSO}_{4} \cdot 7 \mathrm{H}_{2} \mathrm{O}$, and $0.45 \mathrm{~g} \mathrm{CaCl}_{2} \cdot 7 \mathrm{H}_{2} \mathrm{O}$ in $100 \mathrm{ml} \mathrm{ddH} 2 \mathrm{O}$; Stock $\mathrm{C}: 2.25 \mathrm{~g} \mathrm{NaHCO}_{3}$ in

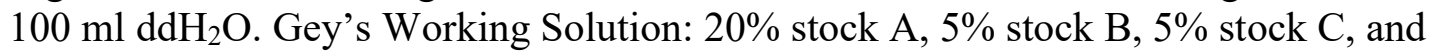
$70 \% \mathrm{ddH}_{2} \mathrm{O}$ ). The cells were then filtered by $70 \mu \mathrm{m}$ sterile cell strainer. Lastly, the cells were washed with PBS 3 times and stored in $200 \mu$ PBS. Lymphocytes: Popliteal lymph nodes were collected from the outside of the thigh, between the skin and muscle. Cells were dissociated using the same technique employed for spleen tissues. $200 \mu \mathrm{PBS}$ was then added into the cells. Leukocytes: EL (erythrocyte lysis) buffer was used to eliminate erythrocytes and dead cells from the blood. Purified leukocytes were placed in $200 \mu \mathrm{l}$ PBS. Fluorescently labeled antibodies specific for CD45 (APC-Cy7), CD3 (AlexaFluor 700), CD4 (Pacific Blue), CD8 (PE), CD19 (peridinin chlorophyll-cyanine 5.5 [PerCPCy5.5]), and CD25 (PerCP-Cy7) were obtained from BD Biosciences (San Jose, CA, USA). Intracellular staining for Foxp3 was performed using anti-mouse Foxp3 antibody labeled with FITC according to the manufacturer's instructions (eBioscience, San Diego, CA, USA). Labeled cells were washed with PBS, and a minimum of 100,000 splenic 
Table 2-1. The Ifi202b, Ifi203, Ifi204, Ifi205, and Mndal cDNA designed primers.

\begin{tabular}{|c|c|c|c|}
\hline Name & Forward-Primer & Reverse-Primer & Size(bp) \\
\hline Ifi202b-CD1 & ccggtgtcattttcttacca & ttggctctctgtagccactgt & 480 \\
\hline Ifi202b-CD2 & agctgacacactctgcettg & taggagcagcetctgacaca & 538 \\
\hline Ifi202b-CD3 & tcaacagcagtggcatccta & tcctcgaagaccatcactctg & 544 \\
\hline Ifi202b-CD4 & taaaaagtaaaaagatgttccatgc & tttcaccattgaattggggtta & 550 \\
\hline Ifi202b-CD5 & attccagcgtgtctgaggtg & ggaacttaagcatgcagactatga & 550 \\
\hline Ifi203-CD1 & agtctccccaggaagacagc & cctgaagtttctggaagctga & 583 \\
\hline Ifi203-CD2 & caaacaagagtgtaccgtcttcaa & actggaagattgtggcaagg & 583 \\
\hline Ifi203-CD3 & agcaattccttcgagcagac & cctggacattcttggatgct & 596 \\
\hline Ifi203-CD4 & accatgcccagaaacatctc & tgaaagccetggaatagcac & 588 \\
\hline Ifi203-CD5 & tcatcaacagcatccagcag & aaccaccactgccatttttc & 603 \\
\hline Ifi203-CD6 & ctcacaagcaaaggggacat & ggatagtgccaaaggcacac & 577 \\
\hline Ifi203-CD7 & ttctaagaaatggtgctttctcat & tcataagccttcttcatcttgc & 572 \\
\hline Ifi203-CD8 & cggggcgtactattttcaac & tgtaaacctgacaggatctgga & 600 \\
\hline Ifi203-CD9 & aaacttcctcttgcacagca & aatcattttcaaggttcatagcat & 570 \\
\hline Ifi203-CD10 & tcacagtgcaccttccagag & gaaagcaattgtgggcctta & 556 \\
\hline Ifi204-CD1 & atgaacgaaactgggaggag & aagttgttgctgagccttcc & 272 \\
\hline Ifi204-CD2 & gcctacctactcaagccaagc & cagtttgcccaatccagaat & 300 \\
\hline Ifi204-CD3 & attctggattgggcaaactg & cgcettgetctttttcactc & 332 \\
\hline Ifi204-CD4 & gggacttctacagcccagaa & ttgatctccaggatgccttt & 449 \\
\hline Ifi204-CD5 & tgagccagtatttccatgtg & ttccttagcaggctcctttg & 496 \\
\hline Ifi204-CD6 & gcaaccaaagttagtgtgtgga & actcacaaatgtccccttg & 436 \\
\hline Ifi204-CD7 & cctgtgtctctgatgtgaacg & tctgtaattgaatcttatctccaca & 462 \\
\hline Ifi204-CD8 & ggaagactcaccaatgtcagg & gcataaaaattgcaaattgaaca & 406 \\
\hline Ifi205-CD1 & ccccatttttcactttctcag & ctgttgtgaaggacccacag & 629 \\
\hline Ifi205-CD2 & cagcccagaaaaggaaaggt & ccaccacttctatgettcctg & 657 \\
\hline Ifi205-CD3 & aggcatcctggagatcaatg & tttttacagtagagaaatgaaatcaaa & 624 \\
\hline Mndal-CD1 & tgtgtgtgtgtgtgtgtgctt & cagtttttgcgatcgettt & 651 \\
\hline Mndal-CD2 & accgagaaggcaaaagttca & gtattggtgactggcacctg & 589 \\
\hline Mndal-CD3 & ccacccagcagttccttaaa & ccactcccetccacttctat & 680 \\
\hline Mndal-CD4 & ctttgagagcaaaggcatcc & caaaatcagaaatcaggtatgaagg & 557 \\
\hline
\end{tabular}


cells were analyzed from each sample with flow cytometry by using the SR II (BD Biosciences).

\section{Results}

\section{Phenotype of Mice}

In the current study, DBA $/ 1^{-/-}$, DBA.B-1/,, BALB.D-1 $1^{-/-}, \mathrm{BALB} / \mathrm{c}^{-/-}, \mathrm{DBA} / 1$ wildtype, and BALB/c wild-type mice were bred in the animal facility under the same conditions (Figure 2-3). The red arrows indicate the area around the ankle that is exhibiting signs of inflammation. The phenotypes of disease for DBA $/ 1^{-/}$, DBA.B- $1^{-/-}$, BALB.D-1 $1^{-/-}$, and BALB $/ \mathrm{c}^{-/-}$were recorded. Mice were scored twice a week for the condition of the disease on each ankle joint, and the scores from each ankle were added together to calculate the cumulative clinical score for four months. The severity of arthritis in the strains is shown in Figure 2-4A, and incidences of disease are shown in Figure 2-4B. We knew that the phenotype of arthritic mice would be physically evident, therefore we began scoring the ankle joint of four strains of mice at 7 weeks of age so that we would not miss the beginning signs of arthritis. The DBA $/ 1^{-/-}, \mathrm{DBA} . \mathrm{B}-1^{-/}$, BALB.D-1 $1^{-/-}$, and BALB $/ \mathrm{c}^{-/-}$mice were scored from 0 to 4 on each ankle joint following the literature. The mice were measured on day $35,39,42,45,49,52,56,59,63,66,70$, $73,77,80,84,87,91,94,98,101,105,108,112,115,119$, and $122 . \mathrm{BALB} / \mathrm{c}^{-/-}$and BALB.D-1 ${ }^{-/-}$mice showed swelling and redness at the ankle joints, clear arthritic phenotypes on day 45; DBA.B-1 $1^{-/-}$mice had mild swelling and inflammation on the hind ankle joints as early as 10 weeks, while $\mathrm{DBA} / 1^{-/-}$mice had almost no change the whole time. These noticeable differences between the strains indicate that BALB $/ \mathrm{c}^{-/-}$and BALB.D- $1^{-/-}$had phenotypic traits of arthritis, DBA.B- $1^{-/-}$had a mild presentation of the normal arthritic phenotype, and DBA $/ 1^{-/}$showed no phenotypic traits of arthritis. At the 4 th month, the scores for both genders of each strain were averaged; BALB $/ \mathrm{c}^{-/-}$male and BALB $/ \mathrm{c}^{-/-}$female scored 11.67 and 11.50; BALB.D-1 $1^{-/-}$male and BALB.D- $1^{-/-}$female scored 10.67 and 10.60; DBA.B-1 $1^{-/-}$male and DBA.B-1 ${ }^{-/-}$female scored 3.44 and 2.32; $\mathrm{DBA} / 1^{-/-}$male and DBA $/ 1^{-/-}$female scored 0.33 and 0.5 . The males showed an earlier progression of severity. The incidences of disease in $\mathrm{BALB} / \mathrm{c}^{-/-}$male, $\mathrm{BALB} / \mathrm{c}^{-/}$female, BALB.D- $1^{-/-}$male, BALB.D-1 $1^{-/}$female, DBA.B- $1^{-/-}$male, DBA.B-1 $1^{-/-}$female, DBA $/ 1^{-/-}$ male, and DBA $/ 1^{-/}$female was $100 \%, 100 \%, 100 \%, 100 \%, 86 \%, 67 \%, 33 \%$, and $50 \%$, respectively, when they were 4 months old. These data, together with the visual changes noted above, suggest that $\mathrm{DBA} / 1^{-/-}$is resistant to arthritis, and that a lack of IL-1ra leads to resistance as well. Introduction of the BALB $/ \mathrm{c}^{-/-}$gene region into DBA.B-1/- results in a mild arthritis phenotype; BALB/ $/ \mathrm{c}^{-/-}$and BALB.D-1 $1^{-/-}$both have the disease. The organs were weighed when we sacrificed them at 4 months of age (Table 2-2). In the four strains, the males were larger than the females. Most organ weights were similar in all four strains, but the spleens in females and males of BALB $/ \mathrm{c}^{-/-}, 0.1412 \mathrm{~g}$ and $0.1471 \mathrm{~g}$ respectively, were larger than the other three strains. The spleen of the male DBA $/ 1^{-/-}$was $0.1439 \mathrm{~g}$, but the spleens of the other strains, besides BALB $/ \mathrm{c}^{-/-}$, were $\sim 0.11-0.12 \mathrm{~g}$. The weight of the male BALB.D-1//- spleen $(0.0973 \mathrm{~g})$ was smaller than that of all other 


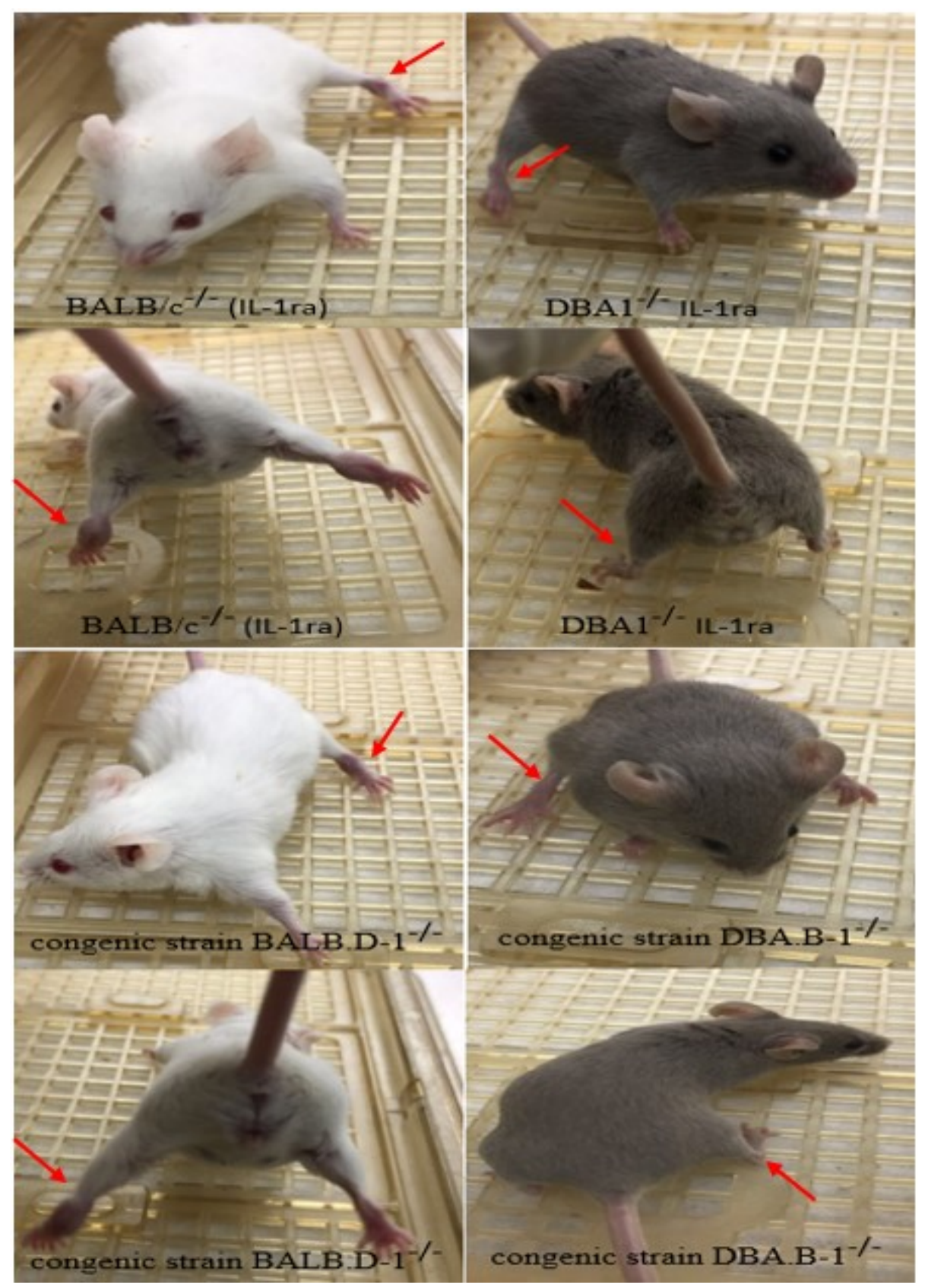

Figure 2-3. The phenotype of DBA/1 ${ }^{-/}$, DBA.B-1 ${ }^{-/}$, BALB.D-1 ${ }^{-/-}$, and BALB $/ \mathrm{c}^{-/-}$ strains.

Four strains of mice were bred in the UTHSC animal facility under the same conditions. The red arrows indicate the hind ankle joints. The ankle joints from hind limbs in the BALB $/ \mathrm{c}^{-/-}$and BALB.D- $1^{-/-}$strains have very severe swelling and redness at 4 months of age. The DBA.B- $1^{-/}$mice have mild inflammation when they are 4 months of age. The $\mathrm{DBA} / 1^{-/-}$strain never had inflammation. 


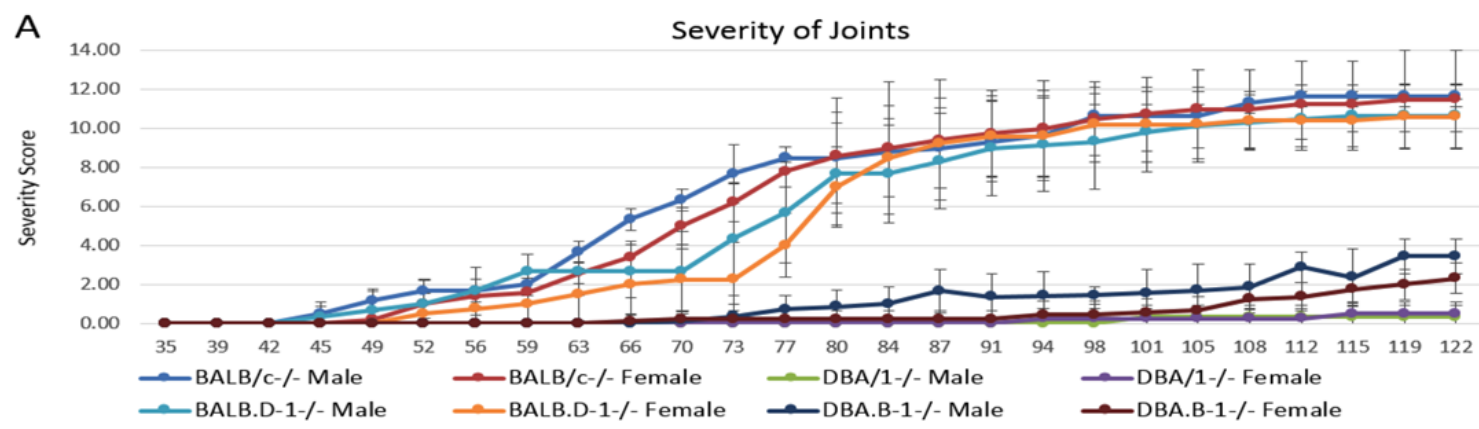

B

Incidence Rate

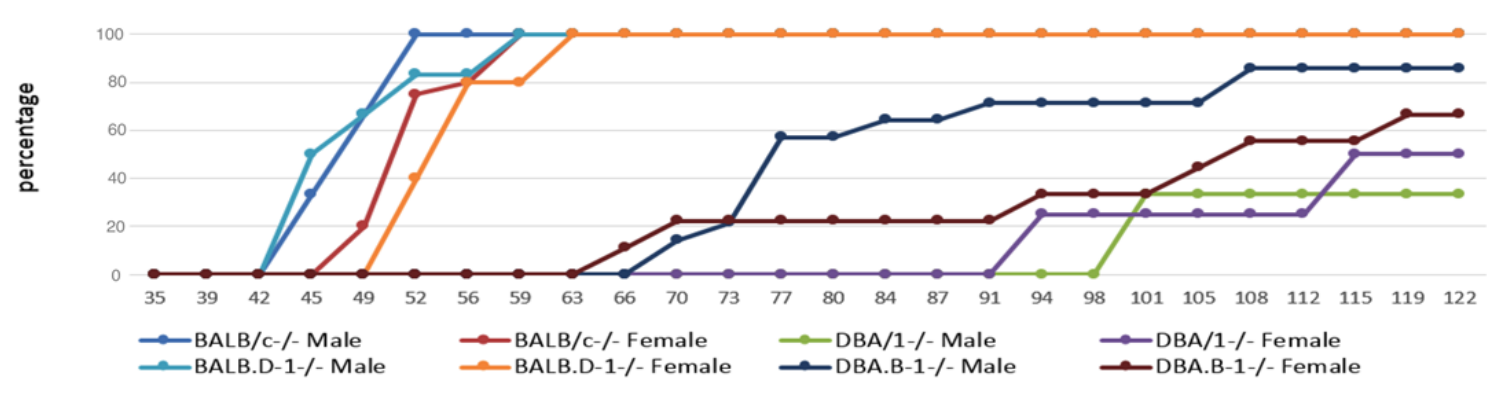

Figure 2-4. Arthritis relative severity and incidence in male and female $\mathrm{BALB} / \mathrm{c}^{-/}$, DBA $/ 1^{-/}$, BALB.D-1 ${ }^{--}$, and DBA.B-1 ${ }^{-/}$mice.

(A) The severity of joint arthritis in both genders of four strains. The days are listed below the horizontal axis and the severity scores are listed to the left of the vertical axis. The BALB $/ \mathrm{c}^{-/-}$mice reach maximum levels of disease severity earlier than the other strains. The congenic BALB.D-1/- have severe swelling and redness, but later and with less severity than BALB $/ \mathrm{c}^{-/}$mice. BALB.D-1 $1^{-/-}$have a later and less severe onset as a result of the fragment of DBA $/ 1^{-/-}$DNA. The DBA.B-1 $1^{-/}$mice begin to have mild arthritis when they are ten weeks old. The severity of arthritis slowly increased over time until the end, when it was higher. The males showed quicker progression of severity among these three strains. The DBA $/ 1^{-/}$mice have almost no arthritis the entire time $(n>6)$. (B) The incidence of ankle joint inflammation in the BALB $/ \mathrm{c}^{-/-}$, DBA $/ 1^{-/-}$, BALB.D-1 ${ }^{-/}$, and DBA.B $-1^{-/}$mice. The days are listed below the horizontal axis and the incidences are listed to the left of the vertical axis. The BALB $/ \mathrm{c}^{-/}$and BALB.D-1 $1^{-/-}$mice have $100 \%$ incidence at a very early stage. At nine weeks DBA.B-1 ${ }^{-/-}$mice began to have incidence of disease. $\mathrm{DBA} / 1^{-/-}$showed incidence around thirteen weeks. The incidence in DBA $/ 1^{-/-}$ is skewed because scoring one mouse as having swelling or redness can change the incidence rate by a great deal. The DBA $/ 1^{-/}$and DBA.B-1/- mice have lower percentages than the BALB/ $/ \mathrm{c}^{-/-}$and BALB.D-1 $1^{-/-}$mice $(\mathrm{n}>6)$. 
Table 2-2. Tissue weight comparison in males and females of the four strains at time of collection. (4 months old) (n=6)

\begin{tabular}{|c|c|c|c|c|c|c|c|c|c|c|}
\hline Mice & $\begin{array}{l}\text { IL- } \\
\text { 1ra }\end{array}$ & $\begin{array}{l}\text { Weight } \\
\text { (g) }\end{array}$ & $\begin{array}{l}\text { BL } \\
\text { (CM) }\end{array}$ & $\begin{array}{l}\text { TL } \\
\text { (CM) }\end{array}$ & $\begin{array}{l}\text { Liver } \\
\text { (g) }\end{array}$ & $\begin{array}{l}\text { Spleen } \\
\text { (g) }\end{array}$ & $\begin{array}{l}\text { Kidney } \\
\text { (g) }\end{array}$ & $\begin{array}{l}\text { Thymus } \\
\text { (g) }\end{array}$ & $\begin{array}{l}\text { Heart } \\
\text { (g) }\end{array}$ & $\begin{array}{l}\text { Lung } \\
\text { (g) }\end{array}$ \\
\hline BALB/c IL-1ra F & $-/-$ & $\begin{array}{l}21.4250 \pm \\
0.6987\end{array}$ & $\begin{array}{l}8.0500 \pm \\
0.2624\end{array}$ & $\begin{array}{l}8.8500 \pm \\
0.2380\end{array}$ & $\begin{array}{l}1.1617 \pm \\
0.0772\end{array}$ & $\begin{array}{l}0.1412 \pm \\
0.0162\end{array}$ & $\begin{array}{l}0.2706 \pm \\
0.0144\end{array}$ & $\begin{array}{l}0.0288 \pm \\
0.0031\end{array}$ & $\begin{array}{l}0.1074 \pm \\
0.0065\end{array}$ & $\begin{array}{l}0.1335 \pm 0 \\
.0095\end{array}$ \\
\hline $\mathrm{BALB} / \mathrm{c}$ IL-1ra M & $-/-$ & $\begin{array}{l}24.8400 \pm \\
0.9289\end{array}$ & $\begin{array}{l}8.6333 \pm \\
0.2517\end{array}$ & $\begin{array}{l}8.6333 \pm \\
0.3055\end{array}$ & $\begin{array}{l}1.4203 \pm \\
0.0748\end{array}$ & $\begin{array}{l}0.1471 \pm \\
0.0484\end{array}$ & $\begin{array}{l}0.3723 \pm \\
0.0432\end{array}$ & $\begin{array}{l}0.0254 \pm \\
0.0047\end{array}$ & $\begin{array}{l}0.1594 \pm \\
0.0305\end{array}$ & $\begin{array}{l}0.1364 \pm 0 \\
.0096\end{array}$ \\
\hline DBA/1 IL-1ra F & $-/-$ & $\begin{array}{l}20.6250 \pm \\
1.4795\end{array}$ & $\begin{array}{l}8.2000 \pm \\
0.1414\end{array}$ & $\begin{array}{l}8.0500 \pm \\
0.1732\end{array}$ & $\begin{array}{l}1.2006 \pm \\
0.1181\end{array}$ & $\begin{array}{l}0.1121 \pm \\
0.0185\end{array}$ & $\begin{array}{l}0.2748 \pm \\
0.0119\end{array}$ & $\begin{array}{l}0.0189 \pm \\
0.0038\end{array}$ & $\begin{array}{l}0.1042 \pm \\
0.0118\end{array}$ & $\begin{array}{l}0.1349 \pm 0 \\
.0084\end{array}$ \\
\hline DBA/1 IL-1ra M & $-/-$ & $\begin{array}{l}23.7200 \pm \\
1.3670\end{array}$ & $\begin{array}{l}8.2000 \pm \\
0.1732\end{array}$ & $\begin{array}{l}7.8667 \pm \\
0.3055\end{array}$ & $\begin{array}{l}1.3153 \pm \\
0.1416\end{array}$ & $\begin{array}{l}0.1439 \pm \\
0.0212\end{array}$ & $\begin{array}{l}0.4314 \pm \\
0.0365\end{array}$ & $\begin{array}{l}0.0132 \pm \\
0.0056\end{array}$ & $\begin{array}{l}0.1199 \pm \\
0.0102\end{array}$ & $\begin{array}{l}0.1347 \pm 0 \\
.0064\end{array}$ \\
\hline BALB.D-1 IL-1ra F & $-/-$ & $\begin{array}{l}20.2605 \pm \\
1.8202\end{array}$ & $\begin{array}{l}8.0086 \pm \\
0.4010\end{array}$ & $\begin{array}{l}8.2343 \pm \\
0.4677\end{array}$ & $\begin{array}{l}0.9338 \pm \\
0.1967\end{array}$ & $\begin{array}{l}0.1183 \pm \\
0.0201\end{array}$ & $\begin{array}{l}0.2670 \pm \\
0.0263\end{array}$ & $\begin{array}{l}0.0313 \pm \\
0.0074\end{array}$ & $\begin{array}{l}0.1101 \pm \\
0.0121\end{array}$ & $\begin{array}{l}0.1342 \pm 0 \\
.0121\end{array}$ \\
\hline BALB.D-1 IL-1ra M & $-/-$ & $\begin{array}{l}22.9225 \pm \\
3.2306\end{array}$ & $\begin{array}{l}8.2500 \pm \\
0.4212\end{array}$ & $\begin{array}{l}7.9850 \pm \\
0.6011\end{array}$ & $\begin{array}{l}1.0313 \pm \\
0.3043\end{array}$ & $\begin{array}{l}0.0973 \pm \\
0.0279\end{array}$ & $\begin{array}{l}0.3669 \pm \\
0.0644\end{array}$ & $\begin{array}{l}0.0238 \pm \\
0.0065\end{array}$ & $\begin{array}{l}0.1354 \pm \\
0.0276\end{array}$ & $\begin{array}{l}0.1471 \pm 0 \\
.0198\end{array}$ \\
\hline DBA.B-1 IL-1ra F & $-/-$ & $\begin{array}{l}19.0836 \pm \\
1.2814\end{array}$ & $\begin{array}{l}7.8455 \pm \\
0.2382\end{array}$ & $\begin{array}{l}8.1727 \pm \\
0.3101\end{array}$ & $\begin{array}{l}1.0147 \pm \\
0.1258\end{array}$ & $\begin{array}{l}0.1174 \pm \\
0.0210\end{array}$ & $\begin{array}{l}0.2677 \pm \\
0.0280\end{array}$ & $\begin{array}{l}0.0201 \pm \\
0.0042\end{array}$ & $\begin{array}{l}0.1130 \pm \\
0.0129\end{array}$ & $\begin{array}{l}0.1248 \pm 0 \\
.0450\end{array}$ \\
\hline DBA.B-1 IL-1ra M & $-/-$ & $\begin{array}{l}24.6382 \pm \\
1.4114\end{array}$ & $\begin{array}{l}8.3727 \pm \\
0.2005\end{array}$ & $\begin{array}{l}8.4727 \pm \\
0.1902\end{array}$ & $\begin{array}{l}1.2769 \pm \\
0.2293\end{array}$ & $\begin{array}{l}0.1201 \pm \\
0.0124\end{array}$ & $\begin{array}{l}0.4773 \pm \\
0.0340\end{array}$ & $\begin{array}{l}0.0154 \pm \\
0.0038\end{array}$ & $\begin{array}{l}0.1446 \pm \\
0.0119\end{array}$ & $\begin{array}{l}0.1375 \pm 0 \\
.0176\end{array}$ \\
\hline
\end{tabular}

IL-1ra: Interleukin 1 receptor antagonist protein. BL: body length. TL: tail length. 
strains. The weights of the other organs show no major differences. These data were interpreted to mean that arthritis or IL-1ra was not causing the change in the spleen weight, thus we do not know the reason for heavier spleen than that of other strains.

\section{Expression Profile Among Different Strains}

DBA.B- $1^{-/-}$contains a genomic fragment from BALB $/ \mathrm{c}^{-/-}$on a $\mathrm{DBA} / 1^{-/-}$ background. Through biomarker testing, we know that it is located somewhere between marker D1Mit506 and the distal end on chromosome 1. BALB.D-1 $1^{-/-}$contains a genomic fragment from $\mathrm{DBA} / 1^{-/-}$on a BALB $/ \mathrm{c}^{-/-}$background. Through biomarker testing, we know that it is located between markers D1Mit55 and D1Mit426 on chromosome 1. The whole genome gene expression similarities were compared between the two congenic mice (DBA.B-1 $1^{-/-}$and BALB.D-1 $1^{-/}$) and their parental mice (BALB/c, DBA $/ 1, \mathrm{DBA} / 1^{-/-}$, and BALB/c-/-) by using the mouse- 6 v1.1 expression beadchip from the Illumina. The beadchip includes 30774 probes that cover 29940 mouse genes. The R (correlation) of expression levels of probes between DBA.B-1 $1^{-/-}$and BALB.D-1 ${ }^{-/-}$was 0.9895 . (Figure 2-5A, B). The expression levels of both DBA.B-1 ${ }^{-/-}$and BALB.D-1/- were highly correlated to that of DBA $/ 1^{-/}$, while DBA.B-1 $1^{-/-}$showed more correlation than that of BALB.D-1 ${ }^{-/}$. Because DBA.B-1 ${ }^{-/}$was deficient in IL-1ra and under the genomic background of $\mathrm{DBA} / 1^{-/-}$, its expression profile was more similar to $\mathrm{DBA} / 1^{-/-}$than to any other strain. Surprisingly, the similarity between DBA.B-1/-- and DBA/1 was less than that between DBA.B-1 and BALB/c and BALB $/ \mathrm{c}^{-/}$, implying the possibility that the QTL fragment from $\mathrm{BALB} / \mathrm{c}$ makes the gene expression profiles of the DBA.B-1 ${ }^{-/-}$similar to that of BALB/c[97].

\section{Gene Expression Profiling Between BALB.D-1 ${ }^{-/}$and DBA/1 Wild Type}

Greater than $97 \%$ of all genes expressed by BALB.D-1 ${ }^{-/-}$and DBA/1 wild type mice showed similar expression levels. All gene expression levels were also identified in the QTL region, and the expressions were at similar levels in the two strains. There were 264 probes down-regulated and 472 probes up-regulated in BALB.D-1 $1^{-/}$compared with the expression levels of DBA/1 wild type (Figure 2-6A, B). There were 344 known genes in these 472 up-regulated probes. By comparing the known genes in the probes with the expression levels of DBA/1 wild type by searching on PGMapper, sixty-one out of the 344 known genes were shown to be associated with arthritis. The Darc and Fcgr4 were located in the QTL regions. There were 189 known genes in the 264 down regulated probes. Of these known genes, twenty-six genes were classified as arthritis related genes by PGMapper. Three genes, Kmo, Fcrla, and Ephx1, were within the QTL regions. GeneNetwork was used to analyze the correlation of the sixty-one up-regulated genes, twenty-six down-regulated genes, and the interleukin family with the UTHSC Affy MoGene 1.0 ST spleen program. For all of these up- and down-regulated genes, no strong correlation between these genes and the IL-1 family was found. Therefore, there was no candidate gene that could increase the resistance to SAD, as revealed through differential expression levels. 


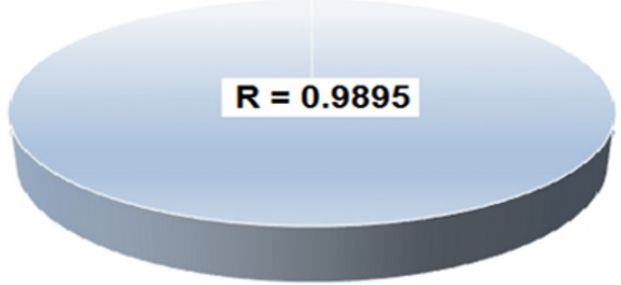

B

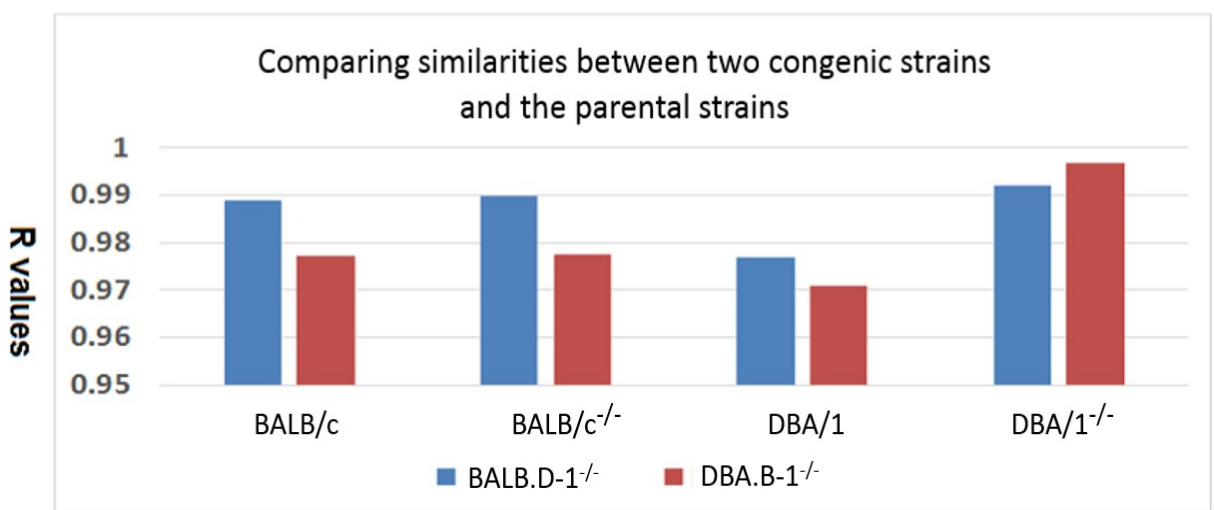

Figure 2-5. Correlation of whole genome gene expression levels between DBA.B-1'-, BALB.D-1 ${ }^{-/}$, and their four parental strains.

(A) Similarity between two congenic mice DBA.B-1 $1^{-/-}$and BALB.D-1 ${ }^{-/}$. The similarity between the two strains is $98.95 \%$. (B) Comparison of the similarities between the two congenic strains and their four parental strains. Strain names are listed under their respective bars on the horizontal axis. $\mathrm{R}$ values are listed to the left of the vertical axis. The gene expression profile of DBA/1 wild type has the lowest similarity with both congenic mice, while DBA $/ 1^{-/}$, which has a mutation of IL-1 $\mathrm{rn}$ and is under the DBA/1 genomic background, has the highest similarity to both congenic strains. The BALB.D-1 ${ }^{-}$ ${ }^{1-}$ has more similarity with BALB/c background mice $\left(\mathrm{BALB} / \mathrm{c}\right.$ wild type and $\mathrm{BALB} / \mathrm{c}^{-/}$) than with DBA.B-1 ${ }^{-/}$mice. 


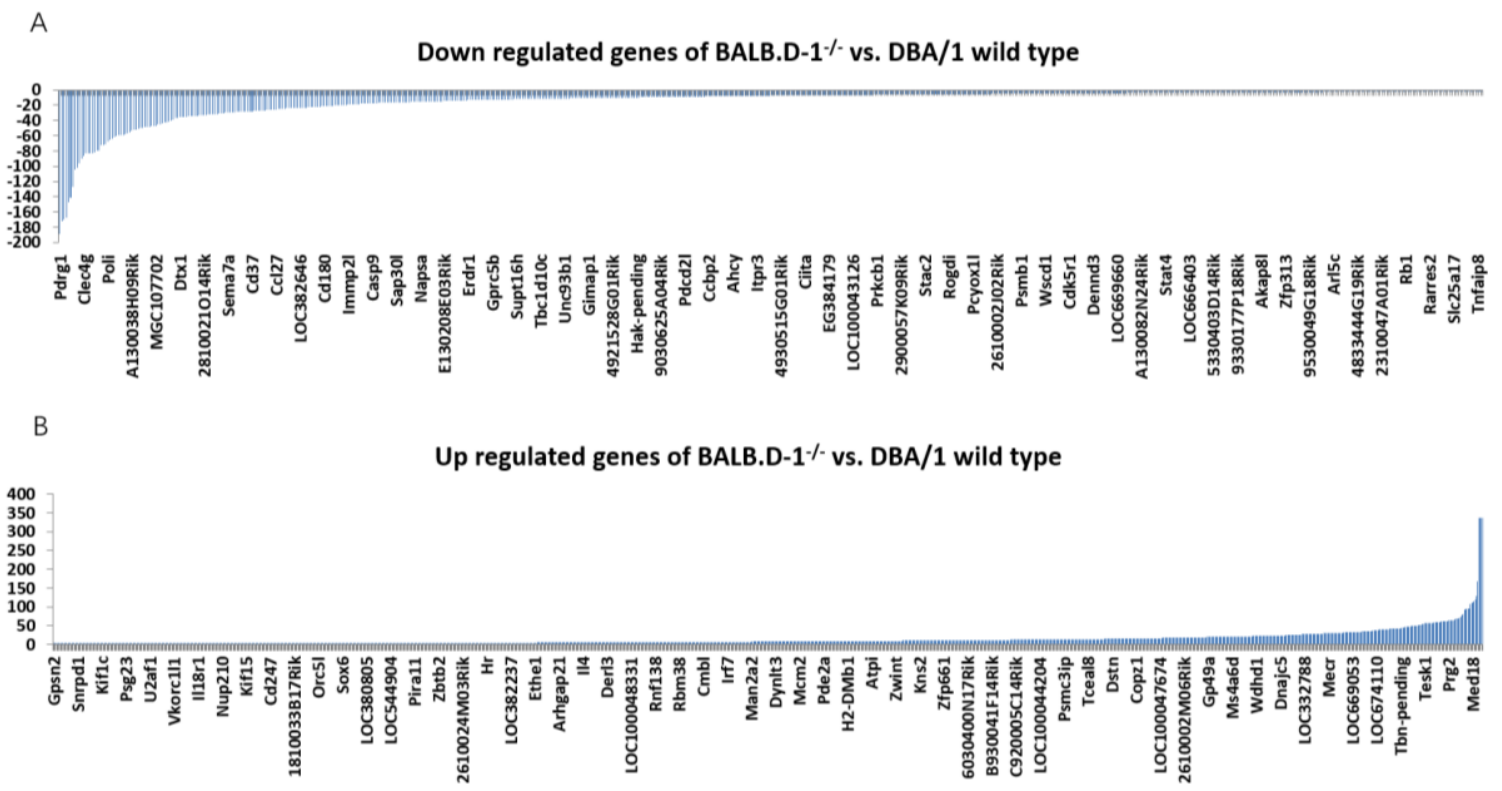

Figure 2-6. Up and down regulated genes in BALB.D-1 ${ }^{-/-}$mice in comparison to that of DBA/1 wild type mice.

(A) Downregulated genes in BALB.D-1/- mice compared with DBA/1 wild type. The gene names are shown below the horizontal axis. Numbers to the left of the vertical axis are the fold changes. There are 264 probes downregulated and 189 of them are known genes. Twenty-six of them are related to arthritis and three of them (Kmo, Fcrla, and Ephx1) are on QTL region. (B) Upregulated genes in BALB.D-1 $1^{-/}$mice compared with DBA/1 wild type. The gene names are shown below the horizontal axis. Numbers to the left of the vertical axis are the fold changes. There are 472 probes upregulated and 344 of them are known genes. Sixty-one of them are related to arthritis and two of them (Darc and Fcgr4) are on a QTL region. 


\section{Gene Expression Profiling Between BALB.D-1 ${ }^{-/-}$and DBA $/ 1^{-/-}$}

There was approximately $99 \%$ similarity between BALB.D-1 $1^{-/}$and DBA $/ 1^{-/-}$ mice. Both lack the IL-1rn gene. The gene expression levels in BALB.D-1/- and DBA $/ 1^{-}$ ${ }^{1-}$ showed more similarities compared to BALB.D-1 ${ }^{-/-}$and DBA/1 wide type mice. There were 241 probes down-regulated and 310 probes up-regulated in BALB.D-1 ${ }^{-/-}$(Figure 2-7A, B). 235 of the 310 up-regulated probes were known genes. From PGMapper, fortythree known genes were related to arthritis. There were 212 known genes in the 242 down-regulated probes. Twenty-nine of these known genes were related to arthritis according to PGMapper. Forty-three upregulated and twenty-nine downregulated probes and IL-1rn family genes were identified using the UTHSC Affy MoGene 1.0 ST Spleen program. BALB.D $-1^{-/}$compared with DBA $/ 1^{-/-}$was very similar to the DBA wild type mice. There were none directly related to the IL-1 family.

After eliminating duplicate probes, there were 101 probes left to analyze. Similar to the DBA wild type mice, the data analysis of the gene network showed no strong correlation between these genes and the IL-1rn family. Thus, there was no candidate gene to account for the increased susceptibility to SAD.

\section{Gene Expression Profiling Between BALB.D-1 ${ }^{-/-}$and BALB/c Wild Type}

Between the BALB.D-1 $1^{-/}$and BALB/c wild type mice, the similarity between them were around $98.8 \%$. There were seventy probes up-regulated and thirty-one probes down-regulated (Figure 2-8A, B). Among the seventy up-regulated probes, all were from known genes and among the thirty-one down-regulated probes, thirty were from known genes. In these changing genes, Siglec1 was only one associated with arthritis. Ifi202b was one of the up-regulated genes and was found in the QTL region. Ifi203 was one of the down-regulated genes and was also located in this QTL region. In these ninety-two up and down regulated probes, there was no correlation to the Interleukin-1 family by GeneNetwork. There was no candidate gene between BALB.D-1// and BALB/c wild type mice.

\section{Gene Expression Profiling Between BALB.D-1 ${ }^{-/-}$and BALB/ $\mathbf{c}^{-/-}$}

The similarity between BALB.D-1 $1^{-/}$and BALB $/ \mathrm{c}^{-/-}$was $99 \%$. There were twelve down-regulated probes and no up-regulated probes. Eight of the twelve down-regulated probes were known genes (Figure 2-9). These nine genes are LOC100040462 (Mndal), LOC639001, Ifi203, LOC665425, Lefty1, Trbc6, LOC638301, Ifi204, and Ifi202b. There was no relationship between these genes and arthritis using PGMapper. The Ifi202b, Ifi203, Ifi204, Mndal, and Lefty1 genes are located in the QTL region on chromosome 1. In comparing these genes with the IL-1 family, there is no strong correlation between the IL-1 rn and the interferon-activatable protein family members. Searching the genetic pathway and gene correlation, the T-cell receptor beta chain gene was not in the QTL 


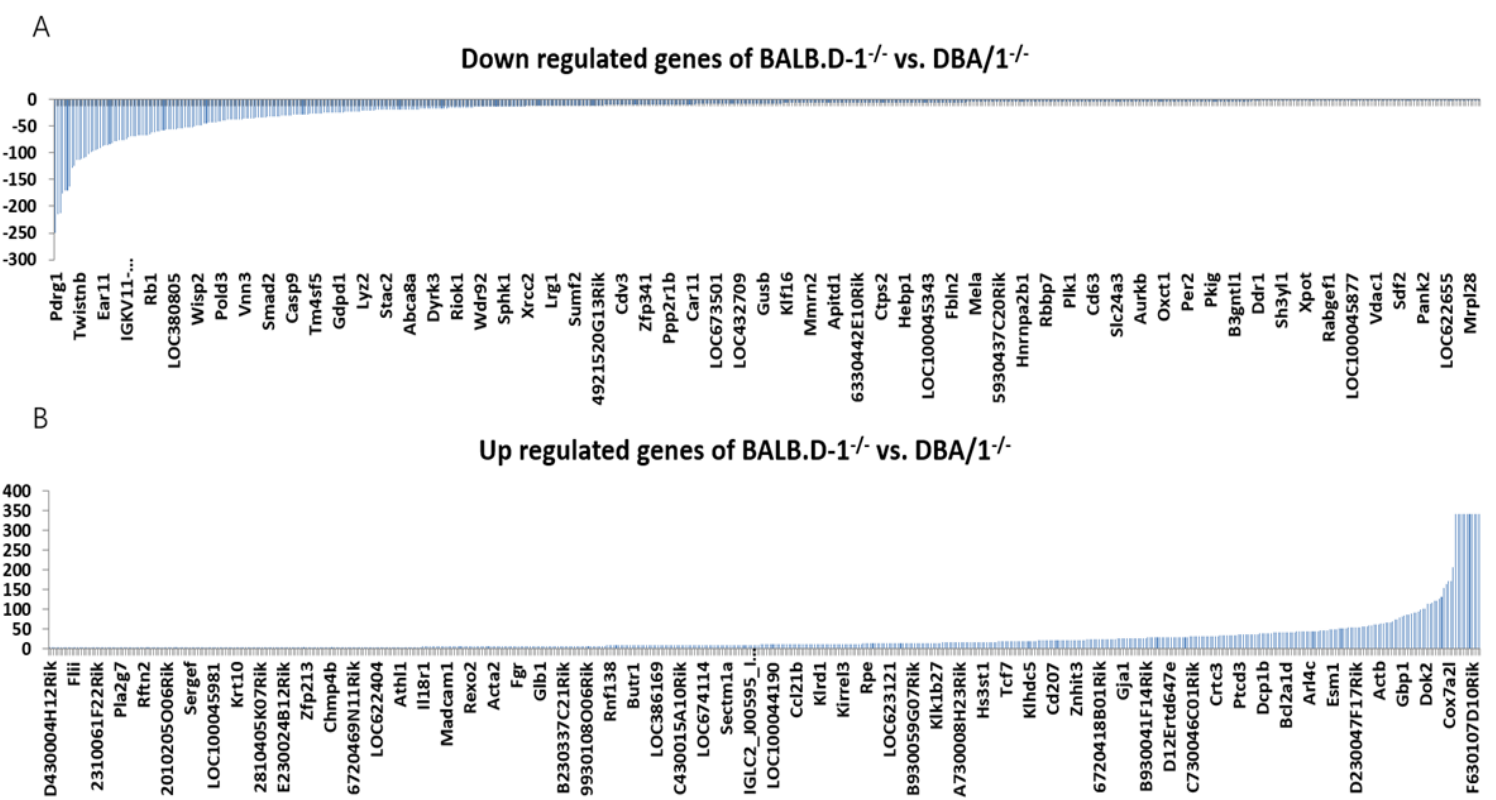

Figure 2-7. Up and down regulated genes in BALB.D-1 ${ }^{-/-}$mice in comparison to that of $\mathrm{DBA} / \mathbf{1}^{-/-}$mice.

(A) Downregulated genes in BALB.D-1/- mice compared with DBA/1-/-. The gene names are shown below the horizontal axis. Numbers to the left of the vertical axis are the fold changes. There are 241 probes downregulated and 212 of them are known genes. Twenty-nine of them are related to arthritis. (B) Upregulated genes in BALB.D-1 ${ }^{-/}$mice compared with DBA/1-/-. The gene names are shown below the horizontal axis. Numbers to the left of the vertical axis are the fold changes. There are 310 probes upregulated and 235 of them are known genes. Forty-three of them are related to arthritis. 


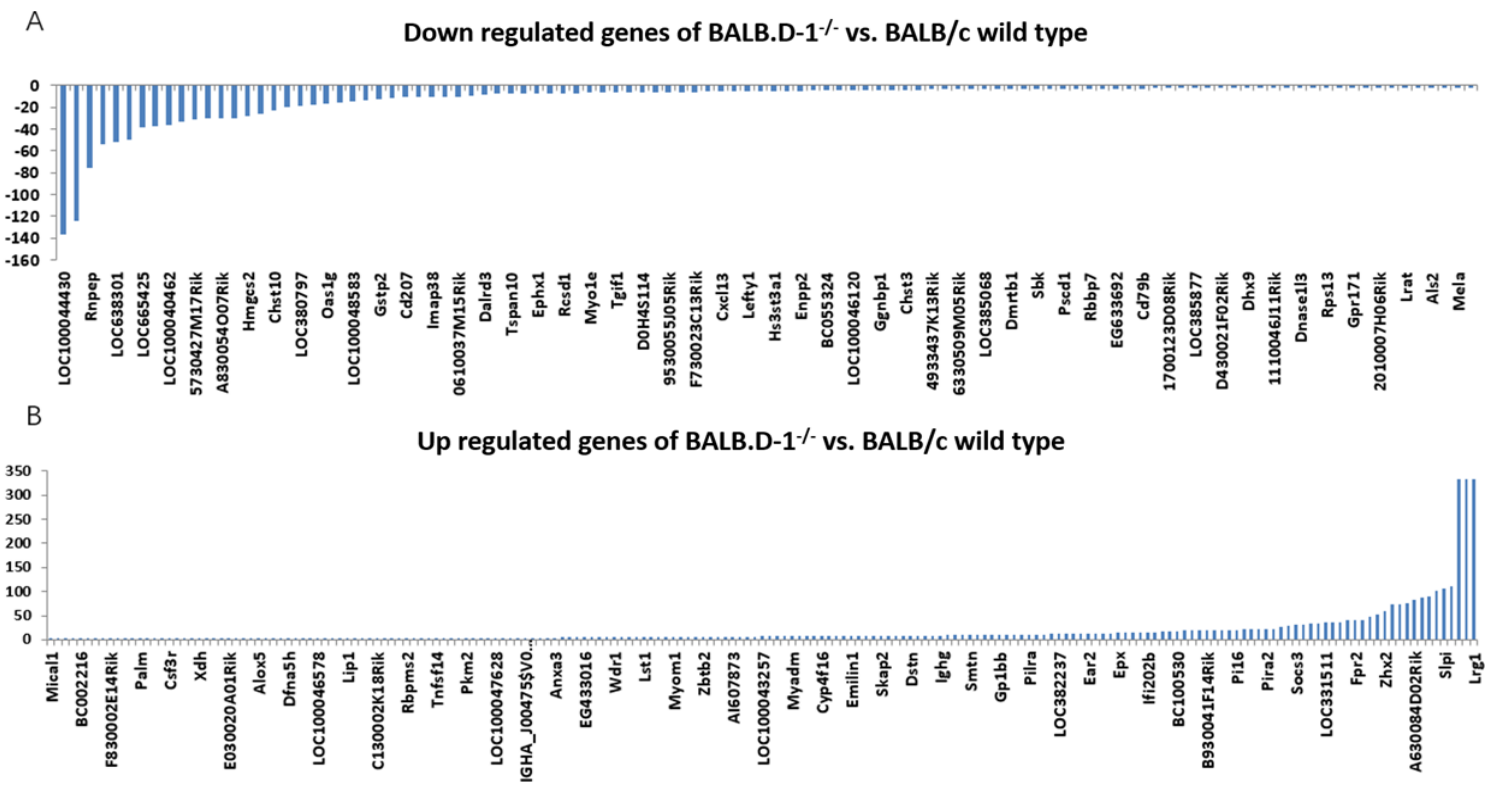

Figure 2-8. Up and down regulated genes in BALB.D-1 ${ }^{-/-}$mice in comparison to that of BALB/c wild type mice.

(A) Downregulated genes in BALB.D-1/- mice compared with BALB/c wild type. The gene names are shown below the horizontal axis. Numbers to the left of the vertical axis are the fold changes. There are thirty-one probes downregulated and thirty of them are known genes. None of them are related to arthritis. (B) Upregulated genes in BALB.D-1 ${ }^{-/}$ mice compared with the BALB/c wild type. The gene names are shown below the horizontal axis. Numbers to the left of the vertical axis are the fold changes. There are seventy probes upregulated and all of them are known genes. Only one of them (Siglec1) is related to arthritis. Ifi202b is one of the upregulated genes and Ifi203 is one of the downregulated genes located in this QTL region. 


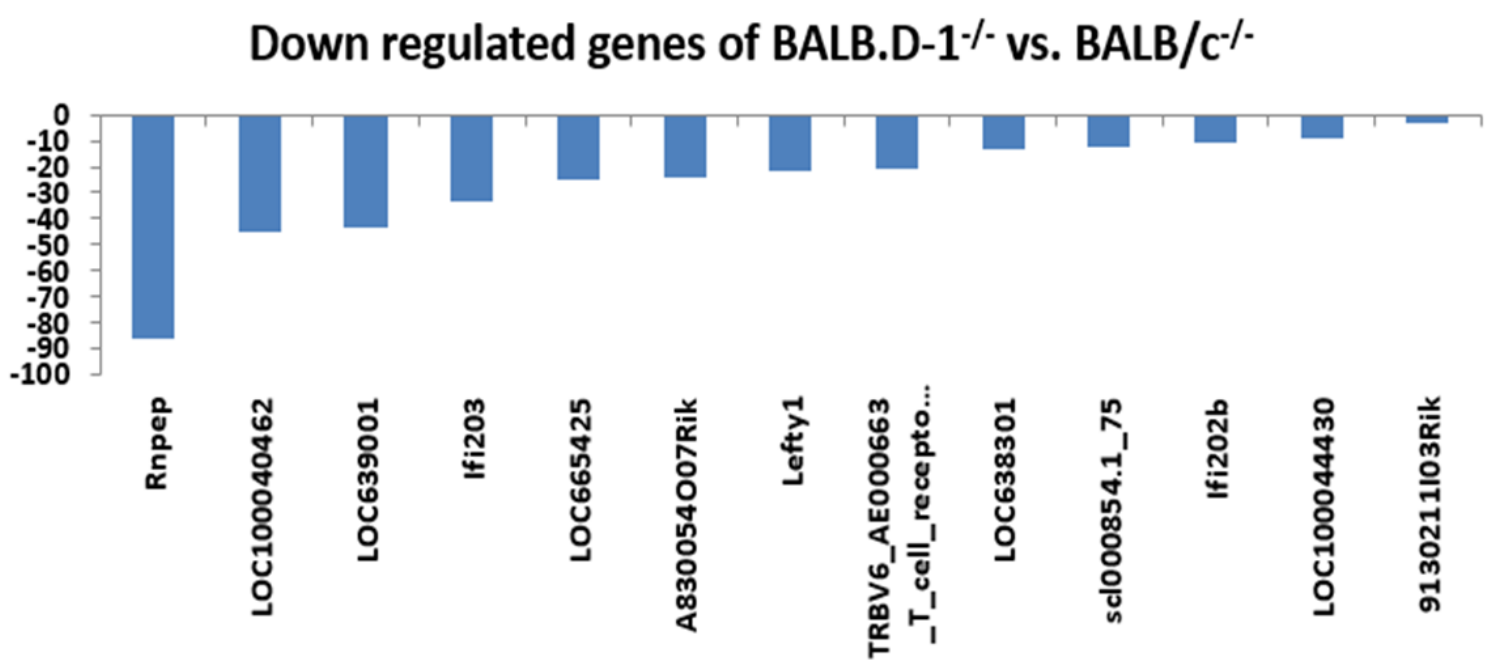

Figure 2-9. Down regulated genes in BALB.D-1 ${ }^{-/}$mice in comparison to that of BALB/c-/- mice.

There are twelve probes downregulated and no probes upregulated when BALB.D- $1^{-/}$is compared with BALB $/ \mathrm{c}^{-/-}$mice. The gene names are shown below the horizontal axis. Numbers to the left of the vertical axis are the fold changes. There are twelve probes downregulated and nine of them are known genes. None of them are related to arthritis, but there are five of them (Ifi202b, Ifi203, Ifi204, Mndal, and Lefty1) that are located in the QTL region on chromosome 1. 
region, but the T-cell receptor beta chain gene was positively associated with the Ifi family. The location of Ifi202b, Ifi203, Ifi204, Mndal, and Lefty1 genes in the QTL region indicate that these could be the candidate genes.

\section{Gene Expression Profiling Between DBA.B-1 ${ }^{-/}$and DBA/1 Wild Type}

Comparing DBA.B-1 $1^{-/}$to DBA/1 wild type mice, there was around $97 \%$ similarity between DBA.B-1 $1^{-/}$and DBA/1 wild type. Compared to the expression levels of DBA/1 wild type, there were 255 up-regulated probes and thirty-six down-regulated probes in DBA.B-1 ${ }^{-/}$(Figure 2-10A, B). From these probes, 194 of 255 up-regulated probes were known genes and twenty-eight of thirty-six down-regulated probes were known genes. The data of DBA.B- $1^{-/-}$and its parental strain were very different from BALB.D1-1 ${ }^{-/}$and its parental strain, where the number of down regulated genes was much larger than that of up-regulated genes. Forty of the up-regulated probes were located on chromosome 1 and five of them are within the transferred genomic region. They are: Dermatopontin (dpt); Integrator complex subunit 7 (ints 7); CDNA sequence BC055324 (bc055324); Interferon activated gene 203 (Ifi203); and Fc receptor, IgG, low affinity IV (fcgr4). By searching PubMed using PGMapper, there was only the HtrA serine peptidase 1 (htra1) down-regulated gene related to arthritis, but this gene was on chromosome 7. There were no genes located in the QTL region.

\section{Gene Expression Profiling Between DBA.B-1 ${ }^{-/-}$and BALB/c Wild Type}

Between the DBA.B-1/- and BALB/c wild type mice, the similarity was more than $97.5 \%$. There were 305 probes with down-regulated expression levels and 336 probes with up-regulated expression levels when DBA.B-1/- was compared with BALB/c wild type mice (Figure 2-11A, B). The number of up and down regulated genes were many greater than that found in BALB.D1-1 ${ }^{-/}$when it was compared to BALB/c. These data are reasonable considering the fact that DBA.B-1 $1^{-/}$is under the background of a different genome. 164 of 336 up-regulated probes were known genes in DBA.B-1 $1^{-/}$, and seventy-one of them were reported as relevant to arthritis by PGMapper. Ten genes were located on chromosome 1; however, only one gene, Epoxide hydrolase 1 (ephx1), was located in the QTL region. In these 305 down-regulated probes, there were 214 known genes. Fifty of these known genes were relevant to arthritis according to PGMapper. Eleven genes were on chromosome 1 and three of them were located within the QTL region. They were Olfactomedin-like $2 \mathrm{~B}$ (olfml2b), Selectin platelet (selp), and Low affinity immunoglobulin gamma Fc region receptor IV (fcgr4).

These four genes on QTL, along with IL-1rn family genes were analyzed for their gene correlation using the same whole genome expression profiles of spleen used above for DBA/1. One probe was found for each of the twelve genes. GeneNetwork indicated that the expression levels of all four genes are positively correlated with the expression levels of genes in the IL-1rn family. 


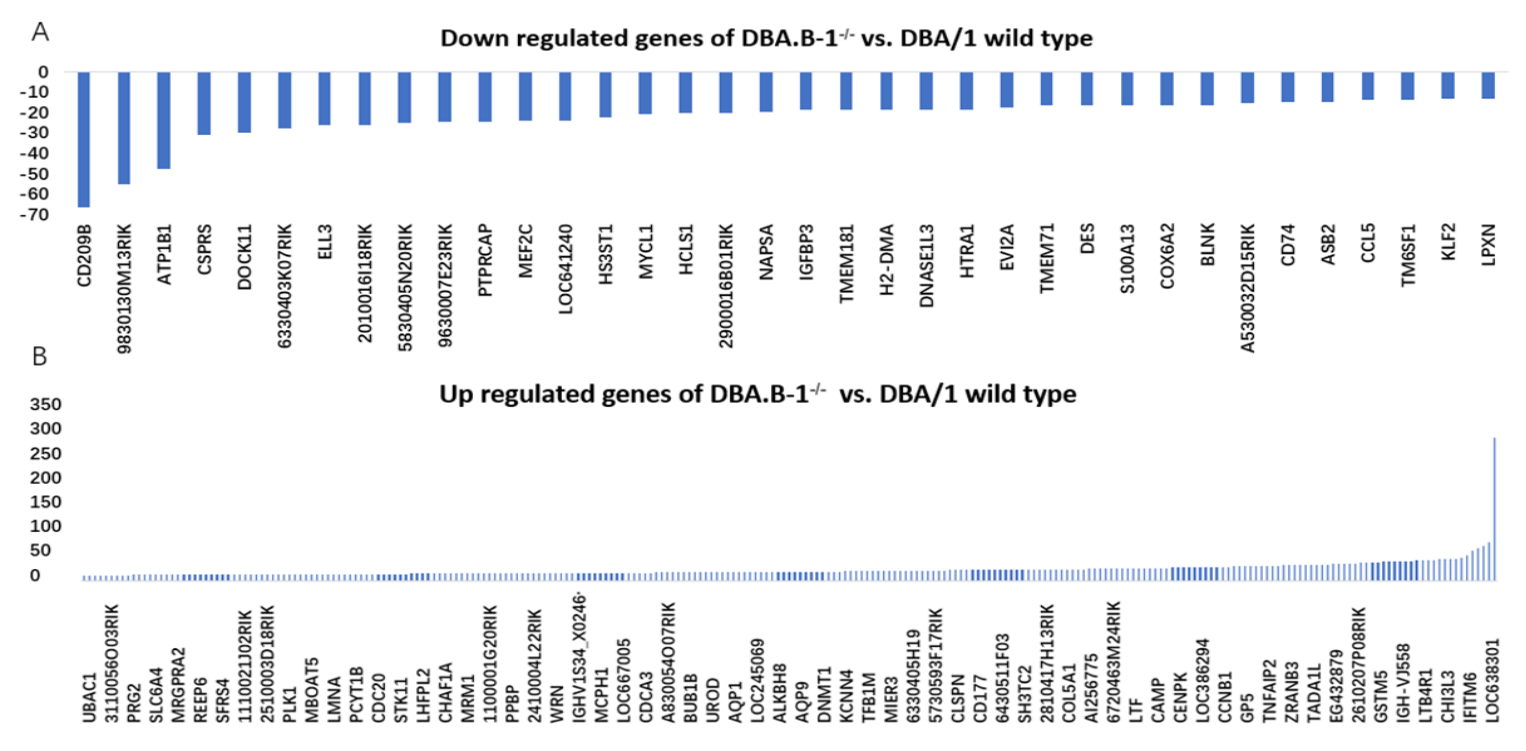

Figure 2-10. Up and down regulated genes in DBA.B-1 ${ }^{-/-}$mice in comparison to that of DBA/1 wild type mice.

(A) Downregulated genes in DBA.D-1/- mice compared with DBA/1 wild type. The gene names are shown below the horizontal axis. Numbers to the left of the vertical axis are the fold changes. There are thirty-six probes downregulated and twenty-eight of them are known genes. One of them (htra1) is related to arthritis. (B) Upregulated genes in DBA.D-1 $1^{-/}$mice compared with DBA/1 wild type. The gene names are shown below the horizontal axis. Numbers to the left of the vertical axis are the fold changes. There are 255 probes upregulated and 194 of them are known genes. Forty of them are related to arthritis and five of them (dpt, ints7, bc055324, Ifi203, and fcgr4) are on a QTL region. 


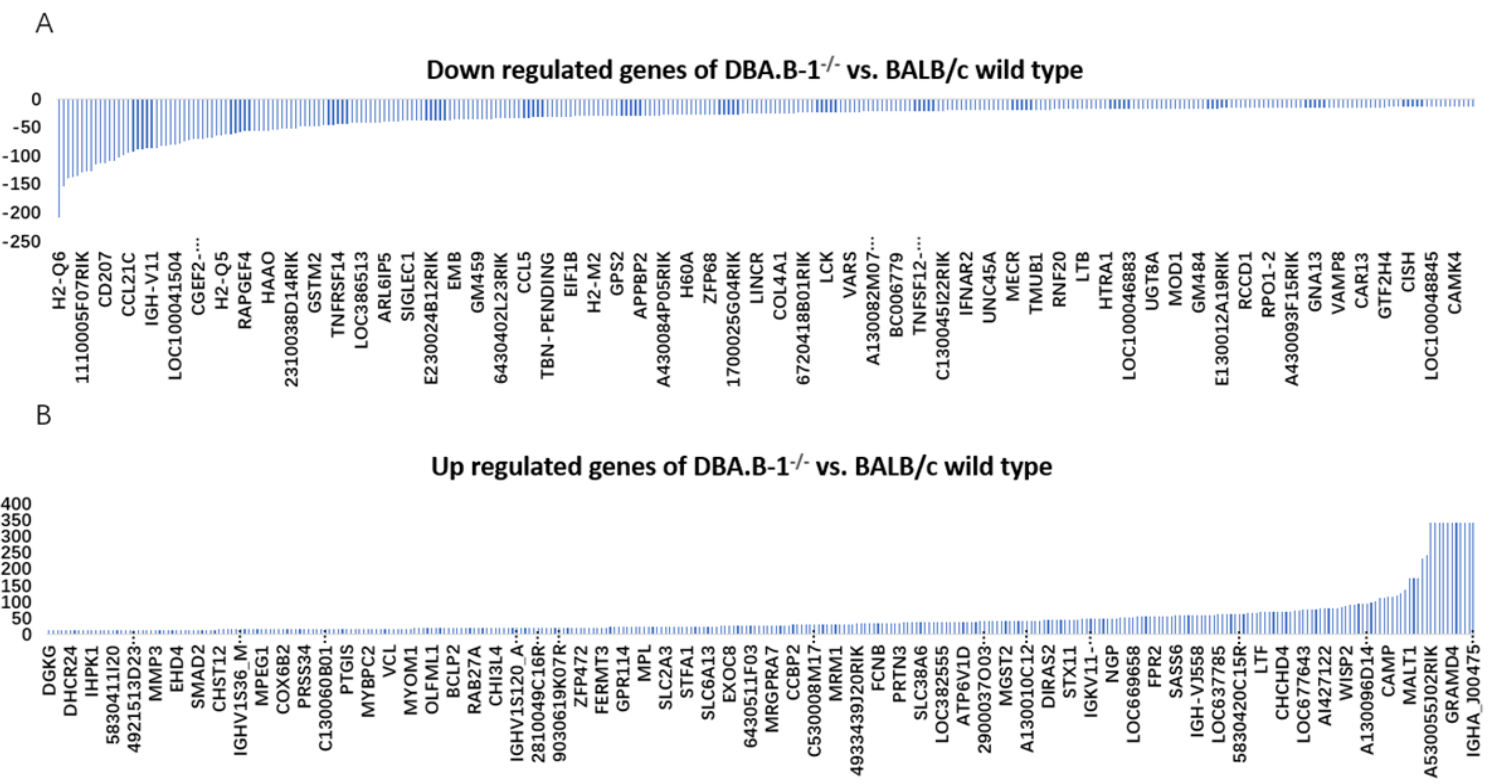

Figure 2-11. Up and down regulated genes in DBA.B-1 ${ }^{-/-}$mice in comparison to that of BALB/c wild type mice.

(A) Downregulated genes in DBA.D-1 $1^{-/}$mice compared with BALB/c wild type. The gene names are shown below the horizontal axis. Numbers to the left of the vertical axis are the fold changes. There are 305 probes downregulated and 214 of them are known genes. Fifty of them are related to arthritis. There are eleven genes on chromosome 1 and three of them (olfml2b, selp, and fcgr4) are in the QTL region. (B) Upregulated genes in DBA.D-1 $1^{-/}$mice compared with BALB/c wild type. The gene names are shown below the horizontal axis. Numbers to the left of the vertical axis are the fold changes. There are 336 probes upregulated and 164 of them are known genes. Seventy-one of them are related to arthritis. There are ten genes on chromosome 1 and only one of them (ephx1) is in the QTL region. 


\section{Gene Expression Profiling Between DBA.B-1 ${ }^{-/-}$and BALB/ $\mathrm{c}^{-/-}$}

The similarity of DBA.B- $1^{-/}$and BALB $/ \mathrm{c}^{-/-}$mice was around $98 \%$. In expression levels, there were 231 probes down-regulated and 158 probes up-regulated when DBA.B$1^{-/}$was compared with BALB/c/ $/ \mathrm{c}^{-/}$(Figure 2-12A, B).

There were 153 known genes in these 231 down-regulated probes. Thirty-three of those known genes were connected to arthritis by using the PGMapper. Among the 158 up-regulated genes, 109 were known genes. Twenty-seven of these genes were arthritisrelevant. However, none of these up or down-regulated genes are located in the QTL region on chromosome 1 . This result is significantly different from the data which compared BALB.D- $1^{-/}$to BALB $/ \mathrm{c}^{-/}$, where only a few genes, mainly Ifi family members, were down regulated in BALB.D1-1 ${ }^{-\digamma}$. Probes for Ifi204, Ifi205, and Fcgr4 were identified from the spleen genome expression profile. They were used to construct a gene network with genes of the IL-1rn family. The gene network indicated that Ifi204 and Ifi205 are weakly positively correlated to the genes of the IL-1rn family while hsph1 is not. None of these genes have a relationship to arthritis. Among these differentially expressed genes, the Ifi cluster is located within the transferred QTL genomic region.

\section{Gene Expression Profiling Between DBA.B-1 ${ }^{-/-}$and DBA $/ 1^{-/-}$}

There was about $97 \%$ similarity between DBA.B-1 $1^{-/}$and DBA $/ 1^{-/ /}$; both of them lack the IL-1rn gene. Comparing the expression levels of DBA.B-1 $1^{-/}$to DBA $/ 1^{-/ /}$, there were only three down-regulated probes and five up-regulated probes (Figure 2-13). In these three down-regulated genes, one was heat shock $105 \mathrm{kDa} / 110 \mathrm{kDa}$ (hsp $105 / 110 \mathrm{hDa}$ ). Another one was immunoglobulin kappa variable 2-112 (Igkc2-112). There was no useful information about the third one. In the five up-regulated genes, three of them are for interferon-activatable proteins (Ifi). LOC100040462 is a predicted new gene for interferon-activatable proteins called myeloid nuclear differentiation antigen like (Mndal). LOC100044430 is predicted as Ifi205, and LOC638301 is predicted as Ifi204, because the probes and the genes have the same sequence. The Ifi family genes had a highly up-regulated expression level in DBA.B- $1^{-/-}$that compares favorably with that of DBA $/ 1^{-/}$.

\section{Interferon-activatable Protein Gene Expression Levels in BALB.D-1 ${ }^{-/}$and DBA.B-1-1- Compared with the Four Parental Strains}

Ifi gene expression levels of the BALB.D-1 $1^{-/}$strain were compared with the four parental strains. The Ifi gene family expression levels in the BALB.D-1// strain were lower than $\mathrm{BALB} / \mathrm{c}^{-/}$and $\mathrm{BALB} / \mathrm{c}$, but there was no significant difference between the other two strains, DBA $/ 1^{-/-}$and DBA/1 (Figure 2-14A). A lower expression level in the candidate genes would be expected because BALB.D- $1^{-/ /}$has the genetic fragment from $\mathrm{DBA} / 1^{-/-}$. The differences in expression levels of the Ifi family genes between DBA.B-1 $1^{-1-}$ and DBA $/ 1$ are similar to that of DBA.B- $1^{-/-}$and DBA $/ 1^{-/}$. However, there is no 


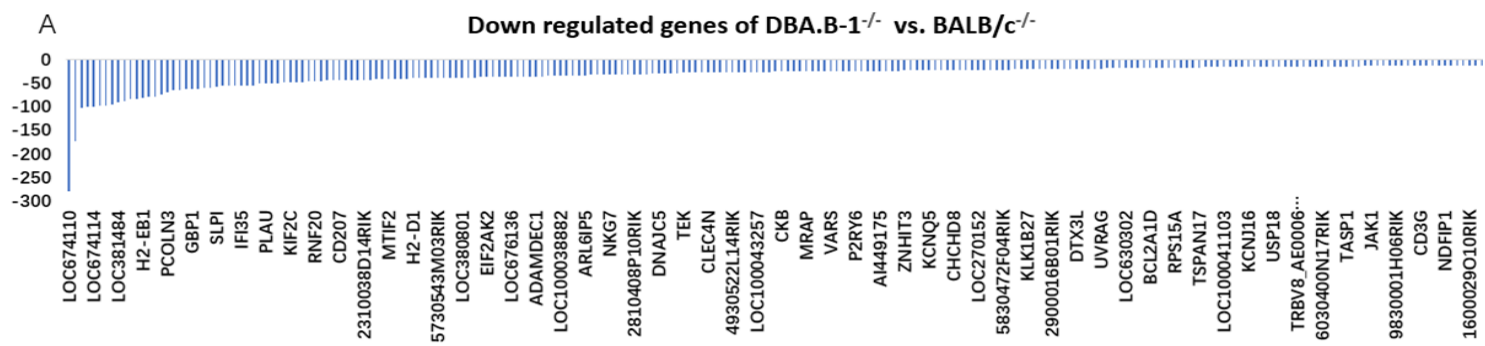

B

Up regulated genes of DBA.B-1 $1^{-/-}$vs. BALB/c ${ }^{-/-}$

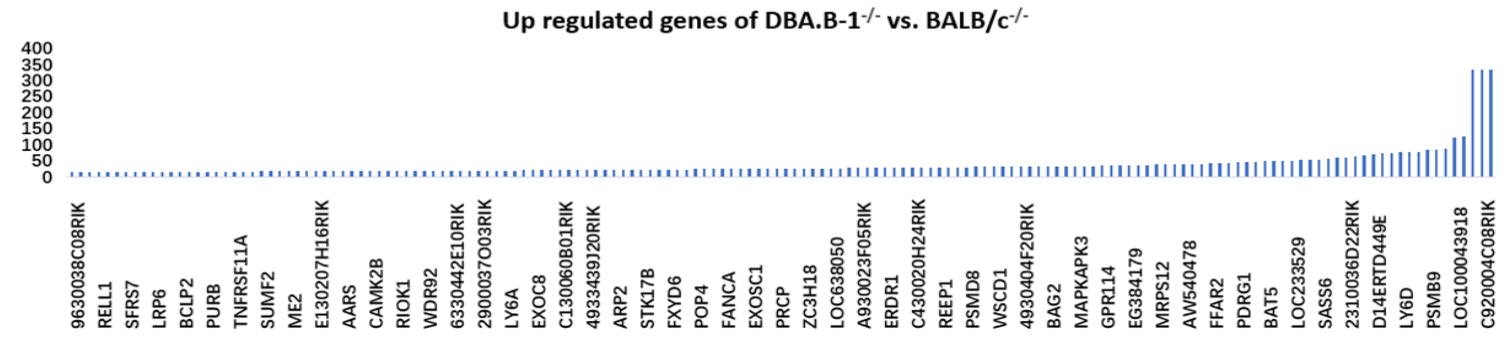

Figure 2-12. Up and down regulated genes in DBA.B-1 ${ }^{-/}$mice in comparison to that of $B A L B / c^{-/-}$mice.

(A) Downregulated genes in DBA.D-1 ${ }^{-\digamma}$ mice compared with BALB/c-/. The gene names are shown below the horizontal axis. Numbers to the left of the vertical axis are the fold changes. There are 231 probes downregulated and 153 of them are known genes. Thirty-three of them are related to arthritis. None of them is in the QTL region on chromosome 1. (B) Upregulated genes in DBA.D-1/- mice compared with BALB/c wild type. The gene names are shown below the horizontal axis. Numbers to the left of the vertical axis are the fold changes. There are 158 probes upregulated and 109 of them are known genes. Twenty-seven of them are related to arthritis. None of them is in the QTL region on chromosome 1 . 


\section{Down and upregulated genes of DBA.B-1\% vs. DBA $/ 1 \%$}

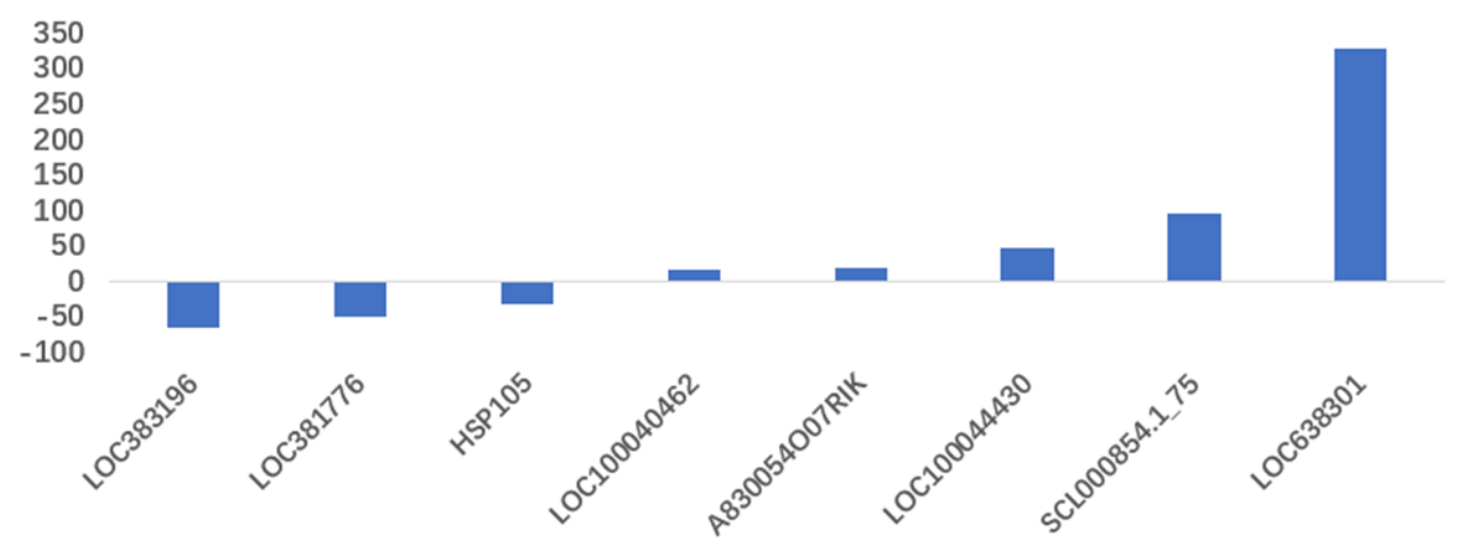

Figure 2-13. Up and down regulated genes in DBA.B-1 ${ }^{-/-}$mice in comparison to that of DBA $/ 1^{-/-}$mice.

Up- and downregulated genes in DBA.D-1 $1^{-/}$mice compared with DBA $/ 1^{-/-}$. The gene names are shown below the horizontal axis. Numbers to the left of the vertical axis are the fold change. There are only 3 downregulated probes and 5 upregulated probes. Two of the downregulated genes (hsp105/110hDa and igk2-112) are known. Three of the upregulated genes are from Ifi family (Mndal, Ifi205, and Ifi204). 


\section{Differential expression scores of IFI family genes in BALB.D-1-/-}

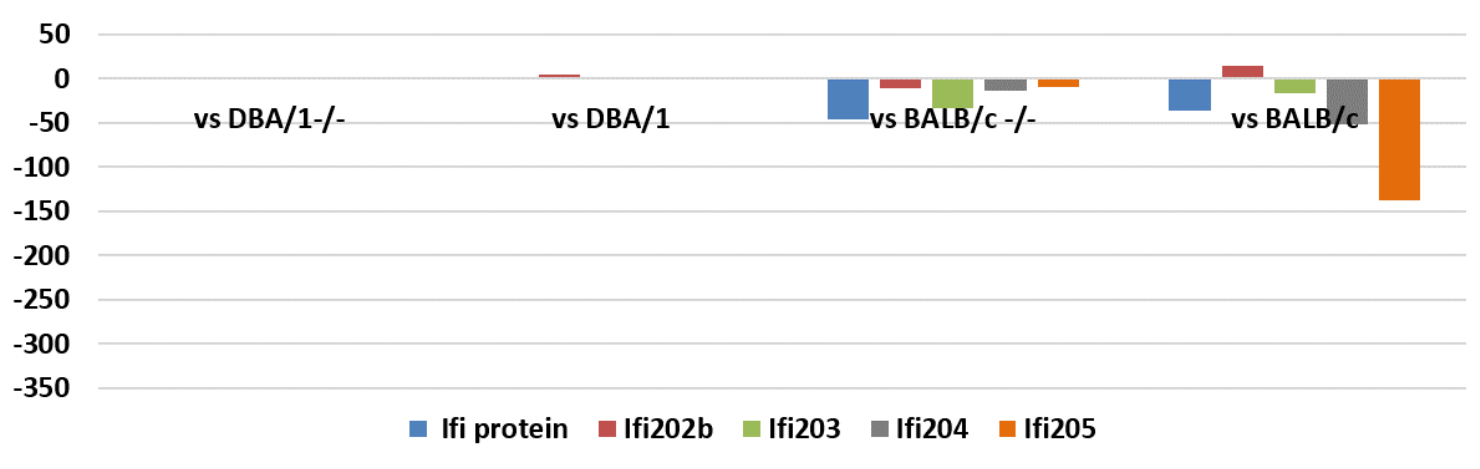

Differential expression scores of IFI family genes in DBA.B-1-/-

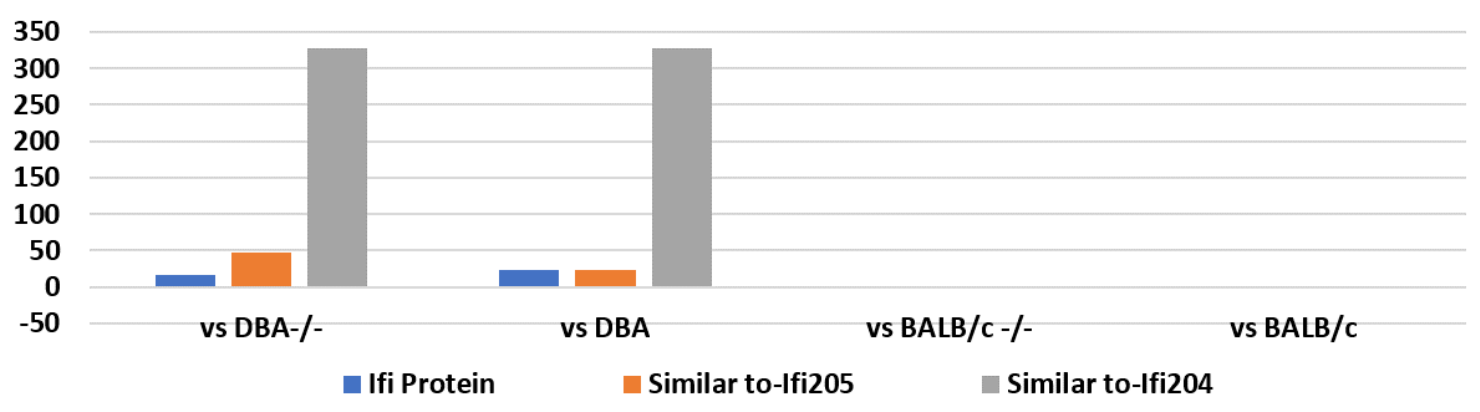

Figure 2-14. Gene expression levels of Ifi family congenic strain BALB.D-1 ${ }^{-/}$and DBA.B-1 ${ }^{-/}$in comparison with four parental strains.

(A) Ifi family gene expression in BALB.D-1/- compared with four other strains. The strains are shown below the horizontal axis. Numbers to the left of the vertical axis are the fold changes. Ifi protein, Ifi202b, Ifi203, Ifi204, and Ifi205 expression levels in BALB.D-1 ${ }^{-/}$are downregulated in comparison with that of BALB ${ }^{-/}$and BALB/c (except the Ifi202b is upregulated when BALB.D-1/- is compared with BALB/c), but no significant difference compared to the other two strains, DBA $/ 1^{-/}$and DBA/1. (B) Ifi family gene expression in DBA.B-1/- compared with four parental strains. The strains are shown below the horizontal axis. Numbers to the left of the vertical axis are the fold change. Ifi protein gene expression was similar to-Ifi204, and similar to Ifi205; expression levels in DBA.B-1/- are upregulated in comparison with that of DBA $/ 1^{-/}$and $\mathrm{DBA} / 1$, but no significant difference in comparison to the other two strains, $\mathrm{BALB}^{-/-}$and BALB/c wild type. 
significant difference between any of the genes when comparing with $\mathrm{BALB} / \mathrm{c}$ and $\mathrm{BALB} / \mathrm{c}^{-/-}$because DBA.B- $1^{-/}$has the genetic fragment from BALB $/ \mathrm{c}^{-/-}$that contains the Ifi family genes (Figure 2-14B). DBA.B- $1^{-/ /}$has higher expression levels of Ifi204 in comparison to $\mathrm{DBA} / 1^{-/}$and $\mathrm{DBA} / 1$ because it has the genetic fragment from $\mathrm{BALB} / \mathrm{c}^{-/-}$.

\section{The Potential Involvement of Interferon-activatable Protein Genes in the Regulation of Susceptibility to SAD}

$\mathrm{DBA} / 1^{-/}$is resistant to $\mathrm{SAD}$, whereas $\mathrm{BALB} / \mathrm{c}^{-/-}$is susceptible to $\mathrm{SAD}$. The increase in expression levels of the Ifi family genes in the DBA.B-1 ${ }^{-/}$strain resulted in a decrease in resistance to arthritis compared to DBA $/ 1^{-/-}$mice. The decreased Ifi family gene expression levels in the BALB.D- $1^{-/ /}$strain also showed increased resistance compared to the $\mathrm{BALB} / \mathrm{c}^{-/-}$mice. Our multiple comparisons confirmed that the increased Ifi gene cluster expression levels in DBA.B-1// constitute the major change that potentially leads to increased susceptibility to SAD, and the conversely - decreased Ifi gene cluster expression levels in BALB.D-1 $1^{-/}$- constitute the major change that potentially leads to increased resistance to $\mathrm{SAD}$. The $\mathrm{BALB} / \mathrm{c}$ and $\mathrm{BALB} / \mathrm{c}^{-- \text {(susceptible }}$ to SAD) strains had higher Ifi gene expression levels than the DBA/1 and DBA $/ 1^{-/}$strains (resistant to SAD). Based on gene expression levels and QTL analysis, the Ifi200 gene family was determined to be our candidate gene family for SAD. Among differentially expressed genes between congenic strains and parental strains, three genes in the Ifi family cluster were differentially expressed and are located in the transferred genomic fragments in the congenic strains. These genes are in the QTL genomic fragment on chromosome 1, which is found between 173,747,293 (Ifi204) bp and 174,031,810 (Ifi205) bp. The transferred region from BALB/ $\mathrm{c}^{-/-}$to DBA $/ 1^{-/}$background in the congenic DBA.B-1 strain is from 163,306,348bp (D1mit506) to the distal end of chromosome 1 . The transferred region contains several hundreds of genes and other genetic elements. None of the probes of other genes showed a significant change in the expression level between DBA.B-1 and DBA $/ 1^{-/}$, while three probes of the Ifi family were upregulated in DBA.B-1 ${ }^{-/}$. Research has shown that interferon-activatable protein is an immune suppressor in viral infection[97, 128].

\section{The Ifi204 as the Most Favorable Candidate Gene for SAD}

The Ifi200 genes are located next to each other and are known to be located in the identified QTL region. Rnpep is located outside of the QTL, therefore, it is eliminated as a candidate for SAD. Leftyl is within the QTL, but there is no indication of it having a role in arthritis. In comparison to Ifi200 genes, Leftyl is of a lower priority.

In order to explore whether all of the genes in Ifi200 or one or two other genes regulate $\mathrm{SAD}$, we examined the expression levels of these genes in congenic DBA.B-1 ${ }^{-1-}$ and DBA $/ 1^{-/}$strains (Figure 2-15A). To our surprise, among these genes, only the expression levels of Ifi204 were at meaningful levels. The other genes were detected at very low levels, indicating that they either express at a minimum level or not at all. We 


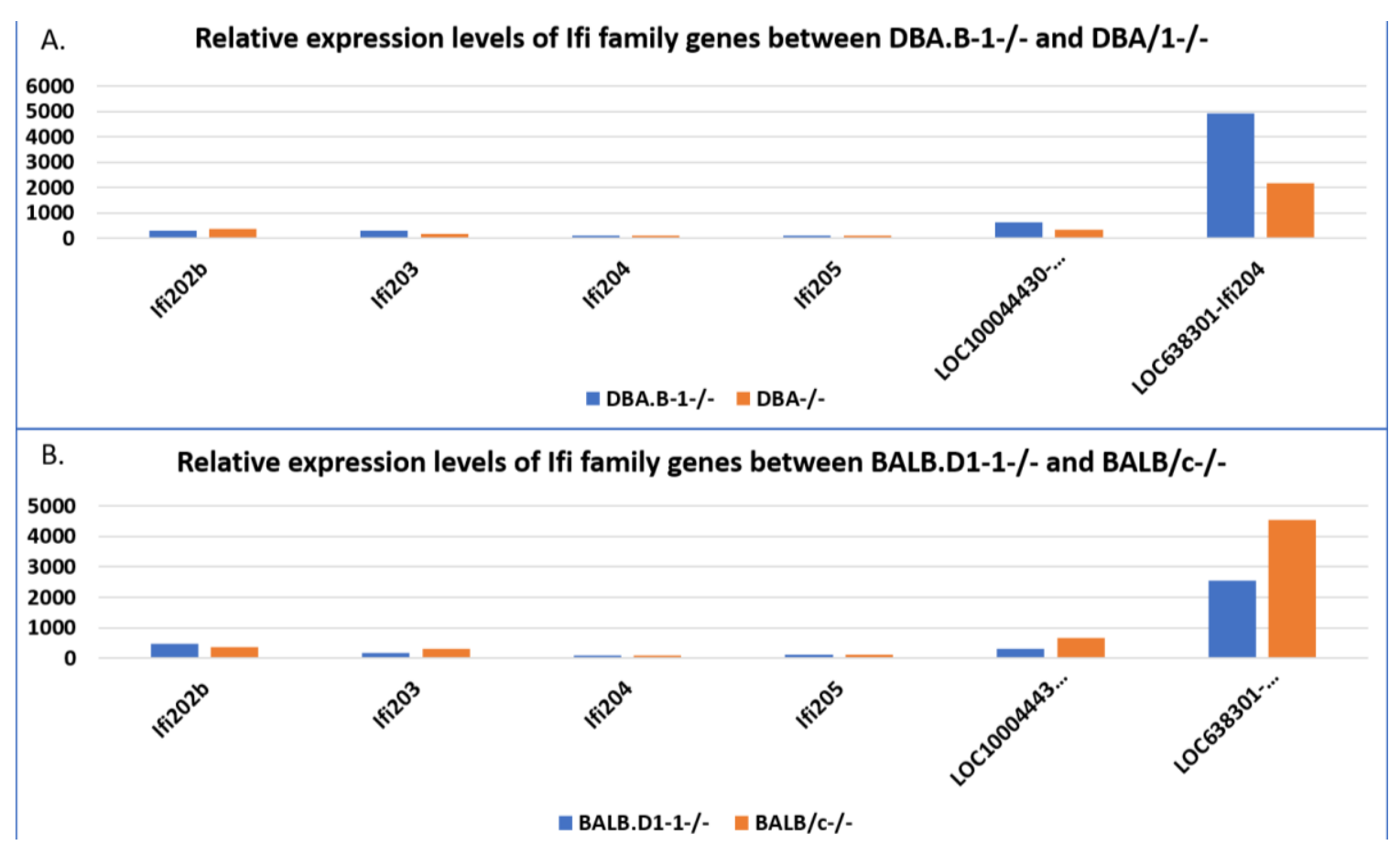

Figure 2-15. Comparison of expression levels of genes in Ifi family.

(A) Relative expression levels of Ifi family genes compared between DBA.B-1 $1^{-/}$and $\mathrm{DBA} / 1^{-\digamma}$. The gene names are shown below the horizontal axis. Numbers to the left of the vertical axis are the scores of relative expression. Ifi202b gene expression in DBA.B-1 ${ }^{-/}$ is lower than DBA $/ 1^{-/-}$. Ifi204 and Ifi205 gene expressions are similar between DBA.B-1 ${ }^{-}$ /- and DBA/1 ${ }^{-/}$. Ifi203, LOC100044430-Ifi205, and LOC638301-Ifi204 gene expressions in DBA.B- $1^{-/}$are higher than in DBA $/ 1^{-/-}$. Ifi204 gene expression is twice as high in DBA.B-1 $1^{-/-}$than in DBA $/ 1^{-/}$. (B) Relative expression levels of Ifi family genes compared between DBA.B $-1^{-/-}$and DBA $/ 1^{-/-}$. The gene names are shown below the horizontal axis. Numbers to the left of the vertical axis are the scores of relative expression. Ifi202b gene expression in BALB.D- $1^{-/-}$is higher than in BALB/ $\mathrm{c}^{-/-}$. Ifi204 and Ifi205 gene expressions are similar between BALB.D-1 ${ }^{-/}$and BALB $/ \mathrm{c}^{-/-}$. Ifi203, LOC100044430Ifi205, and LOC638301-Ifi204 gene expressions in BALB.D-1 ${ }^{-/-}$are lower than in $\mathrm{BALB} / \mathrm{c}^{-/-}$. 
further examined the expression levels of these genes in congenic BALB.D1-1 ${ }^{-/}$and $\mathrm{BALB} / \mathrm{c}^{-/-}$strains (Figure 2-15B). Among these genes, only the expression of Ifi204 was at a meaningful level. The other genes were detected at very low levels. In order to answer the question concerning whether it is possible that the low expression levels of other Ifi cluster genes are the results of cross hybridization among genes in the Ifi200 cluster, we compared the sequences of the probe of Ifi204 with the sequences from other genes in the Ifi200 cluster. Our blast search showed a high similarity of genes among the Ifi200 cluster[97].

\section{The Potential Connection Between Ifi204 and Differentially Expressed Genes within QTL Regions and Arthritis Relevant Genes}

By comparing congenic to parental strains, we identified differential genes within QTL regions and genes that are relevant to arthritis. Our final question was, what was the relationship between Ifi204 and these differentially expressed genes? Any potential association was explored between Ifi204 and these genes. The genes being compared were Dpt, Ints, bc055324, fcgr4, and htral from the comparison between DBA.B- $1^{-/}$and DBA/1 wild type; ephx1, olfml2b, selp, and fcgr4 from the comparison between DBA.B$1^{-/-}$and BALB/c wild type; Fcgr4 and Ifi205, from the comparison between DBA.B-1 $1^{-/-}$ and BALB/c/ ${ }^{-/}$; hsp105/110hDa, Igkc2-112, and Mndal from the comparison between DBA.B $-1^{-/-}$and DBA $/ 1^{-/}$.

A graphic gene network created using the literature was made, based on gene expression levels. The expression level of Ifi204 is only weakly positively connected to that of Fcgr4, with an R value of 0.405 , suggesting that the expression level of this gene is not strongly influenced by Ifi204 (Figure 2-16A). This network indicated that the majority of these genes were studied or were reported with Ifi204, suggesting that their functions are potentially connected to that of Ifi204 (Figure 2-16B). In particular, Htra1 was linked to arthritis through the destruction of the extracellular matrix causing a degradation in cartilage[144]. As seen in the figure, Htral is strongly connected to Dpt with a very high positive correlation value, and two of them were found to both be highly enriched in hip cartilage[145]. Htra1 and Dpt are also connected to Ifi204 with a high positive correlation value, as seen in figure 2-16B. This suggests that Dpt may play an important role in the development of arthritis. Both Htra1 and Dpt may be involved in the Ifi204 molecular pathway[97].

\section{The Sequence of the Genes in BALB/ $\mathrm{c}^{-/-}$and DBA/1 ${ }^{-/-}$}

From gene mapping and microarray data, the number of candidate genes were narrowed. We focused on the Ifi cluster on chromosome 1 between 173,680,000 to $174,100,000 \mathrm{bp}$ to identify the differences in Ifi202b, Ifi203, Ifi204, Ifi205, and Mndal genes between BALB $/ \mathrm{c}^{-/}$and DBA $/ 1^{-/}$strains (Figure 2-17, Table 2-3). RNA sequencing was used to reduce the genomic interval. Each gene was searched online and known each of their expression levels in different tissues and how many transcripts they had. The 
A

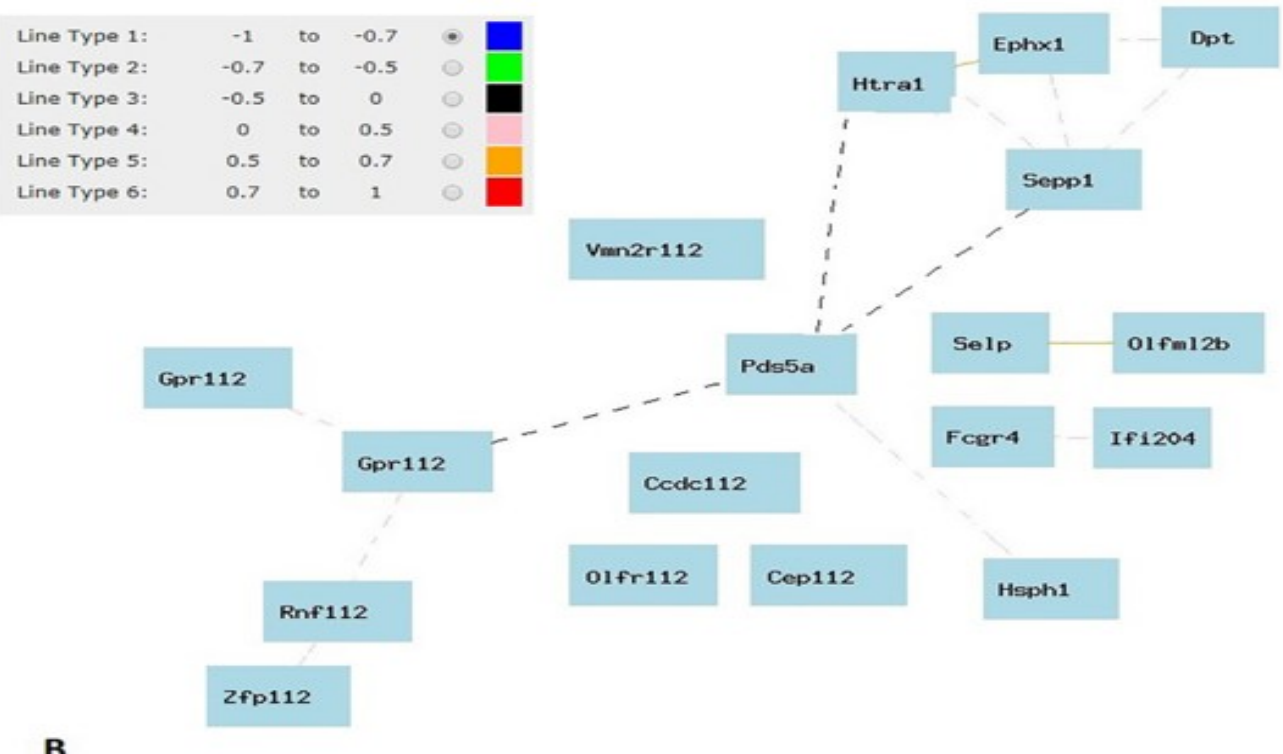

B

\section{Fcer 4}

01 fr 112

Selp

$\operatorname{Vman} 2 \operatorname{ri12}$
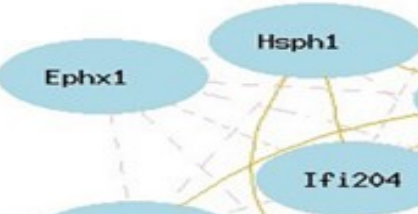

Sepp1

Dpt

$01 \mathrm{fm} 12 \mathrm{~b}$

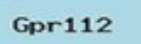

Gpr112

tra1
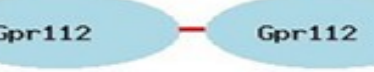

01 Fal $2 b$

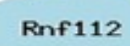

Codc112

Zfp112

Cep112

Pds5a

Figure 2-16. Graphic gene network between Ifi204 and genes within the QTL region and genes relevant to the immune system.

(A) Graphic gene network based on expression correlations. The 18 nodes in the graph show the selected traits below. All nodes are displayed. The 14 edges between the nodes are shown, filtered from the 153 total edges. (B) Graphic network based on literature reports. The 18 nodes in the graph show the selected traits below. The 33 edges between the nodes are shown, filtered from the 153 total edges and drawn as curves, showing Pearson correlation coefficients greater than 0.35 or less than -0.35 . 


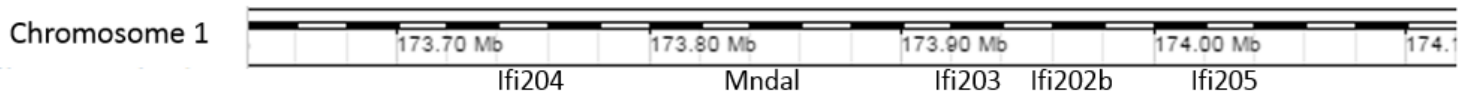

Ifi204 gene: Chromosome 1: 173,747,293-173,766,943

Mndal gene: Chromosome 1: 173,849,126-173,942,491

Ifi203 gene: Chromosome 1: 173,920,407-173,942,672

Ifi202b gene: Chromosome 1: 173,962,568-173,982,744

Ifi205 gene: Chromosome 1: 174,011,998-174,031,810

Figure 2-17. Ifi200 cluster is located on chromosome 1 between in 173.7Mb and 174.1Mb.

The Ifi200 gene cluster is located on chromosome 1 in a genomic region of a QTL for non-MHC arthritis. This is the same position for Ifi204, Mndal, Ifi203, Ifi202b, and Ifi205 genes on chromosome 1. 
Table 2-3. The Ifi202b, Ifi203, Ifi204, Ifi205, and Mndal genes ID.

\begin{tabular}{|c|c|c|c|c|c|c|c|c|}
\hline Name & Transcript ID & bp & Protein & Translation ID & Biotype & CCDS & UniProt & Flags \\
\hline Ifi202b-201 & $\begin{array}{l}\text { ENSMUST0000 } \\
0000266.8\end{array}$ & 1697 & $445 \mathrm{aa}$ & $\begin{array}{l}\text { ENSMUSP0000 } \\
0000266\end{array}$ & $\begin{array}{l}\text { Protein } \\
\text { coding }\end{array}$ & CCDS35794 & Q9R002 & $\begin{array}{l}\text { TSL:1GENCODE } \\
\text { basicAPPRIS P1 }\end{array}$ \\
\hline Ifi203-201 & $\begin{array}{l}\text { ENSMUST0000 } \\
0042228.14\end{array}$ & 3754 & $457 \mathrm{aa}$ & $\begin{array}{l}\text { ENSMUSP0000 } \\
0042071\end{array}$ & $\begin{array}{l}\text { Protein } \\
\text { coding }\end{array}$ & CCDS48453 & A0A0R4J0H6 & $\begin{array}{l}\text { TSL:1GENCODE } \\
\text { basicAPPRIS ALT2 }\end{array}$ \\
\hline Ifi203-202 & $\begin{array}{l}\text { ENSMUST0000 } \\
0081216.11\end{array}$ & 3610 & 409aа & $\begin{array}{l}\text { ENSMUSP0000 } \\
0079976\end{array}$ & $\begin{array}{l}\text { Protein } \\
\text { coding }\end{array}$ & CCDS35793 & E9PUG6 & $\begin{array}{l}\text { TSL:1GENCODE } \\
\text { basicAPPRIS P3 }\end{array}$ \\
\hline Ifi203-209 & $\begin{array}{l}\text { ENSMUST0000 } \\
0156895.7\end{array}$ & 3605 & $457 \mathrm{aa}$ & $\begin{array}{l}\text { ENSMUSP0000 } \\
0114221\end{array}$ & $\begin{array}{l}\text { Protein } \\
\text { coding }\end{array}$ & CCDS48453 & A0A0R4J0H6 & $\begin{array}{l}\text { TSL:1GENCODE } \\
\text { basicAPPRIS ALT2 }\end{array}$ \\
\hline Ifi203-203 & $\begin{array}{l}\text { ENSMUST0000 } \\
0123708.7\end{array}$ & 3482 & 409aa & $\begin{array}{l}\text { ENSMUSP0000 } \\
0121480\end{array}$ & $\begin{array}{l}\text { Protein } \\
\text { coding }\end{array}$ & CCDS35793 & E9PUG6 & $\begin{array}{l}\text { TSL:1GENCODE } \\
\text { basicAPPRIS P3 }\end{array}$ \\
\hline Ifi203-205 & $\begin{array}{l}\text { ENSMUST0000 } \\
0129829.7\end{array}$ & 3054 & 871 aa & $\begin{array}{l}\text { ENSMUSP0000 } \\
0122424\end{array}$ & $\begin{array}{l}\text { Protein } \\
\text { coding }\end{array}$ & CCDS78754 & E9QAN9 & $\begin{array}{l}\text { TSL:1GENCODE } \\
\text { basicAPPRIS ALT2 }\end{array}$ \\
\hline Ifi203-204 & $\begin{array}{l}\text { ENSMUST0000 } \\
0128430.7\end{array}$ & 1884 & No protein & - & $\begin{array}{l}\text { Processed } \\
\text { transcript }\end{array}$ & - & - & TSL:1 \\
\hline Ifi203-206 & $\begin{array}{l}\text { ENSMUST0000 } \\
0135331.7\end{array}$ & 658 & No protein & - & $\begin{array}{l}\text { Processed } \\
\text { transcript }\end{array}$ & - & - & TSL:3 \\
\hline Ifi203-208 & $\begin{array}{l}\text { ENSMUST0000 } \\
0140143.1\end{array}$ & 444 & No protein & - & $\begin{array}{l}\text { Processed } \\
\text { transcript }\end{array}$ & - & - & TSL:3 \\
\hline Ifi203-207 & $\begin{array}{l}\text { ENSMUST0000 } \\
0138143.7\end{array}$ & 2471 & No protein & - & $\begin{array}{l}\text { Processed } \\
\text { transcript }\end{array}$ & - & - & TSL:1 \\
\hline Ifi204-201 & $\begin{array}{l}\text { ENSMUST0000 } \\
0111214.3\end{array}$ & 2296 & 619aа & $\begin{array}{l}\text { ENSMUSP0000 } \\
0106845\end{array}$ & $\begin{array}{l}\text { Protein } \\
\text { coding }\end{array}$ & CCDS35792 & E9QKL6 P0DOV2 & $\begin{array}{l}\text { TSL:5GENCODE } \\
\text { basicAPPRIS P1 }\end{array}$ \\
\hline Ifi204-202 & $\begin{array}{l}\text { ENSMUST0000 } \\
0192414.1\end{array}$ & 1659 & No protein & - & $\begin{array}{l}\text { Processed } \\
\text { transcript }\end{array}$ & - & - & TSL:1 \\
\hline
\end{tabular}


Table 2-3. Continued.

\begin{tabular}{|c|c|c|c|c|c|c|c|c|}
\hline Name & Transcript ID & bp & Protein & Translation ID & Biotype & CCDS & UniProt & Flags \\
\hline Ifi205-201 & $\begin{array}{l}\text { ENSMUST0000 } \\
0059226.6\end{array}$ & 1613 & 404aa & $\begin{array}{l}\text { ENSMUSP0000 } \\
0062409\end{array}$ & $\begin{array}{l}\text { Protein } \\
\text { coding }\end{array}$ & CCDS15534 & Q8CGE8 & $\begin{array}{l}\text { TSL:1GENCODE } \\
\text { basicAPPRIS P1 }\end{array}$ \\
\hline Ifi205-202 & $\begin{array}{l}\text { ENSMUST0000 } \\
0192166.1\end{array}$ & 3274 & No protein & - & $\begin{array}{l}\text { Retained } \\
\text { intron }\end{array}$ & - & - & TSL:1 \\
\hline Mndal-204 & $\begin{array}{l}\text { ENSMUST0000 } \\
0188804.6\end{array}$ & 2026 & $538 \mathrm{aa}$ & $\begin{array}{l}\text { ENSMUSP0000 } \\
0140610\end{array}$ & $\begin{array}{l}\text { Protein } \\
\text { coding }\end{array}$ & CCDS48452 & D0QMC3 & $\begin{array}{l}\text { TSL:1GENCODE } \\
\text { basicAPPRIS P2 }\end{array}$ \\
\hline Mndal-201 & $\begin{array}{l}\text { ENSMUST0000 } \\
0111210.8\end{array}$ & 1907 & $538 \mathrm{aa}$ & $\begin{array}{l}\text { ENSMUSP0000 } \\
0106841\end{array}$ & $\begin{array}{l}\text { Protein } \\
\text { coding }\end{array}$ & CCDS48452 & D0QMC3 & $\begin{array}{l}\text { TSL:1GENCODE } \\
\text { basicAPPRIS P2 }\end{array}$ \\
\hline Mndal-202 & $\begin{array}{l}\text { ENSMUST0000 } \\
0186442.6\end{array}$ & 1646 & $485 \mathrm{aa}$ & $\begin{array}{l}\text { ENSMUSP0000 } \\
0140539\end{array}$ & $\begin{array}{l}\text { Protein } \\
\text { coding }\end{array}$ & - & A0A087WRA4 & $\begin{array}{l}\text { TSL:5GENCODE } \\
\text { basicAPPRIS ALT2 }\end{array}$ \\
\hline Mndal-208 & $\begin{array}{l}\text { ENSMUST0000 } \\
0190651.3\end{array}$ & 762 & $184 \mathrm{aa}$ & $\begin{array}{l}\text { ENSMUSP0000 } \\
0140191\end{array}$ & $\begin{array}{l}\text { Protein } \\
\text { coding }\end{array}$ & - & A0A087WQG9 & $\begin{array}{l}\text { CDS 3' } \\
\text { incompleteTSL:5 }\end{array}$ \\
\hline Mndal-207 & $\begin{array}{l}\text { ENSMUST0000 } \\
0190071.1\end{array}$ & 931 & $129 a a$ & $\begin{array}{l}\text { ENSMUSP0000 } \\
0141055\end{array}$ & $\begin{array}{l}\text { Nonsense } \\
\text { mediated } \\
\text { decay }\end{array}$ & - & A0A087WSH9 & $\begin{array}{l}\text { CDS } 5^{\prime} \\
\text { incompleteTSL:5 }\end{array}$ \\
\hline Mndal-206 & $\begin{array}{l}\text { ENSMUST0000 } \\
0189501.6\end{array}$ & 860 & No protein & - & $\begin{array}{l}\text { Processed } \\
\text { transcript }\end{array}$ & - & - & TSL:5 \\
\hline Mndal-210 & $\begin{array}{l}\text { ENSMUST0000 } \\
0220623.1\end{array}$ & 512 & No protein & - & $\begin{array}{l}\text { Processed } \\
\text { transcript }\end{array}$ & - & - & TSL:3 \\
\hline Mndal-209 & $\begin{array}{l}\text { ENSMUST0000 } \\
0191500.6\end{array}$ & 367 & No protein & - & $\begin{array}{l}\text { Processed } \\
\text { transcript }\end{array}$ & - & - & TSL:3 \\
\hline Mndal-205 & $\begin{array}{l}\text { ENSMUST0000 } \\
0189474.6\end{array}$ & 1353 & No protein & - & $\begin{array}{l}\text { Retained } \\
\text { intron }\end{array}$ & - & - & TSL:1 \\
\hline Mndal-203 & $\begin{array}{l}\text { ENSMUST0000 } \\
0187636.1\end{array}$ & 667 & No protein & - & $\begin{array}{l}\text { Retained } \\
\text { intron }\end{array}$ & - & - & TSL:3 \\
\hline
\end{tabular}


Ifi202b gene had one transcript; the size of the gene was $1659 \mathrm{bp}$ and the protein size was 445 aa. It had one consensus CDS, CCDS35794. Ifi203 had nine transcripts. All of them had different gene sizes, but only five of them could encode proteins. The Ifi203-201 gene transcript size was $3754 \mathrm{bp}$ and the protein size was 445 aa; the Ifi203-202 gene transcript size was 3610 bp and the protein size was 409 aa; the Ifi203-209 gene transcript size was 3605 bps and the protein size was 457 aa; the Ifi203-203 gene transcript size was $3482 \mathrm{bp}$ and the protein size was 409 aa; the Ifi203-205 transcript size was $3054 \mathrm{bp}$ and the protein size was $871 \mathrm{aa}$. These five transcripts had CCDSes and the rest of the four transcripts did not encode proteins. The Ifi205 gene had two transcripts. Only the Ifi205-201 transcript could be translated to a protein (404 aa) and the gene size was $2296 \mathrm{bp}$. The Mndal gene had 10 transcripts, but only 5 could translate to protein. The Mndal-204 transcript size was 2026 bp and the protein size was 538 aa; the Mndal201 transcript size was $1907 \mathrm{bp}$ and the protein size was 538 aa; the Mndal-202 transcript size was $1646 \mathrm{bp}$ and the protein size was 485 aa; the Mndal-208 transcript size was 762 bp and the protein size was 184 aa; the Mndal-207 transcript size was 931 bp and the protein size was 129 aa. The rest of the transcripts could not translate proteins. Ifi204 had two transcripts, but only one could translate a protein. The Ifi204-201 gene transcript was $2296 \mathrm{bp}$ and the protein size was 619 aa. Its consensus CDS ID was CCDS35792 (Figure 2-18). Ifi204-201 gene was sequenced and found several different polymorphisms between BALB/ $\mathrm{c}^{-/}$and DBA $/ 1^{--}$. At $292 \mathrm{bp}$ and $293 \mathrm{bp}, \mathrm{DBA} / 1^{-/}$was AA and BALB/ $/ \mathrm{c}^{-/-}$ was TG; at $197 \mathrm{bp}, \mathrm{DBA} / 1^{-/}$was $\mathrm{G}$ and $\mathrm{BALB} / \mathrm{c}^{-/-}$was $\mathrm{C}$; at $190 \mathrm{bp} \mathrm{DBA} / 1^{-/-}$was $\mathrm{T}$ and $\mathrm{BALB} / \mathrm{c}^{-/ 2}$ was $\mathrm{G}$. The Ifi 204 protein structure changed between $\mathrm{BALB} / \mathrm{c}^{-/}$and $\mathrm{DBA} / 1^{-1 /}$ (Figure 2-19). The change from $A A$ to $T G$ changed the amino acid from lysine to methionine. The $\mathrm{T}$ to $\mathrm{C}$ change changed the amino acid from tyrosine to histidine. The $\mathrm{G}$ to $\mathrm{C}$ change made the amino acid change from serine to threonine. The fourth polymorphism amino acid change could not be determined because the nucleotide sequence was unclear. The Ifi 204 protein structure is likely to be different as encoded by $\mathrm{BALB} / \mathrm{c}^{-/}$versus DBA $/ 1^{-/}$because of these amino acid changes.

\section{The Ifi204 Expression Levels in Different Strains}

Ifi204 gene expression levels were obtained from 4-month old DBA/1 ${ }^{-/}$, DBA.B$1^{-/}$, BALB.D- $1^{--}$, and BALB/ $\mathrm{c}^{-/}$, DBA $/ 1$ wild type and BALB/c wild type male and female mice (Figure 2-20). In both DBA/1 and BALB/c wild type mice, the Ifi204 expression levels of females were lower than that observed in males. In DBA $/ 1^{-/}$and $\mathrm{BALB} / \mathrm{c}^{-/ /}$strains, there were contrasting expression levels among each gender. In the $\mathrm{DBA} / 1^{-/}$strain, the expression levels in females were higher than that of males, but male expression levels were higher than that of females in the $\mathrm{BALB} / \mathrm{c}^{-/}$strain. In the congenic strains, the expression levels in males were higher than that observed in females in the DBA.B $-1 /$ strain, and females were found to have higher expression than males in the BALB.D-1 ${ }^{-/}$strain. Between the two congenic strains, males and females did not have any significant difference, so we could not use these data for analysis. The data from realtime PCR and microarray had differences indicating that the two experiments used different loci to test. In the DBA/1 background, there were contrasting expression levels within each gender between wild type and IL-1 ra knockout mice, but expression levels 
Ifi204-2439bps

tatgaacgaaactgggaggaggcctggctgattcagcacttctcacccaagggagacagc acagggagagacagccagtgctgttcaagaaatgaaacaactctgagagtgttgtaatca ctaccatctectttacacccaactgttcagtttcttatttactgacttagctgcctacc tactcaagccaagcaggccacttcttgacccggtgaaggtctcaggatctgtacatcact gcagaatatccaggaaggctcagcaacaacttcaaagatggtgaatgaatacaagagaa ttgttctgctgagaggacttgaatgtatcaataagcattattttagcttatttaagtcat tgctggccagagatttaaatctggaaagagacaaccaagagcaatacaccacgattcaga ttgctaacatgatggaagagaaatttccagctg attgcgt tttgtgaagaagtaccagctcttagaaaacgagctgaaattcttaaaaagagagatcag aaggagaaacatcactggaaaaaatggtcaagaagcaggtcctgcaacacctacatcaa ctacaagccacatgttagcatctgaaagaggcgagacttctgcaacccaggaagagactt ccacagctcaggcggggacttccacagctcaggcgaggacttccacagctcaggcgggga cttctacagcccagaalagaaaattatgagagaagaagagactgla

gctaaggaaccagatcagcctccetgttgtgaagaacccacagccaggtgccagt caccaatactccacagctcatcttcagcttcatctaacattccttcggctaagaaccaa aatcacaaccccagaatcagaacattcccagaggtgctgttctccactcagagcccctga cagtgatggtgctcactgcaacagacccatttgaatatgaatcaccagaacatgaagtaa agaacatgcttcatgctacagtggctacagtgagccagtatttccatgtgaaagttttca acatcaacttgaaagaaagttcacaaaaagaattttatcatcatatccaattactttg agagcaaaggcatcctggagatcaatgagacttcctctgtgttagaggctgctcctgacc aaatgattgaagtgcccaacagtattatcagaaatgcaaatgccagccctaagatctgtg atattcaaagggtacttctggagcagtgttctatggagtgtttacattacacaagaaa cagtgaaccgaaagaacacaatctatgaaataaagatggttcaggaagcatagaagtgg tggggagtggaaaatggcacaacatcaactgcaaggaaggagataaactccacctcttct gctttcacctgaaaacaattgacaggcaaccaaagttagtgtgtggagaacacagtttca tcaagatatcaaagagaggaaatgtaclaaaggagcctgctaaggalgaagatcaccatc atggtcccaaacaagtgatggtgctgaaagtaacagaaccatttacatatgacctgaaag aggataaagaatgtttcatgctaccgtggctactgaaactgagttcttcagagtgaagg

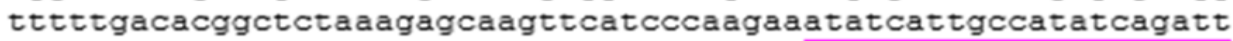
attttgggtgcaatgggtttctggagatatacagagcttcctgtgtctctgatgtgaacg ttaatccaacaatggttatctcaaatacactgagacaaagagctaatgcaactcctaaa tttcttatctttctcacaagcaagggggacatttgtgagtggagagtacttagtaaata Ifi204 CD6 agaaaacggagaggaataaattcatttactatggaattggagatgatacagggaaatgg aagtggtggtttatggaagactcaccaatgtcaggtgtgaaccaggcagtaaactaagac ttgtctgctttgaattgacttccactgaagatgggtggcagctgaggtctgtaaggcaca gttacatgcaggtcatcaatgctagaaagtgaaggaaagccactcaacccagactcagtc gggagaacctctctggaaccatacttctgaaaacctgaatgccaatgatatttttttgtg gagataagattcaattacagaaataaatgtgtataagcctattgaaatatcagtcctat aaagaccatctcttaattctaggaaatggtgttttcttatattctttacacatttccat atctaaatcatttgttgtctctataacttctataactgttcaatttgcaatttttatgc ctaaacttataaaataattcacacaattctgtaaa

Figure 2-18. Ifi204 gene sequencing and designed primers on cDNA. Eight pairs of primers are designed in Ifi204. Each color represents a pair of primers. The primers overlapped each other, so there is no missing nucleotide between the first and last primer when we sequence the Ifi204-containing sample. 
A.

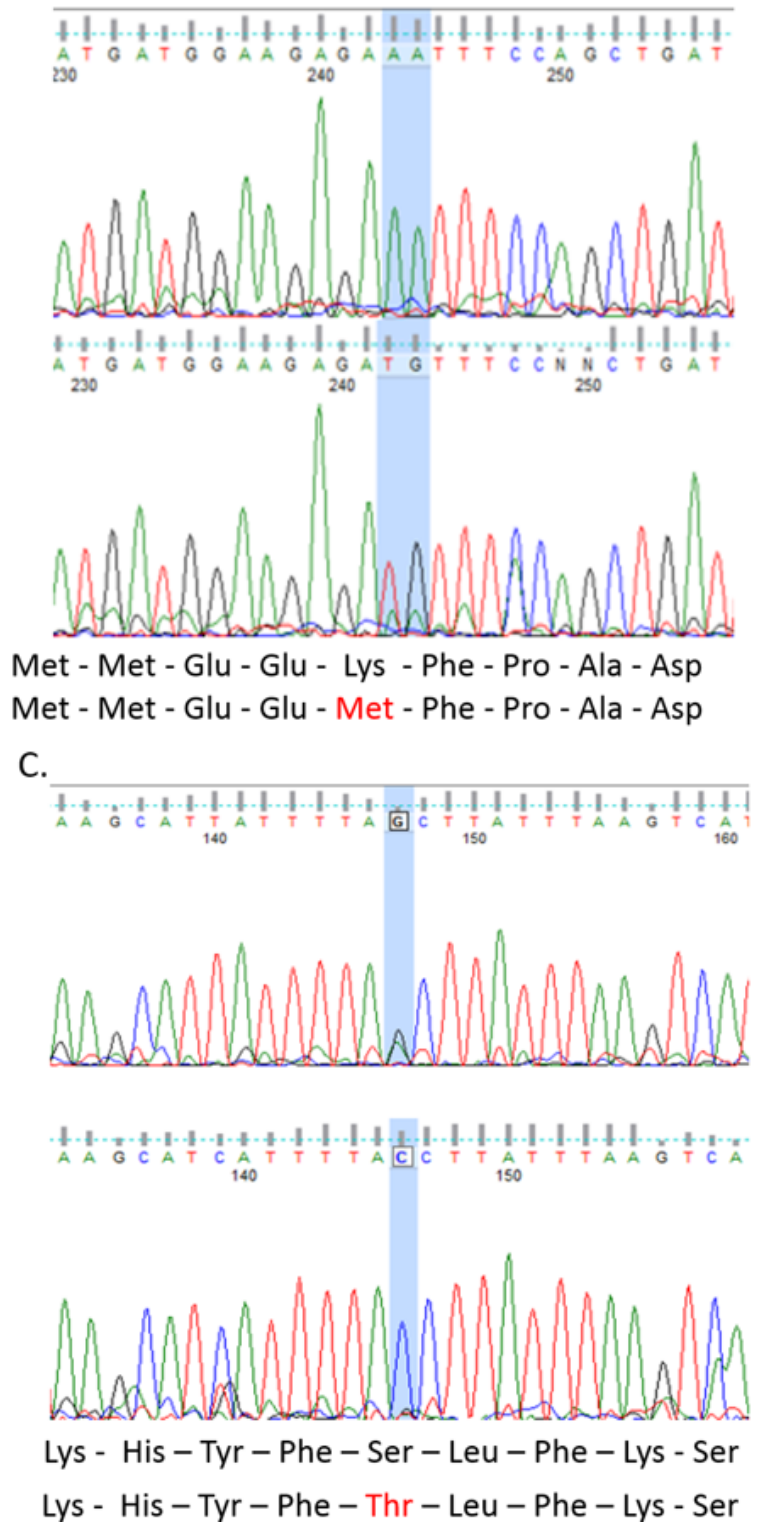

B.

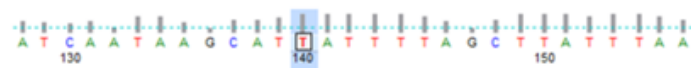
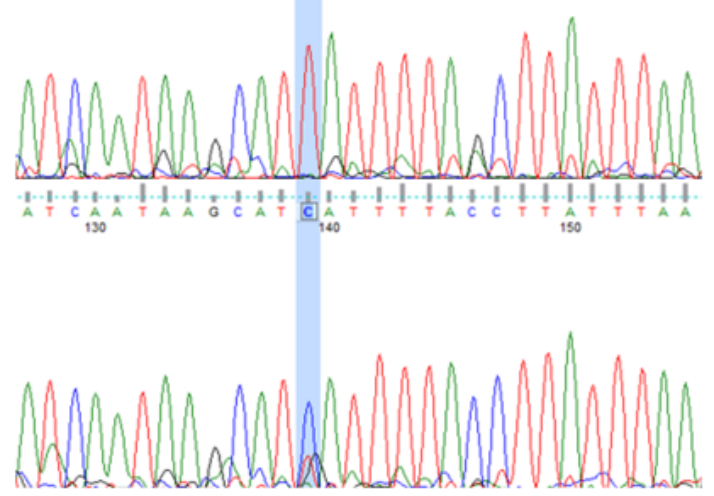

Ile - Asn - Lys - His - Tyr - Phe - Ser - Leu - Phe Ile - Asn - Lys - His - His - Phe - Ser - Leu - Phe

Figure 2-19. BALB/ $\mathrm{c}^{-/-}$and DBA/1 ${ }^{-/-}$have multiple polymorphisms on Ifi204 gene sequencing.

The Ifi204 gene sequence in DBA/ $1^{-/-}$strain is shown on the top, and the bottom representation is the BALB $/ \mathrm{c}^{-/-}$strain. Comparing the sequences in these two strains, there are several polymorphisms on the gene, causing the protein structure to be changed. (A) At $292 \mathrm{bp}$ and $293 \mathrm{bp}, \mathrm{DBA} / 1^{-/}$was $\mathrm{AA}$ and $\mathrm{BALB} / \mathrm{c}^{-/-}$was $\mathrm{TG}$, the amino acid changed from Lys to Met; (B) at $190 \mathrm{bp} \mathrm{DBA} / 1^{-/-}$was T and BALB/ $/ \mathrm{c}^{-/-}$was $\mathrm{C}$, the amino acid changed from Tyr to His; (C) at $197 \mathrm{bp}, \mathrm{DBA} / 1^{-/-}$was $\mathrm{G}$ and BALB/ $\mathrm{c}^{-/-}$was $\mathrm{C}$, the amino acid changed from Ser to Thr. 


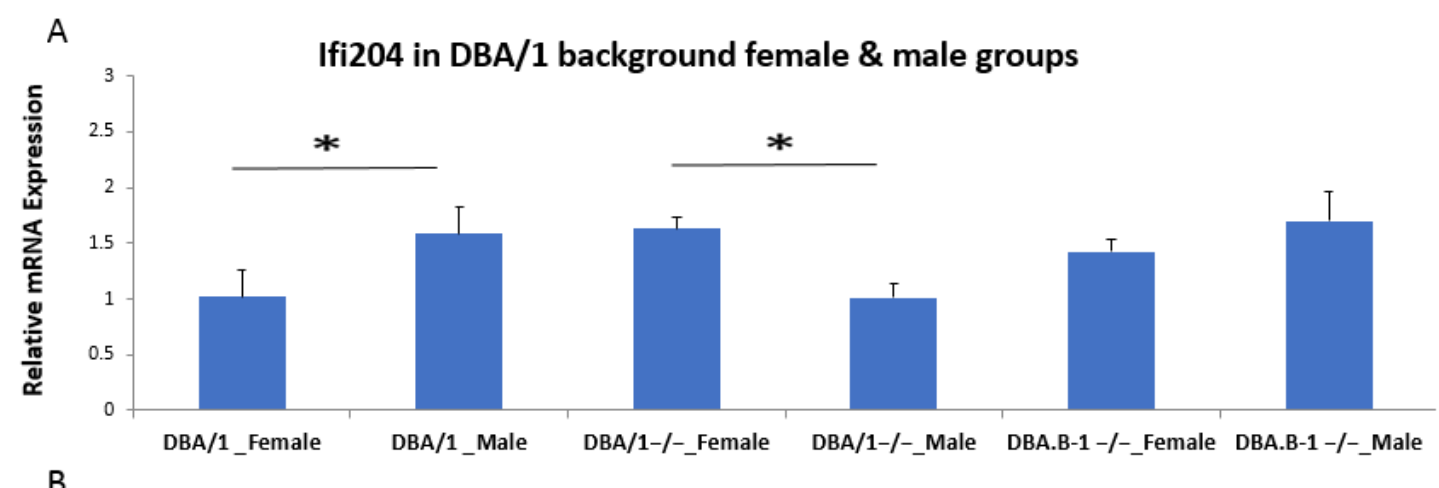

B

Ifi204 in BALB/c background female \& male groups

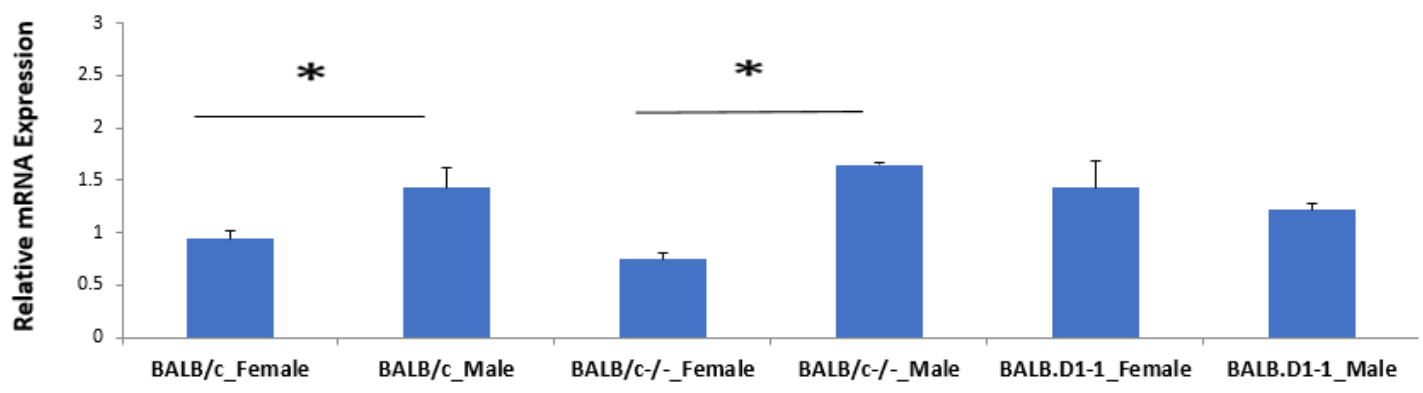

Figure 2-20. Ifi204 gene expression levels in both genders of each strain. Ifi204 gene expression levels of 4-month old male and female DBA $/ 1^{-/}$, DBA.B- $1^{-/}$, BALB.D-1 $1^{-/}, \mathrm{BALB} / \mathrm{c}^{-/}$, DBA/1 wild type, and BALB/c wild type mice expression levels were measured from spleen tissue. $(n=3)$. (* means $p>0.05)$ (A) Ifi204 gene expression levels in DBA/1 background of both genders. The strains are shown below the horizontal axis. Numbers to the left of the vertical axis are the ratios of relative expression. In DBA $/ 1$ and DBA.B-1 $1^{-/-}$strains, female gene expression is lower than that of male. In $\mathrm{DBA}^{-/-}$strain, female gene expression is higher than that of male. (B) Ifi204 gene expression levels in BALB/c background of both genders. The strains are shown below the horizontal axis. Numbers to the left of the vertical axis are the ratios of relative expression. In $\mathrm{BALB} / \mathrm{c}$ and $\mathrm{BALB} / \mathrm{c}^{-/-}$strains, female gene expression is lower than that of male. In BALB.D-1 $1^{-/}$strain, female gene expression higher than that of male. 
were the same within the same gender in the BALB/c background. This is likely a result of differential gender effects of the IL-1ra knockout in the different mice strains studied.

\section{Foxp3+ Regulatory T Cells in Each Strain}

Flow cytometry was used to determine the numbers, frequencies, and phenotypes for specific types of lymphocytes. The percentage of lymphocytes expressing CD3, CD4, CD8, CD25, and Foxp3 were compared for each strain. CD19 and CD3 were used to analyze the concentration of $\mathrm{B}$ cells and T cells. In the $\mathrm{BALB} / \mathrm{c}^{-/-}$strain, the $\mathrm{B}$ cells were $45 \%$ and $\mathrm{T}$ cells were $36 \%$ of total lymphocytes. In the DBA $/ 1^{-/}$strain, the B cells were $62.9 \%$ and $\mathrm{T}$ cells were $24.7 \%$ of total lymphocytes. The congenic BALB.D-1 ${ }^{-/}$strain had $43.2 \% \mathrm{~B}$ cells and $44.9 \% \mathrm{~T}$ cells of total lymphocyte. The T cells in the BALB $/ \mathrm{c}^{-/-}$ strain and the BALB.D-1 $1^{-/}$strain had a higher percentage than did the DBA $/ 1^{-/}$strain, and the $\mathrm{B}$ cells in the BALB $/ \mathrm{c}^{-/-}$strain and the BALB.D-1 $1^{-/}$strain had a lower percentage than did the DBA $/ 1^{-/-}$strain. For T cell subsets, CD4 and CD8 markers were analyzed. Cytotoxic $\left(\mathrm{CD}^{+}\right) \mathrm{T}$ cells were $26.4 \%$ and helper $\left(\mathrm{CD}^{+}\right) \mathrm{T}$ cells were $64.8 \%$ in the $\mathrm{BALB} / \mathrm{c}^{-/-}$strain, cytotoxic T cells were $24.0 \%$ and helper $\mathrm{T}$ cells were $63.5 \%$ in the DBA $/ 1^{-/}$strain, and cytotoxic $\mathrm{T}$ cells were $22.4 \%$ and helper $\mathrm{T}$ cells were $71 \%$ in the BALB.D-1 ${ }^{-/}$strain. Cytotoxic T cells and helper T cells had similar percentages in the three strains. Treg cell percentages in BALB $/ \mathrm{c}^{-/-}, \mathrm{DBA} / 1^{-/-}$, and BALB.D-1 $1^{-/-}$were $25.7 \%$, $37.6 \%$, and $26.4 \%$, respectively, in lymphocytes. The DBA $/ 1^{-/-}$strain had a higher percentage than the other two strains. The DBA $/ 1^{-/-}$strain was arthritis-resistant and the $\mathrm{BALB} / \mathrm{c}^{-/-}$and BALB.D-1 ${ }^{-/-}$strains were susceptible to arthritis (Figure 2-21).

\section{The Effect of Arthritis on the Ankle Joint Area}

SAD is observed in mouse ankle joints. This conclusion was based on the previous observation that changing the genotype results in a different phenotype in the ankle joint area in each strain. The ankle joint's degree of severity in arthritis presentation is most prevalent when the mice are growing. We scored and calculated the four limbs, following the scale and the data given above. The severity of swelling and redness in the ankle joint of hind legs was more serious in BALB/ $\mathrm{c}^{-/-}$than found in $\mathrm{DBA} / 1^{-/}$.

Inflammation affects the cartilage and synovium. Ankle joints will lose function when the synovial tissue is eroding. The inflammation can also affect the joint bones and result in bone erosion. $\mu \mathrm{CT}$ is the best tool for testing our hypothesis. As Figure 2-22 shows, the $\mathrm{DBA} / 1^{-/}$strain did not have arthritis as shown by the very smooth bone surface. In the $\mathrm{BALB} / \mathrm{c}^{-/-}$strain, the bone surface is obviously rough. We enlarged the ankle joint apart from the whole leg so that we could display the difference between the two strains more clearly. The whole bone volume and bone mineral density were measured for both the males and females in the four strains. In whole bone volume, males were slightly greater than that observed in females, but they were similar among each strain. We believed that arthritis could not change whole bone volume. In bone mineral density, males were higher than females in all strains. The bone mineral density in the DBA $/ 1^{-/}$strain was 
Figure 2-21. Analysis of foxp3 in lymphocyte cells of BALB. D-1 ${ }^{-/-}$compare with BALB $/ c^{-/ 2}$ and DBA $/ 1^{-/}$.

Cells were harvested at 4 months. Representative flow cytometry histograms show CD3, CD19, CD4, CD8, CD25, and foxp3 expression on splenocytes from BALB/ $\mathrm{c}^{-/-}$, DBA $/ 1^{-/ \text {, }}$, and BALB.D- $1^{-/-}$female mice $(n=3)$. (A) Percentages of $T$ cells and $B$ cells in each strain. In the $\mathrm{BALB} / \mathrm{c}^{-/-}$strain, the B cells were $45 \%$ and $\mathrm{T}$ cells were $36 \%$ of total lymphocytes. In the DBA $/ 1^{-/-}$strain, the B cells were $62.9 \%$ and $\mathrm{T}$ cells were $24.7 \%$ of total lymphocytes. (B) Percentages of Helper T cells and cytotoxic T cells in the three strains. Cytotoxic T cells were $26.4 \%$ and helper T cells were $64.8 \%$ in the $\mathrm{BALB} / \mathrm{c}^{-/}$strain, cytotoxic $\mathrm{T}$ cells were $24.0 \%$ and helper $\mathrm{T}$ cells were $63.5 \%$ in the $\mathrm{DBA} / 1^{-/-}$strain, and cytotoxic $\mathrm{T}$ cells were $22.4 \%$ and helper T cells were $71 \%$ in the BALB.D-1/ ${ }^{-/}$strain. (C) Percentages of $\mathrm{T}$ regulator cells (Tregs) in the three strains. Treg cell percentages in $\mathrm{BALB} / \mathrm{c}^{-/}, \mathrm{DBA} / 1^{-/}$, and BALB.D-1 ${ }^{-/}$were $25.7 \%, 37.6 \%$, and $26.4 \%$, respectively, in lymphocytes. 

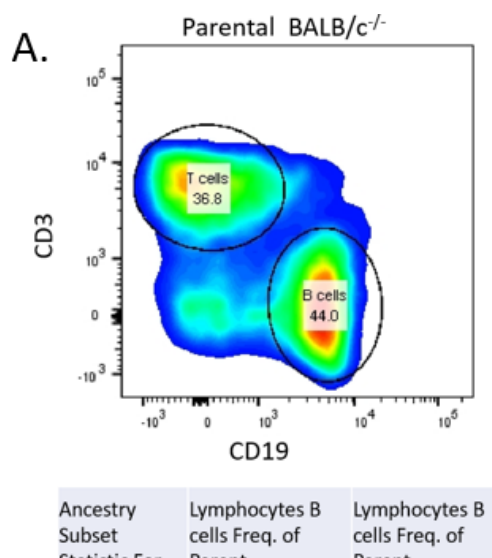

Subset cells Freq. of cells Freq. of

Mean

45.0

SD

3.26

B.

B. Parental BALB/c $/ 1$

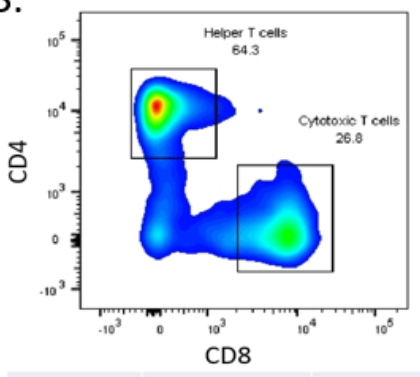

$\begin{array}{lll}\text { Ancestry } & \text { Lymphocytes/T } & \text { Lymphocytes/T } \\ \text { Subset } & \text { cells Cytotoxic T } & \text { cells Helper T } \\ \text { Statistic For } & \text { cells Freq. of } & \text { cells Freq. of } \\ \text { Parent } & \text { Parent }\end{array}$

Mean

26.4

SD

2.85

2.47

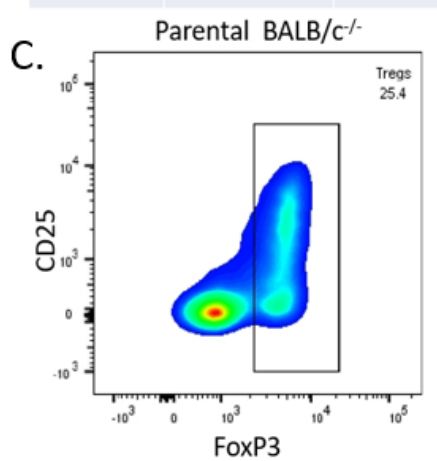

$\begin{array}{ll}\text { Ancestry Subset } & \text { Lymphocytes/T cells/ } \\ \text { Statistic For } & \text { Helper T cells Tregs Freq. of } \\ & \text { Parent }\end{array}$

$\begin{array}{ll}\text { Mean } & 25.7\end{array}$

SD

0.35

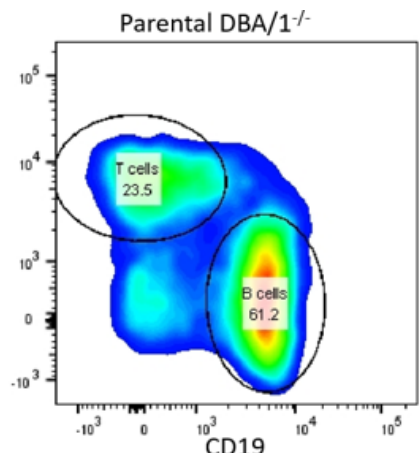

Ancestry Lymphocytes B Lymphocytes B Subset cells Freq. of cells Freq. of Statistic For Parent cells Freq.
Parent 36.8 Mean

62.9

21.7 Mean

3.69

3.44

SD
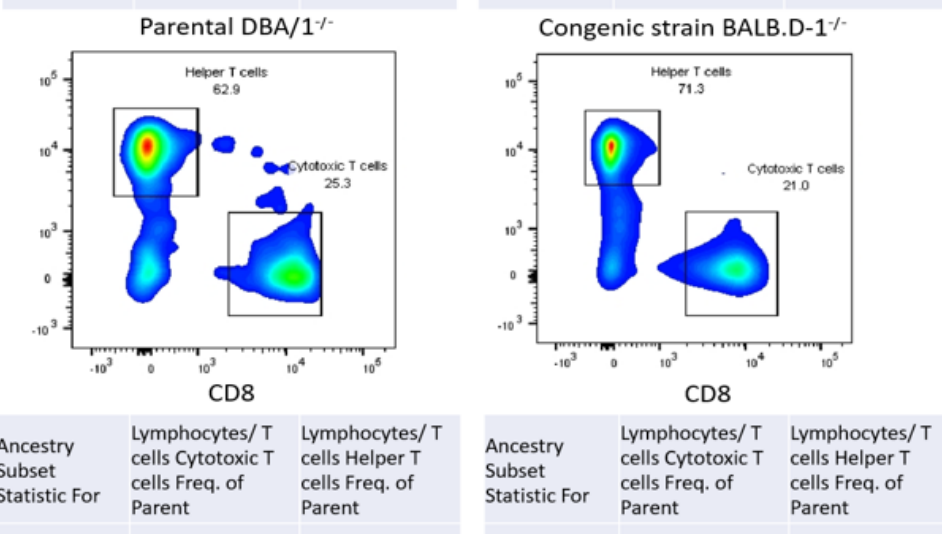

Mean

22.4

2.12 $\begin{array}{lll}\text { SD } & 2.63 & 2.72\end{array}$

Congenic strain BALB.D-1\%

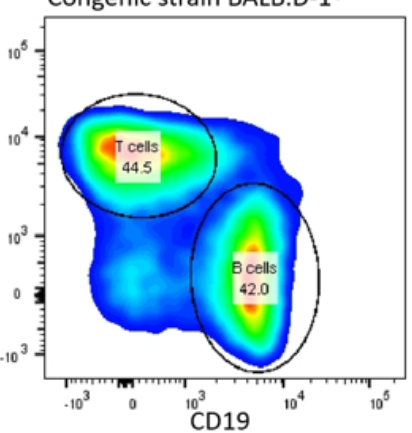

cells Freq. of Parent

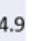

.

1.50

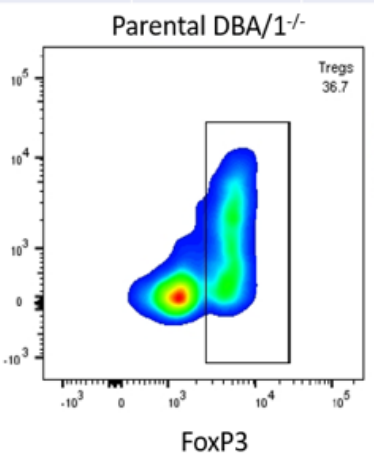

Ancestry Subset Statistic For

Lymphocytes/T cells/ Helper T cells Tregs Freq. of Parent
1.77

SD

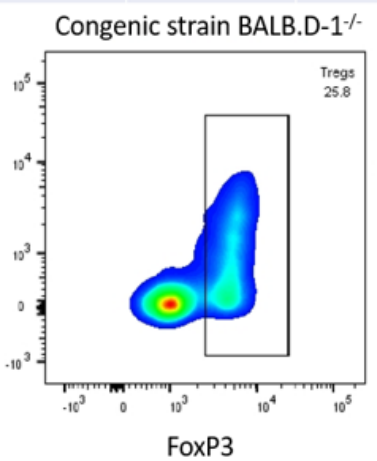

Ancestry Subset

Lymphocytes/ T cells/ Helper T cells Tregs Freq. of Parent 
A.

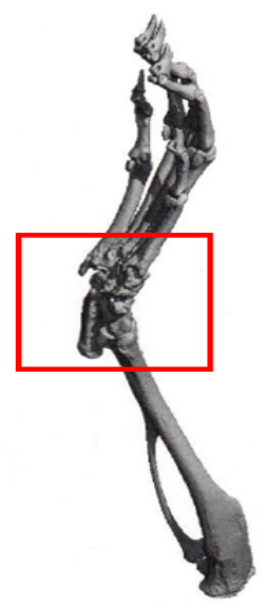

BALB/c-/- strain

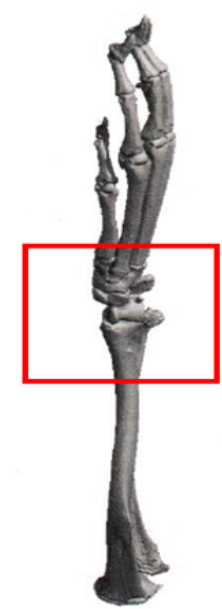

DBA1-/- strain

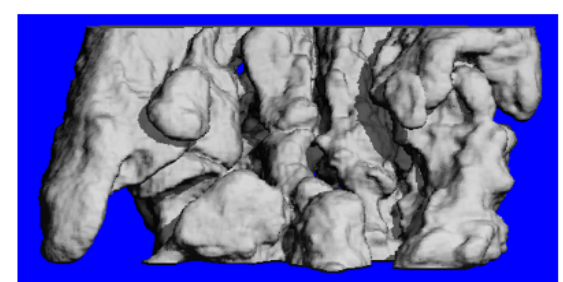

BALB/c-/- strain

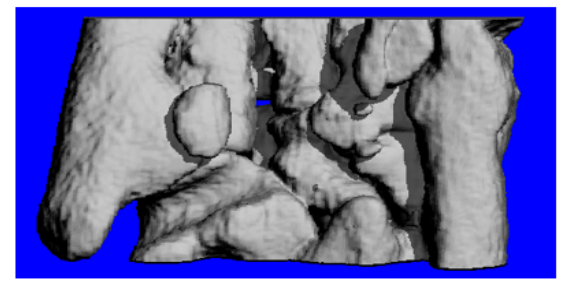

DBA1-/- strain

B.

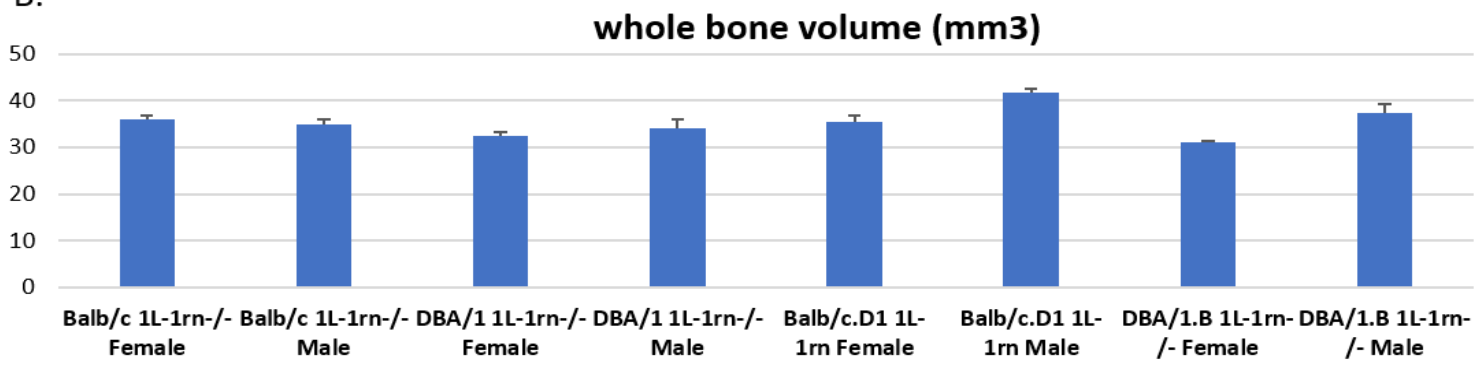

C.

Bone Mineral Density (mgHA/mm3)

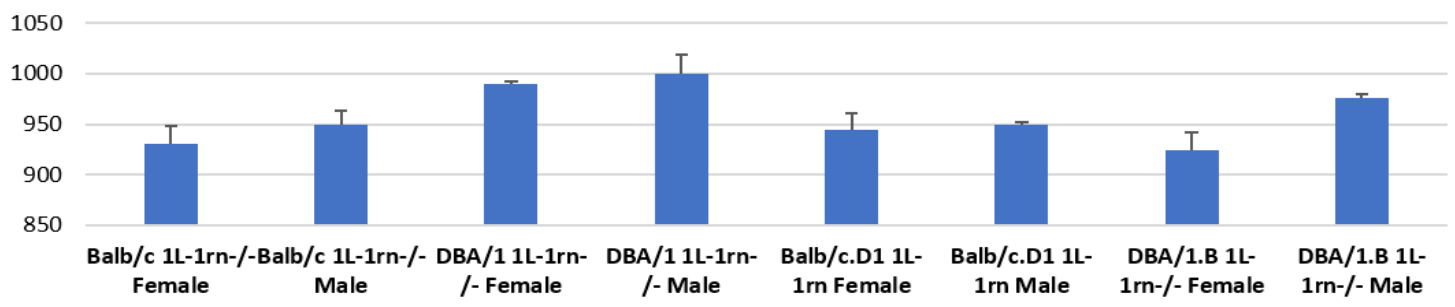

Figure 2-22. The structure of ankle joint bones shows in $\mathrm{BALB} / \mathrm{c}^{-/}, \mathrm{DBA}^{-/}$, BALB.D-1 ${ }^{-/}$, and DBA.B-1 ${ }^{-/}$.

(A) Images from $\mu \mathrm{CT}$ show that the $\mathrm{DBA} / 1^{-/-}$mice have very smooth bone surfaces and the $\mathrm{BALB} / \mathrm{c}^{-/-}$mice have obvious irregularities on the surface of the ankle joint areas. (B) Comparison of whole bone volume differences between BALB $/ \mathrm{c}^{-/-}, \mathrm{DBA}^{-/}$, BALB.D-1 ${ }^{-/}$, and DBA.B-1 $1^{-/}$mice. The strains are shown below the horizontal axis. Numbers to the left of the vertical axis are the bone volume in cubic millimeters. In all four strains, the male expresses a slightly higher volume than the female, but there are no significant differences between strains. (C) Comparison of bone mineral density differences in BALB $/ \mathrm{c}^{-/}$, DBA ${ }^{-/}$, BALB.D-1 ${ }^{-/}$, and DBA.B-1 $1^{-/-}$mice. The strains are shown below the horizontal axis. Numbers to the left of the vertical axis are bone density in $\mathrm{mgHA} / \mathrm{mm}^{3}$. Males have higher bone mineral density than females in all four strains. DBA $/ 1^{-/-}$has higher bone mineral density than that of BALB $/ \mathrm{c}^{-/}$. 
higher than $\mathrm{BALB} / \mathrm{c}^{-/}$in both genders. Arthritis could erode the bone and decrease the bone density. The two congenic strains, DBA.B- $1^{-/}$and BALB.D-1 ${ }^{-/}$, were scored between the two parental strains' observed scores.

\section{Discussion}

Using an $\mathrm{F} 2$ mouse population from a resistant strain, $\mathrm{DBA} / 1^{-/}$, and a strain susceptible to spontaneous arthritis, $\mathrm{BALB} / \mathrm{c}^{-/}$, we were able to study spontaneous arthritis in the absence of IL-1ra QTLs-regulated mapping. From the different QTL location numbers, we discovered spontaneous arthritis is controlled by many genetic factors. The QTLs on chromosome 1 had been found to have a major genetic effect on spontaneous arthritis. Through the QTLs, the region can be narrowed down, and we can thereby reduce the work needed to find the candidate genes. The QTLs on chromosome 1 were very useful in our study. The candidate genes were confirmed in this region, but the genomic region of the QTL was still at too large of a range - more than 300 genes were on this region. Different gene expression levels were identified between the congenic and parental mice on this region. From the online database, the gene function and correlation can be searched. We obtained a list of candidate genes through bioinformatics, gene expression profiles, and molecular pathway analysis.

IL-1 ra has been linked to many diseases: respiratory diseases, aneurysm formation, and periostitis, among others. There were no diseases found in $\mathrm{BALB} / \mathrm{c}^{-/}$, $\mathrm{DBA} / 1^{-/}$, and the two congenic mice strains. Diseases might appear in a small number of mice, but it was not a common phenomenon. CIA involves late steps in the molecular pathway, but IL-1 ra is involved in earlier steps. Because the IL-1ra-deficient arthritis was heritable and spontaneous, the $\mathrm{BALB} / \mathrm{c}^{-/-}$and $\mathrm{DBA} / 1^{-/-}$genomic background were very useful for understanding the QTLs. The homozygous disease mouse model is a useful tool for studying diseases falling under a uniform genomic background, but many of these studies result in failed human trials. The use of multiple animal strains can help us to understand the range and variability in disease regulation of different genes or genetic loci of interest. Parental strains and their congenic mice could enhance our study of the molecular mechanism, and so provide a useful tool for searching the candidate genes.

The QTL region conferring susceptibility to spontaneous arthritis is on chromosome 1 and functions in both directions. The two congenic mice BALB.D-1 ${ }^{-/}$and DBA.B- $1^{-/-}$were created from the DBA $/ 1^{-/-}$and BALB $/ \mathrm{c}^{-/-}$parental strains. A DNA fragment covering the QTL loci was transferred from the DBA $/ 1^{-/}$strain onto the $\mathrm{BALB} / \mathrm{c}^{-/-}$strain background to build the BALB.D-1 ${ }^{-/ /}$congenic strain. The fragment of DNA from the same QTL loci from BALB $/ \mathrm{c}^{-/-}$strain was transferred onto the DBA $/ 1^{-/-}$ strain to build the DBA.B-1 $1^{-/-}$congenic strain. In the BALB.D-1/- congenic strain, the onset of the disease was delayed and it was less severe than found in the BALB/ $\mathrm{c}^{-/-}$ parental strain. The DBA.B-1 ${ }^{-/}$congenic strain showed an increased possibility of suffering from arthritis in comparison to DBA $/ 1^{-/}$. The two congenic strains can be used to confirm the function of the QTL and help us to understand the sequence of the genomic region of the QTL. Most studies only transfer the fragment in one direction, 
transferring one piece of genomic DNA from one strain to another strain, but not transferring the section of DNA from the same location on the second strain to the first. In our study, we exchanged DNA fragments from both strains. They were useful models for studying the interaction of the QTL region and the whole genome in the congenic strains. The genomic DNA from a QTL loci in the two congenic strains can either increase or decrease the susceptibility to arthritis in comparison to their parental strains. The exchange of the DNA fragments in the congenic strains can help inform our understanding of the molecular mechanisms of the genes in the QTL region. The data from the four strains prove that the genotype and molecular pathways interact. By using the two congenic strains, we can confirm the function of the QTL region and clearly define the genes that regulate the susceptibility to spontaneous arthritis.

The phenotype of the mouse strains was studied by scoring the ankle joints at different periods throughout growth and by imaging the bone with a $\mu \mathrm{CT}$ after collection. The two parent strains were on opposite ends of the scoring spectrum, as BALB $/ \mathrm{c}^{-/-}$ showed signs of severe arthritis early, and DBA $/ 1^{-/}$showed no signs. The congenic strains had less extreme results, with BALB.D-1 ${ }^{-/}$having less severe joint swelling and redness than its parent strain, and DBA.B- $1^{-/-}$having more than its parent. The male $\mathrm{BALB} / \mathrm{c}^{-/-}$and BALB.D-1 ${ }^{-/-}$mice had higher severity than the females. A study using mouse models to investigate osteoarthritis found that sex hormones play a significant role in the progression of arthritis in mice, with it being more severe in males. This study concluded that estrogen plays a protective role in osteoarthritis and may explain why males had it with greater severity. They did not establish a correlation between testosterone and osteoarthritis. The role of sex hormones could also be applicable to SAD and may explain why the severity progressed quicker in the males than in the females. Arthritis is affected by genetics and the environment. This means that although the $\mathrm{DBA} / 1^{-/-}$strain does not have the genetic background to cause arthritis, it is susceptible to the disease because of its environment. However, the severity of arthritis would be much lower than the genetically influenced disease. The substantial influence genetics has on arthritis is demonstrated by the incidence rate in Figure 2-4. BALB.D-1 ${ }^{-/}$has delayed incidence and severity compared to its parent $\mathrm{BALB} / \mathrm{c}^{-/-}$because of the transferred genomic region from DBA $/ 1^{-/-}$. DBA.B $-1^{-/-}$has a higher chance of getting the disease, and at an earlier age, in comparison to its parent $\mathrm{DBA} / 1^{-/-}$as a result of the genomic region from $\mathrm{BALB} / \mathrm{c}^{-/-}$. Swelling and inflammation are evident in the images of the BALB $/ \mathrm{c}^{-/-}$and BALB.D- ${ }^{-/-}$mice in Figure 2-3. Using congenic strains allows us to prove that the genes affecting arthritis are found in the region that we predicted. As discussed above, transferring the genomic pieces from $\mathrm{DBA} / 1^{-/-}$and $\mathrm{BALB} / \mathrm{c}^{-/-}$to the other strain affects the incidence and severity of arthritis; allowing us to conclude that the candidate gene(s) are in this region. When watching the affected mice, it was obvious that they walked slower and more cautiously so as to not put pressure on their hind legs. The study indicated erosion of the soft tissue and synovium as a result of the inflammation from arthritis, and after collection, it was found that the bones of the arthritic mice have irregular surfaces, compared to the smooth surfaces of the healthy mice. The whole bone volume did not show any major differences between the four strains; however, the bone mineral density showed differences between BALB $/ \mathrm{c}^{-/}$and $\mathrm{DBA} / 1^{-/}$and between genders. This indicates that arthritis decreases the bone mineral density. Besides being a 
direct effect of arthritis, the bone mineral density may decrease as a result of physical inactivity due to pain from joint damage. Physical inactivity can cause a decrease in bone mineral density because of a decrease in muscle strength that subsequently leads to less loading of the bone. Studies have shown that bone loss in rheumatoid arthritis is a direct result of the disease and is most prominent in areas surrounding the affected joints. The severe erosion seen in Figure 2-22A is likely a result of these bones surrounding the affected ankle joints. The tissue weights of the strains were similar when we collected them at the same age. Normally, autoimmune system diseases like arthritis do not affect the weight of organs because it is localized.

In our microarray data, a high correlation $(\mathrm{R}=0.9895)$ of gene expression was found between the two congenic strains. Since the expression levels between the strains are mostly the same, it allows us to identify the differences that could explain the genes' varying susceptibility to $\mathrm{SAD}$. The similarities are also found between the parents and the congenic strains. As Figure 2-5 shows, the smallest correlation is still relatively high (0.97), meaning we can compare the parent and congenic strains to identify differences that could cause either a resistance or a susceptibility to arthritis. Using two congenic strains allowed us to compare them to the other four strains $\left(\mathrm{DBA} / 1^{-/ /}, \mathrm{BALB} / \mathrm{c}^{-/-}, \mathrm{DBA} / 1\right.$ wild type, and BALB/c wild type) and narrow down the possible candidate genes by examining overlapping upregulated genes between the comparison genes.

The function of the T-cell receptor beta chain and the Ifi cluster genes in SAD susceptibility were confirmed by their expression levels in the BALB.D- $1^{-/}$strain. The decreased expression levels of these genes in BALB.D- $1^{-/ 2}$, in comparison to BALB $/ \mathrm{c}^{-/ \text {, }}$, resulted in an increased resistance to SAD. In the strains that are resistant to SAD, DBA wild type and $\mathrm{DBA} / 1^{-/}$, the expression levels of these genes were similar and were also lower than found in the $\mathrm{BALB} / \mathrm{c}$ wild type and $\mathrm{BALB} / \mathrm{c}^{-/ /}$strains, which are susceptible to SAD. BALB $/ \mathrm{c}^{-/ /}$and BALB.D-1 $1^{-/-}$had very few genes with differences in up- or downregulation because most of the genes are from the $\mathrm{BALB} / \mathrm{c}^{-/}$background. This is also true for the comparison between DBA.B- $1^{-/-}$and DBA $/ 1^{-/}$. The congenic strains compared to the donor allele strains showed many differences in the up- and downregulated genes, since the majority of the congenic strains' genes came from the background. When comparing the congenic strains to their respective donor strains and the wild type of the donor strain, the congenic strains had fewer differences in comparison with the donor strain. All of the wild type strains had more differences in upand downregulated genes in comparison with the congenic strains than the IL-1ra deficient strains showed, because the congenic strains were also IL-1ra deficient. The data showed an Ifi200 cluster that contained candidate genes for SAD resistance in the BALB.D- $1^{-/-}$strain. The Ifi200 cluster genes between BALB.D-1 $1^{-/-}$and BALB $/ \mathrm{c}^{-/-}$were expressed differentially and located in the transferred genomic fragment in the BALB.D$1^{-/-}$strain. The genes were located on chromosome 1 from D1Mit110 to D1Mit209. The microarray data displays differences between the two strains. The Ifi family genes may not have the greatest difference between the strains, but from our data and that of other studies, there is a large fold change, and therefore the Ifi2 200 cluster contained candidate genes for SAD resistance. It has been published that Ifi proteins are immune suppressors. For example, Ifi202b, Ifi203, Ifi204, Ifi205, and Mndal are known as interferon-inducible 
lupus susceptibility genes[146]. Since we believed that the Ifi200 gene family plays an important role in arthritis, the number of transcripts per gene and the protein size of each transcript were important to use as experimental search parameters.

To choose a gene to focus on within the Ifi200 family, we needed to compare the relative expression levels of the family of genes made up by the congenic strains and their parents. We hypothesized that the Ifi200 gene family influences the inflammation found in arthritis, so searching the genes within this family, that had higher expression in the arthritis susceptible strains, is a productive strategy. By comparing the congenic strain to its parent and to the donor allele strain, we were able to determine which genes were different in the DNA region of interest between the arthritis susceptible strain and the resistant strain. Since BALB.D- $1^{-/-}$has the DBA $/ 1^{-/-}$DNA region, it would not be expected to have different gene expression levels than $\mathrm{DBA} / 1^{-/-}$, but we can examine the differences between it and $\mathrm{BALB} / \mathrm{c}^{-/}$to find possible candidate genes. Ifi203, Ifi204, and Ifi205 had negative differential expression scores between these two strains, thus we focused on them as the possible candidate genes. Ifi202b did not have the positive correlation that the other Ifi family genes had. A comparison between DBA.B- $1^{-/-}$and its parent strain and donor allele strain should also show differences similar to the BALB.D$1^{-/}$comparisons. From the narrowed results from the BALB.D- $1^{-/-}$comparisons, the differential expression scores were identified for Ifi205 and Ifi204 in DBA.B-1 ${ }^{-/}$, DBA/1 wild type, and DBA $/ 1^{-/}$. Expression levels of the Ifi family genes between the congenic strain and its background strain were also determined. The candidate gene that is positively correlated with the susceptibility of arthritis should be higher in DBA.B- $1^{-/-}$ than in DBA $/ 1^{-/-}$and lower in BALB.D- $1^{-/-}$than in BALB $/ \mathrm{c}^{-/-}$. Data from Ifi203, Ifi204, and Ifi205 all agreed with this line of prediction. Ifi202b did not have a positive correlation. Ifi204 had the highest overall expression in the arthritis susceptible strains, hence we chose to focus on this one as the most favorable candidate gene.

Taken together, our data support the current evidence that Ifi204 is the candidate gene obtained for the regulation of susceptibility to SAD in mice. There are many aspects of the experimental evidence supporting our conclusion. Our data indicated that expression levels of Ifi204 varied inversely with the resistance to SAD in the congenic strain with the BALB/ $/ \mathrm{c}^{-/}$background; additionally, the expression levels of Ifi204 also varied inversely with the resistance to SAD in the congenic strain DBA.B- $1^{-/-}$. Furthermore, the human homolog to mouse Ifi204, IFI16, has recently been linked to arthritis, and the expression level of Ifi204 is the only gene in the Ifi200 cluster which was found to be at a detectable or functional level. Finally, the Ifi200 cluster genes are the only group of genes relevant to SAD within the QTL region, which showed differential expression. This study will significantly enhance our understanding of the roles of the Ifi204 gene in inflammatory diseases, because the role of the Ifi204 gene in mice was recently found to be very similar to its human homolog IFI16, which is linked to arthritis, as noted above[97].

The Ifi200 family is composed of interferon-activated genes, and thus its role in infection and innate immune responses has been studied. Flow cytometry was used to examine if the genes in the Ifi family interact with the T-cell receptor beta chain family to 
downregulate SAD. The possible interaction between these two families of genes was of interest because the T-cell receptor beta chain family is known to a have a role in controlling susceptibility to arthritis. Flow cytometry results in Figure 2-21 show that the arthritic mice (BALB/ $/ \mathrm{c}^{-/-}$and BALB.D-1 ${ }^{-/-}$) have higher percentages of T cells than does $\mathrm{DBA}^{-/-}$, but lower percentages of cells expressing FoxP3. FoxP3 is a transcription factor that helps regulate immune responses by activating or repressing anti-inflammatory genes. This explains why the strains with severe inflammation have lower levels of FoxP3, but higher levels of T-cells than the strain resistant to arthritis. Within the smaller percentage of $\mathrm{T}$ cells in the $\mathrm{DBA}^{-/-}$strain, there is a high percentage of Treg cells. FoxP3 helps Treg cells to suppress immune responses by a positive feedback mechanism. DBA $1^{-/}$would be expected to have a high percentage of Treg cells and FoxP3, because its phenotype does not present with the inflammation that coincides with immune responses.

Our study again emphasized the power of whole genome analysis, as well as the importance of quality and accuracy in microarray analysis. Because the microarray chip contains more than 30,000 probes of mouse genes, any error in the technique could create a large number of genes with false positive differential expressions. The large number of differentially expressed genes between DBA.B-1 $1^{-/}$, BALB.D- $1^{-/}$, and the other three parental strains suggested that the small number of differentially expressed genes between DBA.B-1 $1^{-/}$and DBA $/ 1^{-/}$are most likely to be the true differentially expressed genes. Furthermore, the precise agreement on the expression level of genes in the Ifi cluster between DBA.B-1 $1^{-/-}$versus DBA $/ 1^{-/-}$and DBA.B-1/- versus DBA/1 wild type confirms the accuracy of this analysis.

One should note that both LOC638301 and LOC100044430 were withdrawn, most likely due to the inaccuracy of their sequences. However, their probes on the Illumina mouse-6 v1.1 were highly similar to that of Ifi204 and Ifi205. Because of the high similarity to the sequences of Ifi family genes, their probes were most likely to detect the expression of Ifi204 and Ifi205, with certain mismatches to other genes. Because differential expression of the Ifi family in our study was not exclusively based on these two probes, we felt that the data were truly representative in terms of the connection between the expression level of Ifi family genes and spontaneous arthritis disease. Zhang et al. indicated in their study that Mndal was absent from DBA/2. With the close genome background between DBA/2 and DBA/1, one would assume that Mndal in the DBA/1 strain is also absent[147]. Considering the similarity among genes in the Ifi200 family cluster, we speculate that the increased level of the expression level of Mndal, in this case, could reflect (1) a partial rather than complete deletion, or (2) crossreactivity to other genes in the Ifi family cluster. Thus, these probes represent probes for the Ifi200 family, and we detect their expression levels at the whole family level, rather than at the level of individual genes in the cluster[97].

Using real-time PCR to test the expression level of Ifi204 between BALB/ $\mathrm{c}^{-/-}$, DBA $/ 1^{-/-}$, BALB.D-1 $1^{-/-}, \mathrm{DBA} / 1^{-/-}, \mathrm{BALB} / \mathrm{c}$ wild type and DBA/1 wild type, there is a noticeable difference between Ifi204 gene expression level in DBA $/ 1^{-/-}$and BALB $/ \mathrm{c}^{-/-}$ strains, but the variation among the sexes within each strain is unexplainable at this 
moment. There is a definite relationship between Ifi204 expression and arthritis, as seen in the comparison between the congenic strains and their parents. DBA $/ 1^{-/ /}$had lower expression levels of Ifi204 than its congenic strain DBA $/ 1^{-/}$, and the congenic strain BALB.D- $1^{-/ /}$had lower expression levels than its parent $\mathrm{BALB} / \mathrm{c}^{-/}$. This is to be expected if Ifi204 plays a large role in SAD, because the DBA congenic strain had arthritis while $\mathrm{DBA} / 1^{-/-}$did not, and $\mathrm{BALB} / \mathrm{c}^{-/-}$had arthritis whereas the disease was lessened in its congenic strain.

Ifi204 plays a regulatory role in SAD. We sequenced the Ifi204 gene in the $\mathrm{DBA} / 1^{-/ /}$and $\mathrm{BALB} / \mathrm{c}^{-/-}$strains. There were several nucleotide polymorphisms in the coding region between the two parental strains. This not only made the expression levels different, but also changed the protein structure between the two strains. Multiple nucleotide changes can have substantial effects on the protein, as just one change in nucleotide can change the amino acid and thus the secondary and tertiary structure of the protein. 1)The nucleotide from AA to TG change caused the expressed amino acid to change from lysine to methionine. This is an exchange of a hydrophilic side chain to a hydrophobic one. Charged amino acids can form ionic bonds, whereas hydrophobic ones cannot. 2)The $\mathrm{T}$ to $\mathrm{C}$ nucleotide swap changed the amino acid from tyrosine to histidine. This changed a hydrophobic amino acid to a positively charged amino acid. The introduction of a positively charged amino acid could disrupt hydrophobic interactions, which was shown to severely impact the phenotype or raise susceptibility to disease. 3)The $\mathrm{G}$ to $\mathrm{C}$ change switched the amino acid from serine to threonine. This did not cause a change in the amino acid's charge. The changes in amino acids could have an effect on the protein's structure and/or function. A change from a charged to an uncharged amino acid, and vice versa, will change the $\mathrm{pH}$ of the protein. The difference in proteins may be an important factor in causing the resistance of DBA $/ 1^{-/-}$mice and the susceptibility of $\mathrm{BALB} / \mathrm{c}^{-/-}$mice to SAD. Because of the way primers function experimentally, we have the complete nucleotide sequence at the beginning for Ifi204. This would not change the start position for transcription but could have an effect on the promoter. We found there are several nucleotides that can cause the gene mutation. 


\section{CHAPTER 3. GENETIC STUDY OF HUMAN SCLERODERMA USING THE TIGHT SKIN MOUSE MODEL}

\section{Introduction}

Scleroderma is a connective tissue disease characterized by hardening and thickening of the skin and multiple other organs caused by an accumulation of collagen. When the condition affects the internal organs, it is called systemic scleroderma, diffuse scleroderma or systemic sclerosis. The disease is mainly divided into the following two categories, localized scleroderma (morphea) and systemic sclerosis (SSc)[148-150].

Localized scleroderma can be further divided into subgroups depending on the shape and distribution of the skin lesions. These subgroups are teardrop-shaped scleroderma, scalded scleroderma, ribbon scleroderma, and generalized scleroderma. Localized scleroderma only affects the skin of the face, hands, and feet. Scleroderma is an autoimmune disorder, characterized by vascular alterations, production of antinuclear antibodies (ANAs)[151], and the excessive accumulation of extracellular matrix (ECM) proteins (mostly collagen) in the skin and some other internal organs[152]. There are two types of scleroderma: the extremities type and the diffuse type. The etiology and pathogenesis are unknown, but it is related to genetic factors, infectious factors, abnormal metabolism of connective tissue, vascular abnormalities, and immune abnormalities. Systemic sclerosis is a prototypic idiopathic fibrosing disease[149]. Fibrosis is the development of excess extracellular matrix in organs or tissues. It can occur as part of the reparative process or can be idiopathic in origin. The abnormal deposition of ECM is stored in the skin, lung, heart, and gastrointestinal tract $[152,153]$. However, many of the basic mechanisms of disease pathogenesis remain elusive. Therefore, there are few effective therapies for preventing fibrosis. Mouse models are useful tools to determine the pathogenesis of the human disease.

There are several animal models for studying scleroderma. There are individual gene deficiencies or overexpression that cause the vasculopathy and lung fibrosis in SSc. The genes include Fos-related antigen-2 (Fra2)[151], endothelin-1 (Edn1)[154, 155], and Friend leukemia integration 1 transcription factor (Fli1)[156]. Besides the genetic models, there are also non-genetic models of SSc[157], such as the bleomycin-induced scleroderma model[158-160] that have been used to study the initiating events of fibrosis. Two main genetic mouse models used to study the skin effects of SSc are the tight skin 1 (Tsk1/+) mouse and the tight skin $2(\mathrm{Tsk} 2 /+)$ mouse. Both mouse models are heterozygotes because the homozygote is embryonic lethal, but these two types of mouse models have different molecular mechanisms. There is a tandem duplication of the fibrillin-1(Fbn1) gene in chromosome 2 of Tsk1/+[161]. The Tsk2/+ mutation mouse model is an ENU-induced dominant mutation on chromosome 1. The cutaneous phenotype is similar to the tight skin 1 (Tsk1/+) mutation. Blankenhorn's group found the candidate gene collagen type III alpha 1 chain (Col3a1) in 2015[162]. Col3al is located on chromosome 1 between 45,311,538 and 45,349,706[163]. It only has one major transcript that encodes proteins. Collagens are a big group of proteins; the collagen proteins can enhance and support many tissues in the body[164, 165]. Col3al can be 
found in the skin, intestine, lung, and blood vessel wall. The data cannot support Col3a1 as the only cause of skin fibrosis, since there is no effect on the other organs[166, 167]. Col3al may not be the only gene that causes the disease.

Our hypothesis is that ENU caused single nucleotide mutations in one or more genes in the Tsk2 locus interval that determines the disease phenotype. Using a combination of high-throughput screening and a bioinformatics approach correlating published data and our own data, we tested this hypothesis to identify the gene(s) underlying the Tsk $2 /+$ phenotype. Tsk $2 /+$ is a mutation that first appeared in the offspring of a male from the $101 / \mathrm{H}$ strain that had been administered the mutagenic agent, ethylnitrosourea, in 1986[168, 169]. Now, the Tsk2/+ mutation mice are under the C57BL/ 6 background. Tsk2/+ mice have many symptoms similar to the human disease; the dermis is tight, the macromolecule deposition dysregulates in the dermal extracellular matrix, and the autoimmune response is disordered. Collagen and extracellular matrix deposition are increased in the dermis of Tsk2/+ mice[170]. The cutaneous phenotype is present in the whole skin and is measured in the interscapular region. Type I and type III collagen are synthesized by fibroblasts in the dermis and deposited in the extracellular matrix. Increased collagen expression by dermal fibroblasts results in the fibrotic condition of the ECM. This is a characteristic of many fibrotic diseases. We will use this Tsk $2 /+$ mouse model to study the genetic factors that regulate fibrosis in the dermis. The location of the mutagenized genes is known; however, the molecular mechanism of the genetic defect is unclear. The genes are located on chromosome 1 from 42.5 to 52.5 megabases $(\mathrm{Mb})[169]$. Microarray data can narrow the number of Tsk $2 /+$ candidate mutation genes in this region. The Fhl2 gene exhibited a high expression level in Tsk2/+ mice; this allowed us to concentrate our focus on this candidate gene. The full name of Fhl2 is gene four and a half LIM domain 2. This gene can encode one of the proteins in the four-and-a-half-LIM-only family[171]. Fhl2 is located on chromosome 1 from $43,123,074$ to $43,196,984$. This gene has 2 transcripts that can encode a protein and is composed of six exons. The protein works as a regulator in the development and differentiation of the cell, as well as in numerous signaling pathways[172-174]. This gene is also connected to bone formation and bone mineral density. Our research goal is to find a connection between this gene and skin.

\section{Material and Methods}

\section{Mice}

Tsk2/+ mice were crossed on the C57BL/6 (B6) background and obtained from Dr. Arnold Postlethwaite (University of Tennessee Health Science Center, Memphis, $\mathrm{TN}$ ). The wild type C57BL/6J strain mice were purchased from the Jackson Laboratory. Both strains of mice were housed at the animal facility in the Coleman Building, University of Tennessee Health Science Center (UTHSC). The animal facility room conditions were $12 \mathrm{hr}$ light $/ 12 \mathrm{hr}$ dark per day, the temperature was $22 \pm 2{ }^{\circ} \mathrm{C}$, and 
relative humidity was controlled between $30 \%$ to $60 \%$. All animal experimental procedures for this study followed the protocol set by the IACUC of UTHSC.

The tight skin disease phenotype in Tsk2/+ mice and B6 mice were bred in standard microisolator cages. The mice had been measured for their body weight (g), body length $(\mathrm{cm})$, tail length $(\mathrm{cm})$ and skin score $(\mathrm{cm})$ when they were anesthetized, on days $21,28,32,35,40,42,45,49,53,56,59,63,66,70,73,80,87,94$, and 101.

\section{Genotyping}

Ear pieces (about $2 \mathrm{~mm}^{2}$ ) of the 3-4-week-old Tsk2/+ mice were taken by using sterilized ear punch (with anesthesia) the first time the mice were marked. The tissue was immediately used for DNA extraction or frozen at $-80^{\circ} \mathrm{C}$. DNA was isolated by "HotSHOT" genomic DNA preparation protocol. The ear pieces were put in $75 \mu 1$ Alkaline Lysis Reagent ( $25 \mathrm{mM} \mathrm{NaOH}: 0.2 \mathrm{mM}$ EDTA, $\mathrm{pH}$ 12) incubated at $95^{\circ} \mathrm{C}$ for 10 min to $1 \mathrm{~h}$, then $75 \mu \mathrm{l}$ Neutralization Buffer $(40 \mathrm{mM}$ Tris-HCL, pH 5) was added. PCR was used to genotype mice. Primers used: Col3a1-dna-T, forward primer: 5'CCCACAGATGAATTGGGAA; reverse primer 5'CAACAGACATGGCTTGCATT; expected product size: $323 \mathrm{bp}$. Col3a1-dna-N, forward primer: 5'CCCACAGATGAATTGGGAT; reverse primer 5'CAACAGACATGGCTTGCATT; expected product size: $323 \mathrm{bp}$ (IDT, CA). mRNAs were also collected for rt-PCR to distinguish between the Tsk2/+ and B6 mice. The rt-PCR primers were used forward primer Col3a1-T-F: 5' -ACGTAGATGAATTGGGAA- 3' with reverse primer Col3a1T/N-R: 5'-ACGTAGATGAATTGGGAT- 3' and forward primer Col3a1-T-N: 5'ACGTAGATGAATTGGGA- 3' with same reverse primer Col3al-T/N-R.

\section{Collection of Mouse Tissues}

Mice were collected at 4, 6, and 10 weeks of age and all tissues (heart, muscle, liver, spleen, lung, kidney, and one piece of skin) were stored separately in $1.5 \mathrm{ml}$ tubes and immediately put on dry ice. One piece of skin was stored in RNAlater solution (Thermo Fisher, CA) at $4^{\circ} \mathrm{C}$ until the skin completely absorbed the solution. After, all mouse tissues were stored at $-80^{\circ} \mathrm{C}$ for subsequent experiments.

\section{RNA/DNA Isolation}

RNA: A piece of tissue that had been stored in the $-80^{\circ} \mathrm{C}$ freezer was cut on dry ice before it melted. The tissue samples were put in $1 \mathrm{ml} \mathrm{TRIzol}$ and then the solution was homogenized. $0.2 \mathrm{ml}$ of chloroform per $1 \mathrm{ml}$ of TRIzol sample was then added. After being centrifuged, the top phase of the solution was moved to a new tube with $0.5 \mathrm{ml}$ of $100 \%$ isopropanol. The mix solution was kept in a fridge for $40 \mathrm{~min}$ and then centrifuged to produce the RNA pellet. Next, they were washed with $75 \%$ ethanol three times. Water and sodium acetate:ethanol (4:96) was added to purify the RNA at $-20^{\circ} \mathrm{C}$ overnight. The 
next morning, the RNA was washed and measured, the concentration was assessed by nanodrop 2000 spectrophotometry (Thermo Scientific, CA). The RNA samples' quality was verified by agarose gel electrophoresis, which should have 3 bands $(5 \mathrm{~S}, 18 \mathrm{~S}$, and 28S). RNAs were stored at $-80^{\circ} \mathrm{C}$ until the experiment.

DNA: DNA was extracted using the DNeasy Blood \& Tissue Kit (Qiagen, CA). The DNA samples' integrity was also verified by agarose gel electrophoresis; most fragments should be larger than $5 \mathrm{~kb}$ and have no distinct smear band. The concentration and contamination were also measured by nanodrop 2000 spectrophotometry (Thermo Scientific, CA). DNA samples were stored at $-20^{\circ} \mathrm{C}$ until the experiment.

\section{Microarray Procedure}

The RNAs were isolated from B6 and Tsk2/+ mouse spleen samples. Three individual RNA samples had been pooled as one group in each well. The SuperScript Choice System (Invitrogen, CA) reverse transferred the RNA samples to cDNA, and then we used Enzo® BioArray HighYield RNA transcript labeling kit to produce cRNA. The cRNA samples were loaded on GeneChip mouse genome U74Av2 array (Affymetrix, $\mathrm{CA}$ ) and hybridized at $45^{\circ} \mathrm{C}$ overnight, following the manufacturer's protocol. The genechip was washed and stained by Affymetrix Fluidics Station 400 and scanned by Agilent GeneArray Scanner. The raw data were analyzed by MAS 5.0 software (Affymetrix).

\section{Semi-quantitative Rt-PCR}

RNA samples were used to measure the gene expression of Col3a1 and Fhl2 between B6 and Tsk2/+. The expression levels were used to confirm the data from the Microarray. The RNA samples were isolated from the skin, muscle, heart, kidney, liver, and lung. Each RNA sample was tested for the expression levels separately. One-step RT-PCR kit from Thermo scientific was used and we followed the manufacturer's protocol. Specific primers were designed by the Primer3 online service. The reaction was performed in a total volume of $12.5 \mu \mathrm{L}$, the total RNA volume was $1 \mathrm{ng}$, and the volume of the forward and reverse primers was $50 \mathrm{nM}$ in the reaction. cDNA synthesis and predenaturation were performed in 1 cycle of $50^{\circ} \mathrm{C}$ for $30 \mathrm{~min}$, and $95^{\circ} \mathrm{C}$ for $15 \mathrm{~min}$. PCR amplification was performed in 35 cycles at $94^{\circ} \mathrm{C}$ for $30 \mathrm{~s}, 60-54^{\circ} \mathrm{C}$ for $40 \mathrm{~s}$, and $72^{\circ} \mathrm{C}$ for $1 \mathrm{~min}$. The final extension was $72^{\circ} \mathrm{C}$ for $5 \mathrm{~min}$. The PCR products were analyzed on a $1.8 \%$ agarose gel.

\section{Sequencing Analysis}

All of the chromosomal regions of interest were sequenced. The exon, intron, and promotor were identified between B6 and Tsk2/+ mice (Table 3-1). DNA or mRNA samples were amplified to their PCR products. All of the PCR and rt-PCR products were 
Table 3-1. The Fhl2 gene primer.

\begin{tabular}{|c|c|c|c|}
\hline Name & Forward-Primer & Reverse-Primer & Size(bp) \\
\hline $\begin{array}{l}\text { Fhl2- } \\
\text { cd1(1417) }\end{array}$ & cattaaagcaacccaatgaagc & aggacaagtccttgcagtcg & 290 \\
\hline $\begin{array}{l}\text { Fhl2- } \\
\operatorname{cd} 1(1566)\end{array}$ & cagctcetgctgcactcc & gcagtcaaagcgttcagtca & 298 \\
\hline Fhl2-CD1 & attaaagcaacccaatgaagc & ctgctgecettgtattccat & 496 \\
\hline Fhl2-CD2 & atggaatacaagggcagcag & gccgcettcaaatatccttt & 505 \\
\hline Fhl2-CD3 & aatggcacaacgactgcttt & aaggaagtcacaaagctgcaa & 481 \\
\hline Fhl2-DNAx1 & caaatggggacgtgcatag & gagctggggtcctgaggt & 452 \\
\hline Fhl2-DNAx2 & ggtctgtggtagcgtcatca & tctcctatcgecagaacetg & 451 \\
\hline Fhl2-DNAx3 & tttccctgaaacttttgagca & gcagctctgctctgctttgt & 451 \\
\hline Fhl2-DNAx4 & gcttgtccacaggcaaatct & gcccagcactgaagtatcaa & 456 \\
\hline Fhl2-DNAx 5 & aggagccattgagagcagaa & caagagaacagatgcgcaag & 436 \\
\hline Fhl2-DNAx6 & agccacaggtccetccat & agacgtccatgttgttccag & 400 \\
\hline Fhl2-DNAx7 & gtacagcgggctcaaacatt & ggatcttgtccccactgaga & 442 \\
\hline Fhl2-DNAx8 & cgcagagattcggatgtttt & gagggagaaaagtcggtgct & 461 \\
\hline Fh2-ax-1 & gtgcagcagcatcagggta & attcggctctcctatgctca & 355 \\
\hline Fh2-ax-2 & ctgtgcetgectttctatcc & gcagtcaaagcgttcagtca & 350 \\
\hline Fh2-ax-3 & aggagtgtggaacacccatc & caagagagtaccgecetgag & 346 \\
\hline Fh2-ax-4 & ccaacagggaggcagtaaca & agtgccgatccttgtaggac & 356 \\
\hline Fh2-ax-5 & ctgtgcaccgactgctattc & aggggtaggggttgagacag & 349 \\
\hline Fh2-ax-6 & tccacttaaaactcccaacca & acaggtgaagcaggtctcgt & 317 \\
\hline Fh2-ax-7 & gccetgctatgagaagcagt & tgaagtcctggaagtgtcacc & 397 \\
\hline Fh2-ax-8 & ctggtttccactccgaaaac & tgctcccggtaagtaacacc & 352 \\
\hline Fh2-ax-9 & actgcctgacctgcttctgt & cccacctagctgtggtttgt & 415 \\
\hline Fh2-ax-10 & tggaaaccagtccetcaaac & tgtactttgtgccacccaga & 353 \\
\hline Fh2-ax-11 & tcaagcacagtgtgtgggact & gcatttgcacatatacacattca & 354 \\
\hline Fhl2-Fdna 1 & cagctgctacagctctctgc & taagggaacccagcggact & 353 \\
\hline Fhl2-Fdna 2 & cagagggagccaactgaatgt & tccagggctagttgctatgc & 358 \\
\hline Fhl2-Fdna 3 & agtcactacccaggccttc & aatgaaccaaaccgatgacc & 353 \\
\hline Fhl2-Fdna 4 & ccaaggtggacagcacttct & tatcctcatgcccaggaaag & 326 \\
\hline Fhl2-Fdna 5 & tgactgcgtggcagttattc & gactggtgctcagcttcctc & 352 \\
\hline Fhl2-Fdna 6 & atccctcaattgcaagatgg & cgtggtggaacctcagaact & 352 \\
\hline Fhl2-Fdna 7 & cagcaaaacaaaacaaaacagg & ggagagtgagcaagctgagg & 313 \\
\hline Fhl2-Fdna 8 & tggagagatggctcagaggt & aagagtaacaaaacgccgattc & 349 \\
\hline
\end{tabular}


cleaned with EXOSA-IT PCR CLEAN-UP PROTOCOL. $5 \mu$ PCR or rt-PCR products and $2 \mu \mathrm{l}$ ExoSAP-IT mix were incubated at $37^{\circ} \mathrm{C}$ for 25 min followed by $80^{\circ} \mathrm{C}$ for 15 min. $3 \mu \mathrm{l}$ cleaned DNA samples, $1 \mu \mathrm{l}$ single primer, and $8 \mu \mathrm{l}$ water was used for sequencing. Samples were loaded on ABI Model 3130XL Genetic Analyzers (Thermo Fisher Scientific, CA). The data were analyzed by Finch TV and ABI Sequence Scanning Software.

\section{Quantitative Real-Time PCR}

The TaqMan Reverse Transcription Reagents (Roche, AG) were used to amplify the individual samples, following the manufacturer's instructions. The cDNA samples were mixed with the TaqMan Universal PCR Master mix. TaqMan gene expression assays containing FAM-labeled primer/probe sets specific for Fh12(Mm00515778_m1) and GAPDH(Mm03302249_g1) were obtained from Applied Biosystems. The real-time PCR reactions were performed in a total reaction volume of $25 \mu \mathrm{L}$ by using FastStart TaqMan Probe Master (Roche) reagent, and results were analyzed using the ABI 7900 real-time PCR-detection system (Applied Biosystems). Relative expression was normalized to $18 \mathrm{~S}$ RNA and calibrated to the respective controls.

\section{Western Blotting}

Western blotting was used to determine Fhl2 expression level differences between the normal control B6 mice and Tsk2/+ mutation mice. Protein from samples of the same region of skin was isolated by using RIPA Lysis Buffer (Santa Cruz Biotechnology, TX). The protein concentration was tested by nanodrop 2000 (Thermo Fisher, CA). All samples were diluted by Sample Buffer, Laemmli 2x Concentrate (SIGMA, MO) to a ratio of $1: 1$ and boiled at $95^{\circ} \mathrm{C}$ for $10 \mathrm{~min}$. The gradient polyacrylamide gel that was used contained $6 \%$ stacking gel on top and $10 \%$ the separating gel on bottom. The $6 \%$ Stacking Gel: $2.9 \mathrm{ml} \mathrm{ddH2O,} 0.75 \mathrm{ml} 40 \%$ Acrylamide, $1.25 \mathrm{ml} 0.5 \mathrm{M}$ Tris, $\mathrm{pH} 6.8,50 \mu \mathrm{l}$ 10\% SDS, $50 \mu 1$ 10\% APS, and $5 \mu \mathrm{l}$ TEMED. The 10\% Separating Gel: $3.8 \mathrm{ml}$ ddH2O, 2 $\mathrm{ml} 40 \%$ Acrylamide, $2 \mathrm{ml} \mathrm{1.5} \mathrm{M} \mathrm{Tris,} \mathrm{pH} 8.8,80 \mu 1$ 10\% SDS, $80 \mu 1$ 10\% APS, and $8 \mu 1$ TEMED. The samples in each well were loaded with $1 \mathrm{x}$ electrophoresis buffer $(25 \mathrm{mM}$ Tris, $0.25 \mathrm{M}$ glycine, $5 \mathrm{mM}$ SDS), with 100 Volts, and were run for $1.5 \mathrm{hr}$. Proteins were then transferred to polyvinylidene difluoride membranes (Millipore Sigma, MA) in a transfer buffer containing $0.2 \mathrm{M}$ glycine, $25 \mathrm{mM}$ Tris, and $20 \%$ methanol, $\mathrm{pH} 8.3$ at $4{ }^{\circ} \mathrm{C}$, $100 \mathrm{~V}$, for $1.25 \mathrm{hr}$. After transfer, membranes were blocked in 5\% BSA in TBST buffer (10 mM Tris and $0.9 \% \mathrm{NaCl}$, and $0.1 \%$ Tween 20 ) for $2 \mathrm{hr}$ at room temperature (RT). After blocking, the membranes were washed with 1x TBST three times. Membranes had been cut to a suitable size and then incubated with the selective antibody against Fhl2 (1st antibody, $1: 2000)$ overnight at $4^{\circ} \mathrm{C}$. On the second day, after washing the membranes three times, the membranes were incubated in the 2nd antibody (1:5000; Abcam, UK) for $1 \mathrm{hr}$ at RT. They were then washed three times, and the membranes were exposed on the Classic Autoradiography film (MIDSCI, MO) for 5 min in the dark room. The Fhl2 protein was $32 \mathrm{kDa}$. The membranes were stripped with Restore Western Blot Stripping 
Buffer (Thermo, CA) and added GAPDH as a control for the protein quantity. ImageJ software (NIH, Bethesda, MD, USA) was used to quantify protein expression levels.

\section{Result}

\section{Mouse Phenotype}

In the current study, the Tsk2/+ mutation and C57BL6/J B6 mice were bred in the animal facility under the same conditions. Body size, body shape, and hair color were similar between the Tsk $2 /+$ and normal mice as compared with the naked eye. The only significant difference between the Tsk $2 /+$ mutation and B6 normal was the tightness of the skin (Figure 3-1). The phenotype of tight skin in Tsk2/+ mice is physically evident and can be felt upon pinching the skin of young mice as early as three weeks of age. The Tsk $2 /+$ mice and age-matched controls were evaluated by body length, tail length, body weight, and skin score at several time points. The mice were measured on days 21, 28, $32,35,40,42,45,49,53,56,59,63,66,70,73,80,87,94,101$. At these selected time periods, the body length and the tail length of the male and female Tsk2/+ and B6 mice did not show any distinct changes (Figure 3-2A, B). The males were heavier than the females of all ages in both B6 and Tsk2/+. Within the same gender, the Tsk2/+ mice were reported to weigh less than their normal B6 littermates (Figure 3-2C). Pictures were taken at the 4 and 6-week time points; in the pictures, the interscapular skin was grasped to measure the skin tightness. An obvious difference could be felt between the two strains. In the photos, the tightness of the skin was marked with a red circle, and there are different circle sizes between the B6 and Tsk2/+ mice. Measuring of the skin was done by the same person to ensure that the same method and location of grabbing were used, providing consistency for the data. The skin of the one and two-week-old mice is too difficult to grasp because they are too small. According to the literature, the disease phenotypes begin to show around three weeks. Both genders of Tsk $2 /+$ and B6 have been measured at all time points. The skin measurements have significant differences; the B6 skin can be grasped $\sim 1.7 \mathrm{~cm}$, but the Tsk $2 /+$ only can be grasped $\sim 0.7 \mathrm{~cm}$ (Figure 3-2D).

\section{Verification of Tsk2/+ Mice}

Four pairs of primers were used to identify the Tsk $2 /+$ and normal mice by PCR and rt-PCR. The pair of primers for PCR were Col3a1-dna-T and Col3a1-dna-N and the primers for rt-PCR were Col3a1-T and Col3a1-N to confirm the Tsk2/+ and B6 genotypes (data not shown) using PCR. The mRNA samples were used to confirm that the Col3al gene is the mutated gene. The mRNA samples 1-3 from 4wks-B6 skin and samples 4-6 from 4wks-Tsk/2+ were amplified by rt-PCR using the Col3a1-T-F and Col3a1-T/N-R pair of primers. Col3a1-T can amplify the 4wks-Tsk2/+ skin RNA, but cannot amplify the 4wks-B6 skin RNA. Both of the Tsk2/+ and B6 skins' RNA can be amplified by Col3a1-N (Figure 3-3A, B). Both Tsk2/+ and B6 can be amplified by Col3a1-N primers because Tsk2/+ is heterozygous. We compared the Col3a1 gene 


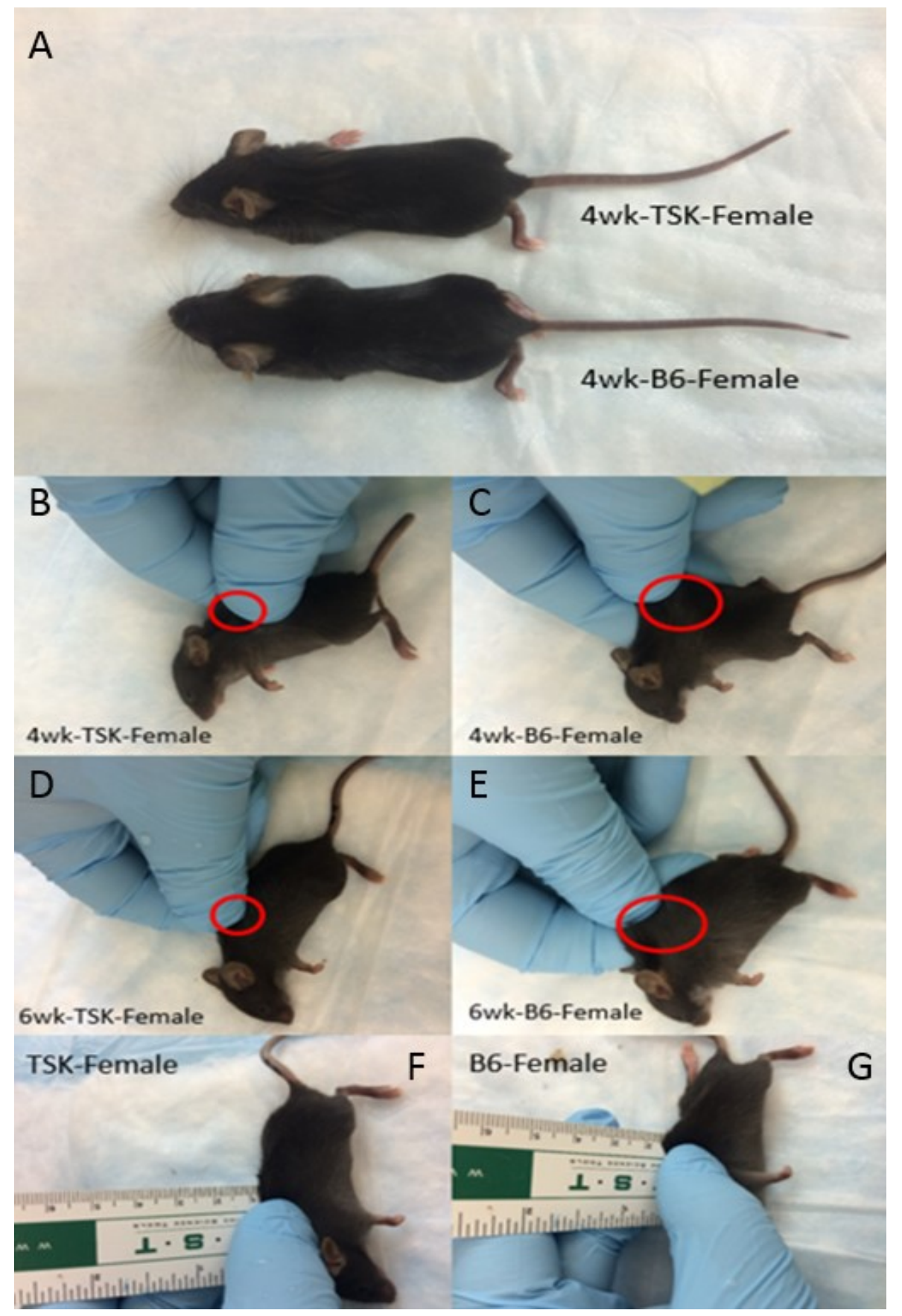

Figure 3-1. The phenotype of Tsk2/+ and B6 skin tightness when they are 4 and 6 weeks of age.

(A) Comparison of the body size, body shape and hair color between Tsk2/+ and B6 mice. $(\mathrm{B}, \mathrm{C})$ Comparing the difference in how much skin is able to be grasped at four weeks old. (D, E) Comparing the difference in how much skin can be grasped at six weeks old. (F, G) The skin score is measured using a ruler when skin is grasped on the back. The body, tail shape, and hair from Tsk2/+ and B6 skin are similar. The interscapular skin in Tsk2/+ is tighter than B6 mice at both 4 and 6 weeks. 


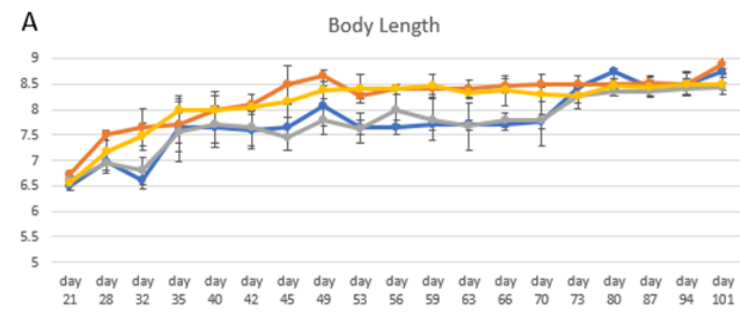

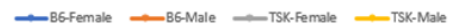

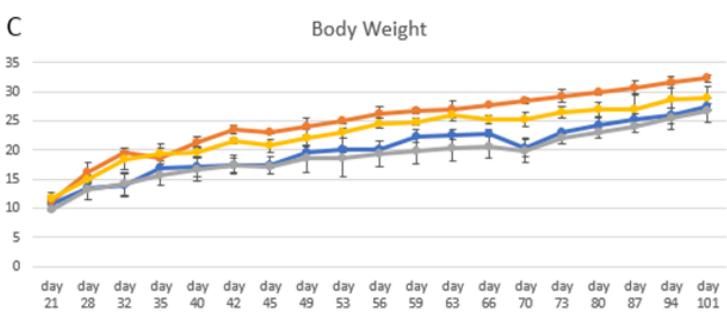

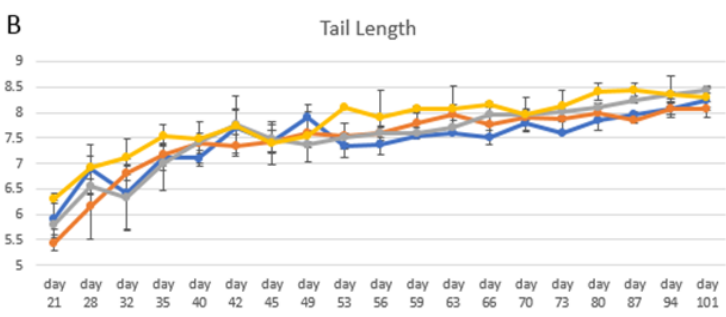

-B6-Female $\rightarrow$ B6-Male $\longrightarrow$ TSK-Female - TSK-Male

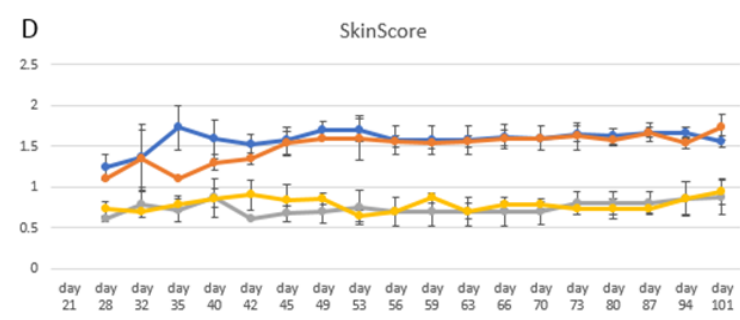

—B6-Female —B6-Male —TSK-Female —TSK-Male

Figure 3-2. Comparison of body length, body weight, tail length, and skin tightness score in male and female Tsk2/+ and B6 mice.

(A, B) The body length and tail length are compared between the Tsk2/+ and B6 mice in both genders. The times (days) are shown below the horizontal axis. Numbers to the left of the vertical axis are the lengths $(\mathrm{cm})$. The body length increases for both strains until about forty-five days, and then it stabilizes. The tail length of both strains increases steadily throughout their lifetime. The Tsk2/+ and B6 body length and tail length of both the males and females do not show obvious changes. (C) The body weight is compared between the Tsk2/+ and B6 mice in both genders. The times (days) are shown below the horizontal axis. Numbers to the left of the vertical axis are the weights $(\mathrm{g})$. The Tsk2/+ mice were reported to weigh less than their normal B6 littermates in both genders. The males of both strains weighed more than the females. The body weights of the two strains steadily grow throughout their lifetime. D) The skinscore is compared between the Tsk2/+ and B6 mice in both genders. The times (days) are shown below the horizontal axis. Numbers to the left of the vertical axis are the lengths $(\mathrm{cm})$. The skin score is stable throughout the mice's lifetime. The B6 skin can be grasped $\sim 1.7 \mathrm{~cm}$, but the Tsk $2 /+$ only can be grasped $\sim 0.7 \mathrm{~cm}$. 


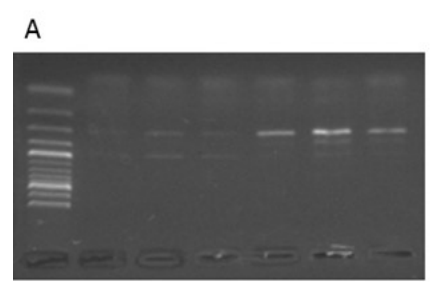

1
B

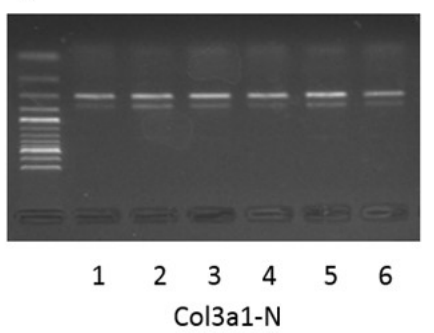

primer:

Col3a1-T-F: acgtagatgaattgggaa

Col3a1-N-F: acgtagatgaattgggat

Col3a1-N-R: aaggccagggtcaccatt
1-3: 4wk B6 F1-F3 4-6: 4wk TSK F1-F3
Col3a1-12

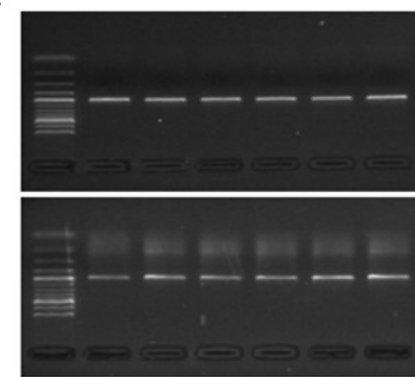

skin

heart

kidney

Figure 3-3. Identifying and comparing the Tsk2/+ and B6 by Col3a1 candidate mutation gene and Col3a1 gene expression levels between Tsk2/+ and B6 tissues.

$(\mathrm{A}, \mathrm{B})$ Identifying the SNP between 4 weeks Tsk2/+ and B6 with skin mRNA. The Col3a1-T can amplify the Tsk2/+, but cannot amplify the B6. Both Tsk2/+ and B6 can be amplified by Col3a1-N. No. 1-3 are 4 weeks B6 skin mRNA samples and No. 4-6 are 4 weeks Tsk2/+ skin mRNA samples. (C) The Col3a1 gene expression levels compared between Tsk2/+ and B6 mice in different tissues. There is no difference between Tsk2/+ and B6 mice in skin, heart, and kidney. No. 1-3 are 4 weeks B6 skin mRNA samples and No. 4-6 are 4 weeks Tsk2/+ skin mRNA samples. 
expression level between $\mathrm{B} 6$ and Tsk2/+ by primer Col3a1-12 (forward:

CGTAAGCACTGGTGGACAGA, reverse: TGGGGTTTCAGAGAGTTTGG; bp: 489)

in the skin, heart, and kidney tissues. There is no obvious difference between Tsk $2 /++$ and normal (Figure 3-3C).

\section{Microarray Analysis of Tsk2/+ Mice}

Tsk2/+ is under the B6 background, and there were a small number of genes changing the expression levels. However, the expression levels of more than $99 \%$ of the genes compared between these two mice are similar. In analyzing the expression levels of genes in B6 and Tsk2/+, the expression levels of eighty-two probes were found to be upregulated and 177 probes were downregulated in Tsk2/+ compare with B6 (Figure 3-4). A previous study found that the candidate gene is located on chromosome 1 from 42.5 to $52.5 \mathrm{Mb}$. In this region, there were twelve probes downregulated and four probes upregulated. The downregulated probes were 1500015O10Rik, Kdelc1, Tgfbrap1, Eroc5, Gulp1, Pou3f3, Gpr45, Uxs1, EG212225, Bivm, Tpp2, and Mrps9 and the upregulated probes were Col3a1, Slc40a1, Slc39a10, and Fhl2.

\section{Comparison of Two Genes}

From the Ensemble database, the positions of Fhl2 and Col3a1 were both on chromosome 1, Fhl2 was from 43,123,074 to 43,196,984 and Col3a1 was from $45,311,538$ to 45,349,706 bp (Figure 3-5A). From the online gene expression database, we searched the BioGPS website (http://biogps.org/\#goto=welcome) and compared the gene expression levels of Col3a1 and Fhl2 in most tissues and organs in mice (Figure 35B). Unfortunately, there is no skin or dermis expression on this list, but most major organs and tissues could be found. Fhl2 gene expression in epidermis, muscle, heart, kidney, liver, and lung is $11.0915 \pm 4.5248,46.2905 \pm 3.489572,21857.0475 \pm 6050.6809$, $194.9005 \pm 27.0645,15.6560 \pm 6.9381$, and $54.7640 \pm 35.6580$ and the Col3a1 gene expression is $1434.9770 \pm 841.9238,1280.4620 \pm 364.6521,389.3040 \pm 167.1120$, $26.5730 \pm 18.3918,15.2225 \pm 8.9442$, and $540.1390 \pm 101.6706$ (Table 3-2). The Fhl2 gene is highly expressed in the heart but is not as highly expressed in the other organs. There are eight organs or tissues where the expression level of Col3al is more than 2000, but the heart is the only organ with an expression level more than 2000 in Fhl2.

\section{Transcript of the Genes}

On the Ensemble online database, there were basic data for the Col3a1 and Fhl2 genes (Table 3-2). The Col3al gene had seven transcripts and Fhl2 gene had three transcripts. For the Col3a1 gene, there were three transcripts, Col3a1-201, Col3a1-205, and Col3a1-204, that encoded proteins, but only Col3a1-201 had a CCDS. For Fhl2, all three transcripts Fhl2-201, Fhl-202, and Fhl2-203 code for proteins, but only Fhl2-201 


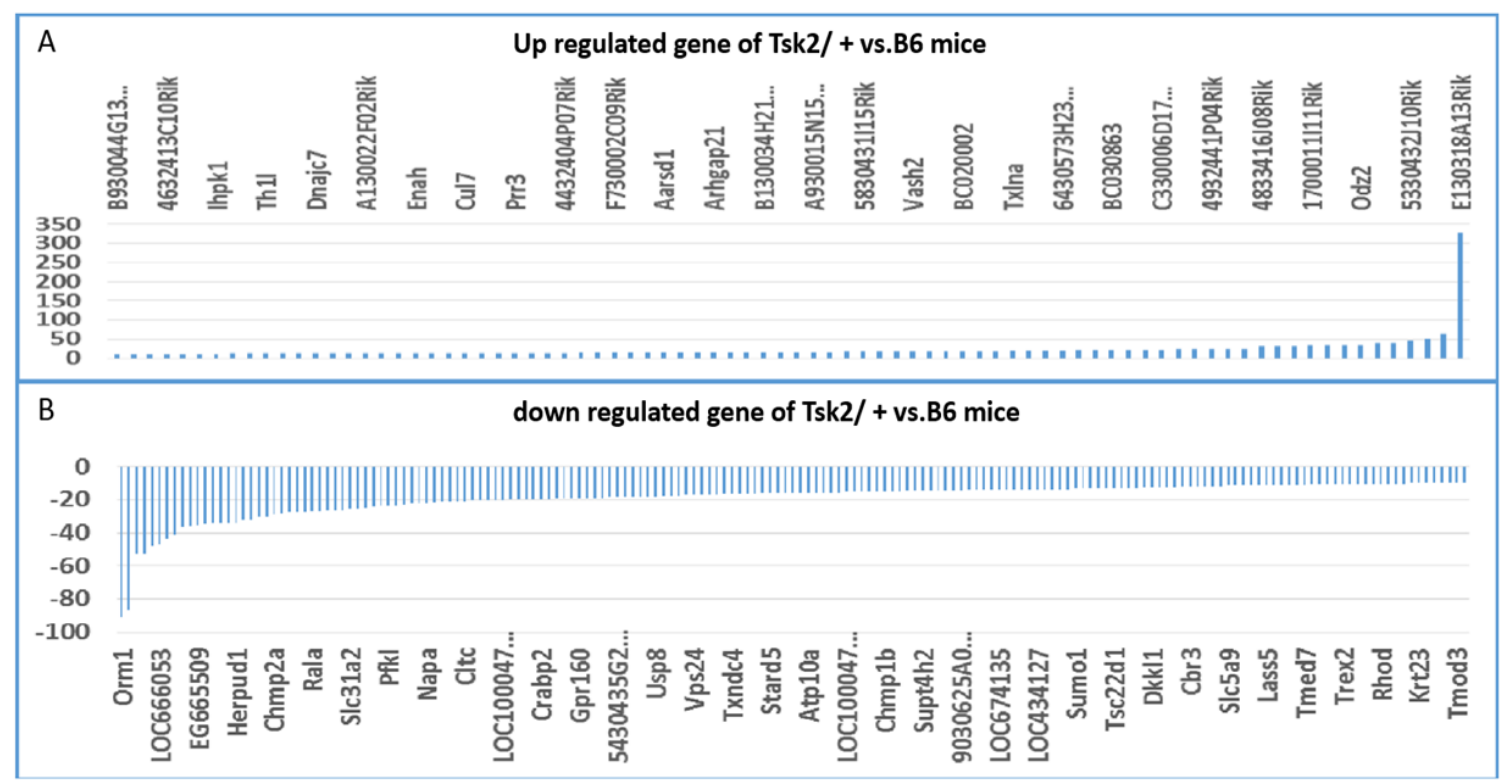

Figure 3-4. Up and down regulated genes and networks in Tsk2/+ mice in comparison to that of $\mathrm{B} 6$ mice.

(A) Upregulated genes in Tsk2/+ mice compared with B6 wild type. The gene names are shown above the horizontal axis. Numbers to the left of the vertical axis are the fold changes. The expression levels of eighty-two probes are upregulated. (B) Downregulated genes in Tsk2/+ mice compared with B6 wild type. The gene names are shown below the horizontal axis. Numbers to the left of the vertical axis are the fold changes. The expression levels of 177 probes are downregulated. 

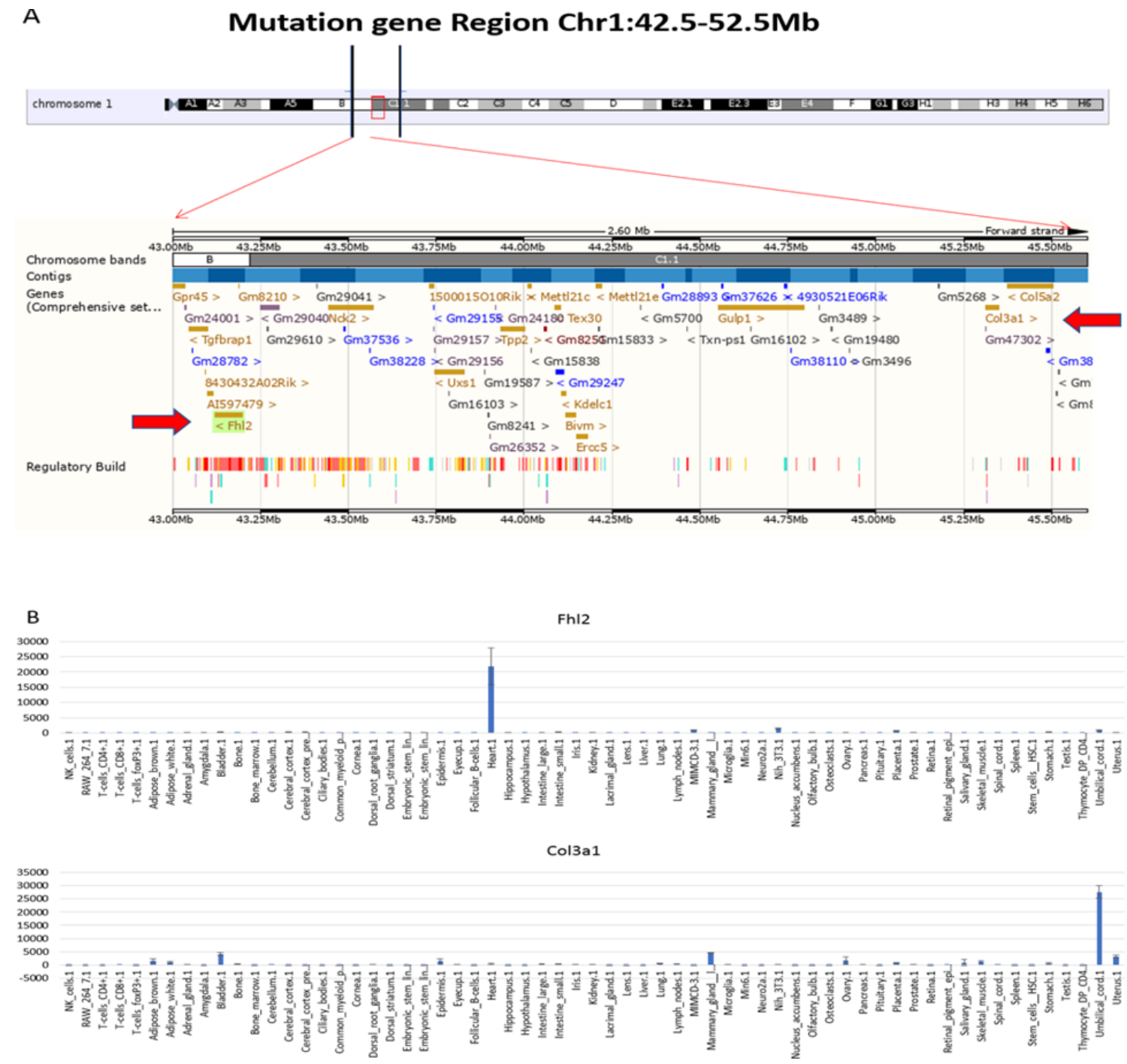

Figure 3-5. Fhl2 and Col3a1 are located on chromosome 1 and they are expressed in different tissues.

(A) Fhl2 and Col3a1 are located on chromosome 1. Genes have been marked by red arrows. Fhl2 is located on chromosome 1 from 43,123,074 to 43,196,984 and Col3a1 on chromosome 1 from 45,311,538 to 45,349,706 bp. (B) Col3al and Fhl2 have different expression levels in different tissues or organs. The organ names are shown below the horizontal axis. Numbers to the left of the vertical axis are the expression level units. The Fhl2 gene expression is high in the heart, where the expression level is more than 21000 , but there are no more than 1500 in other organs. The Col3a1 is expressed more than 1000 in eight organs. 
Table 3-2. The Fhl2 and Col3a1 gene expression levels in each tissue or organ.

\begin{tabular}{|c|c|c|c|c|}
\hline Samples & Fhl2 & Stdev.S & Col3a1 & Stdev.S \\
\hline NK_cells.1 & 149.8985 & 7.2570 & 5.4795 & 0.6272 \\
\hline RAW_264_7.1 & 14.0245 & 4.9179 & 5.5145 & 0.6767 \\
\hline T-cells_CD4+.1 & 14.0400 & 0.5459 & 5.8075 & 0.1633 \\
\hline T-cells_CD8+.1 & 34.9440 & 3.5652 & 5.6920 & 0.0000 \\
\hline T-cells_foxP $3+.1$ & 19.7865 & 3.2308 & 4.9720 & 0.0905 \\
\hline Adipose_brown.1 & 17.8120 & 0.4384 & 1573.9835 & 810.9461 \\
\hline Adipose_white.1 & 39.0065 & 8.6486 & 953.7960 & 384.0452 \\
\hline Adrenal_gland.1 & 128.4775 & 25.1285 & 43.4440 & 9.0708 \\
\hline Amygdala.1 & 157.6655 & 3.7781 & 5.2995 & 0.3019 \\
\hline Bladder.1 & 314.5495 & 55.9597 & 4003.3750 & 566.4618 \\
\hline Bone.1 & 75.1865 & 15.6532 & 320.3745 & 111.4351 \\
\hline Bone_marrow.1 & 32.2440 & 10.5203 & 4.9880 & 0.1131 \\
\hline Cerebellum.1 & 11.0695 & 2.3511 & 5.6920 & 0.0000 \\
\hline Cerebral_cortex.1 & 326.5605 & 70.4611 & 5.7255 & 0.0474 \\
\hline Cerebral_cortex_prefrontal.1 & 388.4195 & 83.9993 & 5.5580 & 0.5162 \\
\hline Ciliary_bodies. 1 & 9.0995 & 1.2268 & 15.2210 & 4.2978 \\
\hline Common_myeloid_progenitor.1 & 23.1110 & 5.2312 & 5.8075 & 0.1633 \\
\hline Cornea.1 & 11.5340 & 6.7854 & 8.2780 & 3.3729 \\
\hline Dorsal_root_ganglia.1 & 25.1470 & 6.6015 & 125.7045 & 43.3520 \\
\hline Dorsal_striatum.1 & 45.6030 & 6.5535 & 9.8780 & 6.8476 \\
\hline Embryonic_stem_line_Bruce4_p13.1 & 101.0710 & 22.5355 & 5.4795 & 0.6272 \\
\hline Embryonic_stem_line_V26_2_p16.1 & 115.9515 & 25.4495 & 7.3240 & 2.3080 \\
\hline Epidermis. 1 & 11.0915 & 4.5248 & 1434.9770 & 841.9238 \\
\hline Eyecup.1 & 36.6610 & 27.0949 & 210.4600 & 19.5416 \\
\hline Follicular_B-cells.1 & 20.0530 & 6.9565 & 5.1365 & 0.1421 \\
\hline Heart.1 & 21857.0475 & 6050.6809 & 389.3040 & 167.1120 \\
\hline Hippocampus. 1 & 161.0325 & 31.4754 & 5.3640 & 0.4639 \\
\hline Hypothalamus.1 & 59.6850 & 18.4385 & 5.3640 & 0.4639 \\
\hline Intestine_large.1 & 187.3630 & 6.8038 & 289.0980 & 21.8652 \\
\hline Intestine_small.1 & 289.4680 & 62.9509 & 209.2300 & 104.5302 \\
\hline Iris.1 & 19.3375 & 9.5622 & 74.6680 & 36.8912 \\
\hline Kidney.1 & 194.9005 & 27.0645 & 26.5730 & 18.3918 \\
\hline Lacrimal_gland.1 & 12.9745 & 5.1074 & 20.5510 & 20.6871 \\
\hline Lens. 1 & 43.1585 & 36.3517 & 4.9720 & 0.0905 \\
\hline Liver.1 & 15.6560 & 6.9381 & 15.2225 & 8.9442 \\
\hline Lung.1 & 54.7640 & 35.6580 & 540.1390 & 101.6706 \\
\hline Lymph_nodes.1 & 9.0635 & 0.8407 & 255.2065 & 242.4238 \\
\hline MIMCD-3.1 & 911.8575 & 63.0152 & 5.5695 & 0.1732 \\
\hline Mammary_gland_lact.1 & 62.0655 & 16.7789 & 4538.4560 & 184.6129 \\
\hline Microglia.1 & 17.5020 & 0.0000 & 71.9650 & 93.7242 \\
\hline Min6.1 & 8.7460 & 1.5401 & 25.5350 & 11.9473 \\
\hline
\end{tabular}


Table 3-2. Continued.

\begin{tabular}{lllll}
\hline Samples & Fhl2 & Stdev.S & Col3a1 & Stdev.S \\
\hline Neuro2a.1 & 11.1510 & 4.6655 & 4.9945 & 0.1223 \\
Nih_3T3.1 & 1437.8815 & 155.7070 & 30.8070 & 26.5123 \\
Nucleus_accumbens.1 & 27.0160 & 4.8663 & 5.8100 & 0.1598 \\
Olfactory_bulb.1 & 121.1285 & 0.1054 & 5.3640 & 0.4639 \\
Osteoclasts.1 & 7.4330 & 0.3168 & 5.4795 & 0.6272 \\
Ovary.1 & 201.6885 & 0.4646 & 1626.7425 & 1414.1690 \\
Pancreas.1 & 32.3720 & 21.4098 & 239.1720 & 22.0349 \\
Pituitary.1 & 41.6095 & 30.1178 & 5.8245 & 0.1393 \\
Placenta.1 & 808.1875 & 52.2220 & 847.4510 & 60.2130 \\
Prostate.1 & 171.2190 & 1.1087 & 206.6360 & 19.3719 \\
Retina.1 & 10.3610 & 3.5879 & 5.4345 & 0.3642 \\
Retinal_pigment_epithelium.1 & 17.0395 & 8.9626 & 5.6920 & 0.0000 \\
Salivary_gland.1 & 38.5275 & 26.7845 & 849.0865 & 1135.8391 \\
Skeletal_muscle.1 & 46.2905 & 3.4896 & 1280.4620 & 364.6521 \\
Spinal_cord.1 & 33.4055 & 4.5163 & 5.6920 & 0.0000 \\
Spleen.1 & 18.1760 & 0.9532 & 21.9085 & 9.1945 \\
Stem_cells_HSC.1 & 17.2505 & 1.7727 & 5.5995 & 0.1308 \\
Stomach.1 & 388.9085 & 87.7640 & 605.5300 & 213.3200 \\
Testis.1 & 70.7280 & 15.3796 & 15.3590 & 6.0712 \\
Thymocyte_DP_CD4+CD8+.1 & 23.5500 & 3.6656 & 5.3275 & 0.4122 \\
Umbilical_cord.1 & 823.8050 & 236.2373 & 27661.4400 & 2335.1692 \\
Uterus.1 & 183.2825 & 21.4911 & 3108.8535 & 594.1910 \\
\hline
\end{tabular}


and Fhl2-201 had CCDSs (they both have two). Thus, Fhl2 has two transcripts that encode proteins (Table 3-3).

\section{Fh12 Transcripts in Different Tissues}

Through the previous searching, there were two transcripts with CCDSs in the Fhl2 gene. The Fhl2 gene was composed of 6 segments of exons. The first exons on Fhl2201 and Fh12-202 were completely different, but the remaining five exons were the same. These two transcripts had different promoters. Fhl2-201 was 1566 bp and Fhl2-202 was 1417 bp (Figure 3-6). Two transcripts were identified per the expression levels in different tissues. The Fhl2-201 transcript was expressed in the skin and kidney, but not expressed in the muscle, heart, liver, and lung. The Fhl2-202 transcript was expressed only in the heart, but not in the skin, muscle, kidney, liver, or lungs (Figure 3-7).

\section{Fhl2 Gene Expression in Different Tissues at Different Ages}

Real-time PCR was used to determine the Fhl2 gene expression levels in different tissues in 4, 6, and 10-week-old female mice. In the skin, the Fh12 expression level from Tsk2/+ mice was higher than that of B6 at all time points. At 4 and 6 weeks, the Fhl 2 expression level in Tsk2/+ were around 1.5-fold over that of B6. At 10 weeks, Tsk2/+ expression level was 2.5-fold. The B6 mouse skin expression remained around 1-fold at 4, 6, and 10 weeks (Figure 3-8A). The expression of Tsk2/+ increased significantly at 10 weeks compared to 4 and 6 weeks. In muscle, Fhl2 expression levels in Tsk2/+ were slightly higher than B6 at 4 and 6 weeks. In heart and lung, Fhl2 expression levels in Tsk2/+ were slightly higher than B6 at 4, 6, and 10 weeks. In the kidney, Fh12 expression levels in Tsk2/+ were slightly higher than B6 at 4 and 6 weeks, but not at 10 weeks. Tsk2/+ were twice as high at 4 weeks and were also 1.6-fold higher than B6 at the same age (Figure 3-8B).

\section{Sequencing the Fhl2 Gene}

We searched for polymorphisms in the Fhl2 gene that would establish it as the likely candidate gene. We employed mRNA sequencing to reduce the genomic interval (Figure 3-9A). We also sequenced the captured genomic DNA (Figure 3-9B), promoter (Figure 3-9C), and introns connecting to each exon (Figure 3-9D). We used the B6 genome sequence as the control group to analyze the polymorphisms within the interval in the Tsk2/+. We read many kilobases in the Fhl2 gene and genomic interval. We wanted to find a polymorphism that would cause an overexpression or degeneration as a result of changes in the protein structure, or protein denaturation as a result of intron changes. We have not yet found a polymorphism in the Fhl2 gene between B6 and Tsk2/+ (Figure 3-9E). We will expand our search to regions farther away in future studies. 
Table 3-3. The Ifi202b, Ifi203, Ifi204, Ifi205, and Mndal genes ID.

\begin{tabular}{|c|c|c|c|c|c|c|c|c|}
\hline Name & Transcript ID & bp & Protein & Translation ID & Biotype & CCDS & UniProt & Flags \\
\hline Col3a1-201 & $\begin{array}{l}\text { ENSMUST000 } \\
00087883.12\end{array}$ & 5564 & $1464 \mathrm{aa}$ & $\begin{array}{l}\text { ENSMUSP000 } \\
00085192\end{array}$ & $\begin{array}{l}\text { Protein } \\
\text { coding }\end{array}$ & CCDS35554 & P08121 Q3TVI5 & $\begin{array}{l}\text { TSL:1GENCODE } \\
\text { basicAPPRIS P1 }\end{array}$ \\
\hline Col3a1-205 & $\begin{array}{l}\text { ENSMUST000 } \\
00186021.1\end{array}$ & 737 & $245 \mathrm{aa}$ & $\begin{array}{l}\text { ENSMUSP000 } \\
00139802\end{array}$ & $\begin{array}{l}\text { Protein } \\
\text { coding }\end{array}$ & - & A0A087WPJ5 & $\begin{array}{l}\text { CDS } 5^{\prime} \text { and } 3^{\prime} \\
\text { incomplete TSL:3 }\end{array}$ \\
\hline Col3a1-204 & $\begin{array}{l}\text { ENSMUST000 } \\
00185687.1\end{array}$ & 583 & 195aa & $\begin{array}{l}\text { ENSMUSP000 } \\
00139894\end{array}$ & $\begin{array}{l}\text { Protein } \\
\text { coding }\end{array}$ & - & A0A087WPS3 & $\begin{array}{l}\text { CDS } 5^{\prime} \text { and } 3^{\prime} \\
\text { incompleteTSL:5 }\end{array}$ \\
\hline Col3a1-206 & $\begin{array}{l}\text { ENSMUST000 } \\
00189818.1\end{array}$ & 1610 & No protein & - & $\begin{array}{l}\text { Processed } \\
\text { transcript }\end{array}$ & - & - & TSL:3 \\
\hline Col3a1-203 & $\begin{array}{l}\text { ENSMUST000 } \\
00129611.1\end{array}$ & 3159 & No protein & - & $\begin{array}{l}\text { Retained } \\
\text { intron }\end{array}$ & - & - & TSL:2 \\
\hline Col3a1-202 & $\begin{array}{l}\text { ENSMUST000 } \\
00123204.1\end{array}$ & 570 & No protein & - & $\begin{array}{l}\text { Retained } \\
\text { intron }\end{array}$ & - & - & TSL:3 \\
\hline Col3a1-207 & $\begin{array}{l}\text { ENSMUST000 } \\
00190943.1\end{array}$ & 431 & No protein & - & $\begin{array}{l}\text { Retained } \\
\text { intron }\end{array}$ & - & - & TSL:2 \\
\hline Fhl2-201 & $\begin{array}{l}\text { ENSMUST000 } \\
00008280.13\end{array}$ & 1563 & 279aa & $\begin{array}{l}\text { ENSMUSP000 } \\
00008280\end{array}$ & $\begin{array}{l}\text { Protein } \\
\text { coding }\end{array}$ & CCDS14922 & O70433 Q543D7 & $\begin{array}{l}\text { TSL:1GENCODE } \\
\text { basicAPPRIS P1 }\end{array}$ \\
\hline Fhl2-202 & $\begin{array}{l}\text { ENSMUST000 } \\
00185893.1\end{array}$ & 1421 & 279aa & $\begin{array}{l}\text { ENSMUSP000 } \\
00141170\end{array}$ & $\begin{array}{l}\text { Protein } \\
\text { coding }\end{array}$ & CCDS14922 & O70433 Q543D7 & $\begin{array}{l}\text { TSL:1GENCODE } \\
\text { basicAPPRIS P1 }\end{array}$ \\
\hline Fhl2-203 & $\begin{array}{l}\text { ENSMUST000 } \\
00187357.1\end{array}$ & 344 & $21 \mathrm{aa}$ & $\begin{array}{l}\text { ENSMUSP000 } \\
00140420\end{array}$ & $\begin{array}{l}\text { Protein } \\
\text { coding }\end{array}$ & - & A0A087WR06 & $\begin{array}{l}\text { CDS } 3^{\prime} \\
\text { incompleteTSL:2 }\end{array}$ \\
\hline
\end{tabular}




\section{- Fhl2-201(1566bps)}

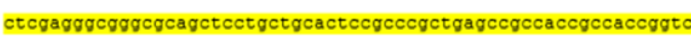
cacagtecgetgggttecettagaceceggececacegegegagtactactgeggecgec caggecacagectgettgggacacaaggategecaceagacegetgecetaggaegegt cgagagcetgtggccagcgcactcggaccgtggggcggagacccaggagaccggagcaga gctgtgcagacagcatca ggattgctgaagacaggtgtcagcatgactgaacgctttga ctgecaccactgcaatgaatctetgtacggeaagaagtacattctaaaggaggagaacec acactgtgtggectgetttgaggaactctatgecaatacetgtgaggagtgtggaacacc catcggctgcgactgcaaggacttgtcctacaaggatcggcactggcatgaaggctgct ccattgctcceggtgtggaagctegctggtggacaagccetttgetgccaaggaggaaca getgetgtgeacegactgetattceaatgaatactegtceaagtgecaggaatgeaagaa aaccatcatgccaggtacccgcaagatggaatacaagggcagcagetggcacgagacctg cttcacctgtcagcgctgccagcagcccattggaaccaagagcttcatacctaaggagaa tcagaact tetgegtgecetgetatgagaageagtatgecetgeagtgegtgeagtgeas aagectatcaccacaggaggtgttact taccgggageagectggeacaaggaatgett tgtgtgcacagcctgcaagaagcagctatctgggcaacgcttcacagcacgggatgagtt tccatactgectgacctgettctgtgacttgtacgetaagaaatgtgctgggtgcaccaa ceccattagtggtetgggtggeacaaagtacatetetttegaggaacgecaatggcacas cgactgctttaactgtaagaagtgetccetgtctctggtgggacgaggcttcctcacaga gagagatgacatcctctgtcctgactgtggaaaggatatttgaaggcggcacagaagcca cagegegtggegeagagatteggatgtttecttcataaccaggcaatgetgtgttctga ttcecaccagecaccacgaggettcetcttgetgecetggettcacatttgttgaaacc tttagttcttttcttctcagtggggacaagatccatccgtaagccccggatgggaagat gttggaattttatagaaatgcaaggcagattaaatgaaaagtcttgagtgtctttata atgeatectecttcacatectattraattettaagtgeaattaacatgtgttatgaac ttgaatgtatttcaagggagagctgggattegcagcttgtgactecttttatgtas aacctagaggaagacttatgtgact tacaataaattattcagaataaacattttgtca agcaca

\section{Fhl2-202(1417bps)}

aacattaaagcaacecaatgaageceagggectgectgeacagtgetggecetcateec actggtctggttgctgggcagaaggaagggctctgacctctaacatcalagattgctgas agacaggtgtcagcatgactgaacgettgactgecaccactgcaatgaatetetgtacg gcaagaagtacattctaaaggaggagaacccacactgtgtggcetgctttgaggaactct atgecaatacetgtgaggagtgtggaacacceateggetgegactgcaaggacttgtect acaaggatcggeactggeatgaaggetgettceattgetcecggtgtggaagctegetgg tggacaagccetttgctgccaaggaggaacagctgctgtgcaccgactgctattccaatg aatactegtecaagtgecaggaatgeaagaaaccatcatgecaggtaceegcaagatgg aatacaagggcagcagctggcacgagacetgcttcacctgtcagcgetgccagcagccea ttggaaccaagagettcatacctaaggagaatcagaacttctgegtgecetgetatgaga agcagtatgecetgcagtgegtgcagtgcaaaagcctatcaccacaggaggtgttact accgggagcagcectggcacaaggaatgctttgtgtgcacagcetgcaagaagcagctat etgggcaacgettcacagcacgggatgagtttceatactgectgacetgettetgtgact tgtacgctaagaaatgtgctgggtgcaccaaccccattagtggtctgggtggcacaagt acatetettegaggaacgecaatggeacaacgactgetttaactgtaagaagtgetece tgtctctggtgggacgaggettcctcacagagagagatgacatcctctgtcctgactgtg gaaaggatatttgaaggeggeacagaagecacagegegtggegeagagatteggatgttt tctttcataaccaggcaatgctgtgttctgattcccaccagccaccacgaggettcctct tgctgecetggcttcacatttgttgaaaccettagttctttectctcagtggggacas gatccatcegtaagececggatgggaagatggtttggaatttatagaatgcaaggeag attaaatgaaaagtettgagtgtcttrataatgcatcctccttcacatcctatttaat ttttraagtgcaattaacatgtgttatgaacttgaatgtattteaagggagagetggga tttgcagcttgtgacttccttttatgtaaacctagaggaagacttatgtgacttaca ataaaattattcagaataaaacattttğtcaagcaca

Figure 3-6. There are two transcripts of the Fhl2 gene.

In the Fhl 2 gene, there are 6 exons used to assemble the gene. The highlighted regions are the first exons of each transcript. The first exon is different in the two transcripts, except for the area in red, which is the same. The rest of the five exons are the same. 


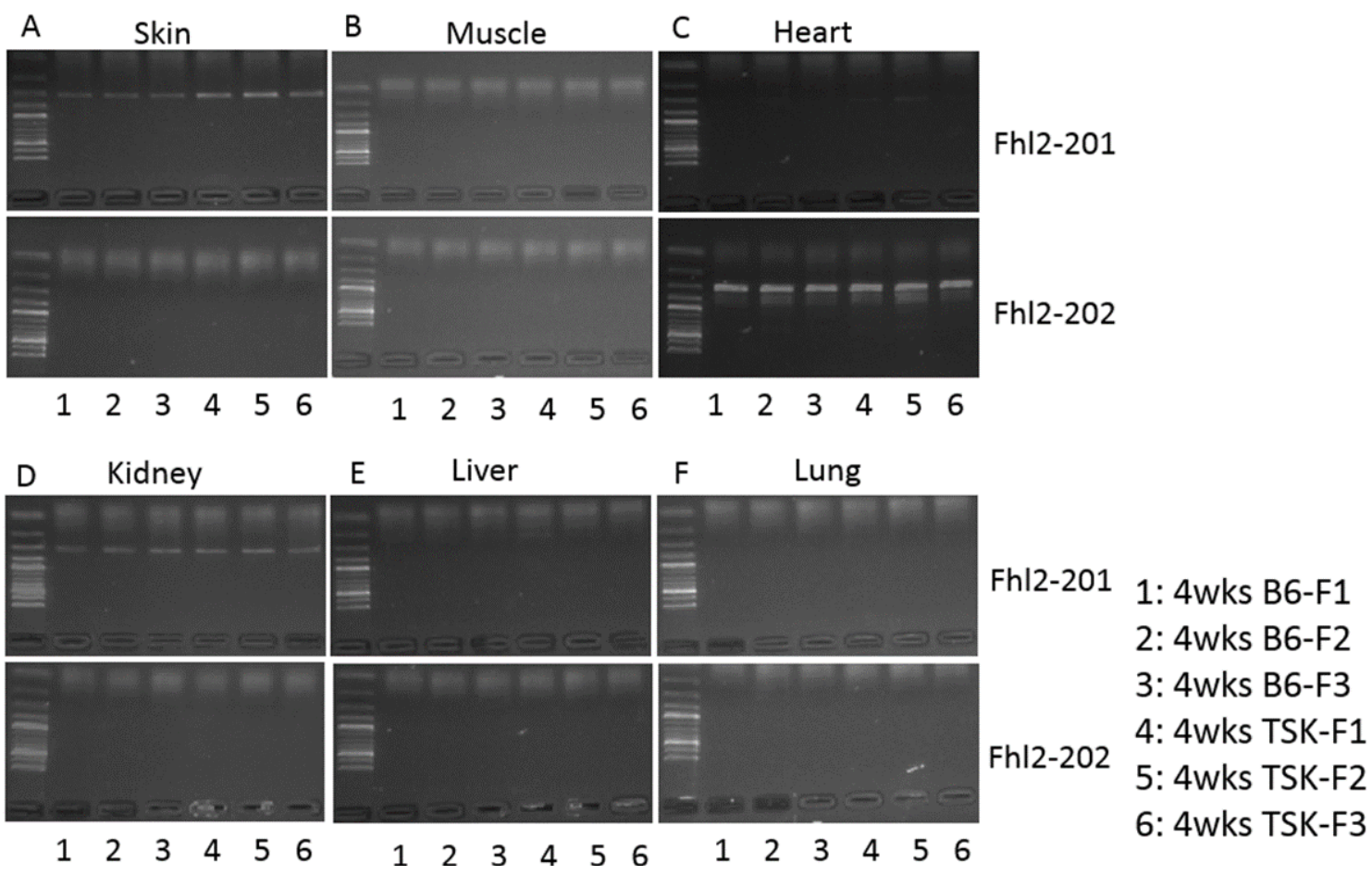

Figure 3-7. Comparing transcripts Fhl2-201 and Fhl2-202 in different tissues. Fhl2-201 and Fhl2-202 expression levels are compared in the skin, muscle, heart, kidney, liver, and lung between B6 and Tsk2/+. No. 1-3 are 4 weeks female B6 skin mRNA samples and No. 4-6 are 4 weeks female Tsk2/+ skin mRNA samples. (A) Fhl2-201 is expressed in the skin and expression in Tsk2/+ is higher than B6. There is no Fh12-202 expression in the skin. (B) In the muscle, there is no expression of either transcripts. (C) Fhl2-202 is expressed in the heart. There is no Fhl2-201 expression in the heart. (D) Fhl2-201 is expressed in the kidney, and expression is not different between Tsk2/+ and B6. There is no Fhl2-202 expression in the kidney. (E) In the liver, there is no expression of either transcripts. (F) In the liver, there is no expression of either transcripts. 
A.

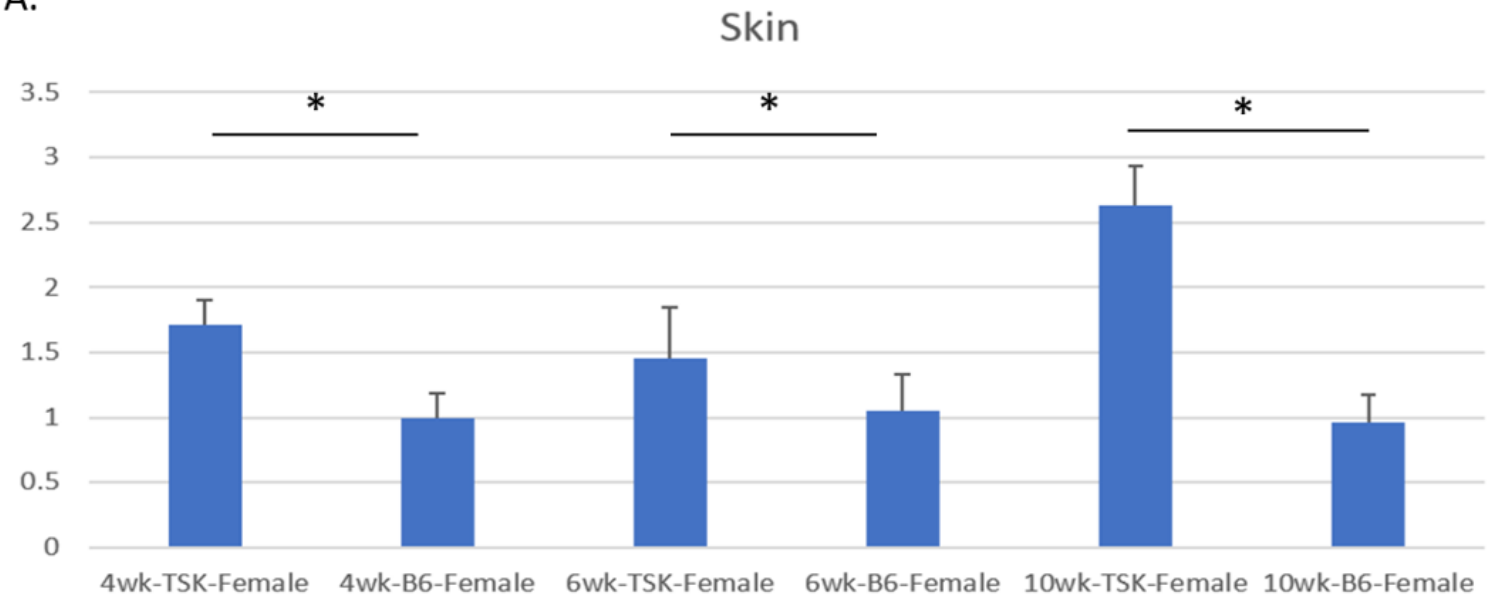

B.
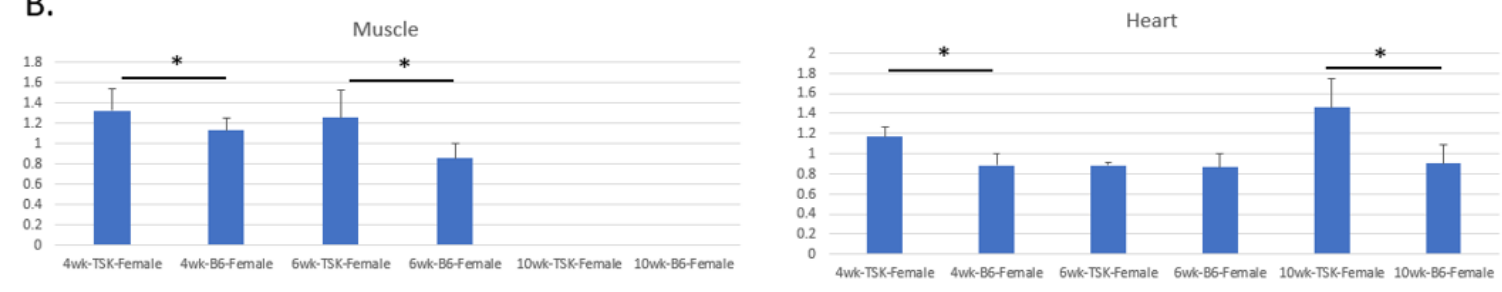

Kidney
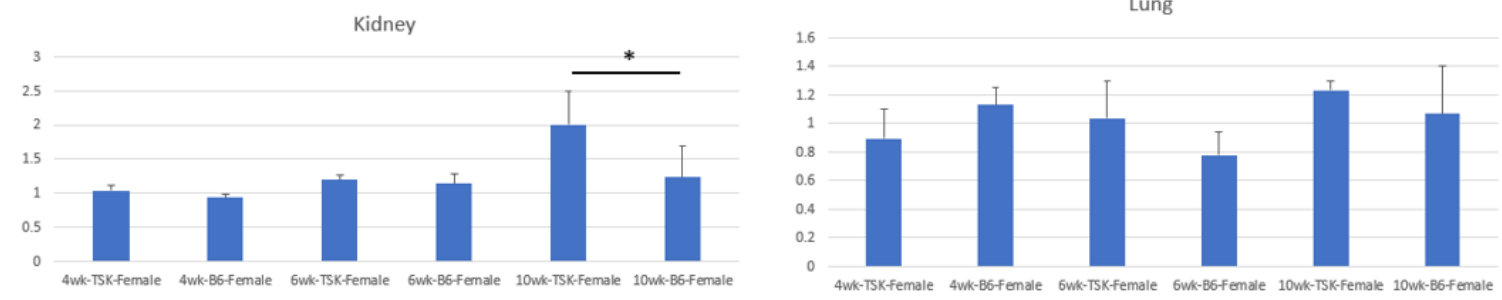

Figure 3-8. The Fhl2 gene expression in Tsk2/+ and B6 mice tissues at 4, 6, and 10 weeks.

(A) The Fhl2 gene expression levels in Tsk2/+ and B6 female skin at 4, 6, and 10 weeks. The strains are shown below the horizontal axis. Numbers to the left of the vertical axis are the ratio of relative expression. At 4 and 6 weeks, Tsk $2 /+$ were around 1.5 -fold more than normal. At 10 weeks, the Tsk2/+ expression level was 2.5 -fold more than normal. (B) The Fhl2 gene expression level in Tsk2/+ and B6 female muscle, heart, kidney, and lung at 4, 6, and 10 weeks. The strains are shown below the horizontal axis. Numbers to the left of the vertical axis are the ratio of relative expression. In the muscle TSK, is higher than B6 at 4 and 6 weeks. There is no overall difference between TSK and B6 in the heart and lung. TSK is higher than B6 in the kidney. 
Figure 3-9. Fhl2 gene sequencing and designed primers on mRNA, genomic DNA, promoter and intron.

The pairs of primers were designed for sequencing the Fhl2 gene. Each color represents a pair of primers. The primers overlapped each other, so there were no missing nucleotides. (A) The mRNA of Fhl2; (B) the genomic DNA covered the Fhl2 gene; (C) the promoter of the Fhl2; (D) the introns beside the Fhl2 exons. (E) The sequences of B6 and Tsk $2 /+$. The top sequence is B6, the bottom Tsk2/+. 
A. aacattaaagcaacccaatgaagcccagggcctgcctgcacagtgctggccctcatcccc actggtctggttgctgggcagaaggaagggctctgacctctaacatcacagattgctgaa agacaggtgtcagcatgactgaacgctttgactgccaccactgcaatgaatctctgtacg gcaagaagtacattctaaaggaggagaacccacactgtgtggcctgctttgaggaactct atgccaatacctgtgaggagtgtggaacacccatcggctgcgactgcaaggacttgtcct acaaggatcggcactggcatgaaggctgcttccattgctcccggtgtggaagctcgctgg tggacaagccctttgctgccaaggaggaacagctgctgtgcaccgactgctattccaatg aatactcgtccaagtgccaggaatgcaagaaaaccatcatgccaggtacccgcaagatgg aatacaagggcagcagctggcacgagacctgcttcacctgtcagcgctgccagcagccca ttggaaccaagagcttcatacctaaggagaatcagaacttctgcgtgecctgctatgaga agcagtatgccctgcagtgcgtgcagtgcaaaaagcctatcaccacaggaggtgttactt accgggagcagccctggcacaaggaatgctttgtgtgcacagcctgcaagaagcagctat ctgggcaacgcttcacagcacgggatgagtttccatactgcctgacetgettctgtgact tgtacgctaagaaatgtgctgggtgcaccaaccccattagtggtctgggtggcacaaagt acatctctttcgaggaacgccaatggcacaacgactgcttlaactgtaagaagtgctccc tgtctctggtgggacgaggcttcctcacagagagagatgacatcctctgtcctgactgtg gaaaggatatttgaaggcggcacagaagccacagcgcgtggcgcagagattcggatgttt tctttcataaccaggcaatgctgtgttctgattcccaccagccaccacgaggcttcctct tgctgccctggcttcacatttgttgaaaccctttagttcttttcttctcagtggggacaa gatccatccgtaagccccggatgggaagatggtttggaattttatagaaatgcaaggcag attaaatgaaaaagtcttgagtgtctttataatgcatccttccttcacatcctatttaat tttttaagtgcaatta tttgcagctttgtgacttcctttttatgtaaaacctagaggaagacttatgtgacttaca ataaaattattcagaataaaacattttgtcaagcaca B. GTGTCCTIGAAACAGGCAGGCCAAATGGGGACGTGCATAGCAGCCCCTICCCAACTGGAG AACATTAAAGCAACCCAATGAAGCCCAGGGCCIGCCTGCACAGTGCTGGCCCTCATCCCC TCATITACTITGITIGITTGITTGGTCITIGITTCITIGTITCTTCAIGCCAGTCAATTC CAGTGCACATICAGGCO

CAAAGGGAGTGICTTAGACCCAGGCAGGCACTGGGACCTCAGGACCCCAGCTCCCCAAAC GAGGGGCGCTCGCTACCGGIACTGGCTCTCCTGGGCCAGCACGCCCAGCCCGCCGCCCGGG

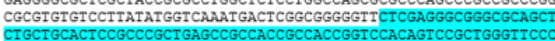
CIGCIGCACTCCGCCCGCTGAGCCGCCACCGCCACCGGTCCACAGTCCGCIGGGITCCCC
FAGACCCCGGCCCCACCGCGCGAGTACTACTGCGGCCGCCCAGGCCACAGCCCTGCTT ACTCGGACCGTGGGGCGGAGACCCAGGAGACCGGAGCAGAGCIGIGCAGACAGCATCAGG

TAAAAAGGG IITCCCTGAAACIIIIGAGCM ITGAAAGTCTGTCGAAGCCACTGCCTTCAT TCATGIGTGGGTITTCTCITCTITITITTIT AATGAATCT CTGTACGGCAAGAAGTACATTCTAAAGGAGGAGAACCCCACACTGIGTGGCC IGCITIGAGGAACTCTAIGCCAAIACCIGIGAGGAGIGIGGAACACCCATCGGCIGCGAC

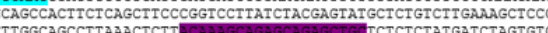
AGCACAGGCTTGTCCACAGGCAAATCIIGCCGTCCTTCCTCGCCCTCCCCCTCCCTCTCTI ACCCACCCACTCCAGCAATGIAGTGCACCAAGGCCCCTGTGCTCTGAGTCAGACAGTAG GICACCTCTCCT GTCCCGCCTCT GACGATTITIGTGTCTGCCTCTCTAGGACTIGTCCTA CATGCCAGGTCAGAACGCATGCCI ITATCATTCGCATGIGGCACT GAGCCAGGTCAGCGATGGACTGIGGGGIGGGACTCTCA IIGICCAGAGACAGACACTGGT GITATACTICAGTGCIGGGCCCT GAACACAGGATATG ITAGAGAGGAGCCATI GAGAGCAGAGAGACTTGCCATGTCATGTAACACTAGGTAGGAG CTCTCGCCTCT GACCACAGGTACCCGCAAGATGGAMTACARGGGCAGCAGCTGGCACGA GACCIGCTICACCIGTCAGCGCTGCCAGCAGCCCATIGGAACCAAGAGCTTCATACCTAA GGAGAATCAGAACITCTGCGIGCCCIGCTATGAGAGCAGIATGCCCTGCAGTGCGTGCA GCCITGCGCATCTGITCTCTIGGGTGICTGTGTGTTGATCTATTGGGTCTGTGATITCTGI

C. TCCCTTCCTCAGCATATTTGTAGAAATGGGTAAGTCTGCTTTTGAAAGACTGGATTTTCCT TAAATCACAGAACATTTAATTAAGAAAGCAACATAGGGGGGTGGAGAGATGGCTCAGAG
GITAAGAGCACTCACTGCTCTTCTGGGAGGTCCTGATCCCAGCAACCACATGGTGGCTCA CAACCATCTGTAATGGGATCCGTTGCCCTCTTCT GATGTGTCTGAAGACAGCTACAGTGT ACTCATATAAAATAAATAAATAAACCTTAAAAAAAAAAAAAGAAAGCAACATAACAATCAA ATAAGAGCTAATGCATAACTCACAGAATTTAAACAGCAMAACAAAACAAAACAGGAAGG GTAAATATAEAATCGGCGTTTTGTTACTCTITGAACCTGAGTTTTAGAAATGAGGCTGAA
GGCTCACCATCATGAGACATTTTGCAGTTTGTAGCTCTIACATATAAGAAAGCTAACTT
GAGTAGCCTCAGAGCCATTAGCCTGTCTACGTACCCTTTACTTTGAATCCAAGATAGAGT GAGTAGCCTCAGAGCCATTAGCCTGTCTACGTACCCLTTACTTTGAATCCAAGATAGAGT GTACCTTGACCATCAGTGGGATTTAGTTAGGTI ITCCCCCAATTGCAAGAGG GGACAG
GAGTGGGAGGATTTCCTGTGTCCCACCTCAGCTTGCTCACTCTCCTCTGGGAAATGT CAACTCCAGGGAGTCACCCGAGTGAATGACGGGAGTTAAGAATTTCTCATCCTTTAAGAT ATTCTCATGGCCTTGCTAGCTCATAGACATCAGTGCAAATCTCAGCTGAAACTCTTCACC TCATCTAGAGTCCTCATCATTTAATTGAGATAACTAACTTTACCAAAAGGGCCTGAAGAT TTCTCAATGGCCAGAGGTAGCTAATGT TGACTGCGTGGCAGTTATTMTAACACCCTIGI ACCAGAAGAAAGCCACCACACAGTTCTTCCTGCCTTTACTGGAAAACGTGTTGCCTTCAG CTCCCCTCGAATGATGGAAACAGCTTCGACCAGTGATGGTTCTTCACTGTCCATTT GACT GGGTTTTGATCACCTAGGAGACACACCTCTAGAAGAATTTTTGTGGTAGTTCCAGAGAG ctcgagggcgggcgcagctcetgctgcactec $g c c c g c t$ gagcegccaccgccaccggtc cacagtccgctgggttcecttagaccecggccccaccgcgcgagtactactgcggccgcc caggccacagcectgettgggacßeaaggatcgccaccagaç cgctgecctaggacgcgt egagagectgtggecagcgeactcggacegtggggeggagacceaggagaccggageaga getgtgcagacag patcalggattgctgaaagacaggtgtcagcatgactgaacgctttgaFn12-cd1 (1566

Fhl2-CD1 ctgccaccactgcaatgaatctctgtacggcaagaagtacattctaaaggaggagaaccc acactgtgtggectgetttgaggaactetatgecaatacetgtgaggagtgtggaacac categgetgegactgcaaggacttgtcetacaaggat cggcactggcatgaaggetget tm12-cd2 (1566

aacattaaagcaacccaatgaagcccagggcetgcctgcacagtgctggccetcatcccc h12-CD2 actggtctggttgctgggcagaaggaagggctctgacctctaacatcalcagattgctgaa agacaggtgtcagcatgactgaacgetttgactgccaccactgcaatgaatetetgtacg gcaagaagtacattctaaaggaggagaaccacactgtgtggectgetttgaggaactct atgccaatacctgtgaggagtgtggaacacccatcggetgcgactgcaaggacttgtcet Fh12-cd1(1417)

$\mathrm{h} \mid 2-\mathrm{CD}$

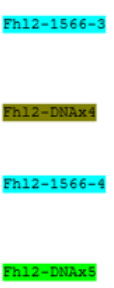
Fh12-1566-3 Fh12-DNAX4 Fn12-1566-4

Fh12-DNAxs

CATCCTITGCTACATAIGTGGCTGGAGCCACAGGTCCCTCCAIGTCGACTITAACAAACT GCATATTIGTIGIGGGTGGGGCTCGTGTCTTACATCATTCATGGGCAACAGCAGT GACAG Fh12-1417-1 ATGTTTACCAGAAACAGGGGTAGCCCTGACTCATACACTTGTCTCCCCCAGCCTATCACC ACAGGAGGTGITACTTACCGGGAGCAGCCCTGGCACAAGGAATGCTTIGTGIGCACAGCC TGCAAGAAGCAGCTATCTGGGCAACGCTICACAGCCAGGIGCACCAACCCCATTAGTGG

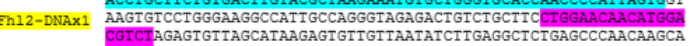
Eh12-DNAX6 Fh12-1566-1 CTCACTGCGCATGIGTCGIACAGCGGGCTCAAACAII GAAGTGGATCGCTCACTGCACAT

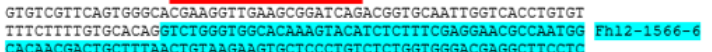
ACAGAGAGAGATGACATCCTCTGTCCTGACTGTGGAAAGGATATTTGAAGGCGGCACAG AGCCACAGCGCGIGGCGCAGAGATTCGGATGITITCITTCATAACCAGGCAATGCTGTGI
TCTGATTCCCACCAGCCACCACGAGGCTICCTCTTGCTGCCCTGGCTICACATTTGITG AACCCTITAGTTCTIITCIICICAGIGGGGACAAGATCCATCCGIAAGCCCCGGATGGGA Fh12-1566-2 TIATAATGCATCCTICCTICACATCCTAITTAATTITTTAAGTGCAATTAACAIGIGITA TGAACTIGAATGTAITITCAAGGGAGAGCTGGGAITTGCAGCTITGTGACTTCCTITIT IGTCAAGCACAGTGTGTGGACTAATGATTAAATGGTAGCACCGACTTTTCTCCCICACGT Fh12-DNAXg

Fh12-dna

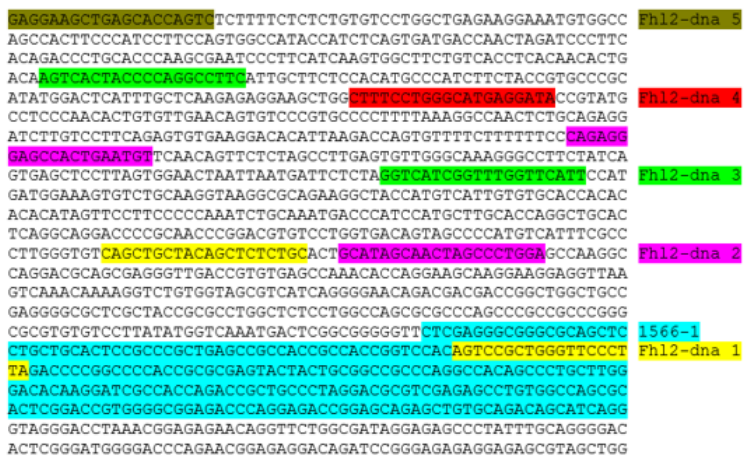

GAGGAAGCTGAGCACCAGTCTCTTTTCTCTCTGTGTCCTGGCTGAGAAGGAAATGTGGCC 作 TATGGACTCATTTGCTCAAGAGAGGAAGCTGGETTTCCTGGGCATGAGGATA CCGTATC 作 ATCTTGTCCTTCAGAGTGT GAAGGACACATTAAGACCAGTGTTTTCTTTTTTTCCEAGAGG GTGAGCTCCTTGICAACAGTTCTCTAGCCTTGAGTGTTGGGCAAAGGGCCTICTACCAT Fh12-dna 3 CTTGGGTGTCAGCTGCTACAGCTCTCTGCACTGCATAGCAACTAGCCCTGGA GCCAAGGC DCCGCTGGCTGCC ACTCGGGATGGGGACCCAGAACGGAGAGGACAGATCCGGGAGAGAGGAGAGCGTAGCTGG 
D

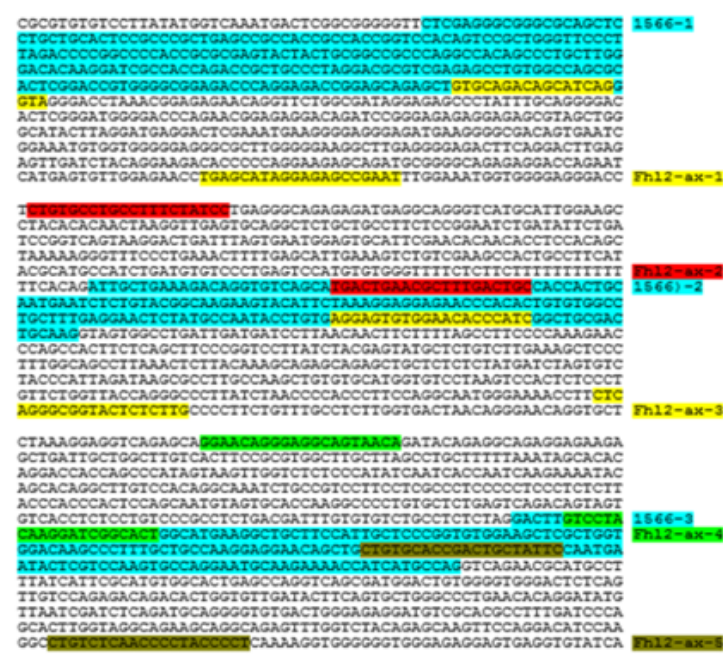

E.

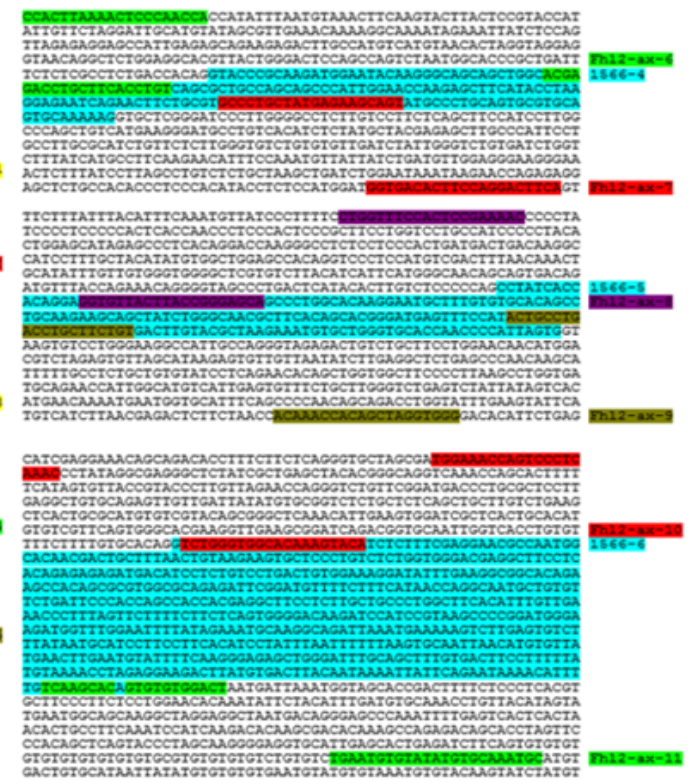

Tsk2/+ mice

H.

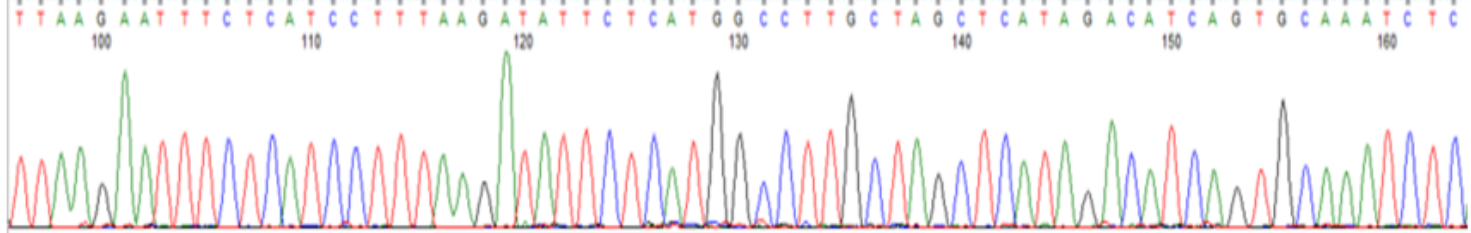

B6 mice

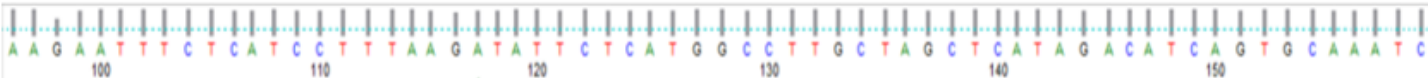

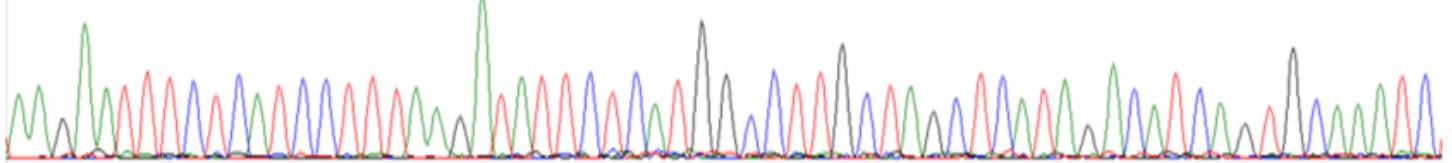

Figure 3-9. Continued. 


\section{Fhl2 Protein Levels in Skin}

As evidenced by the phenotype, Tsk $2 /+$ shows very tight skin and obvious ECM fibrosis. We believe these phenotypic traits are caused by an excess of the Fhl2 protein. Under the same experimental conditions, we measured Fhl2 protein levels in the skin of Tsk2/+ and B6 littermates. We used all parts of the skin to measure the protein levels, including the dermis and epidermis. Higher Fhl2 protein levels in Tsk $2 /+$ compared to the B6 mice verified that Tsk2/+ produces overexpression at the gene level compared to B6. The protein expression was tested from four-week-old mice skin by western blot, and it was found that the Fhl 2 protein expression in Tsk2/+ mice is significantly more than that observed in B6 mice of the same age (Figure 3-10). We duplicated the samples to ensure that it was not an individual difference. We used ImageJ software to quantify the strength of the band.

\section{Gene Regulation of the Expression of Fhl2 in the Spleen}

The genetic factors that regulate the expression of Fhl 2 were measured on GeneNetwork. With 2000 permutation testing, we found that the gene for regulating Fhl2 was on chromosome 5, and that the QTL on chromosome 5 was significant. The significant LRS was 17.14 and suggestive LRS was 10.71. The QTL can reach the level of 15 on Chromosome 5 (Figure 3-11A). The peak region of QTL on chromosome 5 was between 55.00 to $64.00 \mathrm{Mb}$ (Figure 3-11B). There were twenty-two genetic elements, and eight of them were known genes. These were Pcdh7, G6pd2, Arap2, Gm336, Centd1, Dthd1, Nwd2, and Rell1. From these gene networks, we gained understanding regarding the upstream gene location and genetic pathway - from chromosome 5, from 55 to 65 $\mathrm{Mb}$. The upstream gene of Fhl2 should be in this region.

\section{Gene Network of Fh12 in Mouse Spleen}

The UTHSC Affy MoGene 1.0 ST Spleen (Dec10) RMA in GeneNetwork was used to search the expression level data. The probe for Fhl2 and whole genome expression profiles were compared in the spleen. From the top fifty probes, gene expression levels correlated to Fhl2, and nineteen of them were known genes. There were positive or negative correlations to Fhl2. The expression of Fhl2 was positively correlated to translocate demilune cell and parotid protein1 (Dcpp1), kinocilin (Kncn), follistatin (Fst), Lim homeobox protein 3 (Lhx3), amelogenin X chromosome (Amelx), predicted gene 5246 (Gm5246), keratin 31 (Krt31), synaptotagmin-like 5 (Syt15), trace amineassociated receptor 8A (Taar8a), CCR4-NOT transcription complex, subunit 8 (Cnot8), defensin, alpha, related sequence 2 (Defa-rs2), transmembrane channel-like gene family 1 (Tmc1), H1 histone family, member O, oocyte-specific (H1foo), olfactory receptor 1505 (Olfr1505), calcyon neuron-specific vesicular protein (Caly), C1q and tumor necrosis factor related protein 3 (C1qtnf3), extended synaptotagmin-like protein 3 (Esyt3), and predicted gene 597 (Gm597). There was only one negative correlation: heterochromatin 

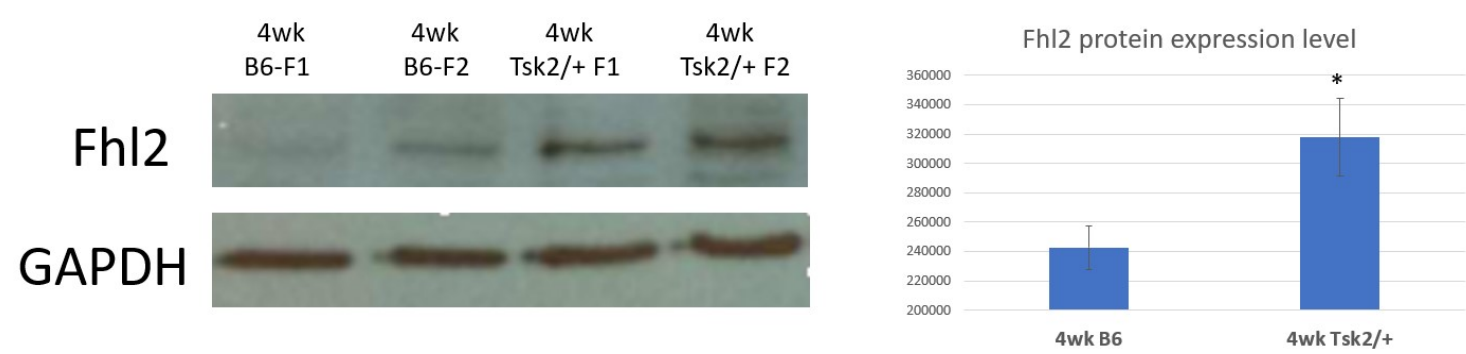

Figure 3-10. Western blot analysis of skin from Tsk2/+ and B6 mice.

Protein samples were collected from the skin of Tsk2/+ and B6 mice when they were 4 weeks old. Samples were duplicated with the Fhl2 antibody. The bands of the 4 week old B6 mice were lighter than those of the Tsk $2 /+$ mice. The intensity of the bands was measured using Image $\mathbf{J}$ software. From the bar graph, the Tsk $2 /+$ mice had significantly higher expression levels of the Fhl2 protein than did the B6 mice. 

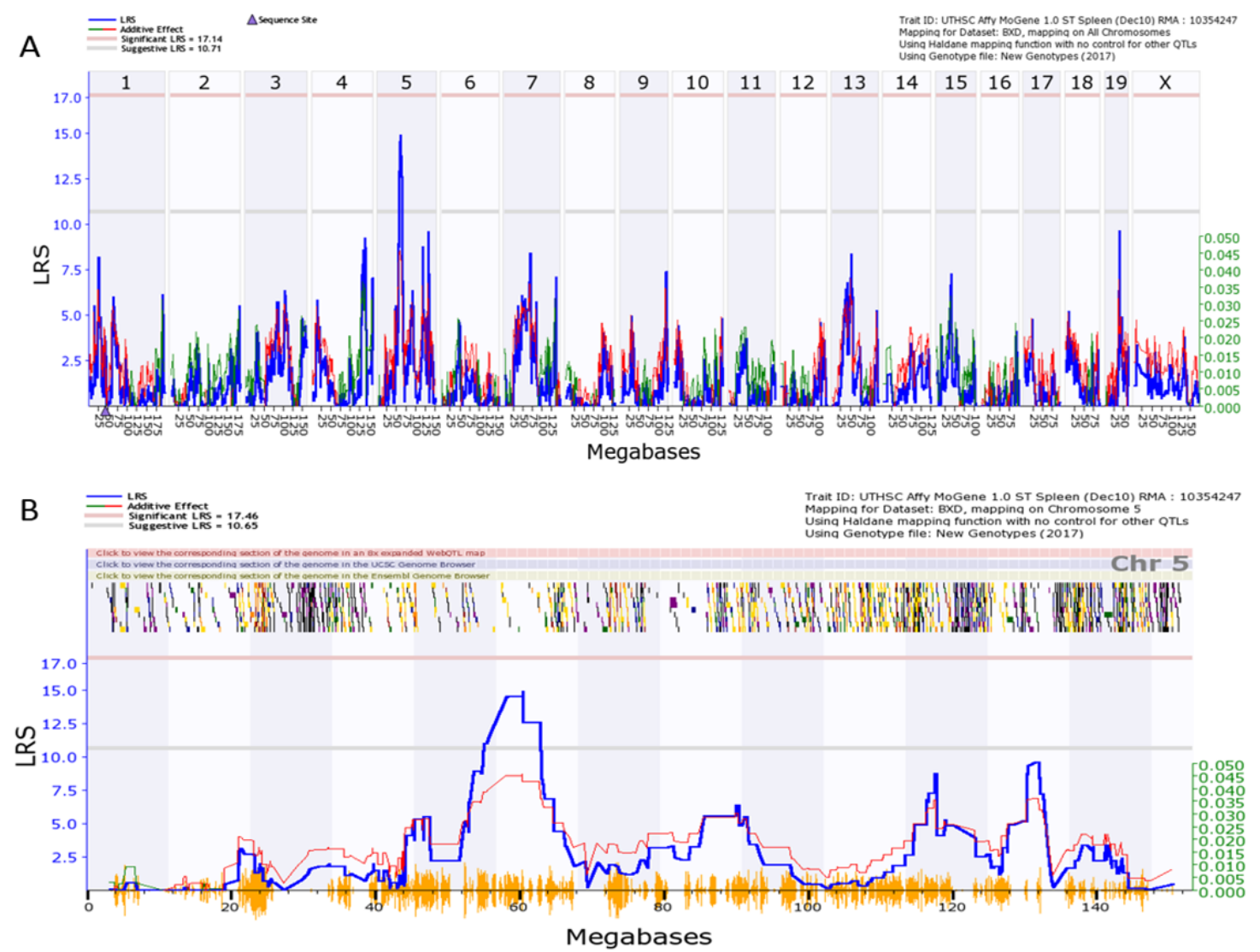

Figure 3-11. Detection of QTL for Fhl2 gene expression levels using RI strains. (A) QTL detection that the upstream gene is on the chromosome 5. The numbers on top of each figure indicate the chromosome number. Numbers on the left vertical axis indicate the LRS values. The pink lines on the top indicate the threshold for the significant level. Light grey lines indicate the threshold for the suggestive level. (B) On chromosome 5, the region is between $55.00 \mathrm{Mb}$ to $64.00 \mathrm{Mb}$. The location is shown below the horizontal axis. Numbers to the left of the vertical axis are the LRS values. The pink lines on the top indicate the threshold for the significant level. Light grey lines indicate the threshold for the suggestive level. 
protein 1, binding protein 3(Hp1bp3) (Figure 3-12). There is only Taar8a gene on chromosome 5 between 35 and $65 \mathrm{Mb}$.

\section{Discussion}

Collagen is very abundant in the body and is the protein that plays the most important role in the fibrotic process of SSc. Previous studies have shown that Tsk2/+ mice develop skin tightness, display ECM anomalies, and produce high ANAs levels. Tsk2/+ mice have a normal life expectancy in comparison to the wild type mice. Male Tsk2/+ mice were bred with B6 females because Tsk2/+ females cannot breed. We examined and quantified the disease signs during aging and in different tissues and determined a causative role for the collagen accumulation in the fibrotic trait. Tsk $1 /+$ mice develop a hunched posture as they age. The Tsk $2 /+$ mice do not have a posture change. To evaluate disease progression, we needed to find a reliable method to determine and quantify disease severity. To eliminate the variability inherent in the physical skin grabbing method, measuring the interscapular skin tightness was used to quantify the disease. Tsk2/+ mice have noticeably tighter scapular skin than their littermates after 3 weeks; it was difficult to gather the skin into a fold. No difference was found between organ size and shape of the two mice strains when they were collected at 4,6 , and 10 weeks. The body length, tail length, body weight, and skin tightness were measured for comparing the Tsk2/+ and B6 mice. The body length and tail length did not show a significant difference between Tsk2/+ and B6 mice. This is expected because this is a skin disease and should not affect the body or tail length. For the body length, males were longer than the females in both strains, but there was no tail length difference between male and female. Weight increased with age in both male and female. Males were heavier than the females in both strains. Both genders of the Tsk2/+ mice were lighter than their B6 littermates. The reason for this is unknown, but we speculate that it may be due to the physically smaller bones and lower bone density of Tsk $2 /+$ mice compared to normal B6 mice[167]. The skin scores were measured by grabbing the interscapular skin at different ages. The mice were measured the first time when they were 3 weeks old. phenotype between Tsk $2 /+$ and B6 was obviously different, and this was an important basis to use to distinguish them. The capability to grasp the skin was measured by placing the pulled skin against a ruler. B6 mice skin can be grasped $\sim 1.7$ $\mathrm{cm}$ and the Tsk $2 /+$ mice skin can only be grasped $\sim 0.7 \mathrm{~cm}$. Upon contact with the skin, you can tell the difference between the two mice strains. The skin of the B6 mice was elastic and one could grab a substantial amount of skin. On the other hand, the skin of Tsk2/+ mice was tight and one was unable to grab very much skin to pull. The skin has some small variation before 7 weeks and is relatively stable during growth. Our goal was to find the mutation gene in Tsk2/+ mice.

The mutation gene for Tsk2/+ was reported as Col3a1 the Jiménez group[168]. The Tsk $2 /+$ mice were identified by a single nucleotide change on Col3al gene by the Blankenhorn group in 2015[167]. There were three DNA sequence differences that were Tsk2/+-specific. All three single nucleotide polymorphisms were at different regions. Two SNPs were on the Gulp1 intron, and they did not change the Gulp 1 mRNA splicing 


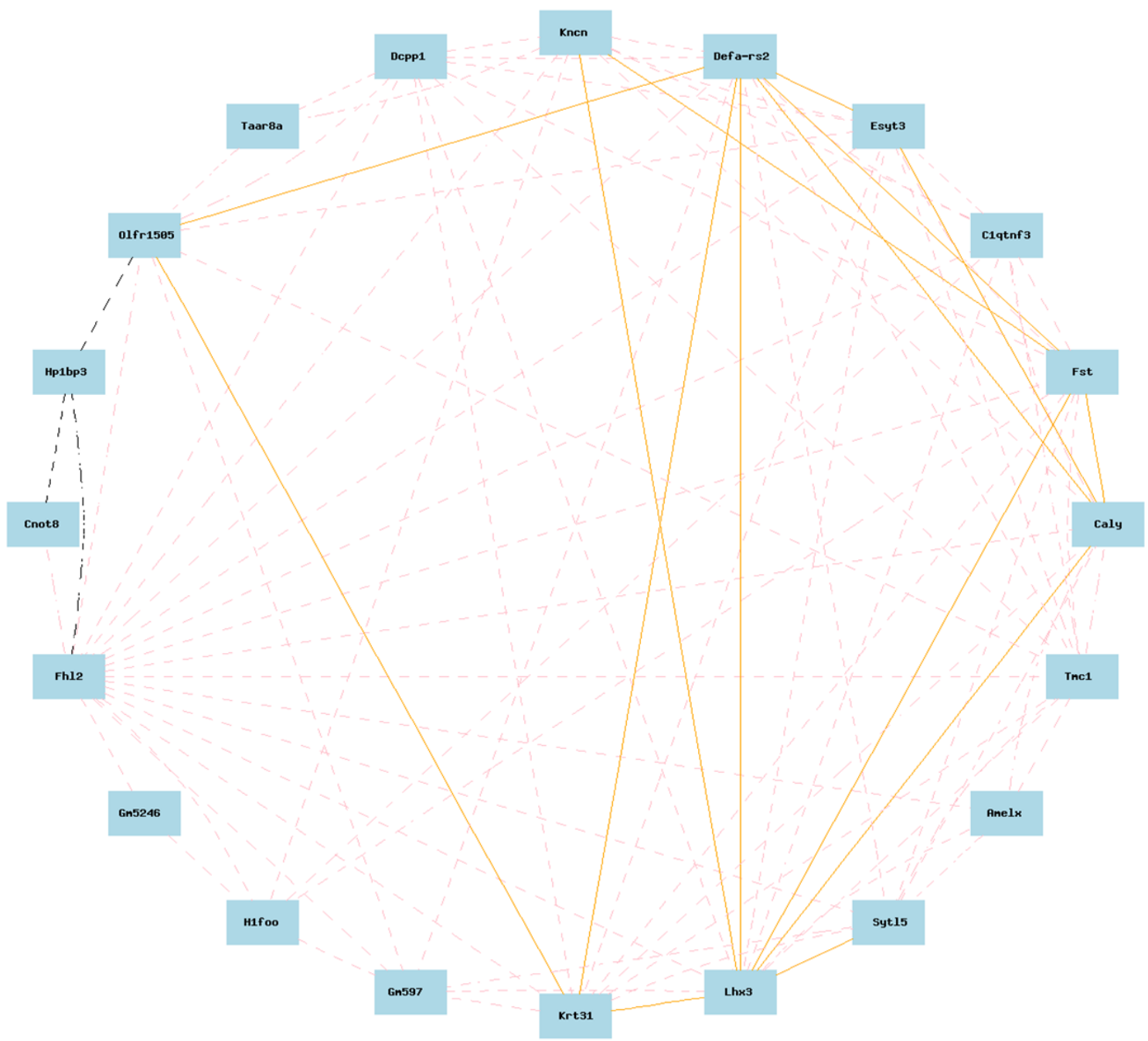

Figure 3-12. Gene network among Fhl2 genes, which are upregulated or downregulated in mice, constructed using expression profiles from spleen BXD mouse strains.

The Fifty most related genes were collected to compare with Fhl2, nineteen of them are known genes. The Taar8a gene is the only one related to Fhl2 and on the chromosome 5 between 35 and $65 \mathrm{Mb}$. 
and gene expression in the skin. These two SNPs cannot cause the mutation. The third SNP was in the Col3al exon. Thymine changed to adenine at 45,378,353 on chromosome 1. This changed the amino acid from cysteine to serine in the Procollagen III amino terminal propeptide segment. Four pairs of primers for PCR and rt-PCR were designed by Primer 3 to identify the Tsk2/+ and normal mice. The pairs of primers for PCR were Col3a1-dna-T and Col3a1-dna-N. The Primers for rt-PCR were Col3a1-T and Col3a1-N. The Col3a1-dna-T and Col3a1-dna-N had the same reverse primer, only the forward primers were different. The Col3a1-dna-T forward primer and the Col3a1-dna-N forward primer had only a single nucleotide difference. The last single nucleotide of the Col3a1dna-T forward primer was $\mathrm{A}$ and the Col3a1-dna-T forward primer was T. Tsk2/+ and B6 strains were confirmed by using PCR (data not shown). On the mRNA level, samples 1-3 from 4wks-B6 skin and samples 4-6 from 4wks-Tsk/2+ were amplified by rt-PCR by using the Col3a1-T-F and Col3a1-T/N-R pair of primers. In this instance, when we amplified the segment of DNA, Col3a1-dna-N can amplify both B6 and Tsk2/+, while Col3a1-dna-T can only amplify Tsk2/+. Our data verified there is an SNP on Col3a1. Verifying the B6 and Tsk2/+ mice by PCR and rt-PCR experiments can prove that there is a single nucleotide polymorphism in Tsk2/+ in Col3al gene.

The single nucleotide polymorphism of thymine to adenine in Col3a1 was one difference between B6 and Tsk2/+. The changing of this single nucleotide causes the amino acid to change from cysteine to serine, and this changed the protein structure. Cysteine and serine are both neutral-polar amino acids with similar structures. The only difference in structure between the two amino acids is a change from a sulfhydryl ( $\mathrm{SH})$ to a hydroxyl $(\mathrm{OH})$ group. We believe that this a negligible difference that makes only a limited change in protein structure or function. The Col3al expression levels were not different between B6 and Tsk2/+ mice in skin, heart, and kidney. There is only one transcript of the Col3al gene. If Col3al is the mutation gene, why is there fibrosis only in the skin, not other tissues or organs? According to an online database, bladder, mammary, osteoblast, and umbilical had very high expression levels. Why was there not any report of these tissues having fibrosis? If Col3al is the only mutated gene, then fibrosis should be found throughout the body, not just in the skin. However, fibrosis has not been reported in other organs; thus, in our hypothesis, there must be at least one other mutation gene influencing susceptibility to tight skin disease. Based on this, there is another regulatory gene that could be found by examining upregulation in Tsk $2 /+$. The upregulated genes were of interest because we knew that the collagen level increased in tight skin and that this was caused by overexpression. In our microarray data, there were eighty-two probes upregulated in Tsk $2 /+$ and four probes upregulated on chromosome 1 between 42.5 and 52.5 Mb. The four genes were Col3a1, Slc40a1, Slc39a10, and Fhl2. Based on our many years of research, Fhl2 was chosen as our candidate gene.

Of the four upregulated genes, the Col3a1 and Fhl2 have had expression levels tested in different tissues, because Col3a1 had been previously reported as a candidate gene, and Fhl2 is located on the QTL region. Col3al and Fhl2 are both located on chromosome one. These two genes are expressed in different tissues, and within the tissues in which they are expressed, their expression levels are different. Since Col3a1 only has one transcript, fibrosis would be expected to be found in the tissues where there 
is high expression, but it is not. The high expression of Fhl2 in the heart can be explained by Fhl 2 having two transcripts and only one of them being the cause of tight skin.

Fhl2 is located on chromosome 1 from 43,123,074 to 43,196,984. In our research, there were two protein coding transcripts: Fhl2-201 and Fhl2-202. Fhl2-201 was determined to be $1566 \mathrm{bp}$ and Fhl2-202 was $1417 \mathrm{bp}$. The difference in these two transcripts is that they have different first exons. The first exons are completely different fragments between the two transcripts, not just that Fhl2-201 is 149 bp longer than Fhl2202. The rest of the five exons were identical. The two transcripts displayed different expression ratios in different tissues and organs, and many tissues and organs only showed expression of one of the transcripts. Although the first exon is different, these two transcripts produce the same protein, but the promoters are different. So, although the same protein is being expressed by these transcripts, the amount of protein produced will be different because of the promoters. A mutation in the promoter of Fhl2-201 could be the cause of upregulation in Tsk2/+, causing tight skin. The expression levels of the two transcripts are relatively independent. In our experiments, the two transcripts, Fhl2-201 and Fh12-202, were tested for expression levels in skin, muscle, heart, kidney, liver, and lung. From the results of our experiments, skin and kidney only showed Fhl2-201 transcript expression. As shown in Table 3-1, the expression of Fhl2 is very low in the kidney and likely does not cause fibrosis. The heart had mainly Fhl2-202 transcript expression and subtle Fhl2-201 transcript expression. In muscle, liver, and lung, both transcripts had no or very low expression. It is clear that the expression level of the Fh12201 transcript in the skin is much higher for the Tsk2/+ mice than that of the B6 mice. The heart expresses Fh12-202 but not Fh12-201, so the high expression of the gene does not affect the heart. These results explain why fibrosis is only found in the skin, and why expression of Fhl2-201 is low or nonexistent in the other organs compared to high expression in the skin.

In our study, we thought there was a single or only a few single nucleotide polymorphisms on the Fhl2 gene. We designed many primers to amplify the segments in order to sequence them and identify the polymorphisms. We sequenced the genomic DNA, cDNA, promoter, and two side introns connecting each exon. We have not yet found a polymorphism between B6 and Tsk2/+. We will increase the scope of sequencing to find the polymorphisms. Since a polymorphism was not found, upstream genes were identified as other possibilities to study. Taar8a was found upstream of Fhl2 and is on chromosome 5. This can be beneficial in the quest to understand the molecular mechanism and pathway of Tsk $2 /+$.

Real-time PCR was used to detect the expression levels in different tissues and organs. Probes were ordered from Applied Biosystems, so we did not know which part of the gene they selected. The Fhl2 gene expression levels in Tsk $2 /+$ mice were higher than that of B6 mice, and the expression variability increased with age. The Fhl2 gene expression levels were tested in different tissues at 4, 6, and 10 weeks in female mice. In the skin, the Fhl2 expression levels of Tsk $2 /+$ mice were higher than that of B6 mice at all the same time points. At 4 and 6 weeks, Tsk2/+ were around 1.5-fold more than normal. At 10 weeks, the Tsk2/+ expression level was 2.5 -fold more than normal. In the muscle, 
heart, kidney, and lung tissues, the Fhl2 expression levels were slightly higher in Tsk2/+ than B6. The expression of Fhl2-202 in Tsk2/+ and B6 tissues or organs were the same. The Fhl2-201 gene expression levels were different among Tsk2/+ and B6 tissues and organs. In the skin, the Fhl2 gene mainly expresses the Fhl2-201 transcript, so there was a clear difference between Tsk2/+ and B6 in real-time PCR. In muscle, heart, kidney, and lung, we found that the Fhl2 expression levels in Tsk2/+ were higher than B6, but the difference very minor. Both Fhl2-201 and Fhl2-202 were present in these tissues or organs, but Fhl2-202 accounted for a more dominant role. Fhl2-201 is suspected as being the mutated gene and not Fh12-202 as supported by these data because the RT results showed that there was no difference in Fhl2-202 between Tsk2/+ and B6, but there is a difference in Fhl2-201. Through Western blot experiments, we measured Fhl2 protein levels to substantiate our position. The protein levels of Fhl2 in Tsk2/+ skin were higher than that found in B6 skin.

This study identified Fhl2 as a possible candidate gene for Tsk2/+, but the research on this gene and its role in the disease is not yet complete. Even if this gene is not the mutated gene, it has very important implications in the molecular mechanism and pathway for this disease. We have not yet found the SNP between the Tsk2/+ and B6 mice yet, but Fhl2 is clearly a very important gene for the disease. 


\section{CHAPTER 4. CONCLUSION}

Diseases of the immune system are a very important issue. They are always very complicated because they have multiple influencing factors. Currently, there are at least 80 known autoimmune diseases, of which rheumatoid arthritis and systemic sclerosis are two. Arthritis and systemic sclerosis are serious, debilitating autoimmune diseases that collectively affect over fifty-five million people in just the United States. Rheumatoid arthritis is a systemic, chronic, inflammatory disorder that is expressed in the wrists, ankles, and small joints of the hands and feet that can cause pain and swelling. Systemic sclerosis is a localized or diffuse skin thickening and fibrosis caused by the body's immune system attacks its own tissue. This disease is a debilitating, chronic autoimmune disease that is potentially fatal, but the underlying cause is unknown. Limited cutaneous and diffuse cutaneous are the two main types of system sclerosis. In past six years, I used our two disease mouse models to improve the understanding of the human diseases. This study aimed to evaluate the molecular mechanisms of these two diseases by studying wild type and mutated genes in mouse models. Understanding the molecular mechanisms that lead to these diseases is of great importance for discovering therapeutic remedies and possibly preventing or curing the RA and systemic sclerosis.

Spontaneous arthritis was studied in mice because of the strong similarities found between arthritis in humans and in mice. We discovered the candidate genes in our IL$1 \mathrm{rn}$ deficient spontaneous arthritis mouse models to understand the pathogenesis and treatment of inflammatory arthritis. The model is of interest because it is spontaneous in onset and involves a signaling pathway implicated in human arthritis. Fully understanding the model may provide insight into what triggers disease and ultimately how to prevent arthritis. To better understand the pathogenesis of SAD, we bred susceptible, resistant and congenic mice: BALB $/ \mathrm{c}^{-/-}$, DBA $/ 1^{-/-}$, BALB.D-1 $1^{-/}$, and DBA.B$1^{-/}$. Our study produced useful data on the genetic regulation of spontaneous arthritis under the $\mathrm{BALB} / \mathrm{c}^{-/-}$and $\mathrm{DBA} / 1^{-/-}$genomic background. The QTLs and the information on candidate genes provide a basic analysis of the molecular mechanisms of spontaneous arthritis. We located a genetic factor that regulates SAD on chromosome 1. The expression levels of Ifi200 cluster genes were decreased while the resistance to SAD is increased in the congenic strain BALB.D1-1 ${ }^{-/}$, in comparison to its recipient parental strain $\mathrm{BALB} / \mathrm{c}^{-/ 2}$. The expression level of Ifi204 is the only gene in the Ifi200 cluster which showed a significant difference at a detectable or functional level, suggesting Ifi204 within the QTL region is most likely the causal gene for the regulation of SAD between mice with $\mathrm{BALB} / \mathrm{c}^{-/-}$and $\mathrm{DBA} / 1^{-/}$genomic background. We sequenced the coding gene between $\mathrm{BALB} / \mathrm{c}^{-/-}$and $\mathrm{DBA} / 1^{-/ /}$mice and found several polymorphisms. The function of the protein may be changed by alterations in the protein structure that is modified by the polymorphisms. In future studies, we will compare the specific protein structure between $\mathrm{BALB} / \mathrm{c}^{-/-}$and $\mathrm{DBA} / 1^{-/-}$by first getting a complete sequence of the genes to compare. The difference in protein structure can help us understand why the two strains do or do not have arthritis when they lack IL-1rn. Through this research we were able to determine a genetic component that regulates susceptibility to SAD, and then identify Ifi204 as a candidate gene in the causal pathway of spontaneous arthritis. The 
theory that Ifi204 is a favorable candidate gene is supported by the results. They show that the expression levels of Ifi204 decreased while resistance to SAD increased, but the expression levels increased in relation to a decrease in SAD resistance. This data can be used to further study Ifi204 and its relationship with spontaneous arthritis in hopes of developing a drug that targets Ifi204.

Systemic sclerosis $(\mathrm{SSc})$ or scleroderma is a prototypic idiopathic fibrosing disease. These fibrotic diseases are influenced by many environmental and genetic factors and have been extensively studied. However, many of the basic mechanisms of disease pathogenesis remain elusive. There are only a few effective therapies for preventing fibrosis. We used a mouse autoimmune disease model called tight skin 2 (Tsk2) to study genetic factors that regulate fibrosis in dermal tissues. Tsk $2 /+$ is a mouse model containing a mutation that causes tight skin and excessive deposition of dermal ECM proteins, a presentation very similar to that of systemic sclerosis in humans, and thus making it a perfect animal model to study the molecular mechanism of the disease. Studies indicated that excess collagen production was the result of an increased number of collagen expressing dermal fibroblasts, as well as elevated collagen expression on a per cell basis. We focused on identifying the mutated gene in the disease locus of the Tsk2/+ mouse. The mutation has been localized to mouse chromosome 1 between 42.5 and 52.5 megabases $(\mathrm{Mb})$, and considerable effort has been expended in the study of the molecular mechanisms of the disease. We used data from microarray expression profiles to select candidate genes. A single nucleotide polymorphism was found in COL3A1 between the diseased model (Tsk2/+) and the normal model (B6) that results in a change in protein structure. From the microarray data and gene mapping, Fhl2 gene was found to be the potential candidate gene. We confirmed Fhl2 gene expression levels were different in Tsk2/+ and normal mice skin by PCR, rt-PCR and real time PCR. There are two transcripts of the Fhl2 gene and each transcript is expressed in different tissues which explains why only the skin has fibrosis. We hypothesized that there would be one or more nucleotide polymorphisms between Tsk2/+ and B6 in this gene, but one has not been found. We intend to increase the scope to find the polymorphism(s). In future studies, we will increase our sequencing region and carefully examine the data to make sure we do not miss any potential heterozygotes in Tsk 2 mice. We will search the molecular pathway to understand the genes upstream and downstream of the Fhl2 gene. 


\section{LIST OF REFERENCES}

1. Chandra, R.K., Nutrition and the immune system: an introduction. Am J Clin Nutr, 1997. 66(2): p. 460S-463S.

2. Springer, T.A., Adhesion receptors of the immune system. Nature, 1990. 346(6283): p. 425-34.

3. Grode, L., et al., Prevalence, incidence, and autoimmune comorbidities of celiac disease: a nation-wide, population-based study in Denmark from 1977 to 2016. Eur J Gastroenterol Hepatol, 2018. 30(1): p. 83-91.

4. Harrison, C.A. and D. Taren, How poverty affects diet to shape the microbiota and chronic disease. Nat Rev Immunol, 2018. 18(4): p. 279-287.

5. Siegel, I., T.L. Liu, and N. Gleicher, The red-cell immune system. Lancet, 1981. 2(8246): p. 556-9.

6. $\quad$ Kerschensteiner, M., et al., Activated human T cells, B cells, and monocytes produce brain-derived neurotrophic factor in vitro and in inflammatory brain lesions: a neuroprotective role of inflammation? J Exp Med, 1999. 189(5): p. 865-70.

7. Knight, J.A., Review: Free radicals, antioxidants, and the immune system. Ann Clin Lab Sci, 2000. 30(2): p. 145-58.

8. Rosenthal, A.S., Determinant selection and macrophage function in genetic control of the immune response. Immunol Rev, 1978. 40: p. 136-52.

9. Adams, D.O. and T.A. Hamilton, The cell biology of macrophage activation. Annu Rev Immunol, 1984. 2: p. 283-318.

10. Deighton, C. and L.A. Criswell, Recent advances in the genetics of rheumatoid arthritis. Curr Rheumatol Rep, 2006. 8(5): p. 394-400.

11. Coteur, G., N. Corriere, and P. Dubois, Environmental factors influencing the immune responses of the common European starfish (Asterias rubens). Fish Shellfish Immunol, 2004. 16(1): p. 51-63.

12. Zemskov, A.M., et al., [Immune reactivity and environmental factors]. Fiziol Cheloveka, 1997. 23(6): p. 98-105.

13. Alfsen, A., Environmental factors in HIV/AIDS epidemic development: new perspectives for gender equity and global protection against HIV transmission. Ann N Y Acad Sci, 2004. 1023: p. 164-74.

14. Traylor, M., et al., Genetic and environmental risk factors for rheumatoid arthritis in a UK African ancestry population: the GENRA case-control study. Rheumatology (Oxford), 2017. 56(8): p. 1282-1292.

15. Duntas, L.H., Environmental factors and thyroid autoimmunity. Ann Endocrinol (Paris), 2011. 72(2): p. 108-13.

16. Rewers, M. and J. Ludvigsson, Environmental risk factors for type 1 diabetes. Lancet, 2016. 387(10035): p. 2340-2348.

17. Joe, B., Quest for arthritis-causative genetic factors in the rat. Physiol Genomics, 2006. 27(1): p. 1-11.

18. Oliver, J.E. and A.J. Silman, Risk factors for the development of rheumatoid arthritis. Scand J Rheumatol, 2006. 35(3): p. 169-74. 
19. Duncan, M.R., et al., Cultured fibroblasts in avian scleroderma, an autoimmune fibrotic disease, display an activated phenotype. J Autoimmun, 1992. 5(5): p. 603-15.

20. Shiozawa, S., et al., An approach to identify new genes in autoimmune diseases: lessons from rheumatoid arthritis. Rev Immunogenet, 2000. 2(1): p. 133-9.

21. Blencowe, B.J., Exonic splicing enhancers: mechanism of action, diversity and role in human genetic diseases. Trends Biochem Sci, 2000. 25(3): p. 106-10.

22. Smith, M.L. and G.V. Glass, Meta-analysis of psychotherapy outcome studies. Am Psychol, 1977. 32(9): p. 752-60.

23. Watson, J.D. and F.H. Crick, Molecular structure of nucleic acids; a structure for deoxyribose nucleic acid. Nature, 1953. 171(4356): p. 737-8.

24. Hershey, A.D. and M. Chase, Independent functions of viral protein and nucleic acid in growth of bacteriophage. J Gen Physiol, 1952. 36(1): p. 39-56.

25. Hartwell, L.H., Macromolecule synthesis in temperature-sensitive mutants of yeast. J Bacteriol, 1967. 93(5): p. 1662-70.

26. Hubscher, U., DNA polymerases in prokaryotes and eukaryotes: mode of action and biological implications. Experientia, 1983. 39(1): p. 1-25.

27. Grantham, R., Viral, prokaryote and eukaryote genes contrasted by $m R N A$ sequence indexes. FEBS Lett, 1978. 95(1): p. 1-11.

28. Koo, H.S., H.M. Wu, and D.M. Crothers, DNA bending at adenine . thymine tracts. Nature, 1986. 320(6062): p. 501-6.

29. Shafer, R.H., Stability and structure of model DNA triplexes and quadruplexes and their interactions with small ligands. Prog Nucleic Acid Res Mol Biol, 1998. 59: p. 55-94.

30. Duncan, B.K. and J.H. Miller, Mutagenic deamination of cytosine residues in $D N A$. Nature, 1980. 287(5782): p. 560-1.

31. Cathcart, R., et al., Thymine glycol and thymidine glycol in human and rat urine: a possible assay for oxidative DNA damage. Proc Natl Acad Sci U S A, 1984. 81(18): p. 5633-7.

32. Ezkurdia, I., et al., Multiple evidence strands suggest that there may be as few as 19,000 human protein-coding genes. Hum Mol Genet, 2014. 23(22): p. 5866-78.

33. Guenet, J.L., The mouse genome. Genome Res, 2005. 15(12): p. 1729-40.

34. Prockop, D.J., et al., The biosynthesis of collagen and its disorders (first of two parts). N Engl J Med, 1979. 301(1): p. 13-23.

35. Prockop, D.J., et al., The biosynthesis of collagen and its disorders (second of two parts). N Engl J Med, 1979. 301(2): p. 77-85.

36. Kogan, S.C., M. Doherty, and J. Gitschier, An improved method for prenatal diagnosis of genetic diseases by analysis of amplified DNA sequences. Application to hemophilia A. N Engl J Med, 1987. 317(16): p. 985-90.

37. Kim, J., J.J. Kim, and H. Lee, An analysis of disease-gene relationship from Medline abstracts by DigSee. Sci Rep, 2017. 7: p. 40154.

38. Cargill, M., et al., Characterization of single-nucleotide polymorphisms in coding regions of human genes. Nat Genet, 1999. 22(3): p. 231-8.

39. Smithies, O., Animal models of human genetic diseases. Trends Genet, 1993. 9(4): p. 112-6. 
40. Rowley, J.D., Letter: A new consistent chromosomal abnormality in chronic myelogenous leukaemia identified by quinacrine fluorescence and Giemsa staining. Nature, 1973. 243(5405): p. 290-3.

41. Sharma, S., et al., Homology and enzymatic requirements of microhomologydependent alternative end joining. Cell Death Dis, 2015. 6: p. e1697.

42. Rodgers, K. and M. McVey, Error-Prone Repair of DNA Double-Strand Breaks. J Cell Physiol, 2016. 231(1): p. 15-24.

43. Leimar, O., The evolution of phenotypic polymorphism: randomized strategies versus evolutionary branching. Am Nat, 2005. 165(6): p. 669-81.

44. Gordon, W.G., J.J. Basch, and M.P. Thompson, Genetic polymorphism in caseins of cow's milk. VI. Amino acid composition of alpha-s-1-caseins A, B, and C. J Dairy Sci, 1965. 48(8): p. 1010-3.

45. Wang, M. and G. Caetano-Anolles, The evolutionary mechanics of domain organization in proteomes and the rise of modularity in the protein world. Structure, 2009. 17(1): p. 66-78.

46. Siepel, A., Darwinian alchemy: Human genes from noncoding DNA. Genome Res, 2009. 19(10): p. 1693-5.

47. Audic, S. and J.M. Claverie, The significance of digital gene expression profiles. Genome Res, 1997. 7(10): p. 986-95.

48. Chomczynski, P., A reagent for the single-step simultaneous isolation of $R N A$, DNA and proteins from cell and tissue samples. Biotechniques, 1993. 15(3): p. 532-4, 536-7.

49. Orphanides, G., T. Lagrange, and D. Reinberg, The general transcription factors of RNA polymerase II. Genes Dev, 1996. 10(21): p. 2657-83.

50. Murray, V. and R. Holliday, Mechanism for RNA splicing of gene transcripts. FEBS Lett, 1979. 106(1): p. 5-7.

51. Breathnach, R., et al., Ovalbumin gene: evidence for a leader sequence in $m R N A$ and DNA sequences at the exon-intron boundaries. Proc Natl Acad Sci U S A, 1978. 75(10): p. 4853-7.

52. Winick, M. and A. Noble, Quantitative changes in DNA, RNA, and protein during prenatal and postnatal growth in the rat. Dev Biol, 1965. 12(3): p. 451-66.

53. Roeder, R.G. and W.J. Rutter, Multiple forms of DNA-dependent RNA polymerase in eukaryotic organisms. Nature, 1969. 224(5216): p. 234-7.

54. Sawadogo, M. and R.G. Roeder, Interaction of a gene-specific transcription factor with the adenovirus major late promoter upstream of the TATA box region. Cell, 1985. 43(1): p. 165-75.

55. Parker, C.S. and J. Topol, A Drosophila RNA polymerase II transcription factor contains a promoter-region-specific DNA-binding activity. Cell, 1984. 36(2): p. 357-69.

56. Furth, P.A., et al., Temporal control of gene expression in transgenic mice by a tetracycline-responsive promoter. Proc Natl Acad Sci U S A, 1994. 91(20): p. 9302-6.

57. Gossen, M. and H. Bujard, Tight control of gene expression in mammalian cells by tetracycline-responsive promoters. Proc Natl Acad Sci U S A, 1992. 89(12): p. 5547-51. 
58. $\quad \mathrm{Wu}, \mathrm{H}$., et al., Tissue-specific RNA expression marks distant-acting developmental enhancers. PLoS Genet, 2014. 10(9): p. e1004610.

59. Schena, M., et al., Quantitative monitoring of gene expression patterns with a complementary DNA microarray. Science, 1995. 270(5235): p. 467-70.

60. Li, X., et al., Clinical utility of microarrays: current status, existing challenges and future outlook. Curr Genomics, 2008. 9(7): p. 466-74.

61. Brown, M.P., et al., Knowledge-based analysis of microarray gene expression data by using support vector machines. Proc Natl Acad Sci U S A, 2000. 97(1): p. 262-7.

62. Lababidi, S., Challenges in DNA microarray studies from the regulatory perspective. J Biopharm Stat, 2008. 18(1): p. 183-202.

63. Bailey, D.W., Recombinant-inbred strains. An aid to finding identity, linkage, and function of histocompatibility and other genes. Transplantation, 1971. 11(3): p. 325-7.

64. Paigen, B., et al., Atherosclerosis susceptibility differences among progenitors of recombinant inbred strains of mice. Arteriosclerosis, 1990. 10(2): p. 316-23.

65. Nadeau, J.H. and W.N. Frankel, The roads from phenotypic variation to gene discovery: mutagenesis versus QTLs. Nat Genet, 2000. 25(4): p. 381-4.

66. Van Ooijen, J.W., LOD significance thresholds for QTL analysis in experimental populations of diploid species. Heredity (Edinb), 1999. 83 (Pt 5): p. 613-24.

67. Gill, K. and A.E. Boyle, Genetic analysis of alcohol intake in recombinant inbred and congenic strains derived from $A / J$ and $C 57 B L / 6 J$ progenitors. Mamm Genome, 2005. 16(5): p. 319-31.

68. Darvasi, A., et al., Detecting marker-QTL linkage and estimating QTL gene effect and map location using a saturated genetic map. Genetics, 1993. 134(3): p. 94351.

69. Parker, C.C., et al., Systems Genetic Analysis in GeneNetwork.org. Curr Protoc Neurosci, 2017. 79: p. 839 1-8 3920.

70. Williams, R.W. and L. Lu, Integrative genetic analysis of alcohol dependence using the GeneNetwork Web resources. Alcohol Res Health, 2008. 31(3): p. 2757.

71. Williams, R.W., et al., The genetic structure of recombinant inbred mice: highresolution consensus maps for complex trait analysis. Genome Biol, 2001. 2(11): p. RESEARCH0046.

72. Chesler, E.J., et al., Genetic correlates of gene expression in recombinant inbred strains: a relational model system to explore neurobehavioral phenotypes. Neuroinformatics, 2003. 1(4): p. 343-57.

73. Jones, B.C., et al., Genetic correlational analysis reveals no association between $M P P+$ and the severity of striatal dopaminergic damage following MPTP treatment in BXD mouse strains. Neurotoxicol Teratol, 2014. 45: p. 91-2.

74. Kimura, M. and G.H. Weiss, The Stepping Stone Model of Population Structure and the Decrease of Genetic Correlation with Distance. Genetics, 1964. 49(4): p. 561-76.

75. Lu, H., et al., Iris transillumination defect and its gene modulators do not correlate with intraocular pressure in the BXD family of mice. Mol Vis, 2016. 22: p. 224-33. 
76. Witte, J.S., W.J. Gauderman, and D.C. Thomas, Asymptotic bias and efficiency in case-control studies of candidate genes and gene-environment interactions: basic family designs. Am J Epidemiol, 1999. 149(8): p. 693-705.

77. Yamaoka, K., T. Nakagawa, and T. Uno, Statistical moments in pharmacokinetics. J Pharmacokinet Biopharm, 1978. 6(6): p. 547-58.

78. Dunne, A., Statistical moments in pharmacokinetics: models and assumptions. J Pharm Pharmacol, 1993. 45(10): p. 871-5.

79. Forrest, A., et al., Pharmacodynamics of intravenous ciprofloxacin in seriously ill patients. Antimicrob Agents Chemother, 1993. 37(5): p. 1073-81.

80. Moore, P.S., et al., Molecular mimicry of human cytokine and cytokine response pathway genes by KSHV. Science, 1996. 274(5293): p. 1739-44.

81. Tabor, H.K., N.J. Risch, and R.M. Myers, Candidate-gene approaches for studying complex genetic traits: practical considerations. Nat Rev Genet, 2002. 3(5): p. 391-7.

82. $\mathrm{Xu}, \mathrm{Z}$. and J.A. Taylor, SNPinfo: integrating GWAS and candidate gene information into functional SNP selection for genetic association studies. Nucleic Acids Res, 2009. 37(Web Server issue): p. W600-5.

83. Church, G.M. and W. Gilbert, Genomic sequencing. Proc Natl Acad Sci U S A, 1984. 81(7): p. 1991-5.

84. Hyman, E.D., A new method of sequencing DNA. Anal Biochem, 1988. 174(2): p. 423-36.

85. Sanger, F., The Croonian Lecture, 1975. Nucleotide sequences in DNA. Proc $\mathrm{R}$ Soc Lond B Biol Sci, 1975. 191(1104): p. 317-33.

86. Ensenberger, M.G., et al., Developmental validation of the PowerPlex 16 HS System: an improved 16-locus fluorescent STR multiplex. Forensic Sci Int Genet, 2010. 4(4): p. 257-64.

87. Kaji, E.H. and J.M. Leiden, Gene and stem cell therapies. JAMA, 2001. 285(5): p. 545-50.

88. Li, S. and L. Huang, Nonviral gene therapy: promises and challenges. Gene Ther, 2000. 7(1): p. 31-4.

89. Rosenberg, S.A., et al., Gene transfer into humans--immunotherapy of patients with advanced melanoma, using tumor-infiltrating lymphocytes modified by retroviral gene transduction. N Engl J Med, 1990. 323(9): p. 570-8.

90. Cavazzana-Calvo, M., et al., Gene therapy of human severe combined immunodeficiency (SCID)-X1 disease. Science, 2000. 288(5466): p. 669-72.

91. Fuhrman, F.A., Tetrodotoxin. It is a powerful poison that is found in two almost totally unrelated kinds of animal: puffer fish and newts. It has been serving as a tool in nerve physiology and may provide a model for new local anesthetics. Sci Am, 1967. 217(2): p. 60-71.

92. Porsolt, R.D., M. Le Pichon, and M. Jalfre, Depression: a new animal model sensitive to antidepressant treatments. Nature, 1977. 266(5604): p. 730-2.

93. Rao, B.S., J.S. Prasad, and C.V. Sarathy, An animal model to study iron availability from human diets. Br J Nutr, 1977. 37(3): p. 451-6.

94. McKinney, W.T., Jr. and W.E. Bunney, Jr., Animal model of depression. I. Review of evidence: implications for research. Arch Gen Psychiatry, 1969. 21(2): p. 240-8. 
95. Koshman, R.W., J. Koo, and O.G. Thurston, A human/mouse hybrid model for the study of human genetic factors influencing tumor cell growth. J Surg Oncol, 1975. 7(4): p. 323-7.

96. Nair, S., M. Faizuddin, and J. Dharmapalan, Role of autoimmune responses in periodontal disease. Autoimmune Dis, 2014. 2014: p. 596824.

97. Tian, C., et al., Ifi204 as the most favored candidate gene that regulates susceptibility to spontaneous arthritis in mice. Gene Reports, 2018. 12: p. 21-29.

98. Ropes, M.W., et al., 1958 Revision of diagnostic criteria for rheumatoid arthritis. Bull Rheum Dis, 1958. 9(4): p. 175-6.

99. Steinbrocker, O., C.H. Traeger, and R.C. Batterman, Therapeutic criteria in rheumatoid arthritis. J Am Med Assoc, 1949. 140(8): p. 659-62.

100. Sandal, I., et al., Bone loss and aggravated autoimmune arthritis in HLADRbeta1-bearing humanized mice following oral challenge with Porphyromonas gingivalis. Arthritis Res Ther, 2016. 18(1): p. 249.

101. Brennan, F.M., et al., Inhibitory effect of TNF alpha antibodies on synovial cell interleukin-1 production in rheumatoid arthritis. Lancet, 1989. 2(8657): p. 244-7.

102. Harris, E.D., Jr., et al., Collagenase and rheumatoid arthritis. Arthritis Rheum, 1970. 13(1): p. 83-94.

103. Bhatia, G.S. and R.C. Davis, Rheumatoid arthritis and heart failure. Am J Med, 2004. 117(9): p. 709; author reply 709.

104. Bongartz, T., et al., Incidence and mortality of interstitial lung disease in rheumatoid arthritis: a population-based study. Arthritis Rheum, 2010. 62(6): p. 1583-91.

105. Jayson, M.I., Rheumatoid arthritis and the eye. Proc R Soc Med, 1977. 70(4): p. 221-2.

106. Remmers, E.F., et al., A genome scan localizes five non-MHC loci controlling collagen-induced arthritis in rats. Nat Genet, 1996. 14(1): p. 82-5.

107. Otto, J.M., et al., Identification of multiple loci linked to inflammation and autoantibody production by a genome scan of a murine model of rheumatoid arthritis. Arthritis Rheum, 1999. 42(12): p. 2524-31.

108. Otto, J.M., et al., A genome scan using a novel genetic cross identifies new susceptibility loci and traits in a mouse model of rheumatoid arthritis. J Immunol, 2000. 165(9): p. 5278-86.

109. Yu, X., et al., Fine mapping of collagen-induced arthritis quantitative trait loci in an advanced intercross line. J Immunol, 2006. 177(10): p. 7042-9.

110. Ahlqvist, E., R. Bockermann, and R. Holmdahl, Fragmentation of two quantitative trait loci controlling collagen-induced arthritis reveals a new set of interacting subloci. J Immunol, 2007. 178(5): p. 3084-90.

111. Campbell, E.C., A.N. Antoniou, and S.J. Powis, The multi-faceted nature of HLA class I dimer molecules. Immunology, 2012. 136(4): p. 380-4.

112. Brand, D.D., K.A. Latham, and E.F. Rosloniec, Collagen-induced arthritis. Nat Protoc, 2007. 2(5): p. 1269-75.

113. Pietrosimone, K.M., et al., Collagen-Induced Arthritis: A model for Murine Autoimmune Arthritis. Bio Protoc, 2015. 5(20). 
114. Wooley, P.H., et al., Type II collagen-induced arthritis in mice. I. Major histocompatibility complex (I region) linkage and antibody correlates. J Exp Med, 1981. 154(3): p. 688-700.

115. Griffiths, M.M. and E.F. Remmers, Genetic analysis of collagen-induced arthritis in rats: a polygenic model for rheumatoid arthritis predicts a common framework of cross-species inflammatory/autoimmune disease loci. Immunol Rev, 2001. 184: p. 172-83.

116. Adarichev, V.A., et al., Combined autoimmune models of arthritis reveal shared and independent qualitative (binary) and quantitative trait loci. J Immunol, 2003. 170(5): p. 2283-92.

117. Holmdahl, R., et al., Arthritis induced in rats with nonimmunogenic adjuvants as models for rheumatoid arthritis. Immunol Rev, 2001. 184: p. 184-202.

118. Rintisch, C., et al., Finemapping of the arthritis QTL Pia7 reveals co-localization with Oia2 and the APLEC locus. Genes Immun, 2010. 11(3): p. 239-45.

119. Pap, T. and A. Korb-Pap, Cartilage damage in osteoarthritis and rheumatoid arthritis--two unequal siblings. Nat Rev Rheumatol, 2015. 11(10): p. 606-15.

120. Lubberts, E., The IL-23-IL-17 axis in inflammatory arthritis. Nat Rev Rheumatol, 2015. 11(10): p. 562.

121. Adlan, A.M., et al., Autonomic function and rheumatoid arthritis: a systematic review. Semin Arthritis Rheum, 2014. 44(3): p. 283-304.

122. Scott, I.C. and D.L. Scott, Spleen tyrosine kinase inhibitors for rheumatoid arthritis: where are we now? Drugs, 2014. 74(4): p. 415-22.

123. O'Shea, J.J., A. Laurence, and I.B. McInnes, Back to the future: oral targeted therapy for RA and other autoimmune diseases. Nat Rev Rheumatol, 2013. 9(3): p. 173-82.

124. Jesus, A.A. and R. Goldbach-Mansky, IL-1 blockade in autoinflammatory syndromes. Annu Rev Med, 2014. 65: p. 223-44.

125. Besenyei, T., et al., Non-MHC risk alleles in rheumatoid arthritis and in the syntenic chromosome regions of corresponding animal models. Clin Dev Immunol, 2012. 2012: p. 284751.

126. Dinarello, C.A., Biology of interleukin 1. FASEB J, 1988. 2(2): p. 108-15.

127. Dower, S.K., et al., The cell surface receptors for interleukin-1 alpha and interleukin-1 beta are identical. Nature, 1986. 324(6094): p. 266-8.

128. Dinarello, C.A. and R.C. Thompson, Blocking IL-1: interleukin 1 receptor antagonist in vivo and in vitro. Immunol Today, 1991. 12(11): p. 404-10.

129. Hurme, M. and S. Santtila, IL-1 receptor antagonist (IL-1Ra) plasma levels are co-ordinately regulated by both IL-1Ra and IL-1beta genes. Eur J Immunol, 1998. 28(8): p. 2598-602.

130. Horai, R., et al., Development of chronic inflammatory arthropathy resembling rheumatoid arthritis in interleukin 1 receptor antagonist-deficient mice. $\mathrm{J}$ Exp Med, 2000. 191(2): p. 313-20.

131. Zhou, F., et al., Arthritis in mice that are deficient in interleukin-1 receptor antagonist is dependent on genetic background. Arthritis Rheum, 2005. 52(12): p. 3731-8. 
132. Deng, N., et al., Genomic locus on chromosome 1 regulates susceptibility to spontaneous arthritis in mice deficiency of IL-1RA. BMC Immunol, 2014. 15: p. 57.

133. Jiao, Y., et al., Identifying a major locus that regulates spontaneous arthritis in IL-1ra-deficient mice and analysis of potential candidates. Genet Res (Camb), 2011. 93(2): p. 95-103.

134. Liu, X., et al., Decreased expression levels of Ifi genes is associated to the increased resistance to spontaneous arthritis disease in mice deficiency of ILIRA. BMC Immunol, 2016. 17(1): p. 25.

135. Cao, Y., et al., Analysis of candidate genes of spontaneous arthritis in mice deficient for interleukin-1 receptor antagonist. Genes Genet Syst, 2012. 87(2): p. 107-13.

136. Grau, S., et al., The role of human HtrAl in arthritic disease. J Biol Chem, 2006. 281(10): p. 6124-9.

137. Gariglio, M., et al., The murine homolog of the HIN 200 family, Ifi 204, is constitutively expressed in myeloid cells and selectively induced in the monocyte/macrophage lineage. J Leukoc Biol, 1998. 64(5): p. 608-14.

138. Lembo, M., et al., Inhibition of cell proliferation by the interferon-inducible 204 gene, a member of the Ifi 200 cluster. Oncogene, 1998. 16(12): p. 1543-51.

139. Choubey, D. and P. Lengyel, Interferon action: nucleolar and nucleoplasmic localization of the interferon-inducible 72-kD protein that is encoded by the If $i$ 204 gene from the gene 200 cluster. J Cell Biol, 1992. 116(6): p. 1333-41.

140. Alunno, A., et al., Circulating Interferon-Inducible Protein IFI16 Correlates With Clinical and Serological Features in Rheumatoid Arthritis. Arthritis Care Res (Hoboken), 2016. 68(4): p. 440-5.

141. Hoerster, K.D., et al., Health and health behavior differences: U.S. Military, veteran, and civilian men. Am J Prev Med, 2012. 43(5): p. 483-9.

142. Centers for Disease, C. and Prevention, Prevalence of doctor-diagnosed arthritis and arthritis-attributable activity limitation--United States, 2010-2012. MMWR Morb Mortal Wkly Rep, 2013. 62(44): p. 869-73.

143. Storek, K.M., et al., cGAS and Ifi204 cooperate to produce type I IFNs in response to Francisella infection. J Immunol, 2015. 194(7): p. 3236-45.

144. Hou, Y., et al., The inhibitory effect of IFN-gamma on protease HTRAI expression in rheumatoid arthritis. J Immunol, 2014. 193(1): p. 130-8.

145. Hsueh, M.F., V.B. Kraus, and P. Onnerfjord, Cartilage matrix remodelling differs by disease state and joint type. Eur Cell Mater, 2017. 34: p. 70-82.

146. Pellett, F., et al., KIRs and autoimmune disease: studies in systemic lupus erythematosus and scleroderma. Tissue Antigens, 2007. 69 Suppl 1: p. 106-8.

147. Zhang, K., et al., Mndal, a new interferon-inducible family member, is highly polymorphic, suppresses cell growth, and may modify plasmacytoma susceptibility. Blood, 2009. 114(14): p. 2952-60.

148. Pattanaik, D., et al., Pathogenesis of Systemic Sclerosis. Front Immunol, 2015. 6: p. 272.

149. Rodnan, G.P., E. Lipinski, and J. Luksick, Skin thickness and collagen content in progressive systemic sclerosis and localized scleroderma. Arthritis Rheum, 1979. 22(2): p. 130-40. 
150. Tan, E.M., Antinuclear antibodies: diagnostic markers for autoimmune diseases and probes for cell biology. Adv Immunol, 1989. 44: p. 93-151.

151. Maurer, B., et al., Transcription factor fos-related antigen-2 induces progressive peripheral vasculopathy in mice closely resembling human systemic sclerosis. Circulation, 2009. 120(23): p. 2367-76.

152. Sell, D.R. and V.M. Monnier, Structure elucidation of a senescence cross-link from human extracellular matrix. Implication of pentoses in the aging process. $\mathbf{J}$ Biol Chem, 1989. 264(36): p. 21597-602.

153. Kazantsev, V., et al., A homeostatic model of neuronal firing governed by feedback signals from the extracellular matrix. PLoS One, 2012. 7(7): p. e41646.

154. Hocher, B., et al., Endothelin-1 transgenic mice develop glomerulosclerosis, interstitial fibrosis, and renal cysts but not hypertension. J Clin Invest, 1997. 99(6): p. 1380-9.

155. Yang, Z.H., et al., Threshold concentrations of endothelin-1 potentiate contractions to norepinephrine and serotonin in human arteries. A new mechanism of vasospasm? Circulation, 1990. 82(1): p. 188-95.

156. Asano, Y., et al., Endothelial Fli1 deficiency impairs vascular homeostasis: a role in scleroderma vasculopathy. Am J Pathol, 2010. 176(4): p. 1983-98.

157. Artlett, C.M., Animal models of scleroderma: fresh insights. Curr Opin Rheumatol, 2010. 22(6): p. 677-82.

158. Yamamoto, T., et al., Animal model of sclerotic skin. I: Local injections of bleomycin induce sclerotic skin mimicking scleroderma. J Invest Dermatol, 1999. 112(4): p. 456-62.

159. Yamamoto, T., et al., Animal model of sclerotic skin. II. Bleomycin induced scleroderma in genetically mast cell deficient $W B B 6 F 1-W / W(V)$ mice. $\mathrm{J}$ Rheumatol, 1999. 26(12): p. 2628-34.

160. Yamamoto, T., M. Kuroda, and K. Nishioka, Animal model of sclerotic skin. III: Histopathological comparison of bleomycin-induced scleroderma in various mice strains. Arch Dermatol Res, 2000. 292(11): p. 535-41.

161. Siracusa, L.D., et al., A tandem duplication within the fibrillin 1 gene is associated with the mouse tight skin mutation. Genome Res, 1996. 6(4): p. 30013.

162. Long, K.B., C.M. Artlett, and E.P. Blankenhorn, Tight skin 2 mice exhibit a novel time line of events leading to increased extracellular matrix deposition and dermal fibrosis. Matrix Biol, 2014. 38: p. 91-100.

163. Dalgleish, R., M. Woodhouse, and S. Reeders, An RFLP associated with the human type III collagen gene (COL3A1). Nucleic Acids Res, 1985. 13(12): p. 4609.

164. Zafarullah, K., et al., $G$ to A polymorphism in exon 31 of the COL3A1 gene. Nucleic Acids Res, 1990. 18(20): p. 6180.

165. Tromp, G., et al., $C$ to $T$ polymorphism in exon 33 of the COL3A1 gene. Nucleic Acids Res, 1991. 19(3): p. 681.

166. Somasundaram, R. and D. Schuppan, Type I, II, III, IV, V, and VI collagens serve as extracellular ligands for the isoforms of platelet-derived growth factor ( $A A$, $B B$, and $A B$ ). J Biol Chem, 1996. 271(43): p. 26884-91. 
167. Long, K.B., et al., The Tsk2/+ mouse fibrotic phenotype is due to a gain-offunction mutation in the PIIINP segment of the Col3al gene. J Invest Dermatol, 2015. 135(3): p. 718-27.

168. Christner, P.J., et al., The tight skin 2 mouse. An animal model of scleroderma displaying cutaneous fibrosis and mononuclear cell infiltration. Arthritis Rheum, 1995. 38(12): p. 1791-8.

169. Christner, P.J., et al., A high-resolution linkage map of the tight skin 2 (Tsk2) locus: a mouse model for scleroderma (SSc) and other cutaneous fibrotic diseases. Mamm Genome, 1996. 7(8): p. 610-2.

170. Barisic-Dujmovic, T., I. Boban, and S.H. Clark, Regulation of collagen gene expression in the Tsk2 mouse. J Cell Physiol, 2008. 215(2): p. 464-71.

171. Kirfel, J., et al., Impaired intestinal wound healing in Fhl2-deficient mice is due to disturbed collagen metabolism. Exp Cell Res, 2008. 314(20): p. 3684-91.

172. Lai, C.F., et al., Four and half lim protein 2 (FHL2) stimulates osteoblast differentiation. J Bone Miner Res, 2006. 21(1): p. 17-28.

173. Johannessen, M., et al., The multifunctional roles of the four-and-a-half-LIM only protein FHL2. Cell Mol Life Sci, 2006. 63(3): p. 268-84.

174. $\quad \mathrm{Du}, \mathrm{J}$. , et al., The expression pattern of FHL2 during mouse molar development. $\mathrm{J}$ Mol Histol, 2012. 43(3): p. 289-95. 


\section{VITA}

Cheng Tian was born in Suzhou, Jiangsu province, China in 1987. He attended North Dakota State University and received his Bachelor of biological science degree in 2012. In same year, he was accepted into the graduate program in the Department of Pharmaceutical Science, the University of Tennessee Health Science Center. In 2012, he joined Dr. Weikuan Gu's laboratory and worked in Veterans Affairs Medical Center in Memphis. He will graduate with Doctor of Philosophy degree. 